Portland State University

PDXScholar

Summer 8-13-2013

\title{
Elementary Teacher Candidates' Images of \\ Mathematics, Diverse Students, and Teaching: An Exploratory Study With Implications for Culturally Responsive Mathematics Education
}

\author{
Bernd Richard Ferner \\ Portland State University
}

Follow this and additional works at: https://pdxscholar.library.pdx.edu/open_access_etds

Part of the Bilingual, Multilingual, and Multicultural Education Commons, Elementary Education and Teaching Commons, and the Other Mathematics Commons Let us know how access to this document benefits you.

\section{Recommended Citation}

Ferner, Bernd Richard, "Elementary Teacher Candidates' Images of Mathematics, Diverse Students, and Teaching: An Exploratory Study With Implications for Culturally Responsive Mathematics Education" (2013). Dissertations and Theses. Paper 1097.

https://doi.org/10.15760/etd.1097

This Dissertation is brought to you for free and open access. It has been accepted for inclusion in Dissertations and Theses by an authorized administrator of PDXScholar. Please contact us if we can make this document more accessible: pdxscholar@pdx.edu. 
Elementary Teacher Candidates' Images of Mathematics, Diverse Students, and Teaching: An Exploratory Study With Implications for Culturally

Responsive Mathematics Education

by

Bernd Richard Ferner

A dissertation submitted in partial fulfillment of the requirements for the degree of

Doctor of Education

in

Educational Leadership: Curriculum and Instruction

Dissertation Committee:

Karen J. Noordhoff, Chair

Samuel D. Henry

Emily C. de la Cruz

M. Paul Latiolais

Portland State University

2013 
(C) 2013 Bernd Richard Ferner

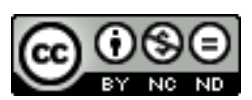

This work is licensed under a Creative Commons Attribution-NonCommercial-NoDerivs 3.0 Unported License. 


\begin{abstract}
Children from many culturally diverse backgrounds do not achieve in mathematics at the same rates as their counterparts from the dominant White, EuropeanAmerican culture (Gay, 2010). This so-called achievement gap is an artifact of an educational system that continues to fail to provide equal learning opportunities to culturally diverse children (Ladson-Billings, 2006; Nieto \& Bode, 2011). Teachers who employ culturally responsive teaching (Gay, 2010) may help to close this opportunity gap and hence, the achievement gap. This study investigated, "How do elementary teacher candidates perceive teaching mathematics in a multicultural environment?" Using a critical constructivism research paradigm, this qualitative instrumental multiple case study involved a questionnaire, two interviews and a focus group with four elementary teacher candidates enrolled in a one-year teaching licensure program. The study examined elementary teacher candidates' images of mathematics and diverse students and the relationship between those images and their perceptions of teaching mathematics in a multicultural environment. The study concluded that the participants', images of mathematics, learners, and the teaching of mathematics were interrelated. The participants struggled to understand how students' diversity based on group membership (e.g., culture) influences a mathematics classroom and their teaching. However, on the basis of these participants, teacher candidates who hold a conceptual image of mathematics could be more open to adopting culturally responsive teaching than teacher candidates who hold a procedural image of mathematics. The study recommends the
\end{abstract}


integration and modeling of culturally responsive teaching throughout all teacher education coursework. 


\section{Dedication}

This dissertation is dedicated to my wife Ines Koerner and my dear friend Jennifer Merkel for being with me on this journey 


\section{Acknowledgments}

At Portland State University, the right people came together to help me start my new chapter of learning, and personal and professional growth. From the first moment on, I felt a connection with Audrey Lingley, Jennifer Wells, Sarah Lundy, Katie Toppel, and Edgar Solares, and knew that we all deeply cared about students, their learning, and their well-being. Our faculty advisors, Karen Noordhoff and Samuel Henry, facilitated a learning community which not only gave us room to exchange and discuss our ideas, but also valued everybody as a person and celebrated the many accomplishments along our way. At the end, WE did it!

I am grateful to my dissertation committee, Drs. Karen Noordhoff, Samuel Henry, Emily de la Cruz, and Paul Latiolais, who gave me the guidance and support to develop and conduct my dissertation research and supported my professional development. In Karen and Samuel, I had wonderful co-advisors, colleagues, and teachers, who gave me all the care and mentorship I needed. Karen literally opened doors so that I could meet Emily de la Cruz, who became my faculty mentor and tremendously supported my professional growth and my research.

In Karen Noordhoff, who chaired my dissertation, I have had the most wonderful mentor. I am so grateful that she pushed and challenged me. She always knew how much pressure I needed and what would be too much. She always knew when I needed care and nurturing. Never in my life have I felt more safe and cared for. Karen, even with all the frustrations and struggles I had along the way, you have made this entire journey a wonderful one. I always felt at home. Thanks so much. 
My wife, Ines Koerner, supported me in more ways than I can mention. It isn't easy having your spouse "disappear into his computer" for months at a time, and she has been extremely tolerant waiting for me to re-emerge. Thank you for your patience and love, mein Schatz.

And what is a dissertation without the very special person who reads, edits, and comments on every single word multiple times? Jennifer Merkel-how can I ever thank you enough? A big hug also to Jennifer's family Matthias, Becca, Katie, and Annika for their patience and for being such good friends.

I am so very grateful for your support. It takes a village. Thank you all. 


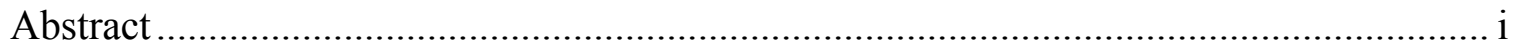

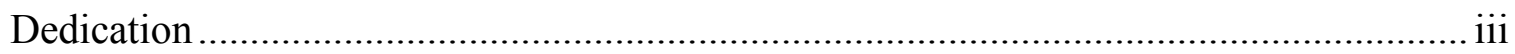

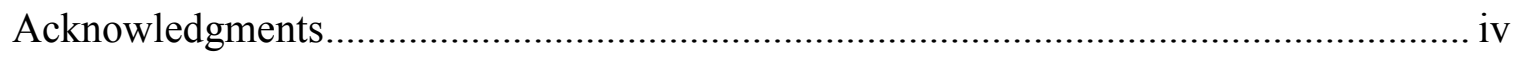

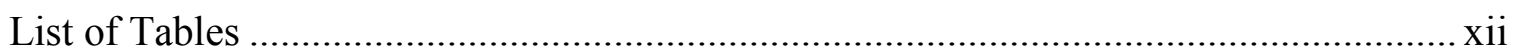

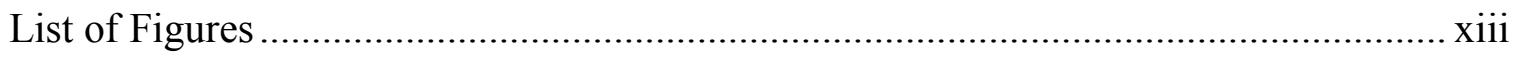

\section{CHAPTER}

I Problem Statement and Theoretical Framework .................................................... 1

From Achievement Gap to Opportunity Gap............................................................. 3

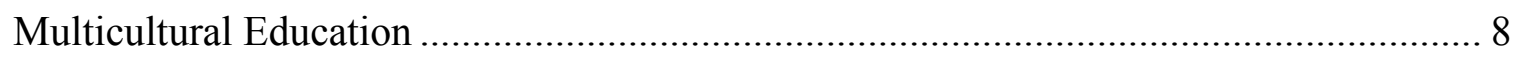

What is Multicultural Education? ..................................................................... 9

The Concept of Culture in Multicultural Education ........................................... 10

Historical Approaches to Multicultural Education ............................................ 11

Dimensions of Multicultural Education.......................................................... 15

Knowledge Construction and Critical Constructivism ............................................ 17

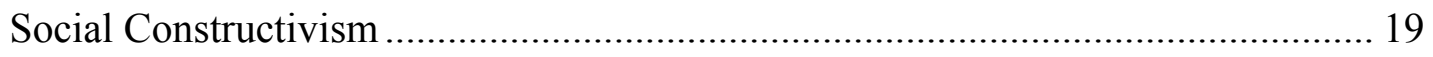

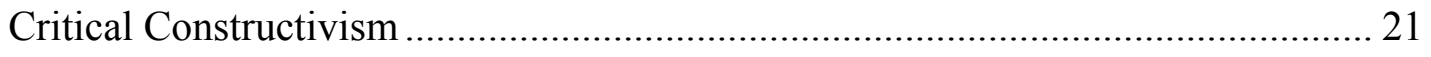

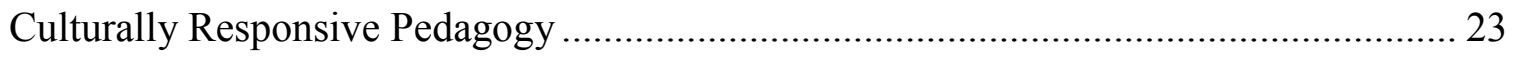

Definition of Culturally Relevant Pedagogy .................................................... 25

Culturally Responsive Teaching ........................................................................ 26

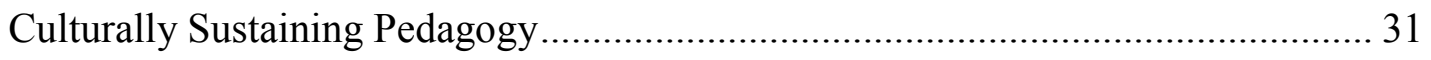

Learning How to Teach in Culturally Responsive Ways...................................... 33 
Focus Statement and Research Questions................................................................ 34

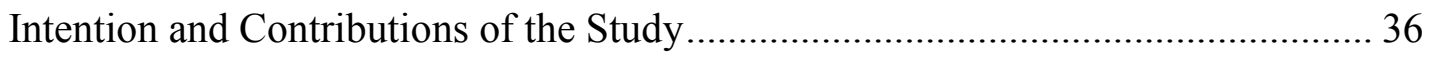

Why I Care About This Problem ............................................................................. 37

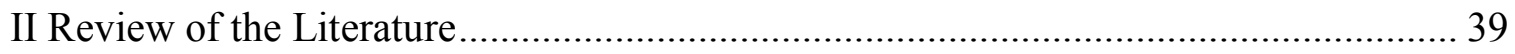

Teachers' Knowledge, Dispositions, and Perceptions ....................................................... 39

Standards for Teacher Education ........................................................................... 41

Teachers' Knowledge ………………………………....................................... 42

The Subject Matter as Content Knowledge ................................................................. 44

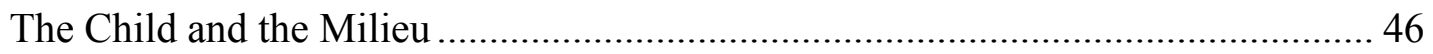

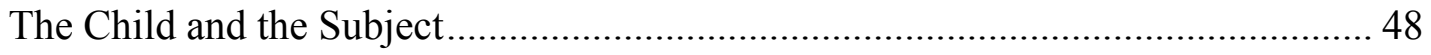

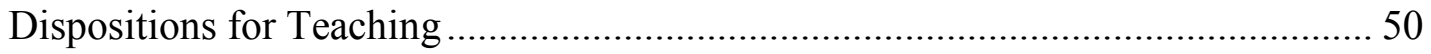

Culturally Responsive Mathematics Teaching ……………….................................... 54

Teachers' Images, Attitudes, and Beliefs About Mathematics .......................................... 67

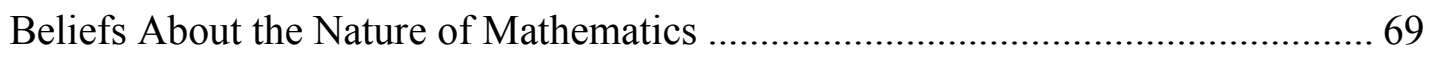

Images of Mathematics and the Perception of Teaching ........................................ 73

Teacher Candidates' Perception of Mathematics, Students, and Teaching .............. 80

The Interplay Among Images, Disposition, and Teaching Mathematics................... 82

Culturally Diverse Learners and the Teaching of Mathematics ................................. 85

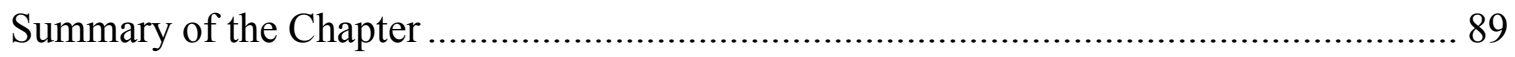

III Research Design and Methodology ………………................................................. 93

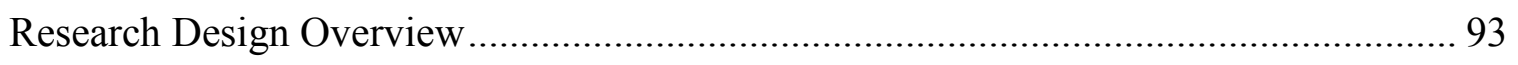

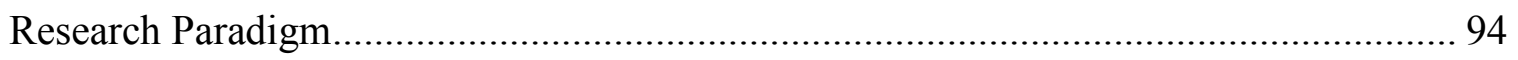

Overview of the Case Study and Rationale .................................................................... 96 


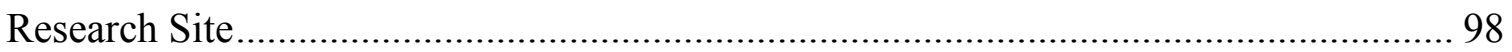

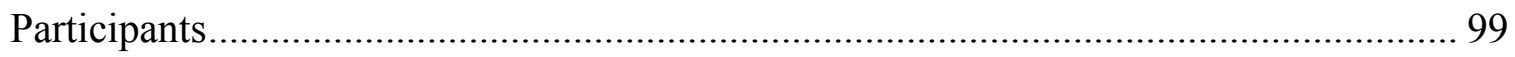

Participants' Personal Profiles and Background..................................................... 103

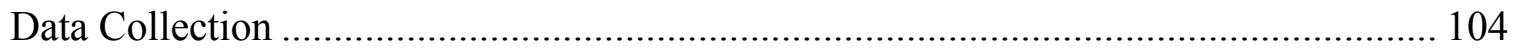

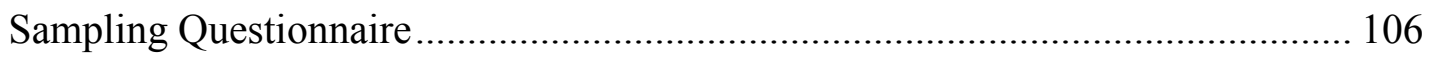

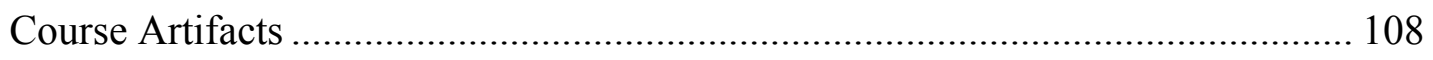

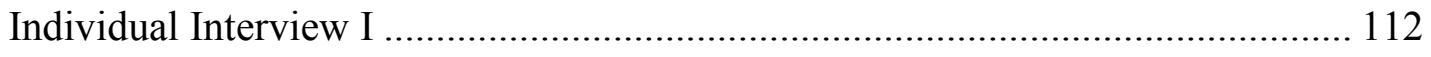

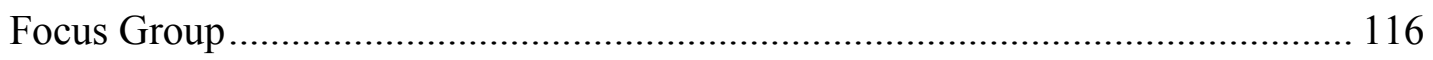

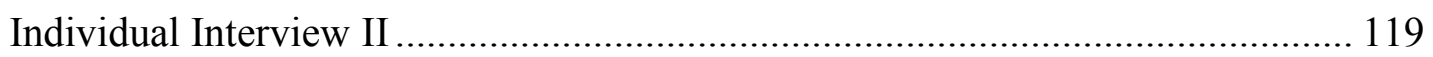

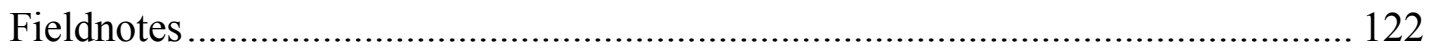

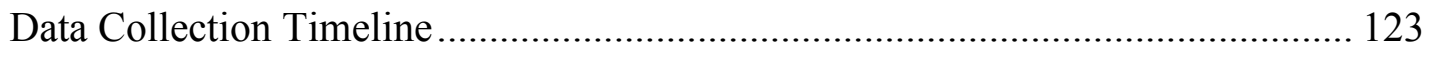

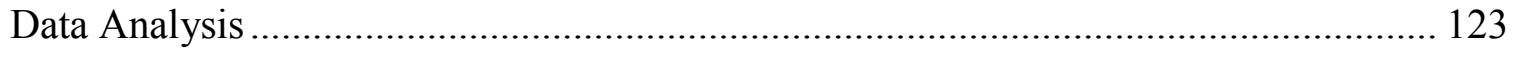

Individual Case Analysis ............................................................................... 125

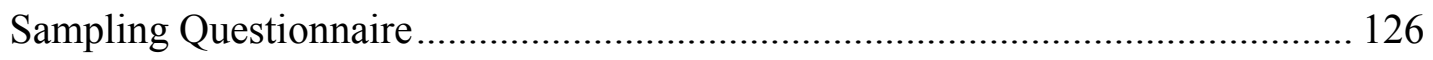

Mathematics Autobiography ............................................................................. 127

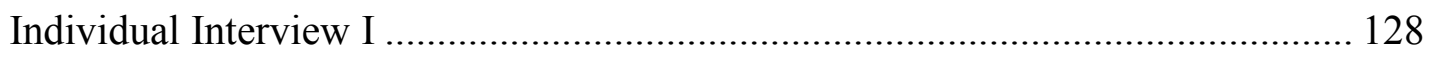

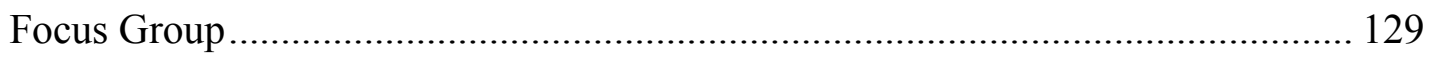

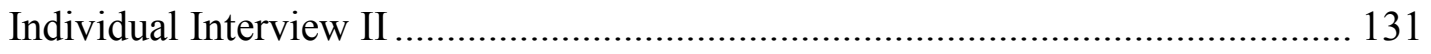

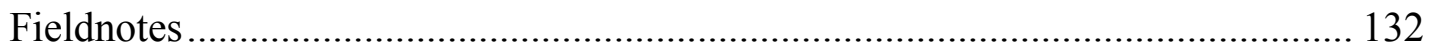

Developing the Case-by-Case Analysis for Each Participant................................... 133

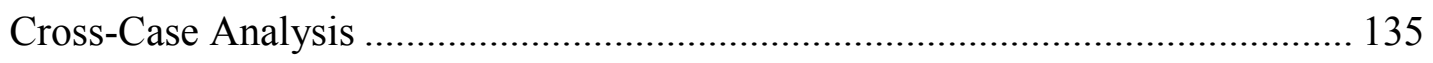

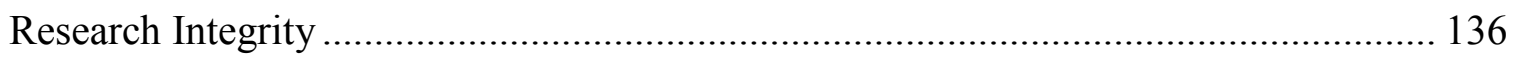

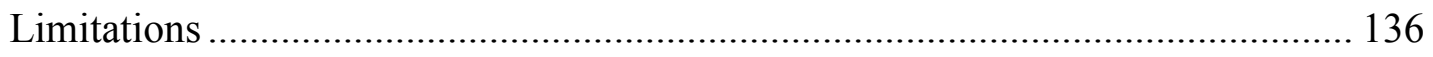


Ethical Considerations and Role of Researcher

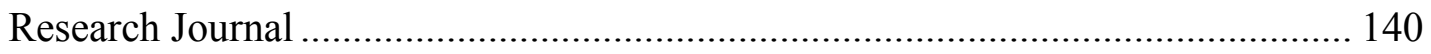

IV Results: Teacher Candidates' Profiles and Cross-Case Analysis ............................... 142

Looking at the Cases: Participants' Images of Mathematics, Culturally Diverse Students and Perceptions about Teaching Mathematics............................................................... 144

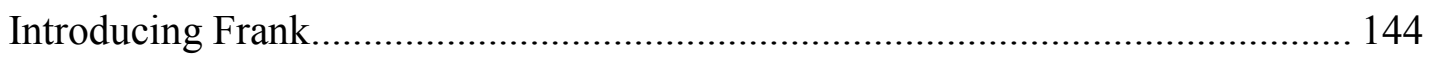

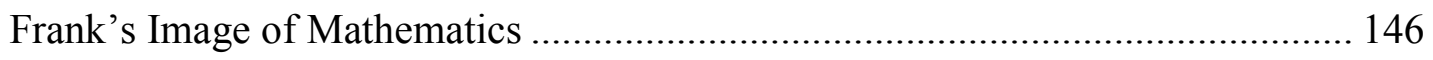

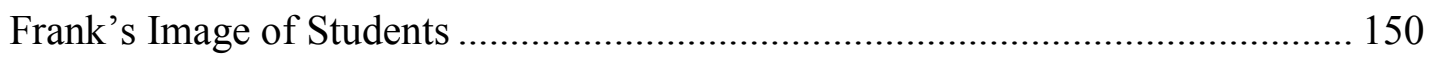

Frank's View of Teaching Mathematics With Culturally Diverse Students .......... 156

Researcher's Discussion: The Relationship Between Frank's Images of Mathematics, Students, Culture, and Teaching .................................................... 163

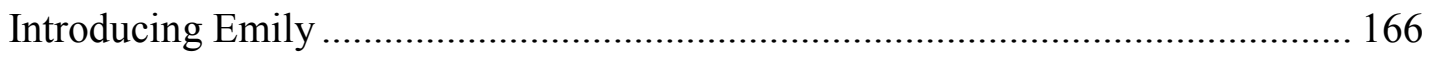

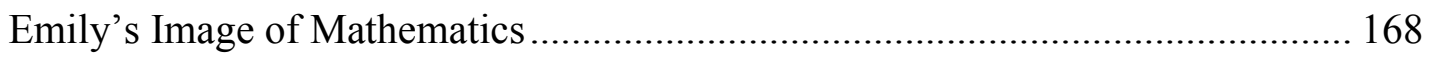

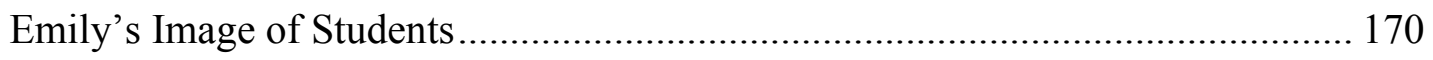

How Emily Perceived Diversity and Culture........................................................ 172

Emily's Perception of Teaching Mathematics........................................................ 175

Researcher's Discussion: The Relationship between Emily's Images of Mathematics, Students, Culture, and Teaching ..................................................... 181

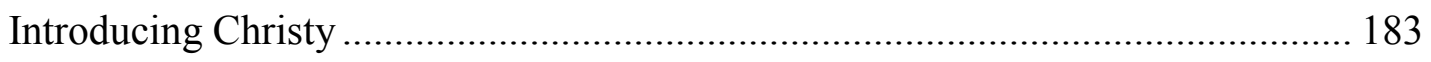

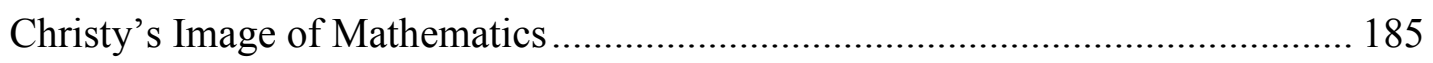

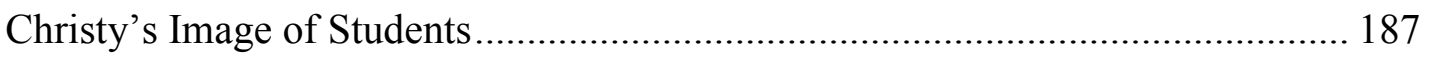

How Christy Perceived Diversity and Culture....................................................... 187

Christy's Perception of Teaching Mathematics ...................................................... 191

Researcher's Discussion: The Relationship Between Christy's Images of Mathematics, Students, Culture, and Teaching 


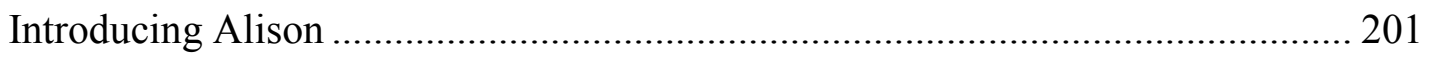

Alison's Image of Mathematics .............................................................................. 203

Alison's Image of Students ............................................................................... 207

How Alison Perceived Diversity and Culture.......................................................... 208

Alison's Perception of Teaching Mathematics ......................................................... 211

The Relationship Between Alison's Image of Mathematics, Students, Culture and

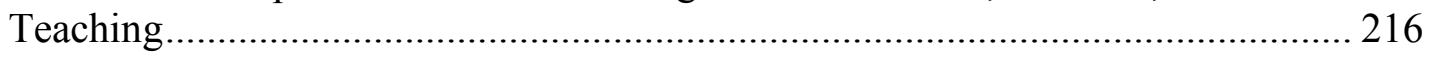

Looking Across Cases: Images of Mathematics and Students .................................... 218

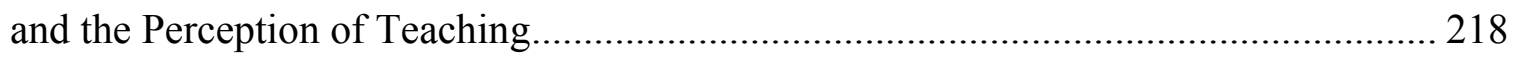

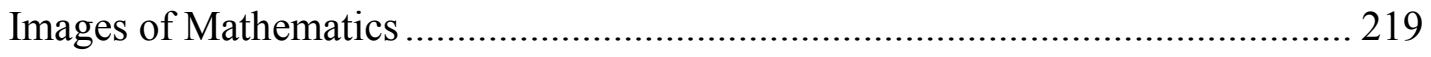

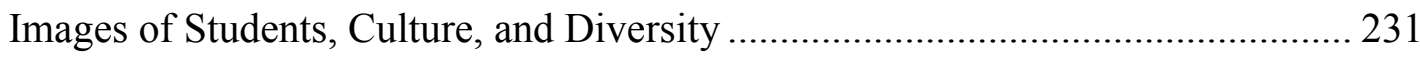

The Perception of Teaching Mathematics With Culturally Diverse Students ........ 234

Culturally Responsive Teaching ......................................................................... 240

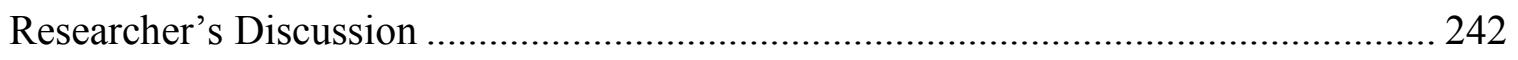

V Discussion, Conclusions, and Implications............................................................. 249

Summary and Conclusions ……………………………...................................... 251

What Images of Mathematics Do Elementary Teacher Candidates Hold?............. 251

What Images of Culturally Diverse Learners in the Mathematics Classroom Do Elementary Teacher Candidates Hold?.................................................................... 254

What is the Relationship, if Any, Between and Among the Images of Mathematics, Culturally Diverse Learners, and the Teacher Candidates' Perceptions about Teaching Mathematics to Such Learners? ............................................................. 255

How do Teacher Candidates Perceive Teaching Mathematics in a Multicultural

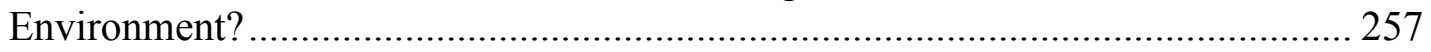

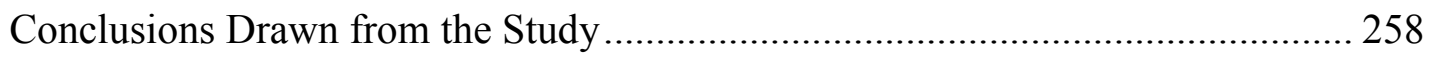

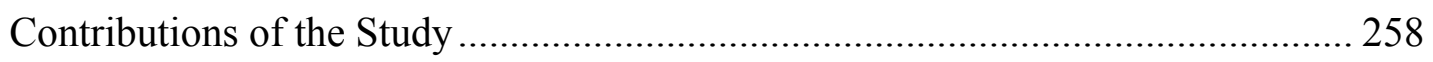




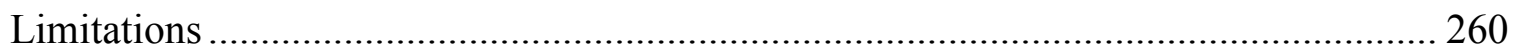

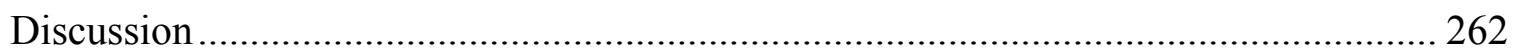

Images of Mathematics and Their Impact on Teaching........................................ 262

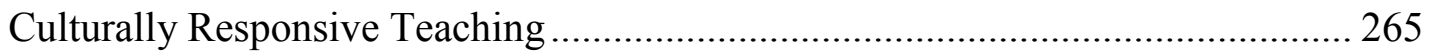

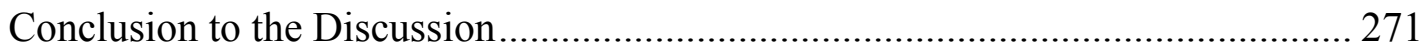

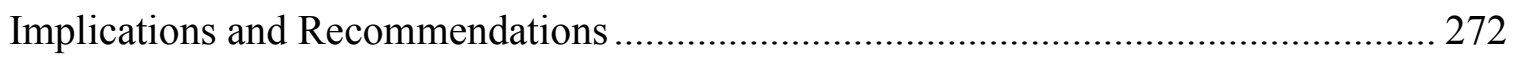

Recommendations for Teacher Education Programs ............................................. 272

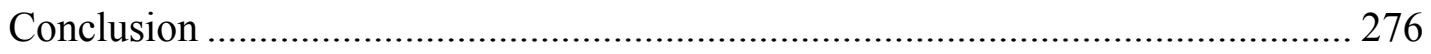

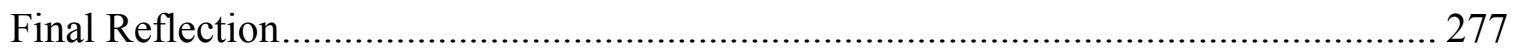

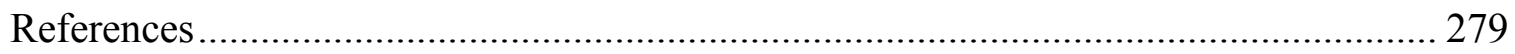

Appendices

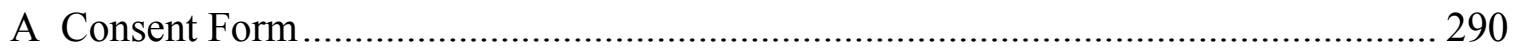

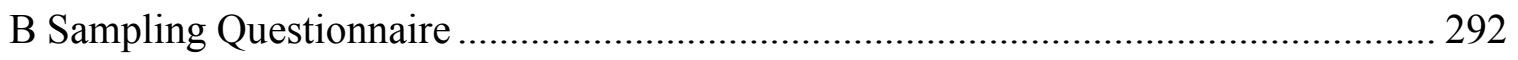

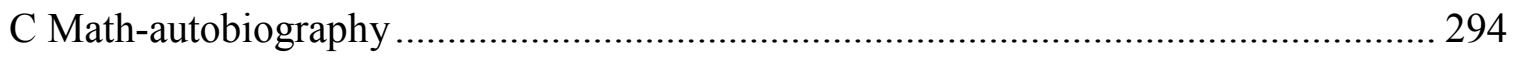

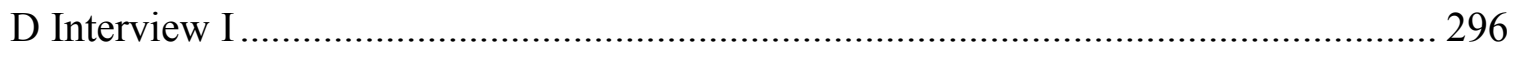

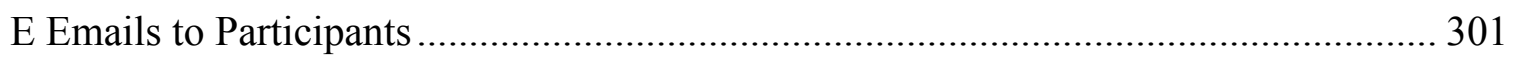

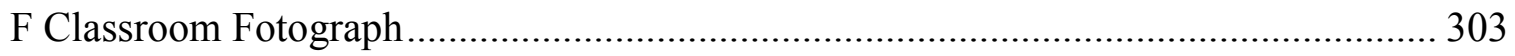

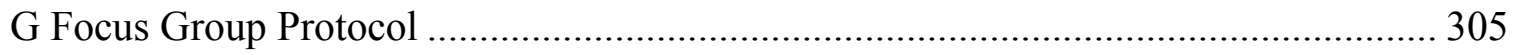

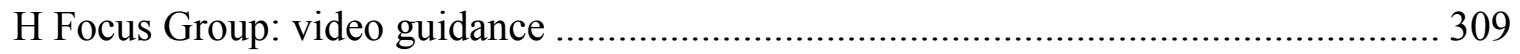

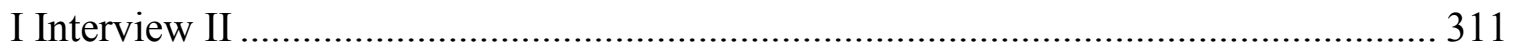




\section{List of Tables}

Table

Page

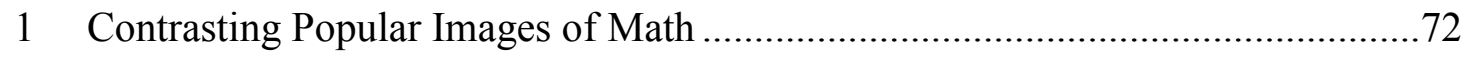

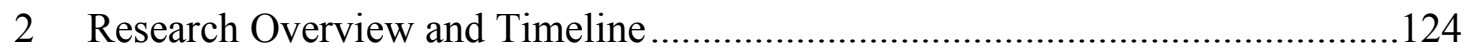

3 Participants' Images of Mathematics............................................................253

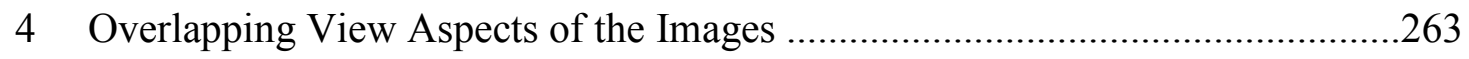




\section{List of Figures}

Figure

Page

1 Theoretical Framework That Ground My Work....................................................23

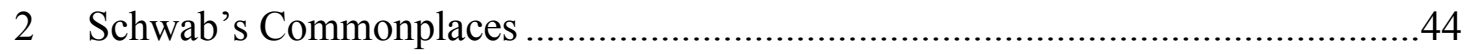

3 The Traditional Image and Teaching ................................................................

$4 \quad$ The Humanistic Image and Teaching ..................................................................

5 The Relationship of Teachers' Images, Knowledge, Dispositions and Perceptions About Teaching and the Learner..................................................90 


\section{CHAPTER I}

\section{PROBLEM STATEMENT AND THEORETICAL FRAMEWORK}

Riding in the elevator with applicants for the teacher education program in which I teach, I listened to a conversation: "I think mathematics is the easiest subject to teach since it is just numbers and there are only right or wrong answers," one of the applicants said. "That's what scares me," another applicant responded, "I never understood what was going on in math and I always had a hard time. I'm not a math person." "Yes, that's how I remember it. I only survived math by doing everything the way I was told, but I never got it either," a third applicant added. "But teaching and learning mathematics is just like teaching and learning another language" offered one more applicant, joining the conversation. I do not know how this conversation ended, but I know that these expectations and experiences may interfere with their perception of mathematics teaching, and therefore influence how teachers teach (Ball, 1990a). When I started teaching fifth grade in my own mathematics classroom, I first had an image of mathematics and understanding of how mathematics should be taught similarly to these applicants. For example, I believed that numbers were always the same and because mathematics was somewhat universal, it was easier to teach than other subjects. I vividly remember how much I struggled to teach to the needs of all my students. I reached most of my students, but I was not able to fully make a connection between the child as a learner and the mathematics. The image of mathematics I held, and my own experiences in learning mathematics, made it difficult for me to see a connection between mathematics and the child as a whole person. I found it similarly difficult to fully 
appreciate the context in which teaching and learning happened. I did not understand why I was unable to provide equal learning opportunities when I first started teaching. Only when I had to prove my own mathematical knowledge in an unfamiliar cultural context did I begin to appreciate the importance of cultural background for the understanding and practice of mathematics. Simple mathematical problems became challenging because the problems were not related to my personal and/or cultural knowledge. This experience changed the image of mathematics I held and the way I teach mathematics. After more than five years of teaching, for the first time, I understood that mathematics is not culture-free, but rather context-dependent.

It became apparent to me that mathematics is socially constructed and embedded in human activity and knowledge-based practice. I agree with Ernest (2009) that an ethnomathematical perspective places mathematics in societal, cultural and historical contexts which have shaped how people integrate mathematics into their behavior and how they see mathematics. In consequence, students bring different values and previous experiences of mathematics to the classroom. Through teaching mathematics to children different from my own cultural background, I became aware of the challenges that culturally diverse students face in the classroom. I began to see how a culturally responsive pedagogy might help to create equal learning opportunities for all students. "A culturally responsive mathematics education needs to acknowledge the pan-human origins and presence of mathematics in all of its diverse forms" (Ernest, 2009, p. 56). The dimensions of culturally responsive teaching are discussed later in this paper. 
That day in the elevator, I wondered whether those future teacher candidates would develop into "adaptive experts" (Bransford, Darling-Hammond, \& LePage, 2005, p. 3), who have the knowledge and moral disposition to "affirm diversity" (Nieto \& Bode, 2011, p. 398) and create equal learning opportunities for all children by implementing culturally responsive pedagogy. In this dissertation, the term all children refers to "students with exceptionalities and of different ethnic, racial, gender, sexual orientation, language, religious, socioeconomic, and regional/geographic origins" (National Council for Accreditation of Teacher Education, 2010, Footnotes, para. 7). An adaptive expert is committed to lifelong learning and is determined to always have the knowledge and skills required to adjust teaching in a setting of ever-changing diversity.

\section{From Achievement Gap to Opportunity Gap}

It is not news that today's classrooms are multicultural in nature, but never in the history of the United States have the demographics of schools changed as rapidly as they are changing today (Cummins, 2000; Darling-Hammond \& Bransford, 2005; Hemphill, Vanneman, \& Rahman, 2011). I agree that "diversity is the nature of the human species, and students are and always have been different from each other in a variety of ways" (Banks et al., 2005, p. 232). This dissertation research therefore focused on the necessary changes in the way we teach and learn mathematics to adapt to the changing cultural and linguistic diversity in our schools. I see diversity as influenced, but not limited, by "family, community, geographical location, designations of race and ethnicity, language, strong interest affiliations, religion, gender, and sexual orientation" (Horowitz et al., 2005, p. 114). Horowitz et al. further elaborated that each individual is shaped by the 
interaction within a society. At the same time, the individual action influences society and culture in which the individual is acting.

According to Banks et al. (2005), 30 years ago students of color made up 22\% of the school population. The percentage of students of color enrolled in public schools increased to 39\% in the year 2000 (United States Census Bureau, 2010). The National Center for Educational Statistics (2013) predicted that in 2021 the enrollment of students who have two or more races will increase by $34 \%$. The United States Census Bureau (2010) stated that the White population had been the slowest growing race group in the nation. While the U.S. population had grown by $9.7 \%$ over the last decade, the White population grew by only $6 \%$. In consequence, the White population decreased from $75 \%$ to $72 \%$. Referring to United States Census (2007) data, Darling-Hammond (2010) stated "that ethnic minorities will increase from one-third of the nation's populations in 2006 to 50 percent in 2042" (p. ix). In addition, immigration has been constantly changing the demographics of schools in the United States. According to Chu (2009), children of immigrants and foreign-born children made up approximately $20 \%$ of the K-12 school system. Chu further stated that about $40 \%$ of these students show limited English proficiency (LEP). In the late $20^{\text {th }}$ century, education in the U.S. was dominated by middle class European-Americans. Disadvantages for children who do not belong to this mainstream cultural group are still present today (Ovando, 2003; Ovando, Combs, \& Collier, 2006). The rapidly changing student population brings new challenges for teachers and teacher educators trying to provide equal learning opportunities for all students (Banks, 2008; Darling-Hammond \& Bransford, 2005). 
Statistically, in Oregon and the entire U.S., the mathematics test scores of students from Hispanic, African American, and Native American backgrounds lag behind those of students from White American backgrounds by approximately 20\% (Hemphill et al., 2011; Oregon Department of Education, 2011). Between 1990 and 2009, fourth-grade mathematics test scores have increased overall. However, there was no significant change in the achievement gap between White and Hispanic, African American, and NativeAmerican students (Hemphill et al., 2011). Referring to the 2005 National Assessment of Education Progress (NAEP) results, Ladson-Billings (2006) stated that in the U.S., students of African American or Latino backgrounds statistically underachieve in mathematics throughout all grades. Gay (2010) stated that "the consequences of these disproportionally high levels of low achievement are long term and wide-reaching, personal and civic, individual and collective" (p. 1). The continuous low level of achievement of students from some diverse backgrounds (e.g., students of color or students of a low socioeconomic status) is a function of unequal access to key educational resources as well as a function of how students are perceived regarding their race, class, or culture (Darling-Hammond, 2010).

While the validity of using test scores to assess student achievement is questionable, Darling-Hammond (2010) stated that "by flagging differences in students' performance by race and class, it shines a spotlight on long-standing inequalities and has triggered attention to the needs of students neglected tin many schools" (p. 76). Students from non-White, European-American backgrounds often do not have the learning opportunities at school which they would need to overcome their disadvantages (Gay, 
2010). Scholars of multicultural education (e.g., Gay, 2010; Ladson-Billings, 2006; Nieto \& Bode, 2011) have argued that the so-called achievement gap is an artifact of an educational system that continues to fail to provide equal learning opportunities to culturally diverse children alongside students who are "White mainstream students" (Banks, 2008, p. 42). Darling-Hammond (2010) stated that although most attention is paid to the achievement gap, less attention is "paid the opportunity gap-the accumulated differences in access to key educational resources-expert teachers, personalized attention, high quality curriculum opportunities, good educational materials, and plentiful information resources-that support learning at home and at school" (p. 30).

This “opportunity gap" (Darling-Hammond, 2010, p. 30) presents an intolerable situation of social injustice. Gay (2010) and other educational scholars like Delpit (2006), Nieto (2005), and Ladson-Billings (1995b) repeatedly stated that the public school system needs to be changed because the values, knowledge and experiences represented in schools are not confirming the values, knowledge and experiences of students from all cultural backgrounds. Students who see themselves and their backgrounds represented in schools are much more likely to make the necessary connections to be actively engaged in learning (Banks, 2006).

One possible way to explain the opportunity gap is that some culturally diverse students are often not familiar with the context upon which instruction is based. Moreover, they are sometimes not able to understand the contextual and instructional language to the extent needed for academic success (Cummins, 2000; Ovando et al., 2006). For example, a typical mathematical problem about the probability of drawing a 
particular card from a deck of cards can easily become a linguistic and cultural challenge. Students must be able to decipher the question before they can turn it into an arithmetic problem that can be solved with a simple operation. When I took my specialty area test in mathematics for my teaching credentials, I experienced firsthand that turning the question into a mathematical formula can be impossible if you are not familiar with a "deck of cards," or in my case, as an adult immigrant from Germany, simply not familiar with an American deck of cards. Other scholars (Cummins, 2000; Ovando, 2003) provided evidence that students who have immigrated encounter learning challenges because they are not familiar with the cultural background of the school community or with the culture of learning within the typical United States school. Heritage, socioeconomic background, cultural and language background, and learning ability all have an impact on students' learning (Banks, 2006; Ladson-Billings, 2006; Nieto, 2000).

I argue that this opportunity gap poses a serious problem to individual learners as well as the society at large. From my experience as a middle school and elementary school teacher, I conclude that students who do not have an opportunity to understand basic concepts of mathematics in elementary schools will most likely struggle in mathematics throughout their career. Moreover, mathematical skills are gatekeepers for college and professional career opportunities (Stinson, 2004). In consequence, I consider providing equal learning opportunities to all students to be a moral obligation for all teachers and for the entire educational system. The purpose of the study was, therefore, to gain understanding of teacher candidates' perceptions of culturally diverse students and 
mathematics, as well as the possible relationships these perceptions have to teaching and learning mathematics.

\section{Multicultural Education}

One way to look at the achievement gap and to understand the problem of the opportunity gap is through the theoretical lens of multicultural education. In this section, I first define multicultural education and ground it in a concept of culture. Later, I elaborate on different approaches of multicultural education as they developed historically, which led me to introduce a reconstructionist approach to multicultural education.

As a theoretical framework, multicultural education centrally informs my work. Sleeter and Grant (2003) developed five approaches to multicultural education. Most important for my framework is the approach called "The Education That is Multicultural and Social Reconstructionst” (p. 195), which Sleeter and Grant (2009) now call "Multicultural and Social Justice Education." However, in this dissertation I continue to use the older term of Social Reconstructionist because I perceive that term as a call to action to change the educational system. I think the term social justice education implies less activism. I argue that a culturally responsive pedagogy is an enactment of the Education That is Multicultural and Social Reconstructionst that can lead to social justice. (Following Sleeter and Grant, I capitalize the five approaches of multicultural education. I use lower case text when I refer to multicultural education in general.) 


\section{What is Multicultural Education?}

Banks (1997), who is often seen as a founding father of multicultural education, defined multicultural education as:

an idea, an educational reform movement, and a process whose major goal is to change the structure of educational institutions so that male and female students, exceptional students, and students who are members of diverse racial, ethnic, and cultural groups will have an equal chance to achieve academically in schools. (p. 2)

Later, Banks (2008) added a focus on students from diverse social classes as well as a call for restructuring the curriculum to his definition of multicultural education.

Furthermore, Banks (2006) stated that multicultural education aims to restructure education so that all children "will acquire the knowledge, skills, and attitudes needed to function effectively in a culturally and ethnically diverse nation and world" (p. 129). He explained that multicultural education empowers "all students to become knowledgeable, caring, and active citizens in a deeply troubled and ethnically polarized nation and world" (p. 129).

Sleeter and Grant $(1987,2003)$ explained that multicultural education emerged from the Civil Rights movement and aims to reform the educational system toward social justice and equal opportunities. Although at first multicultural education was mainly intended to target issues related to racism in schools (Sleeter \& Grant, 1987), "multicultural education has emerged as an umbrella concept that deals with races, culture, language, social class, gender, and disability” (Sleeter \& Grant, 2003, p. 31). Sleeter and Grant (2003) stated that multicultural education takes a stance against "unequal positions of power in the United States" (p. iv) caused by differences. The U.S. 
school system that favors the "haves" (Sleeter \& Grant, 2003, p. iv) needs to be changed so that diverse groups are treated more equally.

\section{The Concept of Culture in Multicultural Education}

The concept of culture is fundamental for the framework of multicultural education. Whereas Banks (2008) saw culture as "the ideations, symbols, behaviors, values, and beliefs that are shared by a human group" (p. 133), McLaren (2007) used the term culture more widely "to signify the particular ways in which a social group lives out and makes sense of its 'given' circumstances and condition of life" (p. 201). He further defined culture "as a set of practices, ideologies, and the values from which different groups draw to make sense of the world" (p. 201). This dynamic system of "culture determines how we think, believe, and behave, and these in turn, affect how we teach and learn” (Gay, 2010, p. 9). Synthesizing these definitions, Gay (2010), McLaren (2007), and Banks (2009) seemed to agree that culture is a constantly changing system of practices, ideologies, symbols, behaviors, values, and beliefs that defines who we are, what we do, and how we live, interact, teach and learn. Culture defines how we interact with and within a group and within society at large.

Gay (2010) described that teachers as well as children bring their own personal, cultural identity into the classroom, which influences how teachers and children see each other and the school itself. Children are influenced not only by their socioeconomic background; social-cultural environment; stage of mental, physical, and spiritual development; knowledge and experiences, but also by the way they see the world and interact with it. Every single child contributes to the classroom diversity (Gill, Ashton, \& 
Algina, 2004). Gay (2010) noted that education is influenced by cultures that are "multidimensional and constantly changing" (p. 10). Putting culture in the center of educational decision-making by teachers might therefore help to provide access to knowledge for all children.

The literature I have read showed a wide range of factors that contribute to culture. Culture simultaneously includes the concepts of "family, community, geographical location, designations of race and ethnicity, language, strong interest affiliations, religion, gender, and sexual orientation" (Horowitz et al., 2005, p. 114). Banks (2008) and Gay (2010) used the term "ethnicity" to describe distinguished groups who share a common history and identity as well as values, beliefs and the way they behave and communicate. I exclusively use the term culture to capture all the entailed social elements simultaneously because all aspects of culture impact learning and a teacher must see them all (Horowitz et al., 2005). Finally, the notion of language diversity is often excluded from definitions of multiculturalism (Sleeter \& Grant, 2003). However, because language and culture are intimately related, I see language diversity as an essential part of cultural diversity.

\section{Historical Approaches to Multicultural Education}

Because educators have not defined a unified, single concept of multicultural education, many scholars have developed different approaches to multicultural education. Sleeter and Grant (1987) based their typology of approaches on a review of the literature, as well as their experiences as practitioners and scholars. Sleeter and Grant developed five approaches-"Teaching the Exceptional and the Culturally Different," "Human 
Relations," "Single Group Studies," "Multicultural Education," and "Education That is Multicultural and Social Reconstructionist" (p. 422)-to categorize multicultural education. Calling all these five approaches "multicultural education" (Sleeter \& Grant, 1987), Sleeter and Grant (2003) elaborated as follows, putting those approaches into historical context.

During the time of desegregation in the United States, White educators often saw students of color as different and "culturally deprived" (Sleeter \& Grant, 2003, p. 32). At the same time, special educators were calling for the acceptance of "disabled students' differences" (p. 33). First, the "Teaching the Exceptional and the Culturally Different approach" emerged. This approach "focuses on adapting instruction to the student differences for the purpose of helping these students succeed more effectively in the mainstream" (p. 33). For example, under the assumption that the students lacked the knowledge of the mainstream culture, the teacher would investigate the students' background and teach them what they did not know about mainstream culture. However, Sleeter and Grant explained that this approach could also lead to the assumption that not all students have the capacity to learn based on their background. A teacher might lower the expectations for culturally diverse students.

At the same time, educators from the post-World War II Intercultural Education Movement developed the second approach, "Human Relations," which holds that "love, respect and more effective communication should be developed in schools to bring people who differ closer together" (Sleeter \& Grant, 2003, p. 33). Sleeter and Grant explained that teaching under a "Human Relations" approach should be embedded in an 
overarching school-wide approach and should focus on cooperative learning in the classroom. For example, a newspaper project could be a way to draw upon everybody's strengths and to build a supportive classroom environment.

Furthermore, in the 1960s the "Single Group Study" approach emerged to "foster cultural pluralism by teaching courses about the experiences, contributions, and concerns of distinct ethnic, gender, and social class groups" (Sleeter \& Grant, 1987, p. 422). This third approach is rooted "in educational, philosophical orientations that agree that education is not a natural process but rather is used by government and certain others (e.g., labor and business) for social and political purposes" (Sleeter \& Grant, 2003, p. 117). Therefore, schools should help learners to become critical thinkers and guide their behavior based on cultural analysis and reflection. For example, a unit on immigration should focus on historical aspects of immigration as well as current immigration issues. Reasons, issues, similarities and differences should be discussed under a broader social aspect (Sleeter \& Grant, 2003).

The "Multicultural Education" approach developed in the 1970s when educators saw the need for more complex frameworks for educational reforms. "This approach links race, language, culture of gender, disability, and to a lesser extent social class, working toward making the entire school celebrate human diversity and equal opportunity" (Sleeter \& Grant, 2003, p. 33). For example, the school community should stay in close contact and communication with families. Including the community in school-wide events and extracurricular activities is one way to promote "equal opportunity in the school," and "social structural equality and cultural pluralism" (p. 
159). For example, a mathematics unit on measurements could include an investigation of which measurements are used at home, and how. The regular school lesson could be based on the results of the students' investigations. Child-led workshops for parents and family math-nights, planned by students and teachers, would not only improve the communication between home and school, but also show how different mathematics can be in approach and practice.

Finally, in the 1970s and 1980s, the fifth approach, "Education That Is Multicultural and Social Reconstructionist" started to develop. This approach, which according to Sleeter and Grant (2003) has been gaining popularity ever since, "extends the Multicultural Education approach into the realm of social action and focuses at least as much on challenging social stratification as on celebrating human diversity and equal opportunity" (Sleeter \& Grant, 2003, p. 33). More than any of the other approaches, the "Education That Is Multicultural and Social Reconstructionist" approach actively targets oppression and social structural inequality. In schools the curricula should "organize content around current and social issues" (p. 196). Sleeter and Grant elaborated that engaging the learner actively in critical thinking and analyzing alternative viewpoints is needed to involve the learner "actively in democratic decision making" (p. 196).

Whereas all approaches mentioned in Sleeter and Grant (2003) have had their merits over time, I see the "Education That Is Multicultural and Social Reconstructionist" approach (hereafter referred to as simply Reconstructionist) as the one that best captures the need for educational reform, potentially bringing more social justice into education 
and society. I argue that Culturally Responsive Pedagogy, which I discuss later, can be seen as an enactment of the Reconstructionst approach in the classroom.

\section{Dimensions of Multicultural Education}

To conceptualize multicultural education and to make it accessible for practitioners and researchers, Banks described five distinct but interrelated dimensions in his definition of multicultural education: "content integration," "knowledge construction," "prejudice reduction," "equity pedagogy," and "empowering school culture and social structure" (Banks, 2009, p. 15). Banks (2008) elaborated that "content integration" determines how and what content knowledge about selected cultures is included in the curriculum to teach concepts of a subject area. Integrating content that represents the cultural diversity in a school or a classroom is often the only way that multicultural education is integrated. Because of this narrow conception, mathematics teachers often see multicultural education as irrelevant for their subject (Banks, 2008). However, Banks explained that such approaches to content integration, which adapt to the contributions of different cultures, only reflect the views and values of the dominating society of that culture. A transformative approach instead would make it possible to look at the subject matter from another perspective. However, there are ample opportunities for a mathematics teacher for content integration. For example, focusing on the accomplishments of mathematicians who are not White would help students of color to better identify themselves with the subject, but would not transform the students' knowledge. 
In addition, Banks (2008) further explained that building transformative knowledge is an important element of the "knowledge construction process" in multicultural education. Banks described that knowledge is constructed within a discipline or a subject area in specific ways. Knowledge can be constructed and held differently, but not independently by, for example, researchers and students. In multicultural education, the construction process considers the impact a researcher has on the knowledge that is created as well as on the learners themselves. Therefore, the knowledge production process also asks what the role of the teacher is in helping the learner reach an understanding of culture and knowledge construction. Drawing upon transformative learning, a teacher helps the learner to conceptualize knowledge about various groups (Banks, 2008). For example, "Teachers help students understand how knowledge is created and how it is influenced by factors of race, ethnicity, gender, and social class" (Banks, 2006, p. 133). Knowledge that is constructed by an individual or group is influenced by the society and culture they live in, as well as the person's interpretations of experiences and position within a society (Banks, 1993a). A more indepth discussion of teachers' knowledge follows.

Banks (2008) further noted that understanding the knowledge construction process makes students aware of biases, assumptions and frames of reference, and therefore leads into the dimension of "prejudice reduction." "This dimension focuses on the characteristics of students' racial attitudes and how they can be modified by teaching methods and materials" (p. 32). A cultural context autobiography might help learners understand their own backgrounds and change their attitudes toward diversity. When 
teaching and learning reaches beyond the classroom and impacts behavior and attitudes in general, learning might lead to the dimension of "equity pedagogy." Consequently, “equity pedagogy" is builds into the entire school culture. "An empowering school culture and social structure describes the process of restructuring the culture and organization of the school so that students from diverse racial, ethnic, language, and social-class groups will experience educational equality and empowerment” (p. 35). Banks further noted that teachers who understand the impacts of social and cultural contexts on teaching and learning find ways to build on the child's background. This knowledge and understanding is used to create effective instruction toward the needs of all students.

Banks (2008) concluded that reform of the educational system is needed to implement the five dimensions of multicultural education. That is, school reform toward multicultural education has the potential to create equal learning opportunities for all students.

\section{Knowledge Construction and Critical Constructivism}

The definition of knowledge in the Merriam Webster's Collegiate Dictionary (1993) is wide ranging. From "the fact or condition of knowing something with familiarity gained through experiences or association" or "the fact or condition of being aware of something" to "knowledge applies to facts and ideas acquired by study, investigation, observation, or experience..." (p. 647), the definition shows that knowledge is a complex construct built by an individual interacting with the environment and with other members of the community. There is ongoing debate about how 
knowledge is created. Harris and Alexander (1998) explained that there seems to be an agreement among scholars who are constructivists that, at least, knowledge is actively constructed. In this view, a self-regulating learner is at the center of learning. The authors elaborated that deep and meaningful learning can only occur when the learner fully participates in the learning process. Kincheloe (2008) stated that knowledge is socially constructed and therefore dependent on the "knowers" as "historical and social subjects" constituting knowledge and constructions of the world in "special and temporal settings" (p. 9). Furthermore, he noted that constructivism is concerned with the nature of knowledge and how knowledge is validated. Phillips (1995) summarized the rich varieties of constructivism, saying, "Thus, in sum, human knowledge-whether it be the bodies of public knowledge known as the various disciplines, or the cognitive structures of individual knower and learners-is constructed" (p. 5).

Mulligan and Vergnaud (2006) explained that scholars of mathematics education prefer a constructivist over a behaviorist approach to teaching mathematics. A constructivist approach not only teaches the child mathematics, but also develops the learners' ability to communicate knowledge. In addition, Mulligan and Vergnaud stated that constructivism places mathematics in culture and society, and therefore the social background cannot be neglected in teaching mathematics. I return to this idea in chapter 2 as I discuss images of mathematics as a discipline. The authors further stated that through constructivism, researchers of mathematics education developed an interest in the child as a learner of mathematics. Similar to Mulligan and Vergnaud's thoughts, the idea of constructivism that was applied in the National Council of Teachers of Mathematics 
$(1989,2000,2011)$ standards and principles saw knowledge as uncertain and actively constructed.

Constructivism is not clearly defined and approaches differ mostly in the way reality is seen. Mulligan and Vergnaud (2006) explained that radial constructivism, (e.g., von Glaserfeld, Cobb, Confrey, Richards, \& Steffe), claimed that "it was impossible to represent the real world" (p. 123), and therefore knowledge has to be actively constructed. Mulligan and Vergnaud further stated that the radical approach to constructivism would make communication problematic because words and symbols could have different meanings. According to Mulligan and Vergnaud, von Glaserfeld later developed a weaker form of constructivism because radical constructivism became too dogmatic in its view of the nature of knowledge.

In the late $80 \mathrm{~s}$, research in mathematics education started to focus more on analyzing teaching and learning in the classroom (Mulligan \& Vergnaud, 2006). A social constructivist approach focused more on the interrelationship between teacher and learner and "the development of socially constructed meaning through negotiation and consensus within the community of learners" (Mulligan \& Vergnaud, 2006, p. 125).

\section{Social Constructivism}

Considering the cultural diversity in schools discussed earlier, a social constructivist approach to learning is needed because new knowledge is constructed in the context of preexisting knowledge (Phillips, 1995), and every individual child has a unique perspective (Moschkovich, 2007). Teachers need to know the children as individuals who are shaped differently and influenced by their cultural background (Ball 
\& Cohen, 1999). Banks (1993a) stated that teachers have to see the children's "personal and cultural knowledge" as the "the knowledge of concepts and interpretations that students derive from personal experience in their homes, families, and community cultures (p. 7)"-and make use of it in their teaching. To be able to understand and make the necessary connections, teachers have to become learners of the students' culture (Diez \& Murrell, 2010). I argue that this view moves teaching into the realm of social interaction that engages all learners as well as the teacher.

From my perspective, social constructivism is implied by critical theory while it also adds the action toward social justice. From a perspective of critical theory, McLaren (2007) explained that knowledge is socially constructed as "the product of agreement or consent between individuals who live out particular social relations" (p. 64). He further stated that the world is symbolically constructed through social interaction with others, as well as through culture, context, custom, and history. Learning can only happen when a learner is actively involved in the creation of knowledge (McLaren, 2007). McLaren further noted that this participation possibly empowers the child to act responsibly in a democratic society, which requires that they are taught the culture and language of mainstream society while also maintaining their own cultural identities.

Social constructivism is also used to introduce critical constructivism (Kincheloe, 2008) upon which it is based. Kincheloe saw social constructivism as a basic perspective on learning. He saw knowledge as actively constructed through interaction with the world. These interactions are guided through the influence of society, culture, and history. A focus on the learning and its process of validation makes constructivism 
concerned with the impacts of teaching and learning upon society. This strong foundation of teaching and learning in the context of society and culture adds a critical perspective. Learners should be constantly engaged in critically "analyzing, interpreting and constructing a wide variety of knowledge emerging from diverse locations" (p. 3).

\section{Critical Constructivism}

I see critical constructivism as a framework that guides my research as well as the foundation of multicultural education. In this section I show the parallels between Kincheloe's (2008) epistemology of critical constructivism and the multicultural education movement described earlier, with a particular focus on the Reconstructionist approach. "The social epistemology of critical constructivism addresses the socio-cultural contexts of knowledge construction and serves as a powerful reference for cultural reform" (Taylor, 1996, p. 151). I summarize Kincheloe's main ideas of critical constructivism as: The world, all knowers, and all knowledge is socially constructed and embedded in a historical context. Social constructivism is concerned with the processes of knowledge production and validation through and for research and teaching. The learning process entails active and critical involvement of the learner. Critical constructivists are concerned with role of power dynamics in learning and in society, striving to embed social justice into the educational system.

Both critical constructivism and multicultural education place teaching and learning in a social environment. Learning takes place in and is influenced by the interaction between all learners and their social environment (Banks, 2008; Kincheloe, 2008; Taylor, 1996). Within the concept of critical constructivism, the learners can only 
act within their own reality. At the same time, reality is constantly shaped by the learner and reality does not exist until it is constructed in the mind of the learner (Kincheloe, 2008). Critical constructivism as well as multicultural education see the importance of the learner's self-awareness of their different individualities and their positions in the world. The learner and the teacher have to acknowledge these differences and influences and make them a central part of their actions (Banks, 2008; Kincheloe, 2008).

In addition, like critical constructivism, an important aspect of the Multicultural Education That is Reconstructionist is the education toward action on social justice. This empowerment requires not only that the learners create knowledge based on their experience and culture, but also know the impacts of culture and society on their knowledge (Banks, 2008; Kincheloe, 2008). It seems to be clear that a Reconstructionist approach based on critical constructivism would follow the described five dimensions of multiculturalism, "content integration,, "knowledge construction," "prejudice reduction," "equity pedagogy," and "empowering school culture and social structure" (Banks, 2009, p. 15). All five dimensions are interdependent and interrelated. For example, teaching mathematics for social justice (equity pedagogy) requires that teachers integrate the learners' knowledge as well as their cultural and social knowledge into the knowledge construction process at school (Gutstein, 2003).

I conclude that the Reconstructionist approach to multicultural education resonates with critical constructivism. As we have seen, combining critical theory and social constructivism leads to critical constructivism. I have argued that critical constructivism serves as a basic paradigm for an Education That is Multicultural and 
Social Reconstructionist. I further see culturally responsive pedagogy as an enactment of this framework. Consequently, in the next section I discuss culturally responsive pedagogy in detail. Figure 1 visualizes the theoretical framework on which I grounded my work as a teacher and researcher.

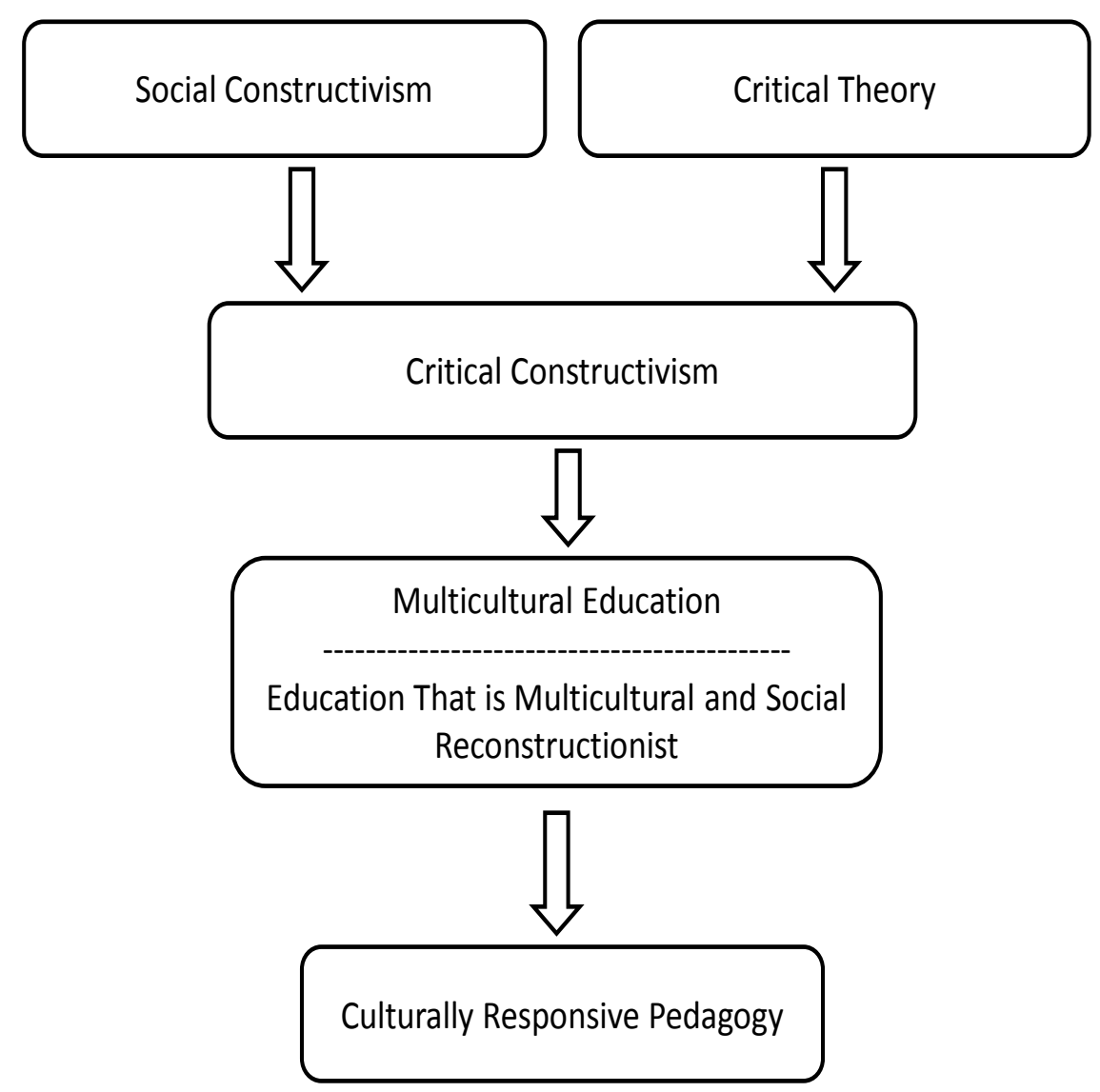

Figure 1. Theoretical framework that grounds my work.

\section{Culturally Responsive Pedagogy}

Culturally responsive pedagogy aims toward social justice and equal learning opportunities for all students (Banks, 2008; Gay, 2010; Ladson-Billings, 1995c).

Culturally responsive pedagogy refers to the "assumption that when academic knowledge 
and skills are situated within the lived experiences and frames of reference of students, they are more personally meaningful, have higher interest appeal, and are learned more easily and thoroughly" (Gay, 2010, p. 106). Following the concepts of social constructivist learning theories, culturally relevant pedagogy places learning in an environment in which knowledge is actively constructed in meaningful interactions. The integration of cultural context affirms diversity and sees diversity as an asset which opens the possibility for students to engage in a community of learners to reach beyond their own culture (Ladson-Billings, 1995c). According to Banks (2006), culturally responsive pedagogy focuses on prejudice reduction and social justice education through learning that is relevant for the learner. Finally, culturally responsive education is not limited to children of color, but serves the needs of all learners by taking the children's cultures and learning styles into account and building upon them (Banks, 2006).

Many terms have been used to describe culturally responsive pedagogy. Although Ladson-Billings (1995c) distinguished between different terms for different approaches, Sleeter and Grant (2003) saw several terms used simultaneously and interchangeably. I, therefore, synthesize the terms culturally relevant pedagogy, culturally responsive teaching, and culturally sustainable pedagogy. First, I argue that culturally relevant pedagogy describes an overarching framework for teaching. Later, I show that culturally responsive teaching is a term describing a practical approach in the classroom. Finally, I argue that the recently emerging term culturally sustaining education appears to not be dynamic enough to bring necessary changes to our educational system. 


\section{Definition of Culturally Relevant Pedagogy}

Ladson-Billings (1995a) defined culturally relevant pedagogy as a "pedagogy of opposition" (p. 160), which is similar to critical theory, as

specifically committed to collective, not merely individual, empowerment. Culturally relevant pedagogy rests on three criteria or propositions: (a) Students must experience academic success; (b) students must develop and/or maintain cultural competence; and (c) students must develop a critical consciousness through which they challenge the status quo of the current social order. (p. 160)

I argue that actions toward social justice cannot be limited to one classroom because culturally relevant pedagogy aims for collective empowerment of the students to challenge the system. According to Ladson Billings (1995c), a teacher who uses culturally relevant pedagogy not only needs to believe in a child's capability of academic achievement, but also has to act toward providing learning opportunities for all learners. At the 2012 annual meeting of the American Educational Research Association (AERA) in a presentation on "Equity pedagogy and culturally responsive teaching, learning, and actions in schools," Gloria Ladson-Billings reconfirmed her claim that achievement cannot be reduced to high test scores in high stakes tests. In her view, achievement is combined with a transformative learning experience that helps the child become a critically thinking member of the society.

Ladson-Billings (1995c) contended that teachers' beliefs and conceptions of knowledge should entail that knowledge is socially constructed and critically viewed. Thus, to facilitate learning, a teacher should scaffold and build bridges between the learner's background and experience and the knowledge presented in schools. Moreover, a teacher who is culturally relevant maintains a vital relationship with and among the 
learners. Within a learning community, children are encouraged to learn in collaborative settings and show responsibility for each other. Finally, the teacher should use a variety of assessments to capture student learning. In a culturally relevant pedagogy, assessments are used to give the learners feedback and to guide planning of future instruction. In addition, the children are able to communicate their learning in the way they prefer or that suits them best.

Ladson-Billings (1995c) described her theory of culturally relevant pedagogy as a theoretical framework for teachers and researchers. As a teacher educator and researcher, Ladson-Billings saw culturally relevant pedagogy as a theoretical framework that bridges theory and practice. Given that pedagogy refers to a framework for teaching, I argue that the choice of the word "pedagogy" indicates a systematic and theoretical nature of her theory with strong applications to the classroom.

\section{Culturally Responsive Teaching}

Building on the Ladson-Billings theoretical framework of culturally relevant pedagogy, Gay (2002) stated

Culturally responsive teaching is defined as using the cultural characteristics, experiences, and perspectives of ethnically diverse students as conduits for teaching them more effectively. It is based on the assumption that when academic knowledge and skills are situated within the lived experiences and frames of reference of students, they are more personally meaningful, have higher interest appeal, and are learned more easily and thoroughly (Gay, 2000). As a result, the academic achievement of ethnically diverse students will improve when they are taught through their own cultural and experiential filters. (p. 106)

From my interpretation of the words "responsive" and "teaching," this definition seems to focus more on the dynamic actions and interactions in the classroom than the 
previously discussed term "relevant." Almost identical to Banks' (2008) five dimensions of multicultural education, Gay (2002) saw "developing a knowledge base about cultural diversity, including ethnic and cultural diversity content in the curriculum, demonstrating caring, building learning communities, and responding to ethnic diversity in the delivery of instruction, as essential elements of culturally responsive teaching” (p. 106). Thus, according to Gay (2010), culturally responsive teaching indicates a communicative, caring and meaningful approach to teaching. She elaborated upon four dimensions of culturally responsive teaching.

Culturally responsive caring. Gay (2010) saw a teacher who cares for the culturally diverse child's "personal well-being and academic success" (p. 48) as a fundamental element of culturally responsive teaching. Going beyond feelings and creating relationships, caring in a culturally responsive way is seeing and valuing the whole child as a learner and a person, including valuing the child's cultural background. Gay explained that caring teachers know their students personally and academically. Caring teachers provide "spaces and relationships where ethnically diverse students feel recognized, respected, valued, seen, and heard" (p. 51). Gay explained that when, for example, a student of color does not comply with standards and rules, caring teachers should confront existing instructional presumptions and practices and take the student into account before they respond. Furthermore, Gay explained that a teacher who cares for the child always puts the child in the center of learning and builds instruction on student interests and experiences. For example, during a morning circle, an elementary teacher could provide a safe environment for the children to voluntarily exchange their 
experiences and feelings to create a classroom community of trust and caring on a daily basis. In addition, the teacher could observe and listen to the children and determine what the children's needs and interests are.

Culturally responsive communication. Gay (2010) stated, "Communication is strongly culturally influenced, experimentally situated and functionally strategic" (p. 125). Gay further stated that all learners in the classroom have their own way of communication. A child's communication style is shaped by cultural and societal norms, conventions, and assumptions. The inability of teachers to value cultural diversity in the classroom often causes academic failure because of miscommunication. Children might not be able to understand what the teacher or another student is trying to communicate and vice versa. Still, a culturally responsive teacher must not try to make everybody communicate in the same way. Knowledge about general communication styles of the groups represented in the classroom is helpful but not enough. Teachers should always reflect on their communication with the learners as well as the communication between the learners to determine how to best promote communication in a culturally diverse classroom.

Culturally responsive curriculum. Culturally responsive teaching aims to empower culturally diverse learners "through academic success, cultural affiliation, and personal efficacy" (Gay, 2010, p. 127). Therefore, the curriculum should draw on knowledge that relates to the learners' experiences within and outside of schools. Gay explained, following a social constructive learning theory, that knowledge can only be constructed in a meaningful interaction with a social environment. 
According to Gay (2010), a teacher should expose the learners to a wide selection of content that represents diversity. Gay explained that "culturally relevant curriculum content should be chosen and delivered in ways that are meaningful to the students for whom it is intended" (p. 128). "Content about the histories, heritages, contributions, perspectives, and experiences of different ethnic groups and individuals, taught in diverse ways, is essential to culturally responsive teaching" (p. 127). For example, students should not only learn about cultural groups, but also they should also deal with concepts, principles and ideas of "oppression, identity, powerlessness, privilege, culture, and struggle" (p. 169). For instance, students may learn about Asian Americans and their lives, experiences, and contributions in general. At the same time, the students learn about the many different ethnic groups in Asia. In mathematics, for example, a unit in geometry could draw upon patterns that have been traditionally used in pottery and basket weaving and relate these patterns to the students' experiences today. Learning should be situated in a meaningful curriculum context that connects to students' experiences and empowers them to take action. Therefore, Gay mentioned that involving students in the curriculum creation process to a certain extent is essential for culturally responsive teaching.

Also, like Banks (2008), Gay (2010) argued that cultural content should be integrated in the curriculum to inform the learner about culture and diversity. Giving the learners access to unbiased information helps to reduce stereotypes and prejudice behavior that is harmful to a child's success. For example, a TV-show could portray an ethnic group as lazy people because they are spending the afternoon sitting a shaded area. 
Children from this group might thus be seen in the same negative way as the characters in the TV show. These children are at risk for not achieving because teachers and other children might assume stereotypical behavior. A learning project to inform children and teachers, as well as the entire school community, about this particular group might show that an extended lunch break and shifting the work into the evening is relevant for construction workers in a hot and dry climate.

The culturally relevant content should be made available to the learners within the scope of the regular curriculum, as well as outside of it. It is important for the teacher to be aware that the children are not only exposed to cultural content in schools, but also at home. For example, mass media influences the images a person has about school, a subject or a group of people. In consequence, these images impact a child's selfawareness as a learner and a member of the community.

Culturally responsive instruction. Teaching and learning in a culturally diverse classroom is a complex and multidimensional task. Each child brings a unique style of learning to the classroom. Learning is shaped by the child's cultural background, values and beliefs. Balancing learning behaviors that might be beneficial for a certain group of children with seeing the child's individual needs, as well as the collective needs of the group, is a task the teacher has to perform during every single moment of teaching. Gay (2010) cautioned teachers to see the students' individual needs, rather than assuming the students behave as stereotypical of their social group. A teacher should help children discover their unique way of learning. Moreover, instruction which draws on the child's accomplishments is more likely to be successful than instruction which focuses only on 
deficits. Finally, a culturally responsive teacher believes in the child's capability to learn and has a disposition to create a safe and supportive learning environment for all children.

For example, reflecting on her own way of teaching, Gay (2010) explained that culturally responsive teachers support and facilitate learning. They give assignments which do not aim toward a single possible product, but rather provide the needed parameters in which students can perform. In addition, Gay mentioned rules and routines that should be established to help create a safe and supportive classroom environment. She also recommended cooperative learning to engage ethnically diverse students in learning. Project learning and open-ended assignments might be opportunities for teachers to enact culturally responsive teaching. For example, when I taught a fifth grade unit on statistics, I usually let my students decide what kind of data they liked to collect, and how to collect and present the data. The students were asked to collect data which reflected the backgrounds of the students in the classroom. The students worked in selfselected groups based on their interest. This instructional strategy allowed the curriculum content to be selected mainly by the students.

In this section I have provided a theoretical framework for culturally responsive teaching with some indications for classroom practice. In chapter 2, I discuss research on culturally responsive mathematics education and provide more specific examples.

\section{Culturally Sustaining Pedagogy}

The fact that Paris (2012) considered it necessary to add "culturally sustaining pedagogy" as another term to describe multicultural education shows how complex and 
difficult it is to conceptualize pedagogy for culturally diverse students and provide equal learning opportunities for all students. He stated,

Culturally sustaining pedagogy seeks to perpetuate and foster - to sustainlinguistic, literate, and cultural pluralism as part of the democratic project of schooling. In the face of current policies and practices that have the explicit goal of creating a monocultural and monolingual society, research and practice need equally explicit resistances that embrace cultural pluralism and cultural equality. (Paris, 2012, p. 93)

Paris explained that, more than ever, culturally and linguistically diverse students risk losing their cultural identity in order to fit into a dominant culture. Thus, taking a stance toward sustaining a child's culture, it is necessary to rethink educational practice. As Paris acknowledged, the concept of maintaining and promoting learners' cultural identity has always been part of culturally responsive and relevant pedagogy. Like LadsonBillings (1995c) and Gay (2010), Paris argued that a sustaining pedagogy embraces diversity and acts toward equality in education, which is essential for student success. His term culturally sustaining pedagogy is an attempt to reemphasize the value of cultural diversity as an asset and the need to maintain and actively support students' existing cultures.

However, my personal association with the term "sustaining" is of passively accepting and maintaining a status-quo. The synonyms for sustaining, provided by Microsoft Word Thesaurus, such as keep, nurture, support, hold up, hold, maintain, nourish, substantiate, affirm, preserve, conserve, etc. do not imply, from my perspective, action toward change. Because this interpretation is clearly not what Paris'(2012) had intended, I think the new term culturally sustaining pedagogy does not capture the scope 
of culturally relevant and responsive pedagogy. However, I would agree with Paris' suggestion to change the wording and our stances, if there were already equal learning opportunities and social justice in our educational system. We are far from it, and we need to continue our efforts to change how we affirm increasing diversity and teach with cultural responsiveness so that all students can learn. No matter which term we use, and no matter which dimension of multicultural education we come from, teachers, administrators, policymakers and researchers have to take action to change the educational system.

Because of the dynamic character and the application to practice, I continue to use the term "culturally responsive teaching" when I refer directly to classroom practice. Alternatively, I use culturally responsive pedagogy when I refer to overarching concepts of teaching as well as to describe research.

\section{Learning How to Teach in Culturally Responsive Ways}

A key element of culturally responsive teaching is paying attention to who the learner is and how the learner can be connected with the subject matter. From my experience as a fourth and fifth grade classroom teacher, I know that seeing the child in the classroom and creating a safe learning environment in which all students can learn is complex and multidimensional. Especially when it came to the teaching of mathematics, it was challenging to find ways to connect the subject matter and the child. As a classroom teacher, I was always morally committed and tried to take actions (Diez \& Murrell, 2010) to find a way to be an "adaptive expert" (Bransford et al., 2005, p. 3), 
always maintaining and improving my flexibility to adjust my teaching to the needs of the learners.

Today these moral dispositions of caring for all learners and their successful learning guide my work in teacher education and my research on teacher education. I agree with Bransford et al. (2005) that a teacher needs to possess the "moral disposition" (p. 5), knowledge and skills to act as an as "adaptive expert" (p. 3) from the very first day of teaching and throughout an entire career.

As an instructor in both a teacher education program for teacher candidates and a master's degree program for practicing teachers, I have noticed that both novices and experienced teachers experience difficulties when they try to apply the concepts of culturally responsive teaching to mathematics. It appeared that, even when these graduate students believed that culturally responsive teaching could be beneficial for all learners, they often hesitated to apply the concepts to mathematics instruction. Although working on the concepts of multicultural education, like Banks (2006), I often heard the comment, "This is all nice but does not apply to math; math is different." Such comments raised the question of whether or not, and if so, how the images that a teacher carries about mathematics influence the teacher's assumptions, beliefs and perceptions toward culturally responsive teaching.

\section{Focus Statement and Research Questions}

The increasing diversity in our classrooms calls for teachers who are able to see the needs of all children in the classroom and are able to build a relationship within the group of learners as well as between children and the teachers themselves. Teachers must 
see and listen to the individual child to create learning opportunities which take the students' cultural backgrounds into account in order to provide equal learning opportunities for all children. The beliefs, assumptions, and perceptions of mathematics that each teacher holds define how the teacher's dispositions and knowledge are reflected in the classroom and the way they connect the child and the mathematics (Ball, 1990a; Gill et al., 2004). Influenced by their previous experiences as a knower and learner of mathematics, elementary teacher candidates might not be able to acquire the necessary knowledge, skills, and dispositions to practice a culturally responsive pedagogy. Consequently, I wondered how elementary teacher candidates perceive teaching mathematics and cultural diversity.

Therefore, I implemented this study to investigate the images of mathematics and culturally diverse students of mathematics that elementary school teacher candidates hold, and how these images manifest in their way of perceiving teaching. That is, the study investigated how teacher candidates "see" mathematics and see children from culturally diverse backgrounds in a mathematics classroom. Furthermore, the study investigated the relation between the images of mathematics and the teacher candidates' perceptions of teaching mathematics in culturally diverse elementary classrooms. The findings of this study could prove useful to re-conceptualize elementary teacher education toward cultural responsiveness in the mathematics classroom in order to provide equal learning opportunities for all students.

Applying a critical constructivist research paradigm, I conducted a three-month qualitative multiple instrumental case study utilizing math-autobiographies, focus groups, 
and interviews to examine the images of mathematics held by four elementary teacher candidates enrolled in a 1-year graduate teacher education program in fall 2012 . The collective case study was guided by the overarching question: How do teacher candidates perceive teaching mathematics in a multicultural environment? Three sub-questions follow:

- What images of mathematics do elementary teacher candidates hold?

- What images of culturally diverse learners in the mathematics classroom do elementary teacher candidates hold?

- What is the relationship, if any, between and among the images of mathematics, culturally diverse learners, and the teacher candidates' perceptions about teaching mathematics to such learners?

\section{Intention and Contributions of the Study}

First, this study was intended to add to the fields of teacher knowledge and teacher education. Little empirical scholarship exists to describe teacher candidates' perceptions of mathematics, images that can shape their instruction, and this research added to our understanding of teacher candidates' knowledge of subject matter, culturally diverse students, and teaching. This study provided results that can be useful in redesigning teacher education programs, including the graduate teacher education program with which I am affiliated. It can also specifically help mathematics methods course instructors to make curriculum design decisions toward helping elementary teacher candidates develop culturally responsive dispositions and capacities in mathematics teaching. Understanding how teacher candidates perceive culturally responsive mathematics teaching might help us to rethink teacher education and the way 
the concept of culturally responsive teaching is integrated in teacher education in general, as well as the how mathematical content should be taught to pre-service teachers.

Second, this study also can add to my own future research relevant to teacher education. The focus of the three research sub-questions represent Schwab's (1973) "commonplaces of curriculum" of teacher, child and subject interacting with and within an environment. To gain a deep understanding of teacher candidates' way of thinking about teaching mathematics in a culturally diverse environment, it was necessary to focus on the interplay of teacher, child and subject matter. At the time and stage of my development as a researcher, all three research questions were equally important. The wide focus in this dissertation research provided me with the foundation and questions to focus on more specific aspects of teacher education at a later time.

\section{Why I Care About This Problem}

I was born and raised in a small town in Germany in a middle class family. I was the first member of my family who went to college.

When I first started teaching mathematics in a German fifth-grade classroom in an area with a low socioeconomic status, I was not prepared to teach to the needs of "my" children. I was surprised because after graduating from a 5-year teacher education program, I assumed I knew all I needed to know about teaching. However, I did not understand where my students came from, and I did not know how to connect with them. I did see the need for professional and personal development, so ever since I have been looking for ways of teaching mathematics which provide equal learning opportunities for all learners. As a cooperating teacher, I always enjoyed supporting teacher candidates on 
their way into the profession. After an action research project on how to improve teaching and learning in a bilingual mathematics classroom, I decided to become a teacher educator and educational researcher.

On several occasions in my life, I have experienced that math is everything else than a universal language. I also learned that mathematics can be a gatekeeper for career opportunities. For example, when I moved to the U.S. 10 years ago after having taught mathematics in Germany for many years, I looked at the test required for an advanced mathematics endorsement and decided to only pursue a basic math endorsement. I knew math would not help me understand anything on the test.

Therefore, I believe that culturally responsive teaching can help all students learn. Educating teachers accordingly is an important step in the right direction. I argue that what teachers know and how they see the subject and the culturally diverse learner shapes their dispositions toward and practice of teaching. 


\section{CHAPTER II}

\section{REVIEW OF THE LITERATURE}

In this chapter, I review literature regarding teachers' knowledge, dispositions, and images of teaching mathematics to culturally diverse learners. This literature review was guided by my overarching research question: How do teacher candidates perceive teaching mathematics in a multicultural environment? First, I focus on the knowledge that a teacher needs to have to teach in general, as well as in a particular subject area or discipline. I then focus on dispositions a teacher might need, and how those dispositions relate to their teaching, particularly in relation to culturally diverse students. I also explore the literature about how teachers' images of mathematics and diverse learners may relate to their way of thinking about teaching. In addition, I position my research within the scheme of existing literature. Finally, I conclude this chapter by arguing that the way teachers see mathematics relates to how the child is seen in the classroom, as well as how mathematics is taught. Given my interest in teacher education, I situate this discussion in that context.

\section{Teachers' Knowledge, Dispositions, and Perceptions}

An effective teacher education offers teachers the skills, knowledge and dispositions as a basic tool set which enables teachers to teach from the first moment they enter a classroom (Darling-Hammond \& Bransford, 2005). Darling-Hammond and Bransford further noted that during teacher education, teacher candidates need to develop the capacity to grow into experienced, highly effective, adaptive experts who are able to see the child and to act accordingly. 
The review of the literature led me to the question of why teachers need to be adaptive experts. Imagine any elementary school classroom, filled with children eager to learn. The children in this classroom come from various social, economic, ethnic, racial, language, religious, and family backgrounds; in short, they are culturally diverse. The children all have different ways in which they think, learn, communicate and interact with each other. There is also a teacher who should connect the content to be learned with the learner (Banks, 2006). Teachers need to find a way to support each child's learning style in order to make learning as successful as possible (Dunn \& Griggs, 1998). Teachers not only need to know their subject, but they also need to be familiar with the concepts that support understanding and teaching the subject (Darling-Hammond \& Bransford, 2005). Darling-Hammond and Branford further explained that, therefore, teachers need to understand a variety of learning theories, approaches to assessments, and pedagogical content knowledge-knowledge specific to teaching that is needed to connect subject matter and students-in order to teach a subject.

Consequently, I wondered about the dispositions that a teacher needs in order to become an adaptive expert and how teacher education can prepare teachers to meet the needs of their students. Banks (2006) noted that teacher education should develop the capacity in teacher candidates to respond to the needs of all students as they take their cultural and personal knowledge into account. How teachers see the child in the classroom depends on their dispositions (Diez \& Murrell, 2010). In addition, how teachers see the subject also shapes their perception of teaching the subject (Noordhoff, 1993). Moreover, teachers should take the context of teaching and learning-such as 
relevance of topics to the community-into account to make sound teaching decisions (Darling-Hammond \& Bransford, 2005). Huebner (1975) explained that successful teaching is much more than the implementation of teaching techniques and assuring that children learn the established rules and tradition of a society and a subject area by following a scripted curriculum. Teaching is about building relationships and creating a community in which everybody has a voice and is heard. Teaching is about seeing the child as an individual learner with unique needs that depend on the environment and situation a child comes from, is currently in, and will go into. In consequence, standards in teacher education should assure that teachers are prepared to teach to the needs of all students.

\section{Standards for Teacher Education}

InTASC has developed assessment standards for teacher education which have been widely used in the revision of teacher education programs. One focus of these standards is on preparing teachers to teach culturally diverse students. The Council of Chief State School Officers (CCSSO, 2011), under the directive from InTASC for teacher education program approval and state license agencies, stated: "An effective teacher must be able to integrate content knowledge with the specific strengths and needs of students to assure all students learn and perform at the high level." The InTASC core standards for teacher education are divided into the four categories: (a) learner and learning, (b) content knowledge, (c) instructional practice, and (d) professional responsibility. Each standard is further divided into the subcategories: "essential knowledge," "performances," and “critical dispositions.” Teachers should be able emphasize students' literacy and problem 
solving skills to improve cross-disciplinary skills. The standards appear to address this important aspect of teaching diverse learners. InTASC standards acknowledged that “teachers need knowledge and skills to customize learning for learners with a range of individual differences" (p. 3). It is further stated that teachers should consider their own and their students' backgrounds for any teaching decision. Furthermore, there are multiple references to diversity of students and cultural diversity in the introductory material as well in the standards themselves. For example, InTASC standard one focuses on preparing teachers to take the development of the learner into account. Standard three aims toward a social constructivist teaching and learning approach. This pattern of learner-oriented teaching and assessment continues to be reflected in all other InTASC standards. For instance, some of the standards refer to the goal to teach to all students and to the teacher's ability to be able to draw on students' cultures to create a social learning environment.

\section{Teachers' Knowledge}

The InTASC standards for teaching reflect the complexity of the knowledge that a teacher needs in order to teach in today's classroom. In this section, I focus on the knowledge that teachers need to teach in the classroom of the $21^{\text {st }}$ century. I first give a general overview of the domains of knowledge relevant for teacher education, highlighting subject matter knowledge and pedagogical content knowledge. I continue to discuss literature on curricular knowledge and the knowledge of teaching and learning. I conclude by showing that knowledge might have an impact on how teachers see their 
subject, the culturally diverse learner, and teaching mathematics with culturally diverse learners.

From the very first day to the last day in a classroom, teachers have to turn the theoretical construct of curriculum into practical, useable lessons and units for teaching. From a simplified perspective, a teacher connects content and students by following a curriculum. I use the four elements of Schwab's (1971) curriculum theory to establish a basic frame to explain teaching in that teaching always depends on what to teach and how to teach "in concrete situations loaded with concrete particulars of time, place, person, and circumstances" (p. 494). In "The Practical 3: Translation into Curriculum," Schwab (1973) defined teacher, learner, subject matter, milieu, and curriculum-making as the "bodies of experiences" (p. 501) that a curriculum specialist needs. Considering curriculum-making as an overarching theoretical knowledge that brings the other four domains together, Schwab (1973) defined subject matter, teacher, learners, and milieu as “commonplaces" (p. 501) of teaching (see Figure 2). According to Schwab, all four commonplaces are equally important. None of the four commonplaces can be neglected, nor should one dominate over the other. However, Schwab explained that a focus can be put on one select commonplace while others are still considered equally important and put in "proper relation" (p. 509). I would argue that a culturally responsive pedagogy focuses on putting the child back into the picture of teaching, but also focuses on the "milieu," which might possibly impact how teachers and students see the subject matter.

When we take Schwab's commonplaces from a theoretical curriculum level to an applied teaching level, we can see that teacher's knowledge comes down to knowing the 
subject matter, the learner, the teacher (knowledge of the self), as well as the milieu/environment and how to bring them all together. Hawkins (1974) described the special connection that is needed between those four elements. He looked at the teacherchild relationship and the importance of knowing the child and how the child thinks and the environment that shaped the child as a person and a learner. Hawkins further noted that the teacher has to see the world with the eyes of the students in order to help the students make sense of the subject matter as part of the world in which they participate.

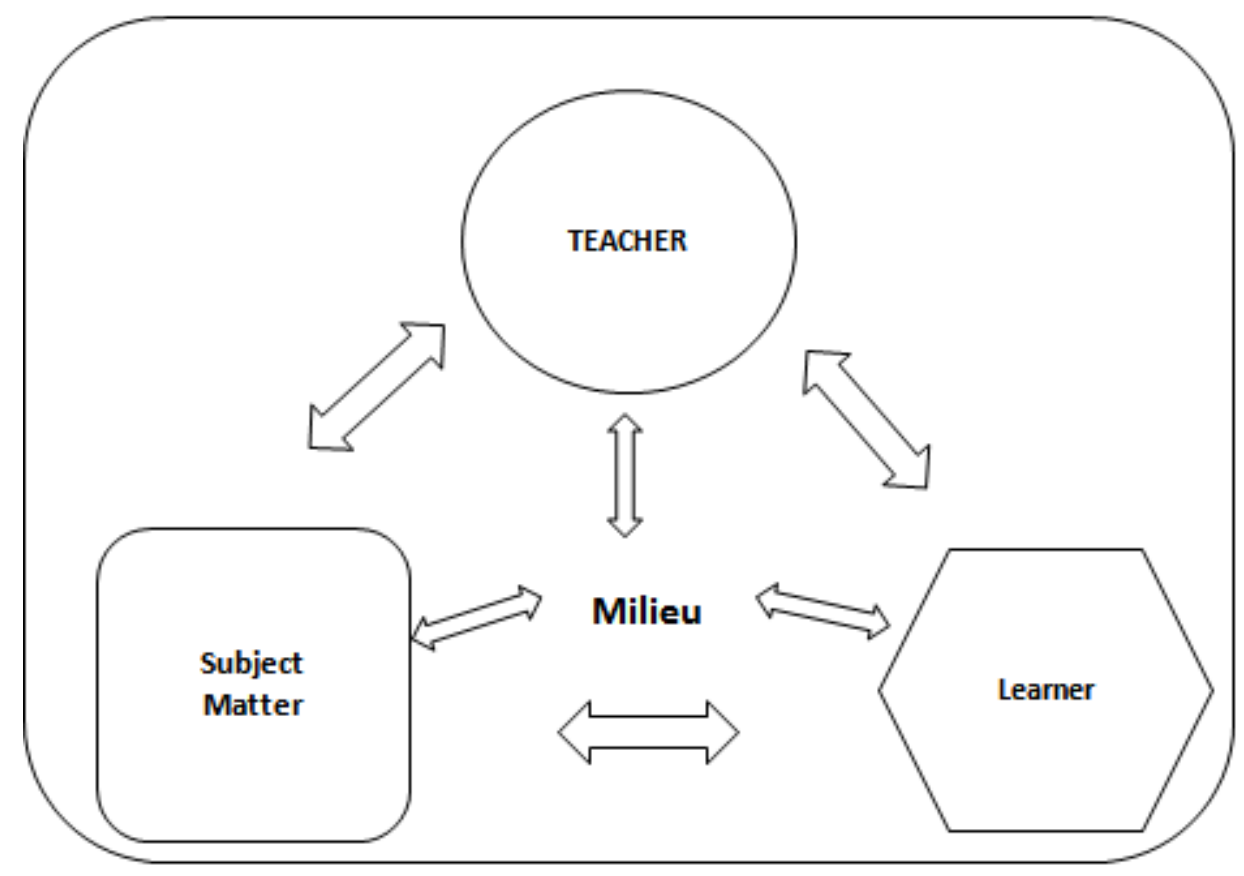

Figure 2. Schwab's commonplaces.

\section{The Subject Matter as Content Knowledge}

Shulman (1986) set the knowledge of the "subject matter" (p. 6) as a frame of reference for his theoretical framework. Shulman discussed the importance of knowing and understanding the subject matter as "content knowledge" (p. 9). Because the content 
knowledge that is required for teaching is highly complex, Shulman (1986) divided content knowledge into the categories "(a) subject matter content knowledge, (b) pedagogical content knowledge, (c) curricular knowledge" (p. 9). Shulman noted that "subject matter content knowledge" (p. 9) refers to deeply knowing the discipline and understanding the structure and concepts of a discipline. This concept entails understanding foundations and relations of its concepts. However, Moschkovich and Nelson-Barber (2009) illustrated that different cultures create concepts and knowledge of a discipline differently. In consequence, schools" "western notion of mathematical knowing" (p. 119) often conflicts with the concepts that culturally diverse students bring to school. Culturally responsive teaching needs to respond to conflicting notions of knowing.

Shulman (1986) noted that pedagogical content knowledge describes a dimension of subject matter knowledge specifically needed for teaching. A teacher must not only know how to present the ideas of a subject, but also has to find a way to make those ideas understandable to students. Pedagogical content knowledge goes beyond basic understanding of the discipline; it is knowledge that helps the teacher connect the learner and the subject matter. Pedagogical content knowledge includes an "understanding of what makes the learning of specific topics easy or difficult; the conceptions and preconceptions that students of different ages and backgrounds bring with them to the learning of those most frequently taught topics and lessons" (pp. 9-10).

Finally, curricular knowledge is an understanding and knowledge of material that represents the subject in school settings. Curricular knowledge is knowledge about what 
resources are available to teach and how to use the resources, and how they can most effectively be used to teach a subject.

I agree with McDiarmid and Clevenger-Bright (2008) that Shulman (1986) was instrumental in helping to raise awareness for the importance of pedagogical content knowledge. However, they argued that Shulman's focus on content and pedagogical content knowledge seems to be geared toward the subject, without giving much attention to the learners. What Shulman counted as pedagogical content knowledge neglects the importance of understanding how students learn, as well as the importance of the social environment in which learning takes place (McDiarmid \& Clevenger-Bright, 2008). Because teachers need pedagogical content knowledge to teach the discipline to diverse learners, teachers' knowledge must include a pedagogical content knowledge that focuses on the child's learning, background knowledge and individual culture in its whole complexity (McDiarmid \& Clevenger-Bright, 2008).

\section{The Child and the Milieu}

Moreover, like McDiarmid and Clevenger-Bright (2008), Grossman (1990) added to Shulman (1986) the knowledge of the environment which is similar to Schwab's (1973) commonplace of milieu. While Schwab focused on the curriculum and the immediate context in which the curriculum is developed and applied, Grossman acknowledged that the child is an important element of the learning environment. When "knowledge of context" (p. 9) is defined as the understanding of a particular environment in which teaching and learning happens, teachers have "to adapt their more general knowledge to the specific school setting and individual students" (p. 9). Grossman added 
a layer of understanding of the school culture as well as understanding the child's background, community, and family to her notion of knowledge of environment. Finally, Grossman saw knowledge of the child's particular strengths, weaknesses, and general interests as important elements of knowing the environment.

Ball and Cohen (1999) put the child as a person shaped by culture into the picture of teaching. Teachers constantly read the child to see what their needs are. I agree that "teachers would need to learn that knowing students is not simply a matter of knowing individual children....they need to become acquainted with cultural differences, including differences in language, class, family, and community....Teachers have to understand their learners" (Ball \& Cohen, 1999, p. 9).

Given the teacher's need to understand the child and the context of learning, both inside and outside the school, the construct of and research on "funds of knowledge" (Gonzalez, Andrade, Civil, \& Moll, 2001, p. 116) could be helpful for teachers to make necessary connections. Funds of knowledge are "historically accumulated bodies of knowledge and skills essential for household functioning and well-being" (Gonzalez et al., 2001, p. 116). The basic concept of funds of knowledge is that "classroom learning can be greatly enhanced when teachers learn more about their students and about their students' households" (Gonzalez et al., 2001, p. 116). Teachers need to make knowledge accessible to learners by building connections between the child, the subject, and the environment. Doing so is aided by teachers' knowledge of the child's specific funds of knowledge as well as knowing what children are like, what they are likely to find interesting, and what they have trouble with (Ball \& Cohen, 1999). While affirming 
children's differences, the teacher needs to avoid generalization and assumptions (Moschkovich \& Nelson-Barber, 2009, p. 129).

We have seen that knowledge of the context and the knowledge of the child are tremendously important. Teachers act on their understanding of the school environment and their understanding of the learners. This knowledge of who the individual students are and where they are coming from is a key to connect the child with the knowledge represented in school. This knowledge of the child as an individual person, which entails knowing and understanding the child's cultural identity, is particularly important to connect children with a multicultural background to the subject.

\section{The Child and the Subject}

In his landmark article "The Canon Debate, Knowledge Construction, and Multicultural Education," Banks (1993) provided a typology of knowledge encompassing “(1) personal/cultural knowledge, (2) popular knowledge, (3) mainstream academic knowledge, (4) transformative academic knowledge, and (5) school knowledge" (p. 6). He explained that the child's cultural and personal knowledge can be seen as "concepts, explanations, and interpretations that students derive from personal experiences in their homes, families, and community cultures" (Banks, 1993, p. 7). I see this knowledge as related to, but not exactly the same as, the previously described concept of "funds of knowledge" (Gonzalez et al., 2001, p. 116) in that the teacher needs to know students' home, family, and environment in order to be able to connect the child and the subject. In addition, the child is influenced by popular knowledge which is shaped by mass media and pop culture. There is also mainstream academic knowledge which usually represents 
scientific and historical knowledge that is shaped by traditional western-centric concepts and paradigms. Finally, Banks explained that the knowledge represented by teachers, textbooks, and guidebooks can be seen as school knowledge. Banks further explained that a transformative knowledge is needed to challenge the mainstream academic knowledge. He argued that this transformative knowledge makes it possible to present school knowledge that is no longer opposed to the cultural and personal knowledge of the children. In consequence, teachers need to have an understanding of the possible conflicts between school and popular knowledge and personal and cultural knowledge. Banks (2006) also noted that teachers need to understand their own and the children's cultural backgrounds to be able to make a connection between the child and the subject.

Bringing it all together. We have seen that teaching requires a deep understanding of a subject's concepts and its importance (Hammerness et al., 2005). Moreover, "an understanding of how the knowledge is developed and validated within the different social contexts" (Hammerness et al., 2005, p. 387) is necessary. As well, the understanding of how to teach a subject depends on the understanding of the child as a learner (Hammerness et al., 2005). Moreover, teachers need to understand their own position in the learning process to make pedagogical decisions about how to connect the child with the subject. From the literature I have read, I conclude that teachers' knowledge is central to the interplay of the learner, subject matter, and teacher in the triangle of learning embedded in the social and educational context.

However, a teacher also needs to hold certain dispositions, in other words "the habits of thinking and actions regarding teaching and children" (Hammerness et al., 2005, 
p. 368). A vision of teaching and desirable learning should inspire and guide teachers' professional practice (Hammerness et al., 2005).

\section{Dispositions for Teaching}

Dispositions are key elements which shape teachers' thinking and their performance in the classroom (Diez \& Murrell, 2010). Diez and Murrell defined dispositions as "habits of professional action or moral commitments that spur such action" (p. 9). According to these authors, dispositions represent a "stance" (p. 9) or a way for teachers of "orienting" (p. 9) themselves in the field of teaching. Diez and Murrell defined five key elements of dispositions.

First, Diez and Murrell (2010) noted that dispositions are also about ethical, moral actions. These dispositions aim toward thinking about teaching and students in a way that moves teachers toward creating equal learning opportunities for all students. A moral dimension of a disposition can lead teachers to consider the learner's interest and cultural background when planning their formal instruction. These elements of professional disposition relate to the "moral foundation of teaching, learning, and education" (Diez \& Murrell, 2010, p. 11) to provide equal learning opportunities for all children (Hammerness et al., 2005). For example, when a teacher teaching a third grade mathematics lesson notices that some of the girls in the classroom do not understand a basic mathematical concept, it would be unprofessional to tell them the process and move on, thinking they cannot do mathematics because they are girls. The teacher would have denied the care for these girls' academic success by not giving them the attention and 
explanation they need. This denial of access to education might lead to academic failure later on.

Second, dispositions depend upon knowledge and skills, which means that knowledge and dispositions are interrelated (Diez \& Murrell, 2010). A teacher needs knowledge in order to act on a disposition, or in other words the "capacity to enact" (Diez \& Murrell, 2010, p. 9). For example, a teacher may believe strongly in culturally responsive pedagogy, but does not have enough knowledge about the children and the subject to act on this commitment. This teacher might fail in culturally responsive teaching, or more likely, driven by the disposition to provide equal learning opportunities to all students, the teacher will try to gain the necessary knowledge and skills.

Third, Diez and Murrell (2010) also noted that dispositions relate to a teacher's professional identity. Teachers should reflect on themselves as a person and as a professional. The ability and the commitment to critique oneself enables teachers to be connected with "external expectations and their own internal intentions" (p. 13). Furthermore, the context influences the enactment of professional dispositions in practice (Diez \& Murrell, 2010). For example, a novice teacher who prefers to actively engage the learner in "noisy" activity might stop doing so because the school prefers a "quiet" learning environment.

Finally, Diez and Murrell (2010) stated that dispositions can be cultivated and developed because "they are commitments and habits of thought and actions that grow as the teacher learns, acts, and reflects" (p. 14). This development indicates that a teacher education program might be able to alter the dispositions of teacher candidates toward 
affirming diversity. Indeed, several of the InTASC (CCSSO, 2011) disposition standards aim toward cultural responsive pedagogy, which does just that.

In summary, in order to be able to successfully teach to the needs of all students, a teacher must "develop a set of dispositions-or habits of thinking and actions-about teaching, children, and the role of the teacher" (Hammerness et al., 2005, p. 387). Consequently, teacher education should have a strong focus on dispositions, just as it does on knowledge and performance.

Dispositions standards in teacher education. "Critical dispositions" (CCSSO, 2011, p. 6) are important for effective practice, according to the CCSSO standards. These stated "that habits of professional action and moral commitments that underlie the performances play a key role in how teachers do, in fact, act in practice" (Council of CCSSO, 2011, p. 6). Evaluating the dispositions standards, it seems as if the standards are aimed toward culturally responsive teaching. They reference seeing the child as an individual learner and building on the child's cultural background and strengths. More generally, the standards focus on building a habit of action toward social justice and equal learning opportunities in the classroom.

One example of how these standards are used can be seen in the teacher education program in which I teach, a program that seeks to integrate standards aiming toward social justice and equality in education that are based on the InTASC critical dispositions. This program stated a "disposition is an inclination to act in a certain way" (CCSSO, 2011, p. 2) and identifies collaboration, honesty, respect, reverence for learning, reflection, flexibility, responsibility, advocacy for social justice, professionalism, and 
dedication as core dispositions of its teacher education. These dispositions relate to the core humanizing dispositions for teacher education which were developed by Salazar, Lowenstein and Brill (2010) based on an analysis of teacher education programs.

Humanizing education. Salazar et al. (2010) noted that teachers, teacher educators, and teacher candidates are aware that they should pay attention to culturally diverse learners in the classroom. The authors considered humanizing dispositions"attitudes, values, and beliefs that advance the dignity, humanity, and achievement of culturally and linguistically diverse learners" (Salazar et al. (2010), p. 29)-to be key elements of teachers' moral and ethical framework (p. 28). Analyzing a teacher education program that aims to prepare teacher candidates to value and build on students' cultures, the authors developed five core humanizing dispositions. "Commitment to being a learner of diversity and its impact on teaching and learning" (p. 29) was based on teachers discovering their own cultural identity and learning from reflection and from others. "Relentless belief in the potential of culturally and linguistically diverse youth" (p. 29) saw the teacher as a caring person who builds relationships with students, their parents, and the community. As "warm demanders" (p. 31), teachers "act on the belief that all children have the potential to reach high academic standards, especially in the face of challenges" (Salazar et al., 2010, p. 31). This belief in the children's academic success led to the core disposition, "conviction to construct knowledge with students and their family" (p. 31). Teachers work closely with their students and families to develop a curriculum that is relevant to the learners and to the society in which they live. Doing so also requires that teachers are open to becoming a part of the community. For example, a 
teacher might have the choice to either teach a lesson on statistics straight from the book, or to create a project, such as the previously mentioned newspaper project, to cooperatively engage children and families in learning. Therefore, teachers need a "willingness to accept, embrace, and navigate the complexity of teaching and learning in collaboration with others" (p. 31). Independent from the teachers' own background, this disposition is especially important when working with culturally diverse children because teachers need to understand the complexity and variation of their students' concepts and approaches that are often different from the teacher's own concepts and approaches.

Teachers need to engage as learners and learn from and with the children and the environment. Finally, "persistence in advocating for students and their families" (p. 31) should encourage teachers to "develop a vision of their role in improving the system" (p. 32) toward equity in education.

As mentioned, I consider culturally responsive teaching to be a way to create equal learning opportunities for all students. Because mathematics is often seen as a subject that cannot or should not be culturally responsive, in the next section I focus on culturally responsive mathematics teaching. Thereafter, I discuss literature on beliefs and images of mathematics to show that there are images of mathematics which are counteractive to culturally responsive teaching.

\section{Culturally Responsive Mathematics Teaching}

In this section I focus on what culturally responsive teaching looks like in a mathematics classroom. Drawing on empirical research, I develop a framework for culturally responsive teaching and elaborate what teachers need to know and be able to 
do in order to create learning opportunities that engage all students in meaningful learning. In consequence, in this section I discuss literature that builds on the theoretical framework of my study to inform my research design and data analysis.

Gay (2002) stated "that when academic knowledge and skills are situated within the lived experiences and frames of reference of students, they are more personally meaningful, have higher interest appeal, and are learned more easily and thoroughly" (p. 106).

Culturally responsive teaching can be defined as using the cultural knowledge, prior experiences, frames of references, and performances styles of ethnically diverse students to make learning encounters more relevant to and effective for them. It teaches to and through the strengths of these students. Culturally responsive teaching is the behavioral expressions of knowledge, beliefs, and values that recognized the importance of racial and cultural competencies. (Gay, 2010, p. 31)

Gay's culturally responsive pedagogy is based on the beliefs that "students must experience academic success, [that] students must develop and/or maintain cultural competence, [and that] students must develop a critical consciousness through which they challenge the status quo of the current social order" (Ladson-Billings, 1995c, p. 160). Following the concepts of social constructivist learning theories, culturally relevant pedagogy places learning in an environment in which knowledge is actively constructed in meaningful interactions. The integration of cultural context affirms diversity and sees diversity as an asset which opens the possibility for students to engage in a community of learners to reach beyond their own culture (Ladson-Billings, 1995c). As a result, the academic achievement of ethnically diverse students will improve when they are taught through their own cultural and experiential filters (Gay, 2002, p. 106). 
Bridging between home and school experiences. Many researchers in the field (e.g., Ladson-Billings, 2006; Nieto, 2000) indicated that the described mismatch between the students' world of experience and the world pictured in school is one of the main reasons for academic failure. The mathematical problems students have to solve are often perceived by the students as meaningless, bearing no connection to their interests, and irrelevant. For example, when students encounter a word problem such as "If cars hold 15 people, how many cars are needed for 165 people?" (Oregon Department of Education, 2013, p. 17), they might not be very motivated to solve this problem. An example of designing mathematics instruction that is meaningful and situated in the students' cultural background is the Algebra Project. Moses, West, and Davis (2009) noted that culturally responsive instruction begins with examining what knowledge and experience students bring to classrooms where they encounter mathematical symbolism and signs. A focus on making meaningful connections between school mathematics and the students' peer values raises math literacy of low performing students (Moses et al., 2009). The Algebra Project described a 5-step process from a familiar and hands-on encounter with mathematics to abstract symbolism of mathematics: physical experience, use of own language to describe the problem, use of everyday language to describe the problem, developing mathematical expressions, developing abstract symbols. Under the Algebra Project, a word problem such as presented above would be based on a real problem, such as a field trip planned by the students, to engage students into learning. Step-by-step, the student would first describe the problem in their own words, drawing on their own communication styles, developing a more and more formalized language, and finally 
ending up using a mathematical expression. I argue that the Algebra Project can be seen as an example of what Gay (2010) has called validating and affirming diversity. As a form of culturally responsive teaching "it builds bridges of meaningfulness between home and school experiences as well as between academics abstractions and lived sociocultural realities" (Gay, 2010, p. 31).

Multidimensional teaching. "Multidimensional culturally responsive teaching encompasses curriculum, content, learning context, classroom climate, student-teacher relationships, instructional techniques, classroom management, and performance assessments" (Gay, 2010, p. 35). Gay explained that culturally responsive teaching also needs to accommodate conflicting notions of knowing in the classroom because students are able to bring in their own way of knowing based on their own preexisting knowledge. However, for a long time, teaching practices in mathematics have focused on a procedural approach that favors linear thinking rather than multidimensional thinking, such as involving students in the curriculum-making process and instructional decisionmaking process, and seeing mathematics in cultural context. From a procedural perspective, mathematics was seen as objective and free of cultural influences (Ukpokodu, 2011). Such practices do not meet the learning and problem-solving styles of culturally diverse urban students, which contributes to their low motivation, interest and successes in learning mathematics (Tate, 2005; Ukpokodu, 2011). A culturally responsive teaching approach, which uses the student culture as a conduit to facilitate teaching and learning, has a positive influence on student learning (Ladson-Billings, 2009; Ukpokodu, 2011; Villegas \& Lucas, 2002). Ukpokodu (2011) stated that research on culturally 
responsive teaching has identified core-dimensions that support learning of urban and low-income students. These dimensions are: (a) high expectations and the belief that the students can be successful, (b) instructional scaffolding, (c) knowing, caring teachers who promote positive teacher-student relationships in a collaborative and cooperative learning community, (d) connecting teaching and learning to the students' lives and communities outside schools, and (e) engaging students in practice of social justice.

In her qualitative study, Ukpokodu (2011) studied pre- and in-service teachers enrolled in a graduate course focused on teaching and learning in an urban classroom, and asked questions about specific culturally responsive teaching practices in mathematics. The study revealed that the teachers were not enacting culturally responsive teaching because of the "view of mathematics as culturally-neutral" (p. 50). The “participants presented that mathematics is an abstract subject, a 'universal language,' that numbers are the same across time, culture, and space, and therefore, mathematics instruction does not have anything to do with culture" (p. 50). The participants of the study also mentioned the convenience and dominance of textbook-based mathematics instruction as a factor which makes it difficult for the teachers to use a culturally responsive approach. Moreover, teachers feel pressured to teach to the test in order to raise test scores. Finally, the participants of Ukpokodu's study noted that there is a lack of culturally responsive mathematics teaching models and her participants lack awareness of such concepts.

Seven major themes regarding culturally responsive mathematics teaching emerged from this Ukpokodu (2011) study. First, Ukpokodu explained that there is a 
misguided belief that teaching and learning mathematics and that the nature of mathematics has to be deconstructed. Ukpokodu reported an observation that approaching teaching mathematics in a culturally responsive way, requires teachers to be convinced that mathematics is a human activity which is grounded in the students' culture and "their attempts to describe and understand physical and social phenomena" (Mukhopadhy \& Greer, 2001 cited in Ukpokodu, 2011, p. 51). Culturally responsive teaching means that a teacher needs to understand that mathematical knowledge "is situated within a sociocultural frame of a given cultural group" (Ukpokodu, 2011, p. 51). The study also named the integration of culturally responsive content, as discussed in chapter 1 , a dimension of culturally responsive teaching. In order to teach in a culturally responsive way, teachers also need to utilize instructional strategies which promote positive teacher-student relationships. The instructional strategies should also focus on students' constructivist knowledge and skill development based on students' language and experience. Ukpokodu mentioned scaffolding, peer support, culturally familiar examples, as well as the use of manipulatives, a form of interactive learning, as teaching strategies that are culturally responsive. Ukpokodu's study also emphasized the importance of communal, cooperative, and collaborative learning opportunities in culturally responsive teaching. Ukopkodu claimed that such learning is not only the preferred learning style of most "minority" students, but it also reflects their cultural identity. She further argued that a culturally responsive teacher needs to be open to students' divergent thinking and problem-solving. In addition, Ukopkodu seemed to be opposed to ability grouping and tracking on a classroom level. She explained that 
detracking the mathematics classroom in order to expose and promote all students to the same high standards is also seen as a dimension of culturally responsive teaching. Finally, the study revealed that another important element of "culturally responsive mathematics teaching involves teachers' critical consciousness, advocacy, and activism" (p. 54).

\section{Culture, communication, and language in mathematics teaching and}

learning. Moschkovich and Nelson-Barber (2009) noted that teaching students from cultural communities who are different from the mainstream demands culturally responsive knowledge from teachers, in order to include knowledge of their students' linguistic backgrounds, such as communication patterns or interactions in a social environment, and to establish a relationship with their students. This relationship motivates students to engage in successful learning. Teachers also need to put the cultural context of a lesson into relation with the cultural context of the students' community. Moschkovich and Nelson-Barber further noted that learning to communicate mathematically goes beyond learning vocabulary and that it is not a question of whether a student is an English language learner or not, noting that "instruction should provide opportunities for students to actively use mathematical language to communicate about and negotiate meaning for mathematical situations" (Moschkovich \& Nelson-Barber, 2009, p. 129).

Khisty (1995) described the challenges that bilingual learners face when they learn mathematics. While students learn new mathematical concepts best in their primary language, they also have to develop proficiency in their secondary language in order to 
solve mathematical problems when they are instructed in this language. Khisty elaborated that different meanings of words and homonyms can confuse a language learner. This situation can be especially challenging when common language is used to express mathematical ideas. For example, Khisty mentioned that the word left is usually used for directional relations. Students with limited language proficiency can be easily confused when it is used in a subtraction problem about "how many are left." A typical mathematics word problem on an example for a state standardized test made it clear that language learners, at least in the elementary classroom I taught, faced similar challenges when they were asked to solve this problem: “ $\square \mathrm{x} \diamond=48$; this math sentence represents the total number of cow legs in the cow pen. If you know that $\square$ represents the number of cows and there are 12 cows in the pen, what does the $\diamond$ represent?" (Oregon Department of Education, 2010, p. 10). Not only were most of my German-American students who lived in an urban or suburban area not familiar with the context of the setting, but they were also not familiar with this usage of the word "pen" because they had never seen a cow pen.

Khisty (1995) suggested that mathematics instruction should focus on academic skill development as well as on language acquisition. Teachers have to pay attention to the terminology and concepts that students bring from home. If it is not possible to bridge between home language and concepts used in school, there is a risk that learning might become less effective or even impossible In a research project on effective mathematics instruction with Hispanic students, Khisty observed that in an effective classroom, a teacher pays attention to use of language in class and uses strategies such as "recasting of 
mathematical terms" (p. 284) and emphasizing meaning through voice variation. She explained that restating and using terms in different context and emphasizing the term made it possible for the students to use mathematical language in a variety of learning and problems-solving activities.

While Khisty (1995) focused on the aspect of culturally responsive classroom communication with linguistically diverse learners, Weinstein, Tomlison-Clarke and Curran (2004) focused on culturally responsive classroom management and developed five criteria:

(a) Recognition of one's own ethnocentrism and biases

(b) Knowledge of student's cultural background

(c) Understanding of the broader social, economic, and political context of our educational system

(d) Ability and willingness to use culturally appropriate classroom management strategies

(e) Commitment to building caring classroom communities. (p. 27)

Weinstein et al. further noted that classroom management should emphasize selfregulation, community building, and social decision making in favor of a culturally responsive approach. In consequence, students should act out of their own personal responsibility, which requires that the students and teacher are aware of their own cultural biases. Only if the teachers have knowledge of the students' cultural backgrounds are they able to develop the necessary skills for cross-cultural interaction. According to Weinstein et al., to successfully manage a classroom in a culturally responsive way, teachers need to have knowledge of their students' family background and structure, 
education (e.g., how much schooling, what kind of instruction), interpersonal relationship styles, the social fabrics of families, hierarchies, food, religion, etc. This concept of knowing the student and their family background relates to the previously described concept of funds of knowledge. While Weinstein et al. focused on the individual students and the immediate family environment, I also reviewed literature that places culturally responsive mathematics teaching in a larger cultural context.

Culture and curriculum. In a long-term research project involving more than 15 quasi-experimental and experimental trials, with more than 300 students and more than 200 teachers, Lipka, Yanez, Andrew-Ihrke, and Adam (2009) studied "Math in a Cultural Context." Math in a Cultural Context was a curriculum that was designed to include cultural content and contextual knowledge about Yup'ik patterns of communication, as well as cultural every day activities into elementary mathematics education. Berry picking, salmon drying and star navigation are examples of the seven units that the curriculum encompasses. Lipka et al. stated that such an ethnomathematics curriculum can be identified as creating meaningful learning situated in a cultural context. They further explained that, for example, cultural content integration (e.g., decorative patterns) has an effect on the way learners think. In addition, seeing mathematics from the perspective of the child and at the same time from a global perspective situates learning mathematics as culturally dependent. Moreover, the integration of mathematical concepts and practices of formal mathematics as well as mathematics of the target culture leads to approaching teaching mathematics from a community-based approach that entails handson activities as well as the integration of community experts. In this case, Lipka and his 
colleagues drew on the local and cultural mathematical expertise of elders of the Yup'ik Alaskan Natives. Lipka et al. concluded that this strong collaboration between community and academia raised the mathematics performance of all students involved in the culturally contextualized mathematics. The teachers and community elders were able to create meaningful learning opportunities which were strongly connected to the Yup'ik culture, which help the students to understand mathematic concepts.

Mathematics needs to be presented in schools as cultural practices related to students' everyday experience.

An important question in thinking about culturally responsive mathematics teaching is to what extent mathematics-as-a-school-subject should take more account of the diversity of mathematical practices rather than, as hitherto, being dominated by the practices of mathematics-as-a-discipline. (Mukhopadhyay, Powell, \& Frankenstein, 2009, p. 68)

Mukhopadhyay et al. noted that from an ethnomathematical perspective, there is mathematical practice that is clearly labeled as such (e.g., mathematics of engineers and mathematicians). Mukhopadhyay et al. further explained that there is also mathematical practice that is embedded in culture and daily activities which is often not recognized as doing mathematics. The authors argued that because school mathematics should be situated practice, school mathematics should reflect the child's world of experience with mathematics in day-to-day activities. When there is a mismatch between school experience and the child's experience with mathematics, the way mathematics is represented in schools has to be challenged. Mukhopadhyay and her colleagues further explained that from a culturally responsive perspective, the "Eurocentric narrative" ( $p$. 74) of mathematics needs to be challenged in schools because it disempowers students, 
by making them aware of the diversity of cultural influences on mathematics today.

According to the authors, therefore, culturally responsive teaching should "start from the point of cultural familiarity" (p. 27) and value the knowledge of particular cultures. This perspective of cultural familiarity puts culturally responsive teaching into the realm of social and political change and consequently promotes social justice.

In his report of a 2-year semi-ethnographic study "Teaching and Learning Mathematics for Social Justice in an Urban, Latino School,” Gutstein (2003) cautioned that even when the standards appear to promote social justice and equal opportunities, the definitions of those terms remain unclear. The document did not address specifically how equity in classrooms could be achieved, but did also note that, in order to address issues of social injustice and inequity in the classroom, the child is the solution. Teachers have to address questions that concern the learners' lives and help them to think critically about their lives. These goals can only happen when the learner's language and culture are valued in the classroom. Gutstein further stated that mathematics can be used to help the students understand and construct their world. I think this perspective of understanding the world and issues of social justice from a child's perspective shows that mathematics education should not just serve to transmit the skills and knowledge that are necessary to do mathematics procedures; it makes mathematics part of the learner's life rather than an abstract tool. It creates meaning for the subject and helps to teach mathematics in a culturally responsive way.

Similar to Gutstein (2003), Tate (2005) noted that the teaching of mathematics should connect to the lives and needs of African American students to "enable them to 
fully take part in our democracy" (p. 31). Like others (e.g., Nieto, 2000; Ukpokodu, 2011), Tate argued that school mathematics and the students' experiences outside school do not interfere with each other. Tate explained that mathematics as a discipline puts too much emphasis on objectivity and neutrality. "Thus very little consideration is given to the cultural appropriateness of mathematics pedagogy" (p. 32).

I argue that a focus on the child and an enactment of culturally responsive education might fail because teachers are not prepared to pay attention to all needs of their students. Averill et al. (2009) implemented three 4-year exploratory studies to investigate pre-service teachers' perceptions of the bicultural content of a mathematics teacher education course, the effectiveness of using cultural activities in the course, and the influence of culturally responsive preparation on teaching. These researchers noted that the integration of culturally responsive perspectives and strategies was not enough to make teacher candidates aware of such strategies. A more targeted and structured approach is necessary in order for teacher candidates to take culturally responsive education into consideration. For example, analysis of culturally responsive aspects of mathematics teacher education makes it more likely that teacher candidates are able to identify and address elements of culturally responsive teaching. The authors suggested basing mathematics methods courses on a holistic cultural perspective. Teacher educators should model culturally responsive mathematics teaching, for example, by using metaphors to present and organize ideas, and by engaging students in practical activities. Systematic planning and integration of culturally responsive teaching in a course seems to change the candidates' dispositions toward culturally responsive teaching. However, 
Averill et al. (2009) noted that dispositions toward culturally responsive teaching do not necessarily appear in actual teaching. Finally, the studies indicated that if teachers have the knowledge and disposition to teach mathematics in a culturally responsive way, they tend toward enacting culturally responsive pedagogy in their classroom.

\section{Summarizing culturally responsive instruction, curriculum, and}

communication. As the reviewed literature showed, culturally responsive mathematics teaching requires teachers to be able to connect the mathematics and the students. Instruction needs to be based on context that is meaningful for the students. Instruction also needs to affirm the students' knowledge and culture. Cultural content needs to be integrated. As well, teachers need to assure that all students can learn by employing instructional strategies which integrates the students into the curriculum creation process and gives them the opportunity to learn according to their needs, backgrounds and experiences. Such culturally responsive teaching not only requires teachers to have the knowledge to do so, but also images of the subject that makes culturally responsive teaching possible. In the next section I discuss literature on the beliefs about mathematics and how these images impacts teaching culturally diverse students.

\section{Teachers' Images, Attitudes, and Beliefs About Mathematics}

We have seen that, in addition to knowledge, certain dispositions are also required in order to enact culturally responsive pedagogy in a culturally diverse environment. However, I argue that even with the knowledge and the "right" disposition for culturally responsive teaching, the way a teacher sees the subject might still influence their desire to act. For example, Banks (2006) described an encounter which, in my experience, is 
somewhat typical when it comes to teaching mathematics in a culturally diverse environment:

After I made a presentation in a school in which I described the major goals of multicultural education, a math teacher told me that what I said was fine and appropriate for language arts and social studies teachers but that it had nothing to do with him. After all, he said, math is math, regardless of the color of the kids. (p. 113)

Banks stated that he saw this comment only as a misconception of multicultural education and that it made him think about how to better explain what multicultural education is. I think another possible alternative to explain this statement could be that the commenting mathematics teacher was under the assumption that multicultural education really does not apply to mathematics. Such an assumption would indicate that the perceptions teachers have about a subject area might impact their disposition toward teaching that subject to culturally diverse learners.

To further introduce the idea of images of mathematics, I first clarify the relationship of images to the concepts of attitudes and beliefs. According to Richardson (1996), to understand teachers' ways of thinking about teaching and learning, one has to understand teachers' beliefs and attitudes. Richardson explained that the idea of “attitudes" first included the term "belief." Later on, research started to distinguish between attitudes as a more affective construct and beliefs as a more cognitive construct. Richardson further explained that the difference between the two terms remains unclear, as does the shift to the term belief. Richardson saw beliefs as "psychologically held understandings, premises, or propositions about the world that are felt to be true" (p. 103). However, Richardson was also not able to find a consistent definition of beliefs in 
the literature, which I certainly found to be true for the literature I read. I also agree with Pajares (1992) that the terms attitudes, beliefs, conceptions, dispositions, and images have been used interchangeably in the literature. In The Coding Manual for Qualitative Researchers, which I used to develop elements of the data analysis framework for this research, Saldaña (2009) explained in the "Values Coding" section that an "attitude is the way we think and feel about oneself, another person, thing, or idea" (p. 89). Saldaña continued to explain that a "belief is a part of a system that includes our values and attitudes, plus our personal knowledge, experience, opinion, prejudices, morals, and other interpretive perception of the social world" (p. 89). Embedding beliefs in the values that are attached to them (Wolcott, 1999) makes an important differentiation for this research between attitudes and beliefs. Because beliefs are much more established and more strongly influenced by culture than attitudes, I continue to focus on literature on beliefs rather than attitudes.

\section{Beliefs About the Nature of Mathematics}

To shift my focus more toward research on beliefs about mathematics, I reviewed work by Alba Thompson, one of the leading scholars in the field. In her synthesis of research on teachers' beliefs and conceptions, Thompson (1992) stated that beliefs can be held with different levels of certainty. Thompson explained that beliefs are not conceptual and that they are disputable. Unlike knowledge, beliefs are often held or justified for reasons that lack validity and agreement on how they can be judged. Thompson further noted that beliefs are not fixed and can change over time through gained knowledge and experience. The notion that beliefs can be changed over time 
further justifies a focus on teachers' beliefs within teacher education. I argue that Wilson and Cooney's (2002) notion of teachers' beliefs about mathematics as a weak form of knowing indicates that teacher education and the experience with mathematics potentially shape teachers' beliefs. Wilson and Cooney promoted that a "belief is a necessary but not sufficient conditional for knowing" (p. 2061). Consequently, it can be concluded that beliefs and knowledge are interrelated and interdependent and cannot be viewed separately.

Therefore, with a focus on mathematics education, Eynde, de Corte, and Verschaffel (2002), reviewed literature on beliefs and developed a framework under which students' mathematical beliefs are defined as:

The implicitly or explicitly held subjective conceptions students hold to be true about mathematics education, about themselves as mathematicians, and about the mathematics class context. These beliefs determine, in close interaction with each other and with students' prior knowledge, their mathematical learning and problem solving in class. (p. 541)

The authors categorized students' beliefs into "beliefs about the mathematics education" (p. 541), which entails the subcategories: beliefs about mathematics as a subject, beliefs about learning mathematics, and beliefs about teaching mathematics in general. Moreover, Eynde, de Corte and Verschaffel further distinguished between "beliefs about the self" (p. 567) and "beliefs about the social context" (p. 590), which encompasses the role of the teacher as well as the class culture and the influence on mathematical learning. Eynde et al.'s framework was geared toward students' beliefs, but it does not appear to be limited to a particular group of students. In consequence, I see this framework as relevant for my research on teacher candidates' images of mathematics. 
One idea that I draw from for this research is the focus on "images of mathematics" as described by Ernest (2009), who defined images of mathematics as an:

informal set of beliefs, views and perceptions of mathematics as a discipline and area of enquiry. It is a system of beliefs or views which may only be partly expressed as well as being partly made up of tacit interference assumptions, and beliefs about the nature of mathematics. (p. 46)

Ernest explained that a well-informed scholar might have a different image of mathematics than a child in elementary school. Images of mathematics can either be held by individuals or groups, and differ depending on the person or group holding these images. The images are also influenced by the person's knowledge (Ernest, 2009).

Ernest (2009) further noted that there is a wide variation of images of mathematics which can be categorized into images that can be labeled as more "traditional" and images which can be labeled as more "humanistic." Analyzing literature on the perception of mathematics, he concluded that there is a "widespread presence of the "traditional image of mathematics"' (p. 47) which sees mathematics as difficult and abstract, as well as beyond the "concerns, interest and capabilities of the majority population" (p. 47). In the context of this traditional image, mathematics is often perceived negatively by students and teachers. Ernest described the less common, but positive, "humanistic" image as an accessible, conceptual tool to solve practical problems. Table 1 compares Ernest's popular images of mathematics. 
Table 1

Contrasting Popular Images of Math

\begin{tabular}{|c|c|c|}
\hline Aspect & Traditional Image & Humanistic Image \\
\hline Approachability & Difficult, forbidding & Approachable and accessible \\
\hline Human dimension & $\begin{array}{c}\text { Cold, neutral, abstract and } \\
\text { impersonal }\end{array}$ & Human and personal \\
\hline Social context & $\begin{array}{l}\text { Abstract tools applied in } \\
\text { advanced societies }\end{array}$ & $\begin{array}{l}\text { Concepts and methods } \\
\text { embedded in all human } \\
\text { history and societies }\end{array}$ \\
\hline Key elements & Theoretical abstract theories & $\begin{array}{c}\text { Practical problem solving and } \\
\text { conceptual tools }\end{array}$ \\
\hline Applications & $\begin{array}{l}\text { Not part of 'real' (pure) } \\
\text { mathematics. Applications } \\
\text { work by coincidence or } \\
\text { because mathematics } \\
\text { describes the necessary } \\
\text { structure of universe }\end{array}$ & $\begin{array}{l}\text { Mathematics is grounded in } \\
\text { applications providing both } \\
\text { inspiration for its concepts } \\
\text { and utility through modeling }\end{array}$ \\
\hline Procedures and methods & $\begin{array}{l}\text { Ultra-rational, strictly following } \\
\text { fixed rules }\end{array}$ & $\begin{array}{l}\text { Creative and flexible uses of } \\
\text { knowledge to solve problems }\end{array}$ \\
\hline Focus & $\begin{array}{l}\text { Only interested in the right } \\
\text { answers and objective facts }\end{array}$ & $\begin{array}{c}\text { Concerned with processes of } \\
\text { personal inquiry and } \\
\text { understanding }\end{array}$ \\
\hline Problem solutions & $\begin{array}{l}\text { Only one right answer exists } \\
\text { for each task }\end{array}$ & $\begin{array}{l}\text { Problems have multiple } \\
\text { solutions methods and } \\
\text { multiple answers }\end{array}$ \\
\hline Source of correctness & Experts have all the answers & $\begin{array}{l}\text { Anyone should be able to } \\
\text { solve problems and check } \\
\text { answers }\end{array}$ \\
\hline Ownership & $\begin{array}{l}\text { Accessible only to a gifted, } \\
\text { stereotypically male, minority }\end{array}$ & Accessible to all \\
\hline
\end{tabular}

In earlier work, Ernest (1988) described three basic views or conceptions of the nature of mathematics that a teacher can hold, as well as how these images impact their view of teaching and learning mathematics: "the view or the conception of the nature of mathematics" (para.3), "model or view of the nature of mathematics teaching" (para. 3), and the "model or view of the process of learning mathematics" (para. 3). The basic view, 
or image, of the nature of mathematics that a teacher holds influences how teachers see the teaching of mathematics and learning process. Ernest elaborated that teaching mathematics depends, mostly on:

- the teacher's mental contents or schemas, particularly the system of beliefs concerning mathematics and its teaching and learning;

- the social context of the teaching situation, particularly the constraints and opportunities it provides; and

- the teacher's level of thought processes and reflection. (para. 1)

Ernest explained that these factors determine how teachers see their role and their instructional decisions.

\section{Images of Mathematics and the Perception of Teaching}

The literature I reviewed (e.g., Ball, 1990b; Gill et al., 2004; Gregoire, 1999;

Williams and Baxter, 1996) noted that a traditional image of mathematics is often combined with a procedural teaching approach focused on finding the right answer and the right way to solve a numerical problem based on behaviorism. In contrast, the humanistic picture of mathematics is usually associated with a social constructivist teaching approach.

Furthermore, Thompson (1984) described three basic philosophies of mathematics that can be observed in teaching: the instrumentalist view, the Platonist view, and the problem solving view. Ernest (1988) described an instrumentalist view as one that sees the nature of mathematics as an "accumulation of facts, rules and skills to be used in the pursuance of some external end. Thus mathematics is a set of unrelated but utilitarian rules and facts" (para. 5). The Platonist view of mathematics sees mathematics "as a static but unified body of certain knowledge. Mathematics is discovered, not 
created" (para. 5). The problem solving view of mathematics pictures mathematics "as a dynamic, continually expanding field of human creation and invention, a cultural product. Mathematics is a process of inquiry and coming to know, not a finished product, for its results remain open to revision" (para. 5).

Ernest (1988) connected these images of mathematics with the teachers' conception of the teachers' role and the teaching of mathematics. Ernest noted that an instrumental view might lead to seeing the role of a teacher as an instructor who "focuses on skills mastery with correct performance" (para. 6). A teacher with Platonist view is likely to be an explainer, focusing on the "conception understanding with unified knowledge" (para. 7). The Facilitator sees mathematics as problem solving and aims teaching toward posing and solving problems. Ernest further argued that the teachers' own conception of their role and the conception of the purpose of teaching influences their instructional and curricular decision-making. In addition, the curriculum that is enacted in the classroom is also powerfully influenced by the expectations of others (e.g., parents, fellow teachers, supervisors, etc.) and institutional constraints (e.g., adapted curriculum). Furthermore, Ernest noted that the teachers' consciousness of their own beliefs can be seen in their teaching as well as in the extent to which teachers reflect on their practice. Ernest concluded that "mathematics teachers' beliefs have a powerful impact on their practices" (para. 15). An instrumental view of mathematics requires little consciousness about instructional decision making, whereas seeing mathematics as problem solving puts the teacher in the role of a facilitator who can make instructional decisions which serve the need of their own teaching and learning situations. 
Wilson and Cooney (2002) also connected the discussed themes of the images of mathematics and the influences of these images on teaching. They explained that the way teachers see mathematics influences how they see teaching and learning mathematics. A "dualistic" (p. 2093) image, which is similar to Ernest's (2009) traditional image, might lead teachers to emphasize the product and procedures without meaning. Wilson and Cooney further noted that a "relativistic" (p. 2093) view of mathematics is based on the context of teaching, which focuses on student understanding. Teachers holding a relativist image of mathematics base their instructional decisions on the context and student understanding.

The literature I reviewed (e.g., Ernest, 1988; Ernest, 2009; Diez \& Murrell, 2010) noted that the teachers' image of mathematics (or any other subject, e.g., Noordhoff, 1993) influences the way they see the learner and the instructional decisions they make. I believe that the common and often dominant traditional image of mathematics is one reason why culturally diverse children do not receive the mathematics education they need. I argue that seeing mathematics as difficult, theoretical, culture-free, and as an abstract construct of knowledge with right answers and objective facts may blind teachers from seeing their students. In a traditional image, mathematics is seen as being detached from the person who is engaged in mathematics (Ernest, 2009). Like Ernest (2009), I contend that such traditional thinking promotes the idea of teaching and learning which sees the teacher as an expert who connects the learner with mathematical knowledge. The teacher, who is the only link between mathematics and the child, might instead become a "roadblock" standing between the learner and learning, even if the teacher's general 
disposition favors a culturally responsive education (see Figure 3). Thus, the traditional image of mathematics appears to favor learning which might be disconnected from the students as learners and their experiences, culture and knowledge because teachers might not be able to see the "whole child."

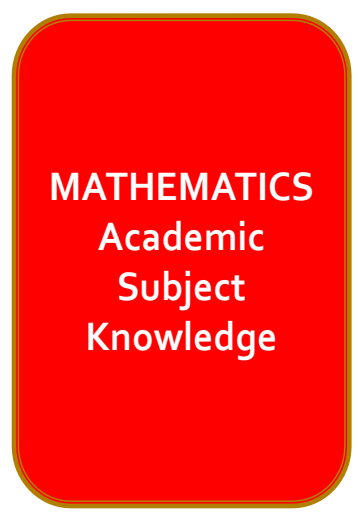

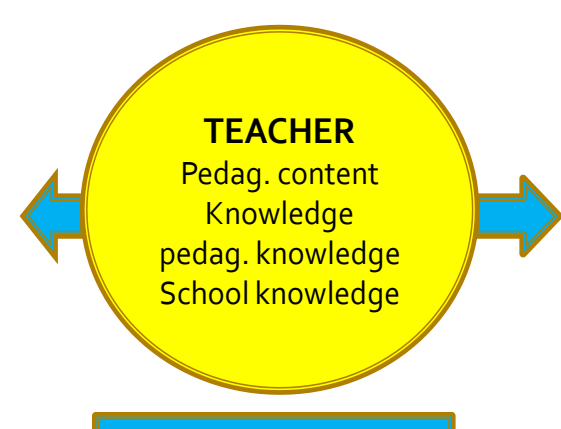

Traditional Image
Not seeing the "whole child"

Figure 3. The traditional image and teaching.

A "humanistic image of mathematics" (Ernest, 2009) opens the door for a culturally responsive education because it sees mathematics as embedded in real life application (Ernest, 2009). By focusing on the learners' cultural and personal knowledge, the teacher is less likely to be a "sage on the stage" and more likely to become a facilitator of learning. I argue that teachers who hold a humanistic image of mathematics 
as approachable and accessible, as culture- and context- dependent, with a focus on problem-solving, personal inquiry, and understanding, are likely to approach teaching and learning mathematics from a constructivist perspective (see Figure 4).

Constructivism might help to move the child into the picture of mathematics and its learning, in order to affirm diversity based on the learner's individual experience, preexisting knowledge, and culture (Moschkovich, 2007).

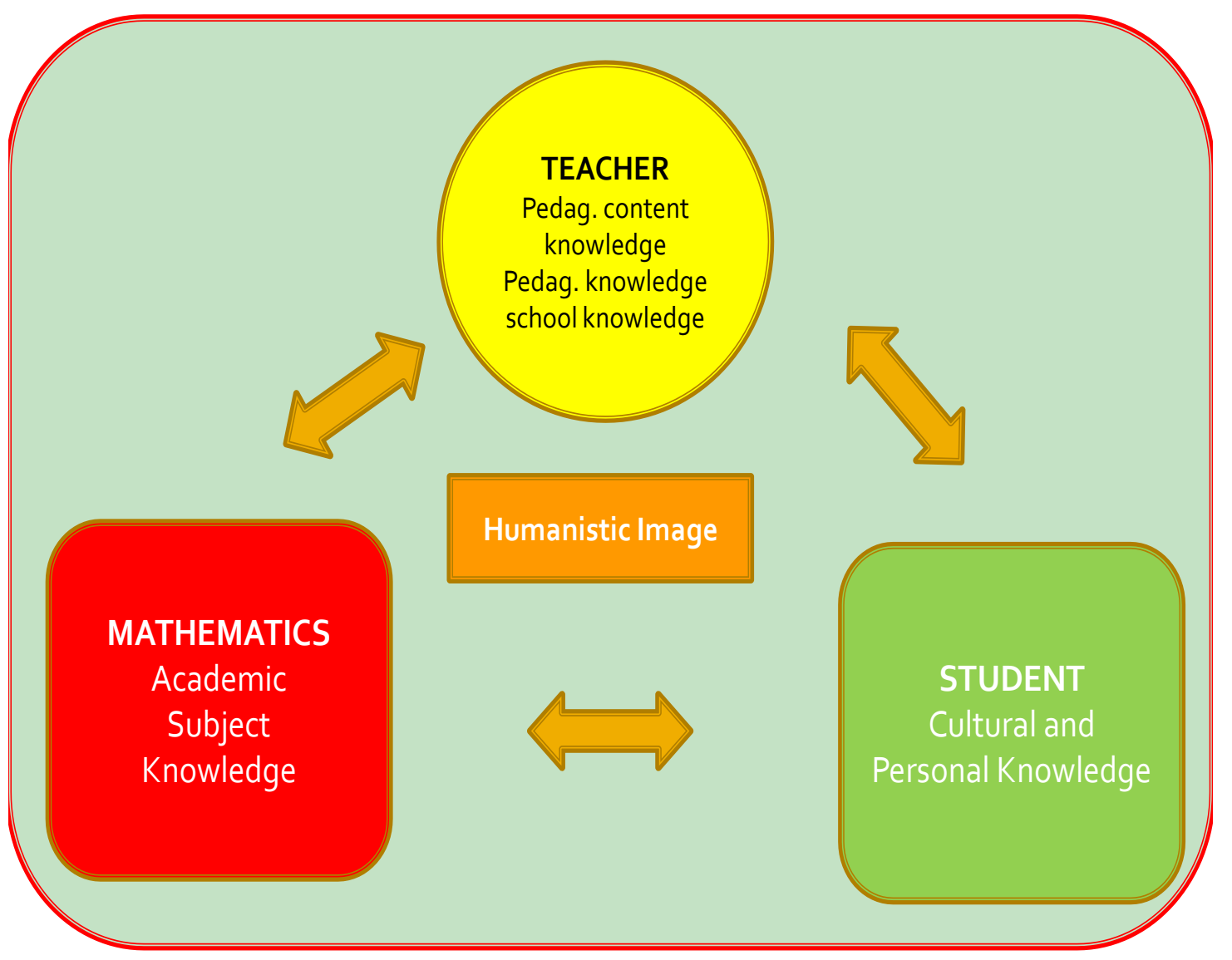

Figure 4. The humanistic image and teaching.

Povey (1997) described a connection between how teachers know the subject and the pedagogical decisions they make. In her qualitative research, Povey interviewed early 
career mathematics teachers and visited their classrooms, noting that the way teachers know mathematics and what teachers believe shapes how they teach mathematics, and consequently their "ways of knowing students" (p. 331). She notes that mathematics is often seen by beginning teachers of mathematics as knowledge "based upon the authority of others" (p. 336). This idea can lead to the belief that the teacher is the only expert in the room able to present knowledge. Povey further noted that, under this belief, it is less likely that a teacher sees mathematical knowledge as co-constructed among learners. I argue that this conclusion affirms my earlier assumption that a traditional image of mathematics might hinder the teacher from involving the whole child in the teaching and learning process.

However, for the last two decades there has been a focus on student-centered mathematics teaching. According to Battista (1994), the National Council of Teachers of Mathematics changed its Curriculum and Evaluation Standards for School Mathematics in 1989 from a traditional teaching approach to a progressive approach, which I conclude is similar to the discussed humanistic approach. This movement, Battista explained, asks teachers to stop seeing mathematics as a subject that uses mechanical work on computation and rigid rules to mindlessly solve problems, but which pretends to be reality-based. Instead, Battista noted that mathematics should be seen as a subject that focuses on meaningful real-life problems, which promotes different thinking, alternative solutions, and cooperative learning.

Therefore, I also reviewed literature on the relationship between teachers' images of mathematics, their teaching and students' learning, and attitudes toward mathematics. 
Woods and Sellers (1996) conducted a 2-year longitudinal study comparing six second and third grade classrooms for arithmetic learning and achievement on standardized tests as well as beliefs about mathematics from students who received 2 years of problemcentered constructivist instruction, in contrast to students who received only 1 year. The study showed that students who were engaged in the problem-centered classroom for 2 years had a better understanding of mathematical concepts and scored significantly higher on standardized tests than the students who received 1 year of textbook instruction and 1 year of student-centered instruction. Moreover, students in the 2-year problembased program demonstrated a more positive attitude toward mathematics as well as their own learning. Wood and Sellers further reported that a belief questionnaire indicated that teachers who volunteered to teach a problem-centered classroom more likely tended toward a constructivist approach than to a traditional approach. After exposure to a constructivist teaching approach, participating teachers rejected what I would call a traditional approach even more strongly.

In another example of a study that investigated the relationship of teachers' perceptions of mathematics and their teaching, Thomson (1984) observed and interviewed three junior high school teachers using a case study approach. The study showed that the participating teachers had different conceptions of mathematics, which impacted their teaching. The two teachers who saw mathematics as a static body of knowledge, those teachers I would characterize as more traditional in their images of mathematics, did not engage the students in knowledge creation, but simply presented the knowledge to the learners. The teachers who held what I consider to be a more 
humanistic image of mathematics engaged the students actively in the creation of knowledge. In addition, their own images of mathematics also influenced how the teachers saw their role in the classroom and the role of the students, as well as their students' learning. The more traditional teachers rated the students' ability to follow procedures and to recognize relationships as evidence of successful learning. The more humanistic teachers saw the application of knowledge as successful learning.

\section{Teacher Candidates' Perception of Mathematics, Students, and Teaching}

Ball (1990a) stated that teacher candidates enter mathematic methods courses with a pre-shaped understanding of mathematics. From the descriptions of the images of mathematics that most of her teachers held, I conclude that they can be seen as traditional images. Shaped through their own experience as learners of mathematics in a traditional school system, the teacher candidates first preferred a procedural step-by-step teaching approach. The candidates often did not understand the mathematical concepts which they had to teach. Ball further stated that in the experience of the candidates, "mathematics is a fixed body of rules, a dull and uninteresting subject best taught through memorization and drill" (p. 12). Therefore, teaching mathematics became a teacher-centered practice of giving directions and assigning practice work. Ball explained that candidates with such an image of teaching mathematics do not consider cooperative learning to be effective.

In a pilot study conducted in the scope of a quantitative research methods course, I saw indications that pre-service teacher tend to believe that mathematics is a universal language (Ferner \& Tilley 2011). The participants in this pilot study also believed that mathematics is a relatively easy subject for English language learners. In addition, most 
of the surveyed pre-service teachers saw mathematics as free of culture and contextindependent. In a tri-state case study on teachers' attitudes toward English language learners and their perception of teaching, Hansen-Thomas and Cavagnetto (2010) indicated that most of the surveyed middle school teachers believed that mathematics is a universal language. In consequence, math should be relatively easy for second language learners.

Previously discussed research indicated that the images of mathematics and the way teacher candidates perceive teaching is shaped by their experience as learners of mathematics. Guillaume and Kirtman (2010) utilized autobiographical math stories to investigate the experiences and images that teacher candidates bring into teacher preparation credential programs, as well how the candidates see themselves as teachers.

Guillaume and Kirtman (2010) declared that "U.S. teachers are products of the school system that they pass through as students and reenter as professionals" (p. 124). They also stated that teacher education seems to have a positive impact on candidates' professional preparation. The study showed that most participants have a neutral image of mathematics, while the mathematics they experienced in school appears to have been traditional. Guillaume and Kirtman explained that teachers with a traditional understanding of mathematics, which focuses on procedural competence, tend to focus their teaching toward finding the correct answers even when they have "reform-minded curricular materials" (p. 133) at hand. Interestingly, in this study the participants' believed that "good teachers" believe in their students and their abilities. The participants of this study further characterized good teachers as teachers who teach conceptual 
understanding, using engaging methods and curriculum content which is interesting for the students. These teachers also create a safe classroom environment, and they care for their students' learning. Moreover, the study participants described a good teacher as one who can "show the connections between mathematics and other facets of life"

(Guillaume \& Kirtman, 2010, p. 138). Such a teacher would most likely hold what Ernest (2009) described as a humanistic image of mathematics. There was no indication of how culturally diverse learners are seen.

In another more recent experimental study on beliefs and content knowledge of prospective elementary school teachers, Philipp et al. (2007) observed a change in undergraduate students' beliefs about mathematics when they were able to experience how children perceive and do mathematics. The change from what Ernest (2009) described as a traditional image to a more what he described as a humanistic image was mostly observed in a guided laboratory setting after analyzing videos of mathematics lessons and being in guided contact with children in a mathematics classroom.

\section{The Interplay Among Images, Disposition, and Teaching Mathematics}

In this section, I discuss literature that addresses the question of what else, other than images of mathematics, might impact the perception of teaching. I present literature that describes the struggle of teaching in ways that are consistent with one's dispositions, especially as images of mathematics challenge those dispositions.

In their case study reports, Ball (1990b) and Gregoire (1999) concluded that perceptions of mathematics impact teachers' abilities to follow their dispositions. For example, Ball (1990b) described the case of a second grade teacher who is disposed 
toward a teaching approach that could be seen as social constructivist. The portrayed teacher saw teaching and learning mathematics as interactive, "hands-on," and multisensory. Nonetheless, despite the teacher's impression that she was enacting her disposition, she instead used a procedural and behaviorist teaching approach.

In her case study, Gregoire (1999) observed an eighth grade pre-algebra classroom. The teacher was supposed to be a "good" teacher as seen by experts in the field of mathematics education. He was described as a good teacher because he first appeared to focus on concept understanding, scaffolding, and multiple activities. Yet, the teacher applied a procedural teaching approach, following strict rules and guidelines. Through observation and interviews, Gregoire came to the conclusion that the procedural teaching approach first seemed to lead to a strong understanding of mathematical concepts. In the end, however, solving "meaningless" mathematics problems actually caused more confusion and misunderstanding than it developed mathematical knowledge and concept understanding in students. I agree with Gregoire that traditionally-focused procedural and rule-based math instruction does not consider learning to be an active, constructive, cognitive process. This observation might be an indication that a teacher who teaches in what Ernest (2009) would call the traditional way may not be able to respond to culturally diverse students because culturally responsive teaching is based on social constructivist learning.

In addition, Williams and Baxter's (1996) case study described a middle school mathematics teacher who believed in what I would describe as social constructivism. Because of her strong disposition to discourse-oriented learning, she was able to enact a 
student-centered approach that was new to her. However, "she sometimes reverts to business as usual, and students fail to arrive at useful knowledge" (p. 37). This study showed how difficult it is to break old habits of teaching. I agree with Williams and Baxter that necessary change in mathematics education must be implemented slowly, and that teachers need to be supported over time to make changes in their classrooms.

In addition, Battista (1994) described the cases of three teachers who share the moral disposition of teaching all students how to achieve. However, these teachers struggled with a constructivist teaching approach because of the traditional image of mathematics they carry. Battista concluded that to change mathematics education, teachers "must acquire knowledge and competencies that their traditional beliefs have heretofore prevented them from accruing" (p. 476). Teachers who have always seen mathematics as following rules will not guide learners to understand mathematics through an active and social process.

After reading Ball's (1990b) study and other research reported in this section, I argue that the dominant focus of the Common Core Standards (which have been adopted by most U.S. states) for mathematics on knowledge and understanding of concepts and procedures that students need to acquire, bears the risk of being seen as highly sequenced and context independent. When following these standards, teachers could potentially fall short of putting mathematical knowledge into a broader context of culture and society. The National Council of Teachers of Mathematics (2011) principles and standards of teaching mathematics seem to counteract this potentially solely procedural approach and add a culturally responsive approach to mathematics education. They call for applying 
constructivist learning theories to teaching and learning, which may make it possible to teach to the needs of all students guided by the Common Core Standards. However, in his report of a 2-year semi-ethnographic study "Teaching and Learning Mathematics for Social Justice in an Urban, Latino School," Gutstein (2003) cautioned that even when the standards appear to promote social justice and equal opportunities, the definitions of those terms remain unclear. The study does not address how equity in classrooms can be achieved.

In the next section, I therefore focus on teaching mathematics with culturally diverse learners. I investigate literature that addresses the question of responding to cultural diversity in the mathematics classroom in order to create equal learning opportunities for all students.

\section{Culturally Diverse Learners and the Teaching of Mathematics}

Gutstein (2003) noted that in order to address issues of social injustice and inequity in the classroom, a focus on the child as a person is the solution. Teachers have to address questions that concern the learners' lives and help them to think critically about their lives. These goals can only happen when the learner's language and culture is valued in the classroom. Gutstein further stated that mathematics can be used to help the students understand and create the world. I think this perspective shows that learning mathematics should not just serve to help students acquire the necessary skills and knowledge to do mathematics procedures; it should make mathematics part of the learner's life rather than an abstract tool. Affirming the whole child and the cultural and 
social environment creates meaning for the subject and helps to teach mathematics in a culturally responsive way.

To learn more about teacher candidates' images of culturally diverse learners and how they might shape their perceptions of teaching, I reviewed McDiarmid and Price's (1990) Accepting Behaviors for Cultural Diversity (ABCD) evaluation of a program focused on pre-service teacher education. Because it is one of the few studies that describes and links images of cultural diversity learners with teaching, I describe it in detail.

McDiarmid and Price (1990) investigated "how student teachers think about diverse teaching and learning in culturally diverse classrooms" (p. 2) and how the ABCD training influenced their fundamental beliefs. The program was designed to provide teachers from a dominant white culture with the knowledge and skills needed to teach students from culturally diverse backgrounds and to view cultural diversity as an asset for learning. The program also attempted to improve the teacher candidates' perception of students from a culturally diverse background. The authors explained that the study was based on the research of beliefs because it was not possible to observe teacher candidates' teaching.

McDiarmid and Price (1990) stated that teachers teach according to their knowledge and beliefs about learners, learning, pedagogy, and subject matter, as well as the political and social context. Regarding the pre-service teachers' beliefs about culturally diverse learners and using written classroom scenarios, McDiarmid and Price evaluated the participants' views on stereotyping. They concluded that most participants 
rejected stereotyping culturally diverse students. As well, the ABCD training did not change the teachers' perception about stereotyping. When asked on a questionnaire about culturally diverse students' abilities to learn, the teacher candidates revealed that there are circumstances, such as home environment or learning disabilities, which might delay learning. At the same time in this study, none of the participants believed before the training that, to be good at math, a student needs to have a "math mind." Two of the participants believed so after the training.

Regarding the teacher candidates' ideas about teaching culturally diverse students, McDiarmid and Price's (1990) questions aimed at evaluating the participants' beliefs on teaching mathematics to students of different achievement levels showed that the participants would teach mathematics differently to high achieving students and low achieving students. The participants' beliefs reflected that a focus on high cognitive tasks are more appropriate for engaging high achieving learners, whereas making mathematics fun was more frequently mentioned to support low achieving learners. The program seemed to have little impact on what the participants considered to be appropriate differentiated instruction. However, the researchers concluded that most of their participants showed at least a weak belief toward avoiding ability grouping. Moreover, while the participants were unsure whether uniform standards should be applied to all students, a majority of the participants believed after the training that differentiated instruction can be successfully implemented to support the learning of all students. In regard to the purpose of teaching, the study showed that almost all participating teacher candidates believed that the main purpose of teaching is to teach and encourage students 
to think and ask questions. Finally, the ABCD training seemed to have had only a small impact on the participants' beliefs about teaching culturally diverse students. However, the study did show that the participants believed a teacher needs to ensure that all students can learn. In addition, McDiarmid and Price (1990) noted that there was also a shift in the participants' perceptions regarding the notion of whether all students can learn. After the training, the participants more strongly believed that equal learning opportunities are key so that all students can learn.

Still, McDiarmid and Price (1990) concluded,

Teachers who believe that the way to deal with diversity is to individualize learning tasks will not create opportunities for pupils to learn from one another, to experience making sense of a problem or issue with classmates, to develop an idea that knowledge is socially mediated. (p. 26)

Like Ball (1990), these scholars observed that teacher candidates' beliefs about teaching culturally diverse students do not change in the relatively short space of 90 days. It is likely that the teachers teach in the way they were taught themselves.

Reviewing the literature, I was able to identify a solid body of work on teacher and teacher candidates' beliefs about mathematics and how these beliefs shape the perceptions of teaching in general. Only a small but significant body of literature focused on teacher candidates' perceptions of culturally diverse students in mathematics.

In consequence, I have drawn on research in other subject areas. For example, in her case study of secondary history teacher candidates' knowledge and beliefs about teaching U.S. history to Alaska Native students, Noordhoff (1993) noted that teaching involves connecting subject matter and the learner. In consequence, knowledge about 
students shapes the instructional decisions of the teacher. Noordhoff described the images of culturally diverse learners that her participants held as not stereotypical, but the participants seemed to have only limited understanding of their Alaskan Native students as learners of history. Rather, the teacher candidates in her study based their teaching approaches on their beliefs about students' general interests and interest in learning. Although Noordhoff did not focus on the teaching of mathematics, her findings are highly relevant to my study. I have found no indications that her findings are limited to the subject of social studies. Noordhoff clearly indicated that all these types of knowledge interact to create a certain kind of learning opportunity for the teacher candidates' Alaska Native students. I see this interaction as an indication that there is a connection between what I call teacher candidates' images of the subject, their images of the culturally diverse learner, and their perceptions of teaching, which is, essentially, the key question in my research.

\section{Summary of the Chapter}

Scholars in multicultural education (e.g., Banks, 2008: Gay, 2010; LadsonBillings, 1995) have been advocating for grounding teaching and learning in social constructivist learning theories. As they and I have described, this social constructivism opens the door for culturally responsive teaching. Connecting child and subject matter while making the learner and the learner's background a foundation for teaching may help students to achieve academic excellence (Banks, 2008; Gay, 2010). The reviewed literature indicated that teachers' and teacher candidates' images, beliefs, dispositions, and knowledge are interrelated and interdependent in teaching practice. Figure 5 
visualizes this interdependency. As stated above, the capacity to enact dispositions is influenced by the images about a subject that a teacher holds.

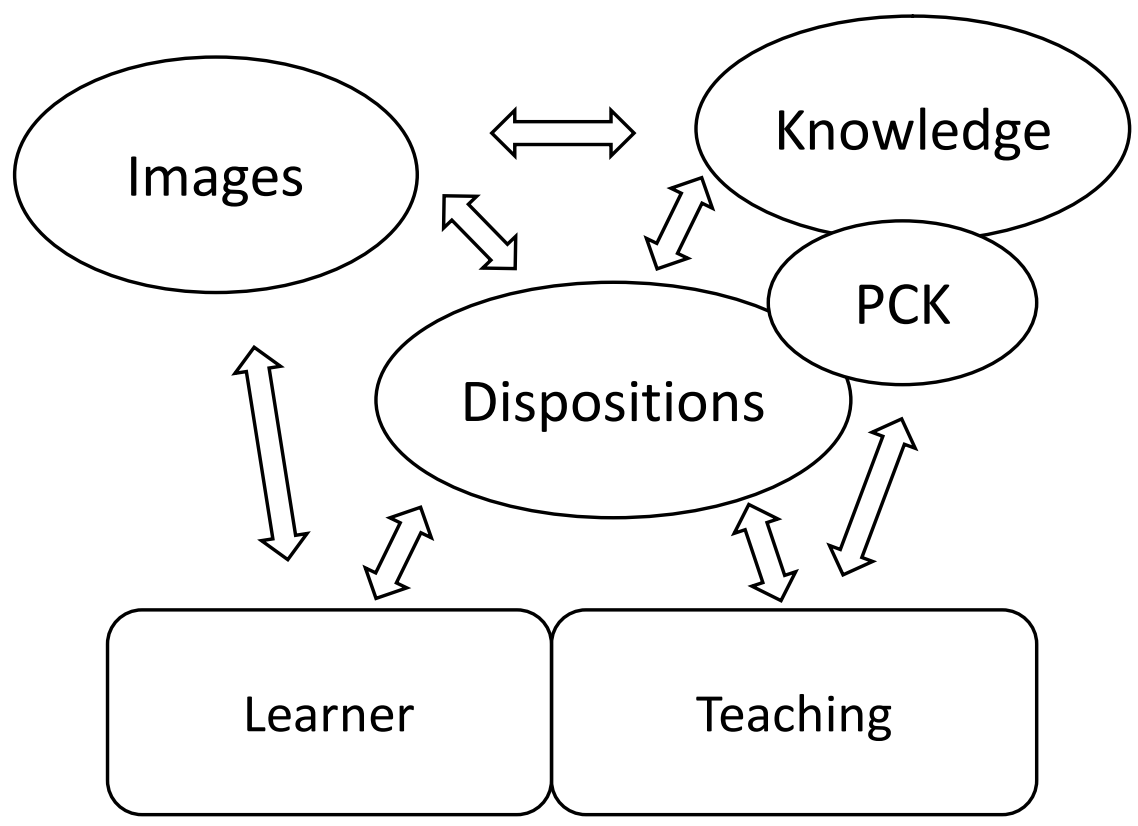

Figure 5. The relationship of teachers' images, knowledge, dispositions and perceptions about teaching and the learner.

In the literature I have read, I see indications that teachers who are morally committed to their learners' success, but hold a traditional image of mathematics, seem to experience difficulties in actively engaging children in meaningful and constructive learning based on the context of the child's reality (e.g., Ball 1990b; Battista, 1994: Williams \& Baxter, 1996). These circumstances might explain one reason why culturally diverse children still do not receive the mathematics education they need and deserve. Other research reviewed (e.g., Gutstein, 2003; Povey, 1997) showed that the image of the subject that a teacher carries shapes how the teacher sees teaching and the role of the 
student as a learner. This suggests that necessary changes in educational practice must come through a change in teachers' images of mathematics (Battista, 1994). Ball's (1990a) report on pre-service methods courses and Philipp's et al. (2007) study of prospective elementary teachers in an undergraduate program indicated that a change in teacher's beliefs is possible, though difficult.

Regarding my research questions, the review of the literature indicated that elementary teacher candidates might hold an image of mathematics that leads them toward a procedural teaching approach to mathematics with a focus on facts. Empirical research, mostly conducted in the 1990s, suggested that such a traditional image of mathematics promotes a procedural teaching approach, whereas a humanistic image promotes a constructivist approach (e.g., Gregoire, 1999). Moreover, there was some evidence that their own images of mathematics influence teachers' dispositions and perceptions of the learner in the classroom. The reviewed literature indicated that there are images of mathematics that might promote culturally responsive mathematics education. The reviewed literature has also suggested that teachers may be morally committed to teach to the needs of all children, but their own images of mathematics often interfere.

The limited amount of recent and relevant literature regarding teacher candidates' images of mathematics and teaching with culturally diverse students in a multicultural elementary classroom warrants more research. This case study, described in the next chapter, adds to the base of knowledge on teachers candidates' perceptions of mathematics and culturally diverse students, as well as how they imagine teaching 
mathematics to such students. Such a base of knowledge might be helpful to close the opportunity gap (Gay, 2010) by enabling elementary teacher candidates to enact a culturally responsive pedagogy in their classrooms. 


\section{CHAPTER III}

\section{RESEARCH DESIGN AND METHODOLOGY}

\section{Research Design Overview}

The goal of this study was to gain a deep understanding of how elementary teacher candidates see mathematics and culturally diverse learners and how the candidates' perceive teaching mathematics in a multicultural environment. I conducted a qualitative Multiple Instrumental Case Study (also called a Collective Case Study) (Creswell, 2012). The study provided fundamental insights which will be useful in providing a framework to change $\mathrm{K}-12$ teacher education practices and may provide a foundation for my own future research on teacher education. The study, conducted during a 12-week period in Fall 2012 at Tree State University (TSU), was guided by the overarching question: How do teacher candidates perceive teaching mathematics in a multicultural environment? Three sub-questions follow:

- What images of mathematics do elementary teacher candidates hold?

- What images of culturally diverse learners in the mathematics classroom do elementary teacher candidates hold?

- What is the relationship, if any, between and among the images of mathematics, culturally diverse learners, and the teacher candidates' perceptions about teaching mathematics to such learners?

Following Kincheloe's (1997) critical constructivist research paradigm, I conducted interviews, solicited math-autobiographies, and held a focus group with four elementary teacher candidates enrolled in the 1-year, graduate-level teacher licensure program, the Teacher Licensure Program of TSU, a large urban public university in the 
Pacific Northwest. As with the names of this university and its program, I have used pseudonyms for all other institutions and persons involved in the project.

\section{Research Paradigm}

While I have already introduced critical constructivism as a learning theory, I now introduce critical constructivism as a research paradigm. From Kincheloe (1997) I conclude that a critical constructivist research paradigm is what Guba and Lincoln (2005) described as a constructivist paradigm combined with elements of the critical theory paradigm. According to Kincheloe, in critical constructivism, knowledge is created in the mind of a person, as well as based on already existing knowledge, experiences, and the individual's interpretation. Using this lens, there is no neutral objective truth, but multiple co-existing truths. Whenever we try to understand something like education, "the constructivist principle tacitly remains" (Kincheloe, 1997, p. 56), which means that coexisting truths are accepted and not questioned. In addition to this basic constructivist perspective, a critical constructivist research paradigm also employs the critical theory worldview, placing knowledge into historical context and relating it to the "role of power and its ability to shape our representation of the world" (Kincheloe, 1997, p. 57).

This critical constructivist paradigm thus informed my position as a researcher with a perspective that has been shaped by experience of the social world and that, therefore, cannot be neutral. For example, the experiences I had as a novice teacher in Germany have shaped my work and research in education ever since. As a novice teacher, I worked with fifth and sixth grade students who came from cultural backgrounds different than mine. Their experience of the world was not represented in 
the materials provided by the school nor in my approach to teaching them. I could see that the students were not motivated to learn because the materials and content did not seem relevant or meaningful to them. They had difficulties understanding the context upon which the teaching was based, which meant that they did not understand the connection of mathematics to their own experience of the world. I could see that the students were struggling, and I also struggled to find ways to connect them to the material. I began to ask questions about who these students were and where they were coming from, which led me to change how I taught and what I taught. As a teacherresearcher, I became passionate about researching and finding ways to do culturally appropriate teaching.

According to Kincheloe (1997), critical constructivism promotes the critical theory element of self-reflection in order to understand the influence of power. In addition, critical constructivist research aims to deeply understand the structures that "shape our understanding of the world and our role in it" (Kincheloe, 1997, p. 57). My research aimed to investigate the power that images of mathematics have on the way teacher candidates see the world of mathematics and the teaching of mathematics with culturally diverse students. While I was initially intrinsically motivated to understand a possible pattern in the achievement gap described above, my research was intended to be an "instrument" (Creswell, 2012, p. 464) toward closing the opportunity gap for culturally diverse children. In addition, my acceptance that multiple truths coexist called for a study that created a holistic picture of teacher candidates' truths through a deep analysis of their experiences, backgrounds, assumptions and images. In order to 
accomplish this end, I focused on the perceptions of four teacher candidates. Although according to a critical constructivist paradigm, none of these individual cases, not even all of them taken together, can represent the entire cohort or even the entire program, they can potentially provide insight into teacher candidate images and thus provide guidance for teacher education.

Moreover, applying a critical constructivist paradigm, I intentionally used research instruments that were self-reflective and instrumental to learning. While I did assume that this research alone had the potential to influence the teacher candidates' perceptions of mathematics, I also saw indications that this research, at the very least, would support the candidates' learning process. My study methods may themselves be used as learning activities. According to Carol Brown, a TSU math methods course instructor, a math autobiography has always been the first homework assignment in her courses. In addition, analyzing and discussing a mathematics lesson, as was done in the focus group discussion, is also a legitimate teaching activity in teacher education. Because of the critical constructivist research paradigm, I observed and reported any potential changes in the teacher candidates' perceptions of teaching mathematics in a culturally diverse environment. Throughout the course of the research project, I reflected on my own biases and my influence on the participants in ways I describe below.

\section{Overview of the Case Study and Rationale}

I conducted a Multiple Instrumental Case Study with a focus on four independent cases (individuals) as the unit of analysis. A further cross-case analysis also gave insights into the power of images of mathematics, culturally diverse students, and teaching. I 
chose a case study approach as "an in-depth exploration" (Creswell, 2012, p. 465) because I intended to gain a deep understanding of the assumptions, perceptions and beliefs which may have contributed to the previously described achievement and opportunity gaps. The teacher candidates, having common educational characteristics (e.g., they all held a bachelor's degree and were all in the same teacher education program), were participants in one phase of a particular teacher education program, which made the teacher candidates the "bounded system" (Creswell, 2012, p. 465) that was explored. Each participating teacher candidate represented one case. The multiple instrumental case study made it possible to get an enhanced perspective on teaching mathematics in culturally diverse environments. This study used multiple cases to explore multiple perspectives because of the potential variation of images of mathematics and culturally diverse students, as those might have shaped candidates' perceptions. In a single case study, I would not have been able to understand the multiple perspectives necessary for the deep exploration of the issue described.

I used the initial coding of math autobiographies to determine participants for the study and explore their images of mathematics. Thereafter, in a semi-structured interview, I explored how the teacher candidates perceived mathematics and culturally diverse learners in mathematics. In the next step, all four participants were engaged in a focus group discussion on teaching mathematics in a culturally diverse elementary classroom. I was able to conclude the data collection process with a follow-up interview, which provided room for questions that looked across all implemented research instruments. 


\section{Research Site}

I purposefully selected the graduate-level Teacher Licensure Program of TSU for my research. As I expected, as a former student and current faculty member in the program, I had convenient access to participants as well as other faculty members who were supportive of my research. In addition, I was familiar with the vision and structure of the program. Moreover, as mentioned above, my research may continue to have some relevance to this specific program and its course design, while also potentially contributing to teacher education more generally.

According to the University's website, there are about 30,000 students enrolled in more than 60 undergraduate and 40 graduate programs at this urban site. The University is committed to improving P-20 education in the metropolitan area and throughout the state. In small classes, TSU undergraduate students are engaged in off-campus learning and capstone projects as seniors. More than $50 \%$ of the students are from the surrounding metropolitan area. With a special interest in globalization and diversity, TSU enrolls students from more than 90 countries.

The Teacher Licensure Program is part of the School of Education, which offers licensure, master's and doctoral programs for P-20 educators and counselors. The graduate, 1-year program, in concert with the school's guiding framework, emphasizes the use of research-based practices to meet the needs of diverse learners and communities. The School of Education is committed not only to preparing teachers who are adaptive experts to meet the needs of all learners, but also to be active members of the community. Partnerships with schools and communities fuse theory, research, and 
practice for the benefit of all. Cohorts are led and supported by pairs of faculty. Early on and throughout the entire program, teacher candidates are engaged in clinical learning experiences. The candidates co-teach and cooperate with experienced teachers in schools who serve as mentors and university supervisors to support them.

In the year 2012-2013 there were approximately 180 general education candidates in several full- and part-time elementary cohorts, as well as several full- and part-time secondary cohorts. About $75 \%$ of the elementary candidates are female. A least $75 \%$ of the candidates identify as White. The majority of the elementary candidates are between 20 and 30 years old. Data related to the portion of the teacher licensure program serving bilingual teacher candidates and programs are not included in these statistics.

\section{Participants}

The participants for this study were selected through "opportunistic sampling” (Creswell, 2012, p. 207) from two separate courses of elementary mathematics methods in the teacher licensure program. Although I attempted to include a minimum of six participants in the study, only four of them completed all data collection activities. Hence, the study focuses on four participants, although I also describe the process by which six participants were sought and some participants withdrew.

In the attempt to find six participants, I approached elementary teacher candidates enrolled in the two integrated math methods courses during regularly scheduled course meetings in the second week of the term, sharing an explanation of the study and the informed consent. After agreeing with the instructors about what would cause the least interruption to the flow of the class session, I presented my research in one course at the 
end of the session and in the other course during the break. In both cases, I observed the entire class session. When I introduced myself and this research project to the candidates, I explained the purpose of my research and its phases, as well as potential risks, benefits, and the anticipated time commitment. In addition, I explained the sampling process to assure the teacher candidates that my choice would not be related to their qualifications as a teacher or their performance in the program. Finally, I handed out the consent forms (see Appendix A) and the sampling questionnaire (see Appendix B), with my contact information attached. I was also available to answer any questions during the break and/or after the class session. Teacher candidates interested in participating contacted me by email and were asked to return the sampling questionnaire within one week. Four of the interested teacher candidates handed in their completed questionnaire and their signed consent forms immediately. When I met both groups of teacher candidates a second time the following week, two more handed in their consent forms and questionnaires. Because six participants was the minimum number with which I intended to start my research, I contacted the other teacher candidates who had expressed interest by email. However, I did not receive any additional positive responses. Consequently, only six teacher candidates completed the sampling questionnaire and gave their signed consents to me. To identify whether or not the six already committed teacher candidates were a suitable group for my research, I conducted a preliminary analysis of the sampling questionnaire. I analyzed the data sets for maximal variation sampling. First, through holistic coding, I looked for contrasting images of mathematics. Secondly, through attribute coding (Saldaña, 2009), I realized that the initial group was representative of the graduate 
teacher licensure program with regard to age, gender, race and ethnicity. The data indicated that the six initial participants carried a variety of stances toward the research topic, which opened the possibility for me to gain deeper insights into a complex phenomenon. Because the participants also seemed to be a representative sample of TSU's graduate teacher licensure program with regards to age, sex, and ethnicity, I did not attempt to find alternate participants.

Due to my opportunistic sampling, I had no specific information about the participants to consider in the planning of the research methodology. I had to rely on the general characteristics of the group, which I had observed and some of which I have already listed above. I now elaborate on the more defined characteristics which are part of the bounded system that was investigated.

All six initial participants stated that they held a bachelor's degree, which is an admissions criterion of the Teacher Licensure Program for the graduate postbaccalaureate program. For elementary teacher candidates, the undergraduate degree does not need to fulfill any major or minor requirements, except a grade point average (GPA) of 2.5 and above on a 4.0 scale. In addition, there are required prerequisite courses. Most important for this study were the three required quarter-length courses in mathematics content appropriate for elementary level teaching. The courses on elementary school mathematics aim to provide candidates with an understanding of the subject matter as a sufficient foundation upon which to build pedagogical content knowledge. The participants had all taken these courses at TSU and other area community colleges at different times. These colleges and universities coordinate the content and delivery of the 
prerequisites with TSU. In addition, all candidates were enrolled in an elementary mathematics methods course in the second term as part of the licensure program during the fall of 2012. However, one of the initial six participants discontinued participation in this research because he withdrew from the program after the first interview.

Due to the cohort character of the licensure program, all participants had taken the same or similar coursework. The participants had completed some coursework during the summer relevant to the focus of this study. A course concerning multicultural education focuses on teaching and learning in a diverse environment, including an emphasis on cultural diversity. This course not only paid attention to teaching with students from diverse backgrounds, but also to the teacher candidates' identities as persons, learners, and teachers. One of the key assignments of the course was a self-reflective cultural autobiography similar to the math autobiography I used in this research project. Moreover, the candidates had taken coursework that introduced them to general concepts of teaching. In their initial field experiences, the teacher candidates all worked in classrooms and attended planning meetings with the teachers. During the term of this research study, all participants were enrolled in coursework at the university as well as working and learning in elementary classrooms. Before I elaborate on data collection strategies, I first introduce the four remaining participants who participated in this research to a level that provided a reliable set of data. The personal background information is based on self-reported data as well as deduced through "attribute coding" (Saldaña, 2009) of the interviews and the focus group. I provide more detailed information on the participants' backgrounds in chapter 4 . 


\section{Participants' Personal Profiles and Background}

Frank was a White male in his early 40 s at the time of his participation in the research study. Frank stated that he grew up in a diverse part of California. Frank, whose parents were public educators, attended a public junior high school and private Catholic high school. Frank held a bachelor's degree in Arts and Communication. Before Frank enrolled in the TSU teacher licensure program to become an elementary school teacher, he worked for almost 20 years for private companies. Because of work-related international travel and collaboration with international business partners, Frank came into contact with people from a variety of backgrounds.

Alison was a Non-White female in her late 20 s at the time of his participation in the research study. Although both of her parents identify as White, Alison identifies as Non-White. In elementary school she used to be the only non-white child in her neighborhood. She explained that she "grew up in a very white-bread community" in a mid-sized town. Alison grew up in a family of three generations of teachers. After high school Alison worked in retail and fast food service. After six years, Alison decided to go back to school to become a teacher and enrolled in a large urban university. For her final project for her bachelor's degree in social sciences, Alison worked with refugees from Somalia.

Christy was a White female in her mid-30s at the time of his participation in the research study. She grew up in a lower-middle class family and attended public neighborhood schools in her hometown in the Midwest. She explained that her "elementary school was probably the vast majority white," and added that starting at the 
junior high level, the school "had a large population of Vietnamese and Laotians" students whose parents came as refugees. Christy explained that in her working class family "college was never really an option." However, she attended the local community college and worked occasional jobs for a while. With an associate degree in a biologyrelated field, Christy worked in that field before she decided to go back to school to earn a higher degree. At the time of the research she held a bachelor's degree with a major in science and a minor in elementary education, and was also working on her master's thesis in science education.

Emily was a White female in her early 20 s at the time of her participation in the research study. She grew up in a family of educators in a rural area of the Pacific Northwest. She attended local public schools and went to the same school where parents worked. She described the neighborhood as quiet and rural, with more animals than other kids around. The closest neighbor lived about a mile away. Emily mentioned that although her family was open-minded, growing up in this rural area did not give her much exposure to diversity. More exposure to diversity was one of the reasons why she decided to enroll in a teacher licensure program at an urban university and move into the city, after she graduated from college with a bachelor's degree in social science.

\section{Data Collection}

For this Multiple Instrumental Case Study research, I used math autobiographies (a course artifact), two individual interviews, and a focus group as my main data gathering methods. I also collected other course artifacts-such as the course syllabi, course assignments and lesson plan templates-as well as conducted one informal 
conversation with a course instructor. In addition, a sampling questionnaire supported my sampling process and initial data analysis. The critical constructivist framework for this research made it possible to construct and adjust research instruments that take the learning process of the participants into account.

I designed each data-gathering method to focus mainly on one of my three research sub-questions. However, data collected from all methods and tools contributed to the analysis. First, I used the sampling questionnaire and a course artifact, the mathautobiography, to analyze and evaluate the image of mathematics each participant held. Next, I conducted a one-on-one interview to get an understanding of how the teacher candidates saw culturally diverse students, following an interview procedure recommended in Seidman (2006) in which the researcher starts with more general questions and, while listening carefully to the responses, refines the questions to a narrowed focus. This interview also sought to clarify their images of mathematics. The follow-up focus group, based on Morgan (1998), honed in on the teacher candidates' perceptions of teaching mathematics to culturally diverse students. A second individual interview provided another opportunity to look back upon the entire research project and to add to my overall impression of the participants' perceptions regarding teaching mathematics to students from a culturally diverse background.

The order of data collection using these strategies and instruments was important because of the constructivist nature of this research. I used the data as it was collected to inform my next steps, which shows the interdependencies of the sub-questions and the data collection strategies. The order of data gathering also guided my method of thinking 
while analyzing data. Moreover, to be able to facilitate a focus group, it was important to first build a relationship with the participants as recommended by Morgan (1998). The initial one-on-one interview provided this opportunity. Finally, an interview at the end gave closure and room for reflecting back upon the entire project.

\section{Sampling Questionnaire}

A sampling questionnaire (see Appendix B) was given to all teacher candidates who expressed interest in participating in my study. The questionnaire asked the potential participants to voluntarily disclose age, gender, and ethnicity/race and the grade level for which they were pursuing a teaching license. This information was intended to be used for the purpose of sampling for maximal diversity.

In the second part of the questionnaire, the candidates were asked to answer questions about their perceptions of the nature of learning and engaging in mathematics as developed by Swan (1993). This set of questions described learning mathematics through metaphors in order to make it easier for the participants to reflect on their own images of mathematics and their perceptions of how it is learned. Swan's statements were developed to access high school students' beliefs about mathematics and learning mathematics. Because I saw no indication that this instrument could not be used with teacher candidates, I incorporated selected statements into my questionnaire. One example stated, "Learning mathematics is like learning a new cooking recipe. The teacher or book gives you step-by-step instructions. You just do what they say.” Whether the teacher candidates agreed or not with such a metaphorical statement provided a first impression on the extent to which they saw mathematics as procedural. The third part of 
the questionnaire was intended to provide data indicating the images of the nature of mathematics the teacher candidates held, as developed by Raymond (1993). The participants rated the statements about the nature of mathematics and the nature of learning mathematics on a five-category Likert scale from strongly agree to strongly disagree. I first categorized the statements using Ernest's (2009) description of "humanistic" and "traditional" images of mathematics. These statements correlated with different categories of perception about mathematics. Statements 1, 3, 5, 16, and 17 described mathematics in a more traditional way because of their focus on procedures and rules that need to be followed. In contrast, statements $6,8,9,12$, and 18 described mathematics and learning mathematics in a more humanistic way. Statements 15 and 13 directly ask about statements that are often heard in the classroom. Mukhopadhyay et al. (2009) stated that one of the traditional beliefs about the nature of mathematics is that mathematics is a universal language. Ernest (2009) further noted that there is a common belief that mathematics is only accessible to people who are intelligent. In addition, statement 2 pictured mathematics as "jumbled up ideas" which makes mathematics difficult to understand and inaccessible, whereas statement 7 sees mathematics "as puzzles that can be put together," using the metaphor of the jigsaw puzzle indicating that every child can learn mathematics. Statements 4 and 10 targeted basic elements of engaging in mathematics such as the understanding of concepts and learning mathematics in a certain order. At first glance, statement 11 indicates a traditional image of mathematics, but a participant who holds a humanistic image of mathematics could also agree with this statement because memorization of facts and procedures can sometimes 
be helpful. For example, students can use procedural knowledge to develop and discuss ideas to solve a problem. However, the focus on the answers to particular statements did not reveal enough information about the participants' images of mathematics to come to a firm interpretation about their perceptions of mathematics. Overall, the teacher candidates' responses to the questionnaire had to be evaluated as a whole to give indications of the images of mathematics each teacher held.

\section{Course Artifacts}

I describe the course artifacts I collected separately: math autobiographies, syllabi, and descriptions of assignments, as well as the lesson plan template. Although not strictly a formal, written course artifact, I also include in this section a brief conversation I had with one of the course instructors.

Math autobiography. In preparation for the elementary mathematics methods course, students were required by the course instructor to write a math autobiography (see Appendix C). The teacher candidates were prompted to reflect on their experiences as learners and knowers of mathematics. In addition, I was able to investigate how the teacher candidates have experienced mathematics throughout their education; these experiences served as an indication of what the teacher candidates consider to be good teaching. Ball (1990a) observed in her mathematics methods course that candidates' manners of thinking about mathematics are often shaped by their previous experiences with mathematics.

After conferencing with the lead instructor of the math methods courses, I adapted that pre-course assignment, which has been used for many years, to also address the 
teacher candidates' experience and perception of mathematics. Consequently, my colleagues administered the tool in the late summer as regular course pre-assignment. To safeguard the integrity of the homework assignment and the research at this time, it was not yet mentioned that the paper teacher candidates wrote might also be later used with permission in a research project. I was intentionally not included when the email with the assignment announcement was sent out, and I was not aware of any other information these messages might have contained. Later, at the early stages of the data collection process, I sent an email (see Appendix D) to all participants, asking them for an electronic copy of their math autobiography, a pre-course assignment which I had coconstructed with the course instructors. This procedure avoided additional work for the course instructors and kept the identity of the participating candidates private from the course instructor.

Guillaume and Kirtman (2010) used a similar instrument to assess the images of mathematics that teacher candidates carry and how those images have developed and manifested over time. I followed Guillaume and Kirtman's example and kept the writing prompt very open, allowing the candidates to draw on experiences which they considered most valuable. To assure that the candidates reflected on all areas that were important for the course instructors and me, as a researcher, the candidates were asked to include how the subject was taught to them, how they felt about it, and how they now view this kind of teaching in the early stages of their teacher licensure program. They were also asked to include how, if at all, their perception of mathematics had changed. Similar to Guillaume and Kirtman's prompt, also included was an invitation to describe school experiences and 
non-school experiences with mathematics. This information gave an indication of the relevance mathematics played in the candidates' families and outside school environment, as well as how they perceived mathematics in general. Guillaume and Kirtman (2010) mentioned that, as a self-reporting instrument, math autobiographies do bear the risk of being selective and incomplete. However, I argue that analyzing what is self-reported gives appropriate and useful insights into images of mathematics included in a study of teacher candidates' perceptions.

Reflective autobiographies are common teaching and assessment tools used in various courses at TSU. For example, I use a similar prompt with a similar purpose for an assignment in my course on curriculum theories. As mentioned before, mathematics methods instructors have regularly used math autobiographies as homework assignments and course pre-assignments. Indeed, the self-reflective nature of the assignment might support candidates' learning because teachers need to know themselves to be able to effectively teach in a culturally diverse environment (Banks, 2008).

Course syllabi. The course syllabi of the elementary math methods courses in which the participants were enrolled during the fall term provided a course description, goals and objectives, description of the assignments, course schedules, and other course related information. I used the syllabi to get a better understanding of the course content and course schedule. I limited my evaluation of the course material to the content and the schedule. For the planning of data collection and for data analysis it was important to know which concepts and methods had already been taught at the time of the interviews and focus group. I did not do an in-depth analysis of the course syllabi, because my 
research was not a course evaluation and did not focus on the influence of the course on the teacher candidates' perceptions. To protect the identity of the program and the privacy of the participants, I did not include a copy of the syllabi in the appendix.

Planning guides and lesson planning templates. The teacher licensure program provided work sample planning guides which included templates for unit and lesson planning. The guides asked the teacher candidates to consider students' backgrounds, preexisting knowledge, and performance levels when planning their teaching. In addition to planning goals and objectives, these guides and templates called for planning content and methods, which included differentiation. At least one of the instructors used an additional scoring guide which asked the teacher candidates to think about how a lesson could be meaningfully connected to the students.

The guides and templates which were used in the elementary math methods courses provided important information pertaining to the kind of knowledge about their students a teacher might collect. In addition, the planning guides gave insights into the origins of the language the participants used when they described teaching and students. To protect the privacy of the participants, there is no copy of the planning guides or templates in the appendix.

Informal conversation with instructors. Although one brief conversation with an instructor cannot be considered to be a formal, written artifacts of the elementary mathematics methods course, I included a conversation here because it best relates to understanding the context of the course in which the study participants were enrolled, which was also the purpose of artifacts described above. 
In addition to consulting course artifacts for content and language used in the course, I had one brief, informal conversation with one of the elementary course instructors to clarify which terms, culturally responsive or culturally relevant, the instructor had established. The instructor mentioned that she had used the term "culturally relevant teaching" because that was the term used in the textbook in class (I did not have access to the course textbook). The instructor also mentioned that she personally prefers the term "culturally responsive teaching" because that term implies more action. However, she also mentioned that she likes to use "culturally relevant teaching" as a useful way to start thinking about "culturally responsive teaching." The instructor seemed to scaffold the terms, using "culturally responsive teaching" as a more advanced concept and "culturally relevant teaching" as a more basic planning concept.

\section{Individual Interview I}

The first of the two 60-minute, semi-structured, individual interviews focused on how the candidates saw students in a culturally diverse mathematics classroom and the images of mathematics the teacher candidate held at the time of the interview and throughout their education. The questions were developed on the basis of a holistic analysis (Saldaña, 2009) of the sampling questionnaires and the candidates' mathautobiographies. Asking follow-up and clarifying questions about the math autobiography and questionnaire helped me to get a better understanding of their perceptions of mathematics and how those have changed, or not, over time. In addition, in almost all questionnaires, there were responses which seemed internally contradictory. Some of the questions in the interview were specifically designed to put the questionnaire 
responses into perspective. For example, I asked the participants what first comes to mind when they hear the term mathematics because I wanted to get a first overall impression of their image of mathematics. During the interview, I was quickly able to assess whether or not my first impressions from their questionnaires were indeed similar to the candidates' answers to this question.

The interviews were conducted in a suitable, quiet and uninterrupted classroom or meeting room on campus, scheduled at the candidates' convenience. The interviews were all recorded using the Notability application on my university-owned iPad tablet. The use of the Notability application allowed me to combine the voice recordings with notes I took during the interview. I transferred the created .mp4 files into a Dropbox folder and shared this folder with a professional transcriber, along with page formatting recommendations (e.g., margins and line spacing). I also asked the transcriber to include conversation-related artifacts such as pauses, cut-offs, laughter, and two people talking at the same time. The professional transcriber transcribed all interviews verbatim and emailed the transcripts as a Word document to me. I stored these documents in a password-protected file on my hard drive and on my secure personal university network drive. To keep field notes during the interview, I used a personally owned Livescribe pen to create voice annotated .pdf files and backup mp4 files. I used the .pdf files during my data analysis and to plan upcoming research steps.

I facilitated each interview guided by an interview protocol (see Appendix E), which was adjusted to the individual participants. Before I started the conversation, I asked each of the participants for permission to record the interview; all teacher 
candidates gave their consent. I then shared that the interview process is like a conversation, in this case, about mathematics, students and teaching. The interviews began with general statements using a conversational tone. I reminded the participants that there were no "right" or "wrong" answers, and that I was interested in their thoughts, even if only partially or tentatively formed. On some occasions during the interviews, I had to remind the participants that there was no right or wrong answer because they asked me if their answers were right. I also ensured that the interviewees knew that they did not have to answer a question if they did not feel comfortable. At the same time, I encouraged them to share what they were thinking, even if not fully formed.

The first individual interview consisted of four phases. The first phase probed the teacher candidates' images of mathematics. These big picture questions helped me to recall what I had already learned about the teacher candidates' images of mathematics from the math autobiography and the questionnaire. These big picture questions also helped the participants to become familiar with the interview process. Two of the five questions used in this phase of the interview were adopted from Raymond (1993).

In the second interview phase, prompts were focused on the teacher candidates' perceptions of culturally diverse students. The first five questions in this second phase of the second interview were directly targeted toward how the candidates perceive students in general regarding their learning of mathematics. In the third phase of this interview, I showed the candidates a photo of a third grade classroom (see Appendix F). The photo shows children who appear to be from a variety of racial, ethnic, and/or religious backgrounds, based on skin color and clothing. The classroom appears to be teacher- 
oriented because all children are facing the teacher, who is standing in front of her class. I intentionally chose this picture, which is a screen shot of an internet movie clip, to make participants familiar with the class because sections of the video were to be watched during the focus group. Another reason why I used this picture was that I assumed that the combination of an apparently traditional classroom setting and children from culturally diverse backgrounds would provide some ground for discussion. Looking at a color printout of the picture, I inquired about how the candidates perceive the children in the sort of classroom represented by this photo. I asked the question, "What do you notice when you look at this classroom?" in order to get an impression about what seemed most important to participants. To focus the attention on the students in the room, I asked questions such as, "What do you notice about the students?" Both to get a better understanding of how the teacher candidates saw the students and to prepare for the focus group discussion, I asked questions such as, "How would you prepare to teach a math lesson in this classroom?"

Then, I focused on the images of culturally diverse learners the teacher candidates had and how they saw students from a culturally diverse background as learners of mathematics. Again, I introduced this phase with more general questions such as, "Do you think all students can learn math?" This question was followed by more specific questions about the culturally diverse learner of mathematics.

In order to fill in my understanding of their mathematics background, I concluded the interviews with an open conversation about the participants' exposure and experience 
with formal learning of mathematics. I also gave the participants a chance to make comments and to add anything they liked to the conversation.

\section{Focus Group}

All five remaining participants took part in a 60-minute focus group. Even though Morgan (1998) stated that the ideal number of participants is between six and eight, I decided to conduct the focus group discussion even with fewer participants. Morgan explained that doing so might bear the risk of the focus group participants not engaging enough to produce valuable data. Because all my focus group participants were in the second term of their graduate teacher licensure program, I assumed that the participants were used to discussing educational issues. Therefore, I did not see a risk to have a relatively small focus group with only five teacher candidates. Following the same justification, the duration of the focus group was on the lower end of Morgan's recommendation. I first tried to schedule a 90-minute focus group session by using the Doodle online scheduling service. However, due to the time constraints of the participants, a 60-minute focus group was the only feasible option.

The focus group was scheduled at the participants' best possible convenience in a conference room on campus. Because the meeting was scheduled during lunch time, I provided food and refreshments for the participants. The session was videotaped with two university-owned flip cameras and audio-recorded using the Notability application on my iPad tablet and my Livescribe pen as a backup. I also added to my fieldnotes after the focus group. The audio recording of the focus group was transcribed verbatim by a professional transcriber. Even though I asked the participants to mention their 
pseudonyms before they spoke, the video recording was often useful in identifing a speaker. In addition, I used the videotapes to analyze nonverbal agreements and disagreements with statements made during the discussion. I placed two cameras in the room to capture at least partial facial expressions of all participants. The focus group was guided by an interview protocol (see Appendix G) and for visual support by a PowerPoint presentation (discussion questions and activity prompts as stated in the interview protocol), which was projected onto a screen in the classroom.

At the beginning of the focus group discussion, I welcomed the participants and briefly explained the procedures. As expected, the participants were familiar with the procedures of a group discussion and, therefore, the introduction phase was kept short. As a warm-up activity, I asked the participants to write on a poster how they feel about mathematics. For easier identification of the participant's statements, each participant used a different colored marker. The responses were briefly discussed in the group. This activity gave participants the opportunity to get used to each other and become familiar with saying their name before any response. In addition, I was able to get a first impression of the group dynamics and communication patterns. The activity that followed focused on the students' overall ideas of the purpose of teaching. In this "index card activity," every participant had three color-coded index cards on the desk; each of the same color cards had the same statement. There were three different statements: "A teacher's main job is to transmit values of mainstream cultures"; "A teacher's main job is to encourage students to think and question"; and "A teacher's main job is to teach subject matter," all drawn from McDiarmid and Price (1990). I chose these three 
statements because McDiarmid and Price identified these statements as fundamental to teachers' beliefs about the purposes of teaching. For later identification the index cards included the participants' pseudonyms. The participants were asked to rank the statements according to their agreement with them. The index card activity led the group into discussing the topics of diversity and teaching, a discussion I facilitated, deviating from my original protocol. Following their own dynamics, the group touched on some planned topics such as culture and cultural diversity. However, due to the limited available time, after I had a general idea of the participants' stances, I decided to move the discussion on to culturally relevant teaching. Based on the syllabi for the elementary mathematics methods course, culturally relevant teaching was the term the methods instructors used in their teaching two weeks before the focus group. I decided to use the same term for consistency, rather than culturally responsive pedagogy. Recall that I agreed with Gay (2010) that the terms culturally responsive and culturally relevant have been used interchangeably in the literature. Hence, having made the decision to use terms during the focus group which were inconsistent with my own theoretical framework, I decided to follow up on the teacher candidates' perception of culturally responsive teaching during the second interview.

The discussion on culturally relevant teaching led into a guided group analysis of sequences of the video clip "Elementary Math Classroom Observation" (Woodward, 2010). The video showed a third-grade teacher teaching how to add decimals. The teacher connected this lesson to the context of how to count money. It appeared that this strategy was an attempt to make the content of the lesson relevant to students. In the 
lesson, the students worked in pairs and used play money in a hands-on activity. Despite the different strategies used, the overall teaching approach in the video appeared to be very teacher-centered and not differentiated. The hands-on activities were sequenced and the students had to strictly follow the teacher's instructions. I chose this video clip because on the one hand, the lesson had elements of teacher-centered procedural instruction. On the other hand, the video left enough room for and could have led into a discussion on differentiation and culturally responsive teaching. More specifically, I provided written focus questions (see Appendix H) to guide the participants' attention while they were watching the video. To start the discussion after viewing the clip, I allowed for a few minutes of individual reflection time and invited the participants to do a "quick-write" to reflect on their observations. These written reflections might have given a first indication of the candidates' perceptions of the teaching they had just seen. However, none of the participants took time to reflect by doing the "quick-write," nor did I insist they do so, and their conversation about the lesson started right away. Following the video discussion, which was guided by the focus questions, I concluded the focus group and decided to move my remaining questions into the second set of individual interviews.

\section{Individual Interview II}

After an initial analysis of the focus group data, I invited each of the five remaining participants to a 60-minute, semi-structured interview to follow up on their perceptions of teaching mathematics in culturally diverse classrooms and how they saw the child in the classroom. Because one of the participants never responded to my 
voicemail and phone invitations, I decided to conclude the data gathering process with four participants.

The second interview gave me the possibility to ask some questions about any aspect of their responses that needed clarification or warranted a follow-up conversation (e.g., the conversation about culturally responsive and culturally relevant teaching which was started in the focus group). In addition, knowing that there would be another opportunity to have a conversation made it possible for me to postpone questions that I had intended to ask during the focus group (e.g., "What is cultural diversity?") Because the content of this interview highly depended on the previously gathered data, I developed the interview protocol (see Appendix I) after an initial analysis of the focus group data. The interview protocols I used with each individual candidate were very similar and contained almost identical questions. I first wanted to get a basic impression of the participants' perception of mathematics and students before I was able to develop the interview protocol for the series of second interviews. Only after the focus group did I have a basic understanding of how the participants thought about teaching mathematics and how they saw the learner in the classroom. Planning interviews based on information I already had made it possible for me to respond to influences which the elementary methods course and the field experience practicum might have had on the teachers candidates' perceptions.

All interviews started with a casual conversation about the teacher candidates' experiences in their field placements. While providing a transition for the participants into the interview, these conversations also gave me an impression of the participants' 
states of mind and how they felt in the program and their field placements. In particular, the conversation about the teacher candidates' experiences in schools provided a transition into the planned interview. In the first phase of this interview, I asked the participants to "give a brief description of the classroom you are working in" to again explore what images of culturally diverse students the candidates hold. In addition, to clarify and extend my understanding of these images, the data gathered in this phase allowed me to see whether or not there was a change in the students' perception.

Next, I guided the conversation from a more general focus on diversity to a more narrow focus on culture and cultural diversity. A key element in these interviews were the questions asking the teacher candidates to explain what they view as culturally responsive teaching and, later, what they viewed as culturally relevant teaching. During the focus group, and when I screened the data that I had collected so far, I was under the impression that the participants did not have a very clear vision of these concepts. One of the elementary math methods instructors confirmed that she also had the same impression that the participants had no clear vision of these concepts. In addition, the conversation about culturally responsive and culturally relevant teaching connected to the focus group discussion where four of the five participating candidates agreed that culturally responsive teaching is not sustainable on a regular basis. Therefore, I asked more detailed questions regarding culturally responsive teaching.

Toward the end of each interview, I asked each participant what, if anything, they had learned from participating in this research project and whether or not their perceptions of culturally diverse students and teaching mathematics had changed. 
Because Ball (1990a) and Ukpokodu (2011) noted that teacher candidates usually do not change their beliefs within the term of a methods course, I inquired about the impact of participating in my research. Although these matters were not the focus of this research, I was under the impression that the candidates' stances might have changed during the course of the research. I also wanted to know what would have shaped such potential change.

To close the interview, I asked the participants to summarize their family and educational background. I used the information to fill in gaps about my participants' identities and backgrounds. The information which I received was helpful in creating profiles of the participants (see chapter 4). At the very end of the interviews, I gave each participant the opportunity to add any other information they thought would be important for me to know. I also offered the participants a copy of the transcripts and the recordings that were made from their interviews. However, none of the participants has requested either.

\section{Fieldnotes}

I wrote fieldnotes on numerous occasions, mostly during and after both interviews and the focus group as well as after the informal conversation with the elementary math methods instructor. For instance, during the interviews made notes about participants' body language as well as significant changes in their voices. Then, after each interview, I reflected on the process and my first impression of the data and the areas where my interview technique needed improvement. In addition, I took fieldnotes about the conversation with the instructor to capture the content of the conversation. I also reflected 
on any personal struggles and biases that may have influenced the research process. These fieldnotes were kept in a research journal in both a traditional paper-and-pencil format as well as in the form of electronic documents on my computer and iPad tablet in secure, password-protected locations.

\section{Data Collection Timeline}

Table 2 summarizes the data collection methods as they relate to the research questions and to the timeline of the research project.

\section{Data Analysis}

Data analysis started as soon as the first data had been collected. The data analysis process in this qualitative study was intended to be "iterative" and "simultaneous" (Creswell, 2012, p. 237). In part, doing so meant that I analyzed data while also collecting new data, going back and forth between the two processes. This strategy allowed for timely data analysis and opened the door to using data analysis to frame the next step of data collection. For example, I used data from the first interview to construct a protocol for the focus group. I also employed a variety of coding strategies to interpret the data.

The data analysis process was divided into two phases. The first phase was an individual case analysis, which consisted of the analysis of each instrument for each participant, and a more focused case-by-case analysis across all instruments. The second

phase was a cross-case analysis. I used an "inductive" (Creswell, 2012, p. 238) data analysis process, codes are created by the researcher through direct interaction with the data. In the first phase of the individual data analysis, I deployed "holistic" and 
Table 2

Research Overview and Timeline

How do teacher candidates perceive teaching mathematics in a multicultural environment?

\begin{tabular}{|c|c|c|c|c|c|}
\hline $\begin{array}{l}\text { Method } \\
\text { (Number of } \\
\text { participants) }\end{array}$ & $\begin{array}{l}\text { Research Sub- } \\
\text { question \#1: } \\
\text { What images of } \\
\text { mathematics } \\
\text { do elementary } \\
\text { teacher } \\
\text { candidates } \\
\text { hold? }\end{array}$ & $\begin{array}{l}\text { Research Sub- } \\
\text { question \#2: } \\
\text { What images of } \\
\text { culturally diverse } \\
\text { learners in the } \\
\text { mathematics } \\
\text { classroom do } \\
\text { elementary } \\
\text { teacher } \\
\text { candidates hold? }\end{array}$ & $\begin{array}{l}\text { Research } \\
\text { Question: } \\
\text { How do } \\
\text { teacher } \\
\text { candidates } \\
\text { perceive } \\
\text { teaching } \\
\text { mathematics } \\
\text { in a multi- } \\
\text { cultural } \\
\text { environment? }\end{array}$ & $\begin{array}{l}\text { Additional } \\
\text { data }\end{array}$ & Time \\
\hline $\begin{array}{l}\text { Sampling } \\
\text { survey (6) }\end{array}$ & $\mathbf{X}$ & & & $\begin{array}{l}\text { Opportunistic } \\
\text { sampling }\end{array}$ & $\begin{array}{l}\text { Early } \\
\text { OCT. }\end{array}$ \\
\hline $\begin{array}{l}\text { Math Auto- } \\
\text { biography } \\
\text { (6) }\end{array}$ & $\mathbf{X X}$ & & $\mathrm{X}$ & $\begin{array}{l}\text { History and } \\
\text { source of } \\
\text { perception of } \\
\text { math } \\
\text { Demographics }\end{array}$ & Early OCT \\
\hline $\begin{array}{l}\text { Interviews I } \\
\text { (6) }\end{array}$ & $x$ & $\mathbf{X X}$ & $x$ & & Early OCT \\
\hline $\begin{array}{l}\text { Conversation } \\
\text { with instructor }\end{array}$ & & & & Use of terms & Early OCT \\
\hline $\begin{array}{l}\text { Focus } \\
\text { Groups } \\
(5)\end{array}$ & $\mathrm{X}$ & $\mathrm{X}$ & $\mathbf{X X}$ & & $\begin{array}{l}\text { OCT, 22, } \\
2013\end{array}$ \\
\hline $\begin{array}{l}\text { Interview } 2 \\
\text { (4) }\end{array}$ & $X X$ & $X X$ & $\mathrm{XX}$ & $\begin{array}{l}\text { Impact of } \\
\text { methods } \\
\text { course }\end{array}$ & $\begin{array}{l}\text { Mid-NOV/ } \\
\text { Early DEC }\end{array}$ \\
\hline $\begin{array}{l}\text { Course } \\
\text { syllabi and } \\
\text { lesson } \\
\text { planning } \\
\text { guides }\end{array}$ & & & & $\begin{array}{l}\text { Use of terms / } \\
\text { Course } \\
\text { schedule / } \\
\text { Goals / } \\
\text { influence of } \\
\text { methods } \\
\text { courses on TC } \\
\text { perception }\end{array}$ & \\
\hline Fieldnotes & $x$ & $\mathrm{X}$ & $X$ & & \\
\hline
\end{tabular}

XX: indicates main focus of the instrument; $\mathbf{X}$ : indicates minor focus 
analysis processes in which I created codes, categories, and themes from the "bottom up." As Johnson and Christensen (2008) explained, in such an inductive data "structural" coding to get an overview of the data and to start developing categories. For a more indepth look, I used "in vivo" coding and "descriptive" coding to create subcategories and develop themes. In a second coding cycle, I added "focused" coding to establish codes throughout all instruments of each individual case. A more detailed description of the coding process follows. In the second phase of analysis, the cross-case analysis, I compared and contrasted the established themes across all participants.

The unit of analysis for this process was the individual case of one teacher candidate. In consequence, I first conducted individual case analyses to describe each individual case. A final cross-case analysis to compare and contrast the individual cases concluded the data analysis. Below, I first describe how I analyzed each data source for each individual case. Then I explain how I triangulated the data from these multiple sources in order to triangulate the analysis. Finally, I elucidate my approach to the crosscase analysis.

\section{Individual Case Analysis}

The analysis of each data source for each participant allowed me to reduce the data into manageable initial codes reflecting the participants' perceptions in the context of the research questions. Such analyses, as they were worked out through multiple readings, also led to the development of subsequent instruments, such as the first interview, the focus group, and the second interview, in succession. Then, I looked across 
the initial codes and revisited the original data sources to develop the individual case profile for each teacher candidate.

\section{Sampling Questionnaire}

The sampling questionnaire provided data on each candidate's background, as well as initial data on the images of the nature of mathematics the candidates held and how they perceived learning and doing mathematics. First, I created individual demographic profiles of the participants, having previously color-coded the questionnaire to highlight the teacher candidates' personal and demographic characteristics. In a second step, in order to look for patterns regarding each participant's perception of mathematics, I optically scanned the 5-point scale to get a first impression of their perceptions and how strong these perceptions were. I also compared and contrasted each individual's responses. In this process, I used "holistic coding” defined by Saldaña (2009) as "an attempt to grasp basic themes or issues in the data by absorbing them as whole ... rather than by analyzing them line by line" (p. 118), to develop an initial basic understanding of each participant's perceptions toward mathematics.

I further identified patterns of similarities and contradictions to get a preliminary impression of each participant's image of mathematics. I color coded and grouped responses that indicated a more traditional image of mathematics or a more humanistic image of mathematics. Contradictions in the responses particularly called for further inquiry in the research process. An example of a contradiction would be a positive response to the statements "Mathematics is a fixed set of rules and procedures which need to be followed" (sampling questionnaire, Q 16) and a negative response to the 
statement "Doing a mathematics problem is like crossing a river on stepping stones. There is only one way to go" (sampling questionnaire, Q 3). Without additional data about the candidate's image of mathematics, such answers appeared to be somewhat contradictory. While the questionnaire initially was intended as sampling tool, I considered the data from this instrument throughout the entire research process. Especially when I developed the individual cases, the questionnaire data was useful to strengthen my picture of the candidates' image of mathematics.

\section{Mathematics Autobiography}

The math autobiography was analyzed primarily with regard to the first research sub-question: "What images of mathematics do elementary teacher candidates hold?" Case-by-case, I read multiple times though each document, first following the "holistic coding" process as described in Saldaña (2009) to get a basic understanding of the themes and issues emerging from the text. Saldaña explained holistic coding as categories developing from the text. As he suggested, I read each text multiple times until I was able to identify elements that I developed into categories related to the candidates' images of mathematics, their experiences with mathematics as a student, and changes in their perceptions of mathematics. Portions in the math autobiography indicated the participants' perceptions of teaching mathematics.

In a next step, I applied a combination of in vivo coding and descriptive coding to "prioritize and honor the participants" voice" (Saldaña, 2009, p. 74). In vivo coding is coding a "word or a short phrase from the actual language found in the qualitative data record" (Saldaña, 2009, p. 74) and "descriptive coding summarizes in a word or short 
phrase... the basic topic of a passage of qualitative data" (p. 70). As Saldaña described, this hybrid coding strategy (descriptive coding and in vivo coding) allowed me to deepen my understanding of the participants' views and use their language, "rather than terms derived from the academic disciplines." As recommended by Saldaña, I first used a paper-pencil approach to get an understanding of the coding process. Later in the research project, I used NVivo software to support my data analysis. The software was useful to generate codes, visually organize my data, and to locate the exact sources of data.

During these multiple readings, I also analyzed for attributes and characteristics of the participants (attribute coding), as well as their perceptions of teaching mathematics, both areas to which the math autobiographies spoke. As Seidman (2006) said, these multiple readings of each text further helped to prepare the next interview, including the development of the interview protocol.

\section{Individual Interview I}

The first interview focused mainly on the question of how the teacher candidates saw culturally diverse students. All interviews were entirely transcribed verbatim by a professional transcriber. I instructed the transcriber to indicate when two people talk at the same time or if any "cutting off" occurred. I also asked for indications of laughter and longer pauses in the conversation. Seidman (2006) noted that researchers who transcribe data themselves can build a better knowledge of the data. However, to save time and receive more accurate transcripts, I decided to instead establish rapport by doing multiple readings of the transcripts while listening to recordings. It was important to establish rapport with the participants as soon as possible because this research followed a 
constructivist design, which called for building the next research steps upon the already collected data.

To analyze the interview transcripts case-by-case, I first applied "structural coding" to identify sections related to my research questions. The structural coding helped me find, label, and sort data in preparation for later analysis. I used the NVivo software to highlight sections of the interview which provided data on the participants' image of mathematics, teaching mathematics, perceptions of students, culture and diversity, and the candidates' personal attributes. Following the same procedures as in the coding of the math-autobiography, I then applied a combination of descriptive coding and in vivo coding to capture the participants' voices. I mostly used descriptive coding to shorten long in vivo codes. This coding strategy helped me to deepen my understanding of the participants' perspective on mathematics, students and diversity, and teaching. Within these areas, I created families of codes belonging to the same topic. To focus on each participant during the interview, and to prepare for the data report, I followed Seideman's (2006) advice and developed individual profiles for each participant.

\section{Focus Group}

Focused on teaching mathematics to diverse learners, the data analysis of the focus group was geared toward the overarching research question "How do teacher candidates perceive teaching mathematics in a multicultural environment?" The analysis of the focus group data also helped to explore the question, "What is the relationship, if any, between the images of mathematics, culturally diverse learners, and the teacher candidates' perception of teaching mathematics to such learners?" 
I audio taped and videotaped the focus group. The audiotape was transcribed verbatim by a professional transcriber as described earlier and I coded the transcripts. The tape-based analysis was supported by video recording as well as fieldnotes. Because in the transcripts prepared by the professional transcriber, it was not always clear which participant was speaking, I listened to the audio recordings multiple times to identify and label all contributors. Moreover, instead of the NVivo software, I started using ATLAS.ti to aid in analyzing the data. I decided to make this switch due to its superior functionality in comparing and contrasting data between different data sources. However, I continued to access data in NVivo occasionally to compare notes and develop codes. Switching software had no drawbacks. On the contrary, repeating parts of the data analysis process seemed to strengthen the data analysis due to a practice effect.

Following Krueger's (1998) advice, I began a tentative data analysis during the focus group. I carefully listened to comments and inconsistencies to foreshadow themes for analysis. I started a preliminary data analysis soon after the focus group session, to be able to relate the audio- and video-tape and notes to my memory. Doing so gave me the opportunity to recall the dynamics in the room related to a topic as well. While watching the video recording of the focus group, I read the focus group protocol. Whenever I saw a participant agreeing or disagreeing with a statement, I made a note. For example, when Emily explained that teachers should only respond to the students' culture when it occurs naturally, I noted that Frank nodded in agreement, whereas the other participants did not show any response indicating agreement or disagreement. 
For consistency in the data analyzing process, I used the same strategies as described in the Interview I analysis section above. I used holistic coding to categorize the data into the main themes: general teaching, teaching culturally diverse learners, teaching culturally diverse mathematics, and additional categories which I had developed at the time of data analysis (e.g., diversity and culture, differentiation). Because of the central position of the focus group in this research, I "interrelate[d] the themes" (Creswell, 2012, p. 251) within the focus group data as well as with already established themes from other data sources (i.e., sampling questionnaire, math autobiographies, and the first interview). For example, from previously analyzed data I thought that some participants' images of culturally diverse students might make it more difficult for them to take culturally responsive teaching into consideration. Because the focus group manifested this hunch, I established a focus on the relationship of this particular image of students and their perceptions of teaching in the second interview as well. In these ways, I continued developing each case individually and tried to reconfirm or disconfirm the teacher candidates' images of culturally diverse learners and their images of mathematics, as well as the relationship of the two with their perceptions of teaching.

\section{Individual Interview II}

As intended, in the second interviews I followed up on previously developed themes. Continuing to use the ATLAS.ti software to analyze the focus group data, I employed the same coding strategies described above: initial holistic coding, along with a combination of in vivo and descriptive coding. Following the same procedures assured consistency in the data analysis. I built my analysis on already-existing codes, and 
developed codes that were geared more toward culturally responsive mathematics teaching. For example, I used in vivo and descriptive coding to identify elements that I interpreted as culturally responsive teaching strategies. I assigned these codes to a code family labeled "CRT." Within this code family I considered codes relating to curriculum, instruction, and seeing the child. Then I compared and contrasted the codes within each category to finally develop themes based on significance. I recognized significance through relating the themes to my research questions and other already established themes. I also started coding across all data sources to identify the same themes that I had developed across the data sources of each case. I did not add any new themes at this point.

\section{Fieldnotes}

I consider the fieldnotes that I made throughout the research process to be a secondary data collection instrument because I used them as an addition to the interview and focus group transcripts. I consulted my fieldnotes during the data analysis process whenever I needed additional information that was not in the transcripts, such as participants' body language during the interviews. For example, when I asked Frank to give me an example of when elementary students might use mathematics outside school, he leaned back and crossed his arms in front of his chest. Later, I related this description of body language to his verbal response to this question. Another example of how the fieldnotes contributed to the transcript was that I noted where the participants pointed when we discussed the classroom picture. 


\section{Developing the Case-by-Case Analysis for Each Participant}

I used the analyses described above to create a case-by-case analysis for each participant, which resulted in a profile of each of the four teacher candidates who participated in all aspects of the data collection. First I used focused coding (Saldaña, 2009, p. 155) to establish themes across all instruments for each individual teacher candidate. Saldaña described focused coding as establishing the most frequent or significant codes. I therefore based the focused coding on the already-existing in vivo and descriptive coding and established them throughout all instruments. An example for frequency was Frank using the term "figuring out." More important in this research was significance, when I interpreted statements toward their significance regarding the research questions and established themes. For example, I evaluated statements for whether they indicated a procedural image of mathematics or a conceptual image of mathematics.

Then, I compared and contrasted the codes again, using the data to identify similarities and contradictions within and between the established themes that had resulted from the focused coding. I used ATLAS.ti software to create document families for each participant for better accessibility of the documents. These document families contained all documents that I had previously coded. Based on the codes in the documents, I created new code families across all documents of each participant. In each code family I combined codes which were all in a particular category. For example, I established code families such as teaching, culture, diversity, students, mathematics, teaching mathematics, CRT, and attributes. 
I used the visualize function of the data analysis software to group the in vivo and descriptive codes within the code families. For example, within the family of teaching mathematics, I grouped the codes according to curriculum and instruction. I used the data analysis software to support this grouping process; the software provided the opportunity to read the section of the document in which the code was created. Doing so was helpful for putting the code into context and to establish subcategories.

Next, I compared and contrasted the codes within the subcategories. I also compared and contrasted the codes across groups. In this step of the data analysis, the data analysis software provided visual support and gave me the option of revisiting documents that were already coded. Through this iterative process, I synthesized themes. I mostly recorded themes and patterns in my research journal. To establish themes and subthemes, I first read through all collected data from each participant multiple times to reacquaint myself with the data as a whole. The main data analysis mostly showed consistency of each participant's images and perceptions across the data collection process. In the case of inconsistencies, I applied an additional level of analysis. If the consistencies remained, I pointed it out in my findings if they were significant. For example, Frank stated that he considered it important to teach mathematical concepts, but the majority of statements he made about teaching indicated procedural teaching.

Moreover, the questionnaires and the math-autobiographies were instrumental in making connections between themes that emerged in different instruments. For example, in the first interview, Emily stated that she considered it important that students understand the concepts of mathematics. However, other data indicated that she had an 
affinity for teaching procedures and algorithms. Taking data from the math-

autobiography and the questionnaire into account showed that what Emily considers to be understanding of mathematical concepts is strongly related to procedural knowledge.

This theme and other themes that emerged from the case-by-case analysis are described in chapter 4 .

\section{Cross-Case Analysis}

I also completed a cross-case analysis that compared and contrasted the single cases. In this cross-case analysis, I looked across the cases to develop themes in categories related to my research questions (e.g., images of mathematics, teaching mathematics). I also looked for other similarities and differences that were not directly related to the research questions (e.g., about when they felt successful learning mathematics). To support the process of comparing and contrasting the cases and to see in which context I had established codes, I returned to my notes in the research journal and the research software. For instance, it was important to reread how the other participants reacted during the focus group when Emily stated that teachers should not plan to respond to culture, but take the opportunity when it occurs naturally. In addition, I sought out any relationships between the teacher candidates' various images and perceptions. For example, I explored whether or not a similar image of mathematics related to a similar way of seeing culturally diverse learners. Thus, this last analysis responds to the third research sub-question: "What is the relationship, if any, between and among the images of mathematics, culturally diverse learners, and the teacher candidates' 
perceptions about teaching mathematics to such learners? I finally developed conclusions that were based on the entire data analysis.

\section{Research Integrity}

In this section I describe the limitations of my research regarding design, analysis and implementation. I also describe my role as a researcher and the influence I might have had on the research.

\section{Limitations}

The study used qualitative research methods to gain insights into teacher candidates' perceptions and images about mathematics, culturally diverse students and teaching mathematics in a multicultural environment. With this multiple Instrumental Case Study involving four cases, I attempted to answer the overarching question, "How do teacher candidates perceive teaching mathematics in a multicultural environment?" Focusing my research question only on the teacher candidates' perceptions may lead to the kind of understanding that is needed to improve teacher education. At the same time, this case study provided no information about how the participants might actually teach mathematics and see culturally diverse learners in a real classroom. Such a research project could follow this study.

The decision to conduct this dissertation research at the university where I work offered the advantage of supportive and knowledgeable fellow faculty members in addition to the dissertation committee on site, all of whom helped me to accomplish this complex research project. Moreover, I was able to use university resources and facilities, which made scheduling and finding rooms for interviews as well as for the focus group 
easier. However, it was also more complicated to keep the identity of the participants confidential. For example, I had to avoid leaving or entering the interview with the participants.

As expected, teacher candidates showed interest in my research because of its potential relevance to their learning and the program in general. For example, Christy stated that she participated in this research because she started the data collection process for her master's thesis at the same time. She mentioned that she liked the idea of helping somebody else with their data collection. Alison saw the research as an opportunity to reflect on the question of race in teaching mathematics, a topic of personal interest for her. The planned research activities were integrated into the teacher candidates' regular schedule as much as possible to reduce the amount of extra time and commitment needed to participate. In consequence, I did not expect the difficulties, described above, in recruiting or retaining participants for this project. I started with six participants and ended with four. I might have lost some valuable perspective.

There might have been minor limitations due to the coding process. The structural coding might have limited my focus to particular sections of the document. I might have use mismatching descriptors during the descriptive coding process. The switch of the software during the data coding software made it necessary to recode my data. However, I believe this move added another layer of coding which enhanced the process. 


\section{Ethical Considerations and Role of Researcher}

The study was designed to gain insights about the teacher candidates' perceptions of teaching mathematics to culturally diverse students in an elementary setting from the perspective of the teacher candidates, using a critical constructivist research paradigm. The fact that I conducted research with candidates who are in enrolled in the program with which I am affiliated might raise some concerns. However, my work does not encompass working directly with students who are currently in the program. Moreover, during the time the research was conducted and, thereafter, I did not teach any of the elementary cohort courses the participants needed to take toward their teaching license. I consequently did not see a conflict of interest. I also did not and will not disclose to any other person any information about the participating teacher candidates and related data. To prevent identification of the participants, I also replaced all names on data sets with pseudonyms. These pseudonyms were used in the research report and in any conversation I had with my dissertation committee. I used general descriptors to mask a participant's identity or provided general descriptions in order to protect their confidentiality. In addition, I have kept all data confidential and password protected or in a locked location on my personal home office.

The participating teacher candidates were kept informed about the research study throughout the entire project. I have been consistently available to the participants to address any concerns or questions regarding the project. My dissertation chair has been also available to address concerns; participants also could have contacted the university's Human Subjects Committee. The participants were informed that their participation was 
voluntary and that they could withdraw from the project at any time or decline to participate in specific aspects without withdrawing from the project overall. It was important that the participating teacher candidates understood that this research project had no influence on their relationship with the university, the program, or their grades.

It is important to note, however, that two participants passively withdrew from the research study. One did so by withdrawing from the program; the second did so by not responding to my invitation to the final interview. I did not include any analysis of their perceptions in this dissertation.

Research participation as a teaching-learning occasion. As stated before, in a critical constructivist research design, the researcher cannot be neutral because of the social justice agenda based in the critical theory element of the critical constructivist research paradigm. In addition, the teacher candidates knew that the teacher licensure program of the School of Education's vision is to prepare teacher candidates to become professionals who cannot only teach to the needs of all students, but also become instructional leaders and change agents. Therefore, an intended byproduct of this research was a teaching occasion. At the same time, accordingly to Kincheloe (1997), critical constructivist research respects the realities of others without questioning and, therefore, I did not actively try to change the teacher candidates' perceptions. I monitored these teaching-learning occasions closely and took this dynamic into consideration during my entire research and data analysis.

Indeed, the participants explained when asked that participating in this research project supported their learning process through self-reflection. Participants also noted 
that they began to think more critically about teaching mathematics. In addition, most of the participants expressed that their participation made them more aware of the needs of culturally diverse students.

\section{Research Journal}

During the entire project, I kept a research journal in both paper-pencil and electronic forms. I used this research journal as a location to keep fieldnotes, as mentioned in the section on data collection. During the data analysis process, I mainly used my research journal to develop ideas and to interpret data. I drew graphics showing relationships to compare and contrast themes or statements made by participants. This strategy was especially instrumental to determine where Frank was "located" on the spectrum of procedural and conceptual teaching. I also used the journal to make notes whenever I realized that a theme I had developed related to literature I knew.

Notably, I used this research journal as a site to keep track of my own experiences, questions, and personal struggles as well as, importantly, a place to reflect on my own biases and their potential impact on the research process and results. For one example, during the interview with Frank whenever we touched on diversity and culture, I caught myself assuming that he might bring up the stereotyping issue. Whenever I had this thought, I made a little note to remind myself not to jump to this conclusion. For another example of keeping my broader assumptions in check during the process of analysis, I turn to the story of periodically identifying with participants and their perspectives. For example, because of Frank's age and gender as well as the answerer he gave, I first thought I had a lot in common with Frank. The interview process felt much 
smoother than with other participants. Through my reflections throughout the research process I realized that I had sometimes projected my own assumptions on Frank and sometimes had the tendency to jump to conclusions. I, therefore asked myself during the entire research project how the participant's perspective was different from my own. I entered these reflections into my research journal. I am the only person who had access to my research journal. The paper version is stored in a locked file cabinet in my office. The electronic file is stored and password-protected on a secure university server. This personal research journal will be an important resource for intended future data analysis toward publication of this research in a professional journal.

In the next chapter I present my findings, developed from the described data collection and analysis process. In the first part of the chapter, I provide single case reports (profiles) for each participant. In the second section I report the findings of the cross-case analysis. 


\section{CHAPTER IV}

\section{RESULTS: TEACHER CANDIDATES' PROFILES AND CROSS-CASE ANALYSIS}

In this chapter, I represent the data that I collected from teacher candidates using sampling surveys, math autobiographies, interviews, and a focus group. Although each individual data gathering method was geared toward a particular research question, all aspects of my research questions appeared across all instruments.

This chapter first develops profiles of each individual participant in order to further explore who the participants are and to examine the participants' perceptions about math, cultural diversity and teaching. When introducing the participants, I rely on information obtained through "attribute coding" (Saldaña, 2009), "which is coding of basic descriptive information such as: field work settings....participants' characteristics or demographics... and other variables of interest" (p. 55). The sampling questionnaire and the math autobiography were strongly focused on the candidates' images of mathematics and were also used to create the interview questions for the first interview. The first interview thus helped me to better understand the questionnaire responses and to clarify confusing responses; so, in addition to a focus on cultural diversity of students, the first interview also focused somewhat on images of mathematics. In the individual profiles below, I explore each teacher candidate's images of mathematics and their perceptions of diversity, culture, and culturally diverse students. I also describe how each participant thought math should be taught to learners from culturally diverse backgrounds, analyzed primarily from the focus group and the second interview. I first 
focus on teaching mathematics in general, which was a topic during the focus group as well as in the second interview. I also rely on data collected mainly during the focus group and the second interview to describe how the candidates perceived teaching with culturally diverse students. The last section of each profile is an analysis of the presented data in response to the question: "What is the relationship, if any, between and among the teacher candidates' images of mathematics, culturally diverse learners, and perceptions about teaching mathematics to such learners?"

In the second section of this chapter, the cross-case analysis, I compare and contrast the images of mathematics across the teacher candidates. I then report the similarities and differences between participants' images of culturally diverse students and how they perceived teaching mathematics in a multicultural environment.

Because of their significance for the report of this research, I restate key definitions I hold as a researcher.

Image: An

informal set of beliefs, views and perceptions of mathematics as a discipline and area of enquiry. It is a system of beliefs or views which may only be partly expressed as well as being partly made up of tacit interference assumptions, and beliefs about the nature of mathematics. (Ernest, 2009, p. 46)

Social Constructivism: My definition follows Kincheloe (2008), who saw social constructivism as a basic perspective on learning and knowledge actively constructed through interaction with the world. These interactions are guided by the influence of society, culture, and history. 
Culture: Culture is a constantly changing system of practices, ideologies, symbols, behaviors, values, and beliefs that defines who we are, what we do, and how we live, interact, teach and learn. Culture defines how we interact with and within a group and within society at large.

Diversity: Diversity is being "different from each other in a variety of ways" (Banks et al., 2005, p. 232). I see diversity as influenced by but not limited by "family, community, geographical location, designations of race and ethnicity, language, strong interest affiliations, religion, gender, and sexual orientation" (Horowitz et al., 2005, p. 114).

\section{Looking at the Cases: Participants' Images of Mathematics, Culturally Diverse Students and Perceptions about Teaching Mathematics}

In this section, I present my data analysis and findings case by case. I also include my own comments to further interpret the data in the form of a "Researcher's Discussion." In this section I provide the sources of the direct quotations, placing the source directly after the quotation. However, when there more than one quote in one sentence I provide the source at the end of the sentence, assuming all the quotations are from the same source, for better readability or if the "flow" of the idea in the sentence would be interrupted by the mention of the source in the middle of the sentence.

\section{Introducing Frank}

Frank was a White male in his early 40 s at the time of his participation in the research study. He grew up in a middle class family. When asked about his family background, Frank explained that both parents were public school educators and that he 
attended public schools except for high school. His parents decided not to send him to the neighborhood public high school due to gang-related violence at the school. Instead, Frank attended a neighborhood Catholic high school. He described the student population at this school as non-diverse and of high socioeconomic status.

After graduating with a Bachelor of Arts degree in Communication from a state college, Frank worked for almost 20 years for private companies. He noted that his business-related travels to Europe and East Asia provided him with the opportunity to come in contact with different cultures. For example, he explained how collaboration with business partners in China helped him to realize some of the challenges facing a language learner in a classroom.

When Frank decided to pursue a career in teaching, he was encouraged by family members and friends to become a mathematics teacher. Frank explained that people who knew him (e.g., his brother and his neighbor) always said that he should become a math teacher because he "gets math" and therefore he would be "good at [teaching] it" (Frank, interview II). To explore the field of teaching mathematics, Frank first started tutoring in an afternoon high school program. He said that this experience showed him that teaching high school was not a good fit for him. He added that he was okay with teaching elementary children and he thought that he could be a good elementary school teacher. Frank seemed to agree with his brother, who is also an elementary teacher, that teaching mathematics is challenging. Frank was confident that "[he]'ll learn how to teach [math]" (Frank, interview II), noting that being able to teach mathematics is one of the main reasons he wanted to become an elementary school teacher. 


\section{Frank's Image of Mathematics}

During the research project Frank offered different images of mathematics which appear to contradict each other. These contractions between what he declared he believed and how he described mathematics built a tension; Frank seemed to see mathematics as a flexible body of knowledge, but at the same time he limited this body of knowledge to established methods and procedures. In Frank's view this mathematical knowledge can be discovered by approaching a problem from different angles with well-established procedures. In this section I provide a picture of these tensions in his beliefs and reason that Frank held a somewhat procedural image of mathematics.

Frank repeatedly indicated that he saw mathematics as a "constructivist" discipline, but he limited his definition of constructivism to seeing mathematics as concerned with solving practical problems and being flexible in the variety of ways he could imagine approaching problems. He explained that mathematics was a constructivist discipline because "we all have different ideas and there are a lot of ways to approach math" (Frank, interview I). However, Frank did not seem to believe that there was more than one right solution to a mathematical problem. He seemed to base his notion of constructivism mainly on approaching and doing mathematics differently, as well as his belief that mathematics is a practical problem solving tool. When Frank explained what "doing math" entailed, he stated:

I think about people doing math as part of a job. So if your job is to build a bridge, you are working on math, so depending on what your job is, you are doing different aspects of math. If you are doing physics, you are trying to figure out $\mathrm{e}=\mathrm{m} \mathrm{c}$ squared or whatever, or if you are trying to find out the slope of a hill to build your bridge, and if the hill comes to a river, you are doing different types of 
math. So whatever type of math you are doing or whatever work you are doing is solving a different type of problem. (Frank, interview I)

He also noted on the sampling questionnaire that he strongly agreed that "mathematics is useful in day-to-day life" and that mathematics had "strong application to solving problems of the real world" (Frank, interview I).

In addition, he explained that school mathematics is constructivist in nature because students can decide to solve a problem by using manipulatives or doing it mentally. Frank explained that there are "many ways to solve a problem" (Frank, interview I). He clarified that students can use their basic knowledge of facts and understanding of concepts to "figure out" (e.g., Interview I) a way that works for them to find the solution to a problem.

The first word that came to Frank's mind when he heard the term mathematics was "puzzles" (Frank, interview I). He explained that mathematics is solving problems and is, therefore, part of everything we do. People have to "figure out how things work" (Frank, interview I). On the one hand, Frank described mathematics as being related to all aspects of human life. On the other hand, Frank saw mathematics as something that is mostly task-oriented and supports other fields such as science, engineering, and accounting. He stated:

Mathematics is not just math, but it is the whole scope of life. It fits into so many different areas. You can't just say it is about numbers because it is about figuring out how to build a bridge or how physics works. (Frank, interview I)

Frank stated in his math autobiography: “I can't say I 'see math everywhere' in the way that conjures up Hollywood scripts but I think I do look for mathematical patterns in everyday situations that others would think have nothing to do with math" (Frank, math 
autobiography). However, the notion that "mathematics is everywhere" (e.g., Frank, interview I) which he expressed during the interviews appeared to be limited to solving professional work-related tasks. Across all interviews, Frank brought up the bridgebuilding example whenever he was pointing out the importance of mathematics in daily life.

Consistent with his view of math as solving puzzles, Frank seemed to see nonwork-related mathematics as artificially creating situations to "figure things out just for fun” (Frank interview I). One example he gave was figuring out how many more miles could be driven with the amount of gas remaining in the tank. Frank also seemed to apply the idea of "figuring out just for fun" to the mathematics children do outside of school. He explained that younger children do not really use mathematics very often because they do not do real problem solving. According to Frank, young children do not figure things out using mathematics. Instead, he elaborated that children use mathematics according to their abilities to understand mathematics. However, he had difficulty coming up with the examples of counting and using the calendar as illustrations of children's mathematics outside of school. He added that it was hard for him to think about a nonschool-related situation in which elementary students do math. However, Frank finally explained that children use mathematics outside school on "the playground, whether it is doing a hopscotch game...different games, whether they are counting in lower grades, maybe, waiting for the swings. They have to count to 10 until it is their turn to be on the swings" (Frank, Interview I). 
On the one hand, Frank saw math as highly flexible and applicable to real-life situations; on the other hand, he also saw math as structured and based on facts and procedures. He explained that mathematics is orderly and structured, with rules that have to be followed and facts that need to be learned, which makes math a "universal language" (e.g., Frank, interview I, interview II). On the questionnaire, but also during the interviews, Frank indicated that "mathematics is a fixed set of rules and procedures which need to be followed" (e.g., Frank, questionnaire) and that mathematics has to be learned in a certain order. Frank believed these rules and procedures are basically the same in any culture. This belief was revealed in his statements that "Numbers are numbers therefore [they] are the same in every culture" (Frank, interview II) and "mathematics is a universal language" (Frank, interview II; questionnaire).

For example, Frank's notions about mathematics as orderly and procedural came forward during our conversation about differentiation, when he stated

In elementary school, if you are not set up to do rotations where you are separating students by skill level and you keep your own 5th grade class for all of math, you are going to have serious differentiations in where students are at. You can't leave $2 / 3$ of the class behind so you can start teaching algebra to the kids who are done with division. It doesn't serve anybody, but you can't leave those kids who are done with everything and totally get it, just sitting there and twiddling their thumbs waiting for you to do another day of long division because there are kids who just need another day of instruction. (Frank, interview I)

Notice in this quotation that Frank believes students need to learn-and perhaps even master-long division before they can learn algebra. He conveys a sense of established order in mathematics.

However, Frank believed that "good math teaching is starting with problems that help students build an understanding before you teach them the rules" (Frank, interview 
I). Otherwise, students would not try to "figure out another way" (Frank, interview I) to solve problems if their initial way does not work. At the same time, he admitted that students do not necessarily need to understand concepts before they can use them, and that procedural mathematical knowledge has its merits in standardized tests. He also explained that he failed math in college because he was missing conceptual understanding. Therefore, he believed that procedural knowledge could be useful in "doing math" when solving problems, but it does not cater to the understanding of mathematical concepts. Because Frank stated that elementary mathematics was based less on concepts than middle school mathematics, coupled with his notion that students need to understand concepts before rules, it was unclear what he really meant when he asked, "how can you manage to make sure every student understands the math, not just having memorized the facts and algorithms?" (Frank, math autobiography). Thus, Frank's perception of math leaned toward a valuing of order, structure, and procedures.

Frank declared his belief in a constructivist nature of mathematics.

However, his responses during this research project also indicated he held apparently contradictory ideas and tensions in his image of the discipline. Later in this chapter I describe in more detail how Frank saw teaching mathematics. We will notice this same familiar tension between his belief that mathematics should be approached from what he calls a "constructivist" perspective and his somewhat procedural notion of teaching.

\section{Frank's Image of Students}

Frank believed that mathematics is accessible to everybody and that all students can learn mathematics. However, Frank saw learning disabilities, a lack of talent, and 
missing motivation as possible obstacles to learning. Addressing the "interesting" question of whether or not everybody can learn math, he said, "I've never met anyone who didn't get the basics, but I haven't met everybody" (Frank, interview I) and speculated that "there are learning disabilities that might prevent moving onwards" (Frank, interview I). When asked what makes a good student in mathematics, it was clear that Frank strongly connected performance in mathematics to the students' motivation. He said that he considered a good student to be someone who "enjoys the challenge" and who could "figure things out" (Frank, interview I) when they do not grasp a concept or when they do not get the answer right immediately. Frank also explained that he considered poor math students to be students who are not up for the challenge of figuring things out. Frank further explained that students who are not even trying to figure things out, or students who give up before they get the right answer, are the most challenging ones for him as a teacher. He seemed to believe that there is always a way to spur a student's interest and that teachers could find a way to motivate students because there are many ways to look at math. At the time of the first interview, Frank said that he had not yet "gotten that deep into the heads" (Frank, interview II) of his students enough to understand how they saw math problems.

How Frank saw culturally diverse students. Frank seemed to believe that a student's cultural background is defined primarily by religious beliefs, linguistic background, and the socioeconomic status of the family. When Frank talked about culture, he mostly gave examples of the church that people attended and the language they spoke. Throughout our conversations, however, Frank generally avoided and often 
resisted speaking about his students as members of groups (e.g., racial, ethnic, etc.), although he did make reference to the Russian community in his school neighborhood and Japanese students. He repeatedly stated that a teacher should try to avoid stereotyping students. He said teachers have to see the child in the sense of "looking deeper to what forms the child....the home life, the community life" (Frank, interview II). Frank explained that when you make judgments about student diversity in a classroom, "It is not like you can go in and stereotype and say, oh, these ELL students aren't going to be reading at level because it is their second language" (Frank, interview II). He further noted that it was "hard" for him not to fall into stereotyping when he was

learning about the Russian culture and you can't apply this to every Russian child. Not every Russian family fits into this. A lot of time you will find this, so that might give you a clue as to what is going on with the kid, but it doesn't give you the answer. (Frank, Interview II)

Frank seemed to be somewhat aware that students are shaped by their culture and a student might therefore act in a certain way. At the same time Frank saw each student as individuals who act differently. However, he seemed not to know how he as a teacher should take this cultural background into account. The tension between noticing that culture influences the students and his over-caution not to stereotype led Frank to not consider the cultural background of a student at an appropriate level.

How strongly Frank tried to avoid stereotyping was apparent when I asked Frank to look at a picture showing a class visibly diverse in gender and race. I asked him to explain what he noticed about the students in the picture and he replied that he could not say anything about the students by just looking at them. Furthermore, he stated that he could not make any judgments based on skin color because "skin color does not tell 
anything about the student" (Frank, interview I). Frank admitted, however, that even when he tried to look at the students he was not free from stereotypes. He explained that whenever he saw a student of color, he assumed that this student might come from a low socioeconomic background, although he knew that he could not draw this conclusion. Furthermore, Frank elaborated that he was aware of his own stereotypes and that he always tried not to let them influence his judgment of students. He also mentioned that in the context of the research process, he had been reminded to keep his mind open, but that his perception of culturally diverse students had not changed.

Furthermore, Frank argued that, "culture is not the color of the skin, but a lot more" (Frank, interview II). For instance, to support his position that skin color is no indication of culture, Frank referred to the White, Russian community in his school's neighborhood. He said "they all clique together," (Frank, interview II) speak their own language, and go to the same church where outsiders do not attend. Although the Russian community in his school's neighborhood was not familiar to him, he noted that in the context of such exclusivity, he felt there was no way for him to get to know this community.

He also gave examples related to styles of interaction based on role relationships and authority between adults and children, as well as cultural valuing of education. For instance, he described a student from Japan who only spoke to adults in response to a question, and always stood up in class when he answered a question to that adult, because of his Japanese culture. In considering whether he thought students from different cultural backgrounds had different learning needs, during the second interview Frank 
explained that they would "if they have grown up in different countries when they are accustomed to different interactions with adults." He elaborated that some students might not be "accustomed to [a] nurturing" environment. They may be "accustomed to an authoritarian," "lecturing environment" with "direct, explicit instruction," whereas other students might "just shut down if there is no nurturing given from the teacher" (Frank, interview II). Again, these statements are indication that Frank seemed to believe that students are shaped by their cultural environment. Frank, therefore, tried to make a connection between the school and home culture. He also mentioned that knowing how education is valued by a culture "would go toward [understanding] the whole student" (Frank, interview I). He said that understanding the student's culture would be helpful for teachers in "understanding home life, the value of education in the home and how much support they have in doing homework, whether education is valued in the home or dismissed or something they have to do" (Frank, interview I). Beyond the support a student might get from home, Frank was not able or willing to go into more details about on how as a teacher of mathematics he would take his students' culture into account.

Frank concluded that he did not know how to respond to cultural differences given "that [it] is a slippery slope because you don't want to start stereotyping and offending cultures" (Frank, interview II). In addition, he pointed out that people from the same culture are different, stating that in his junior high school homeroom there were five students with the same Vietnamese last name, who "came from the same culture, so to speak, but they were very different people" (Frank, interview II). He used this example to emphasize his theory that the way to handle diversity is to focus on the individual. 
How Frank perceived diversity and culture. Despite the high population of students who were first generation immigrants from Eastern Europe, Frank did not consider the school to be culturally diverse because many of the students at this school came from a similar religious background, a high socioeconomic background, and were mostly white. As he explained, culture is

everything that makes up the home life, whether it is religion, politics, language. It is not color of the skin and I've always got to remember that. You can have a lot of white faces with a lot of different cultures. (Frank, interview II)

His comments that "I almost didn't take this placement because it is so white" (Frank, interview II) and that he had chosen this teacher licensure program to work with a "diverse population" (Frank, interview II) emphasizes that Frank does not see the students as culturally diverse even when they are from non-mainstream cultural background. Frank seems to see "diverse" as code for "non-white."

However, Frank believed that to define diversity, "people inside the educational system might look at deeper meanings, socioeconomic status, and then, even further down, learning styles and learning abilities" (Frank, focus group). For him, having a diverse classroom meant that one needed to teach to numerous learning styles. Frank said he pays attention to understanding his students' learning styles, by which he meant whether some "kids can figure something out in their heads" or others "might need manipulatives" (Frank, interview I). He added that they all have "different learning styles" and that being in the teacher licensure "program and learning about learning styles and all that," he knew that students were all different (Frank, interview II). They might be "kinesthetic learners" or "non-kinesthetic" (Frank, interview II). He argued that, "We all 
have different learning needs. We need things explained to us in different ways" (Frank, interview II). Additionally, Frank focused on "performance levels" and students' preexisting knowledge. By performance level, he meant how quickly a student could grasp and solve a problem. Whether or not the students knew how to add or subtract would be an example of preexisting knowledge. Still, Frank revealed that "[he] usually underestimate[s] students" (Frank, interview I) in general and said, "Kids are smart-they get it" (Frank, interview I). He also mentioned that students will always surprise you when you try to judge them too quickly by just looking at them.

In summary, Frank was aware of culture and diversity. He saw students as shaped by their background, experience, and preexisting knowledge. His view on diversity and culture could lead him to see the whole child as a learner. However, his very strong fear that he might use stereotypes led him instead to ignore the students' cultural background. The way Frank tried to avoid stereotyping also shaped his perception of teaching.

\section{Frank's View of Teaching Mathematics With Culturally Diverse Students}

In this section, I first describe this teacher candidate's general ideas about teaching mathematics. Then, I turn to his more specific ideas about teaching mathematics to culturally diverse students. Again, there is tension within Frank's beliefs of teaching mathematics. On the one hand he stated that mathematics teaching should be approached from a constructivist perspective with a focus on concept understanding. On the other hand, Frank only provided the use different procedures and explanations as evidence of the constructivist classroom. 
Frank's perception of teaching mathematics. For Frank, the most important part of teaching was using what he called constructivist methods to ensure that everybody can learn and enjoy mathematics. In his math autobiography Frank described that despite his own success with other teaching approaches it was a constructivist approach that helped him to understand mathematics. He stated that "I guess I was 'school successful' enough to learn math as a child through the direct teaching approach but it was not until I was allowed to learn math through constructivism that I really understood it" (Frank, math autobiography). He added: "What I find frustrating is that now that I understand Math and want to teach children using constructivist methods, class sizes and resources are limiting that ability" (Frank, math autobiography). In other words, Frank seemed to be clearly committed to a constructivist teaching approach. Consistent with a constructivist approach, he also spoke about drawing on students' preexisting knowledge. However, his concern that larger class sizes would limit a constructivist approach, indicated that he might not have clear understanding of constructivist teaching. However, his concern that larger class sizes would limit a constructivist approach indicated that he might not have a clear understanding of constructivist teaching. Frank saw constructivist teaching of mathematics as helping students to understand concepts first, and later giving them the tools and procedural skills to solve problems. According to Frank, the constructivist approach provided differentiated instruction and the ability to explain mathematical concepts from different perspectives. In the first interview Frank explained that he thought 
you have to go at it from all kinds of different directions. It is hitting on their different learning styles overall, giving them lots of entry points and chances to work on things on their own, collaborate with partners and small groups, giving everybody lots of different opportunities to give input to it. (Frank, interview I)

Frank envisioned his teaching as highly differentiated with regard to learning styles and ability grouping. Multiple times during both interviews, Frank explained that it is important to know which students are strong mathematicians in order to provide differentiation. Purposefully grouping these high-performing students could either help other students who struggled or support the strong students and give them the opportunity to work together on advanced concepts. Placing students who work on advanced concepts into "accelerated" (Frank, interview I) groups could motivate them to keep their interest. In addition to grouping by "skill level" (Frank, interview I)—which he construed as the ability to grasp the problem, find a method, and solve a problem—Frank thought differentiation based on learning styles is highly important, but he seemed to have a less developed picture of how to teach for differentiation in learning styles. He mentioned that in addition to letting the children choose whether they solve a problem using manipulatives or just their minds, "tiered levels within the same problem" (Frank, interview I) was a way to differentiate. He explained that this would mean that students who "completed...[one problem would receive] another with a level of complexity" (Frank, interview I).

Frank's approach to teaching mathematics could be described as approaching math in different ways. Frank pointed out that there are many different ways to explain mathematics. He stated, 
We need things explained to us in different ways....We have to understand, as teachers, there are a lot of different ways to approach math so we can understand how students are getting at it and explain it to the other students. (Frank, interview I)

Frank mentioned that presenting a word problem and letting the students try to solve the problem before they learn, for example, how to do long division, would help in finding a solution "without writing down the numbers in the traditional way" (Frank, interview I).

He also believed that together with the student, teachers need to find a way to approach mathematics that fit the needs of the learners. Rather than lecturing, Frank preferred an individual or small group, hands-on approach to teaching. He explained,

I don't really feel like kids stay engaged with lectures. It depends on the student, but between two and ten minutes, third grade, 8 or 9 years old, you don't have long to stand up there and give instructions. You can't give a whole lot of instructions so you have to keep getting back up, to give more instructions and keep them working. At that point, if you have 35 students in the room, within 10 minutes they are going to be across the board in different places in their work. You can't stop everything to help the people who are furthest behind. Putting them in table groups is going to allow them to feed off each other and you can address table groups instead of individuals. (Frank, Interview I)

Even though this way of teaching appeared to be student-centered, I was under the impression that Frank always felt that he, as the teacher, had to give the students a lot of guidance and support, which I would classify as a teacher-guided approach. Another indication that Frank strongly believed in a teacher-guided classroom was the combination of his concern that a constructivist approach would not work in a larger classroom and this statement about students collaborating and working in table groups:

If you can hit a table group of 4 to 6 kids and address an issue that 3 students have at the table, rather than helping one kid in the front corner or back corners. Those kids are really spread out. If they are closer together, working collaborative, you might address issues that more students are having with one conversation. (Frank, interview I) 
I suggest that what Frank described as a collaborative group setting might only qualify as grouping in order the give the teacher easier access to students. The way Frank described collaboration in this and other statements limits the students' interaction with each other and keeps the teacher "in control" of these interactions.

Other elements of what Frank saw as his constructivist approach to teaching mathematics included finding what interests the students and scaffolding (in the sense of layering the complexity of the concepts). Frank saw these approaches as important to "help [students] figure out how things work" (Frank, interview I). When I asked Frank for an example, he stated,

I keep going back to the bridge, but I think if you understand, like scaffolding, if you understand the foundation of it, it is easier to work together the top and apply it, without a teacher telling you, okay, you just need to break it down and divide by 8 . (Frank, interview I)

Frank explained that sometimes a student has to struggle to "figure out" (Frank, interview I) a solution to a mathematical problem. To successfully "struggle through" (Frank, interview I) these challenges, which Frank considered necessary for learning, there had to be a certain amount of interest and motivation in order to solve the problem. As an example he mentioned a "kid getting excited about finding that solution" (Frank, interview I). This student, Frank explained, enjoyed the challenge and was "willing to persevere" (Frank, interview I) and "did not just feel ... like, okay, I solved it, now can I leave" (Frank, interview I). Frank further explained that as a way to encourage their interest in mathematics, he tried to support students to be "creative in their solutions and not just go...for the standard algorithm" (Frank, interview I). However, Frank also mentioned that he felt limited in how he could respond to the students' interest by the 
curriculum that had to be used in his district. He noted that teachers in his district "don't have a lot of freedom to divert from that roadmap set up by the district" (Frank, interview I). Frank explained that, therefore, "there is not a lot of room for going off and doing problem solving, getting away from worksheets" (Frank, interview I).

Consistent with his avoidance of stereotyping, Frank believed that he does not need to teach culturally diverse students any differently. He acknowledged, however, that he has to be aware that diverse students might bring different learning experiences and interests to the classroom.

Teaching math with culturally diverse students. As outlined above, Frank thought that for all students, it was enough to ground teaching in students' interests by using scaffolding, peer support, and grouping. Frank seemed to believe that mathematics was less influenced by culture and that drawing on students' cultures was not very important and sometimes not even possible. He explained that the strong focus on content in mathematics curriculum makes it difficult to bring in culturally-related material. $\mathrm{He}$ said in other subjects, such as reading a subject area where he also felt he had more control over the curriculum, a teacher could bring in books that are related to culture.

Part of it is because it is a little more concrete when it comes to reading. You have content that is easily-you have so much more to choose from, there are a lot of books, a lot of books on different cultures. With math, you are teaching the math. (Frank, interview II)

For Frank, mathematics does not connect easily, if at all, with culture and throughout the research process, he struggled to make that connection. For instance, he stated that mathematics did not provide many entry points for culture and that "we all have different ideas and there are a lot of ways to approach math" (Frank, interview I). Another 
statement that Frank made during the second interview seemed to capture his struggle with the existing mathematics curriculum and his ability to integrate culture into his teaching:

I don't get to make the curriculum and I don't get to write the lessons or the subject matter, so I am not in a place to change books up so that-like in our reading curriculum, so that we are making sure to read books that address different cultures and read respect from every student toward every student. I don't know how that would apply to math. Would we write story problems or word problems that incorporate different cultures? I don't know. (Frank, Interview II)

Again, Frank also argued that he would rather not try to incorporate different cultures into his math teaching because this could lead to stereotyping. He explained that there is no way for him as a teacher to know each student's culture and respond to this culture in an appropriate way. Frank elaborated that, for example, if there were a Japanese student in the classroom, creating a word problem based on sushi would be stereotyping students. He further noted that it is not possible to make any judgment about the students' needs because they were "Asian." This explanation could be seen as an example of Frank considering culturally responsive teaching by being cautious about making assumptions. Hence, Frank also did not consider incorporating his knowledge about cultures and, especially, students' individual cultures, which is a key element of culturally responsive teaching.

Frank's struggle with the concept of culturally responsive teaching could be seen in his response to how culturally relevant math teaching might look. The closest Frank seemed to come to integrating culture into his teaching was bridging to the students' home experience to find out about student interests. Frank concluded that he did not 
know how to respond to cultural differences given "that [it] is a slippery slope because you don't want to start stereotyping and offending cultures" (Frank, interview II). After careful reflection, Frank concluded that creating problems around money or explaining concepts with the use of money might be one way to respond to students' cultures. He explained that money is part of everybody's culture and, therefore, using money to teach mathematics would be culturally relevant.

Frank seemed to acknowledge cultural background and his own stereotypes, but could only see negative potential in addressing cultural diversity openly in the teaching of mathematics.

\section{Researcher's Discussion: The Relationship Between Frank's Images of Mathematics, Students, Culture, and Teaching}

Frank held a positive image of mathematics as being approachable; he was confident that he could teach it. For him, mathematics was a tool for solving the problems and puzzles, which are all around us. Frank saw mathematics as embedded in science and engineering and anything that had to do with numbers. Students used mathematics on the playground, in games, and maybe when they dealt with money. He emphasized that mathematics is based on rules and procedures that have to be followed in order "figure" things out and different ways to solve problems. Even as Frank saw the application of the existing rules and procedures as flexible, he seemed to leave, at least in elementary school mathematics, room for creating new ideas and ways to solve problems. Further, for elementary students, he seemed to emphasize concepts as the foundation of procedures. Thus, Frank's image of mathematics seems to lean toward the procedural, 
even as he would have argued that he held a conceptual image of mathematics. By a procedural image of mathematics, I mean taking an approach to mathematical problems by applying different procedures and algorithms. The emphasis is on facts, procedures, and rules, which can be used to explain the world.

Frank's procedural image of mathematics seemed to have also shaped his perception of teaching mathematics. Frank believed that the purpose of teaching mathematics in elementary schools is to prepare the students for a more content rich math classes in middle school. Frank, therefore, seemed to focus his instruction on learning the basic concepts and procedures in a certain order. Frank indicated that the teacher has to provide different ways to solve a problem and help the student to choose the way which fits their needs and interest. The procedural image of mathematics which Frank held seemed also to limit student collaboration and peer-support to students explaining to each other how to solve a problem. It appears as if Frank believed that math has to learned in a certain order influences his notion of differentiation in the classroom. He mainly seemed to consider differentiating his instruction based on ability level and learning styles.

However, Frank seemed to assume that culture had little or no relationship to mathematics and how mathematics is accomplished or used. Despite his stated belief that mathematics is part of our daily life and that there are many ways to approach mathematics, Frank did not see the students' cultural background as an important factor in teaching mathematics. He believed in using highly differentiated instruction and that it was inappropriate to base teaching on a group's cultural diversity rather than students' individual differences. When Frank talked about individual differences, he said he tried to 
ignore a student's racial identity-and questioned cultural identity-because he tried to avoid stereotyping by all means. In consequence, he negated many experiences that a student had as an individual member of a group. His focus on the individual student was limited to academic performance, knowledge, and skills. Because of the "many ways to do math," (e.g., Frank, interview I) Frank planned to use what he called a constructivist teaching approach to serve the needs of all students. However, his strict rejection of any group characteristic because of his fear of applying stereotypes made Frank ignore the racial and cultural background of the students. Because Frank seemed to see mathematics as universal, with different ways leading to the same solution, he was able to ignore the students' cultures. So, it was not a surprise that he saw culturally responsive teaching as an add-on that could be included occasionally.

During this research, it occurred to me that the most influential element of Frank's image of mathematics, despite being overshadowed by his fear of stereotyping, could have been his notion of mathematics as a constructivist subject. He limited a constructivist mathematics approach to the existence of different strategies to find the one solution to a mathematical problem. This view of mathematics gave Frank the possibility of taking the students' learning styles and skill levels into account and differentiating his instruction accordingly. This previously explained notion of differentiation, in combination with different ways of explaining mathematical concepts, seemed to be the pillar of what Frank believed to be a constructivist approach. However, it seemed as though Frank did not consider it possible that multiple correct solutions to a mathematical problem might exist. This notion of teaching might contribute to what I would call seeing 
the "students (solely) as individual "knower" with individual learning needs, but not to what I would call "students as individual persons" who are learners bringing cultural backgrounds that may influence their views, preexisting knowledge, and applications of mathematics. On the one hand, the perception of seeing the individual knower is that a learner is shaped by preexisting knowledge, school experience, learning style, personal interest, achievement level, and home support. On the other hand, seeing the individual person-seeing the whole child as a knower-is a perception that a knower is shaped by preexisting knowledge, school experience, learning style, personal interest, achievement level, and home support as well as by cultural background and group identity.

Frank's case raised questions about why the fear of responding to group culture is problematic or scary for him and perhaps for other teacher candidates who face cultures other that their own in today's classroom. I also wonder how promising Frank's perception of teaching mathematics would be for working with diverse students, with his strong focus on the individual learner, but not seeing the child as part of a cultural group. It would be interesting to know what, if anything, would persuade Frank to embrace culturally responsive teaching, and to know what cultural forces led him to his own significant fear of stereotyping.

\section{Introducing Emily}

Emily was a White female in her early 20 s at the time of her participation in the research study. She grew up in a family of educators in a rural part of the state. She said that she did not really grow up in a neighborhood; it was "quiet and country" with "more animals than other kids around (Emily, interview II)." She explained that there was not 
much of a neighborhood because the next neighbor lived at least a mile away. Emily mentioned that even growing up in an open-minded family, being in a rural area did not give her much exposure to diversity. This was one of the reasons why she decided to enroll in a teacher education program at an urban university and to move into the city. The diversity focus in the program and the diverse student population she hoped to work with were particularly appealing to her. Emily explained that she enjoys working with and learning from people with different backgrounds. Growing up, Emily attended her local public schools, which she described as not very diverse at the time. When Emily was in middle school, she started helping out in her mother's high school classroom. After graduating from the local high school where both of her parents worked, Emily attended a small rural college. She transferred later to an urban undergraduate program where she earned a Bachelor of Arts degree in Social Sciences. She explained that she chose this particular teacher licensure program because of its proximity to her hometown, the diversity of the fellow students in the program, and the diverse student population in schools.

Emily stated that because of her family background, she wanted to follow family tradition and become a teacher. Even though she knew that an elementary teacher needs to be able to teach everything, she became specifically aware that she has to teach mathematics when she signed up for the required mathematics for elementary teacher courses in college. Emily noted that she felt the need "to brush up" (Emily, interview II) on her understanding of some concepts in order to be able to teach mathematics. 


\section{Emily's Image of Mathematics}

Emily's overall image of mathematic could be described as procedural and highly sequenced with applications to explain the world. Emily expressed a positive image of mathematics, but also considered mathematics to be "complex and difficult" (Emily, Interview I). She explained that because of the many different possible approaches (e.g., different levels of complexity, different procedures), everybody who does not have a learning disability should be able learn mathematics. She saw mathematics as deeply rooted in rules and procedures which can be applied in "different ways to solve problems" (Emily, interview I) relevant to real life.

Emily believed that mathematics can help to understand and explain the world. She explained that mathematics is about "solving everything" (Emily, interview I) and that "[mathematics] is how it represents things in the world, numbers" (Emily, interview I). Budgeting, for example, helps her see if she can "afford new kittens," and "applying for student loans," or "parking a car" and buying a parking pass were all mentioned as examples of her regular use of mathematics (Emily, interview I). Emily considered mathematics to be the most important subject because "it relates to every aspect of life," (Emily, interview I) and elaborated that for her, "mathematics is numbers and procedures with numbers related to real-life situations." Furthermore, she explained that sooner or later what you learn in mathematics will matter. These statements indicate that Emily saw mathematics as procedural and abstract. She spoke about mathematics as based on numbers and only then applied to real-life problems. Abstract numbers are used in concrete situations. 
It was, therefore, not a surprise that Emily felt that "math can be as simple as you want it and it can be as hard as you want it" (Emily, Interview I). Emily believed that how difficult mathematics is depends on how mathematics is presented. One of her goals in becoming a mathematics teacher, therefore, was to learn "how to present how to do math at the different levels" (Emily, interview I). Key to the presentation of mathematics are procedures, equations, algorithms, and "a certain sequence that you have to say things" (Emily, interview I) in. Emily explained that providing structure and guidance can help to find a solution, but they can also easily "throw the class off... [because] you have to be very orderly when you present math" (Emily, interview I). I assume that as Emily talked about how to teach mathematics, she was also reflecting her view of the nature of mathematics. She assumed that mathematicians use their knowledge and understanding to "find the easiest procedure to do [math], just the easiest way to find out the answer" (Emily, interview I). She added that she was "sure a good mathematician gets multiple ways of solving [a problem] and then picks just the easiest way" (Emily, interview I). Overall, then, Emily implied that understanding of mathematical concepts is highly associated with the knowledge of how to use algebraic equations and procedures. Furthermore, during the first interview Emily noted that "mastery of procedures," such as solving equations and the knowledge of facts (e.g., formulas and multiplication tables) were important skills for mathematicians (Emily, interview I). She elaborated that everybody has to "practice a lot [to] solidify what they are doing" (Emily, interview I). Practice "almost makes [mathematics] a kind of routine" (Emily, interview I). Emily further explained she thinks 
the more and more they do it, the more it becomes second nature. I think with math, or actually anything that you are doing, the more you do it, the more it sinks in and I think then the easier it becomes later on. It is kind of like muscle memory-when you do something all the time you get used to it and it just becomes easier. (Emily, interview I)

This statement, which emphasizes that mathematics becomes easier through practice, in combination with the previously presented statement that depending how mathematics is presented, indicate that Emily saw mathematics as comprised of procedures which can be practiced. Emily believed that practice can help find ways to solve problems. It was, therefore, not a surprise that when asked, the first three words that came to her mind when thinking about mathematics were "equations, numbers, solving things and figuring out what is it all about" (Emily, interview I).

Emily's strongly procedural image of mathematics was also apparent in her perception of students and how she perceived teaching mathematics. In the next section, I therefore focus on Emily's perception of students in a mathematics classroom.

\section{Emily's Image of Students}

Emily considered someone who is "really good at math" to be someone who can easily identify a "problem and at least have an idea [of] the direction that they will go in" to solve this problem, somebody who is able to "develop a plan and identify what they know and what they don't know and sort it out," and somebody who would have an "instant plan of what they are going to do next" to find the solution to a problem (Emily, interview I).

Emily also revealed information about the importance of finding the right solution to a problem and checking the answer for correctness. She explained that there 
are "probably...different ways to solve problems" and "different routes that can be taken to solve a problem and [for] checking... answers" (Emily, interview I). Emily further explained that it is always important that students are "taking their time in going through [their solutions] carefully to be sure that their solution is right." In case students get "stuck" with solving a problem, before they ask for help they should be "giving it a try first," to find the "hiccup or mistake and then correcting it from there on is good" (Emily, interview I). This explanation of how students should do mathematics showed that Emily saw mathematics as very procedural in nature and thought that mathematical problems could be solved by applying the right procedure correctly. As an example, Emily explained that when students "mess up" during homework, they should try to pinpoint where the way to the solution went wrong so that the teacher can be "helpful in figuring out that this is what we need to work on now" (Emily, interview I). As our conversation about students and mathematics continued, Emily indicated multiple times, that there were different ways of doing mathematics and that students should find the right way for themselves.

Emily said that she had never thought about whether people with a different culture might do math differently. She said that she would not be surprised if they do mathematics differently, because there are "multiple ways to do math" (Emily, interview II; math autobiography). She explained that she has had limited experience with people from different cultural backgrounds. In the next section I describe how Emily saw culture and diversity in general and how she saw mathematics in a cultural context. 


\section{How Emily Perceived Diversity and Culture}

Emily explained that, "diversity is when you have people of different heritages and languages together" (Emily, interview II). She welcomed classroom diversity because it "brings different experiences to the table [and] different ways of thinking" (Emily, interview II) as well as "different strategies for solving math" (Emily, interview II), but noted that her picture of diversity is built on the fact that she was not exposed to diversity growing up in a rural area. She noted that diversity in the classroom does not mean that there is just one other group of students, but that there are many students from different backgrounds. For example, she did not consider a classroom to be diverse when there are "not very many other ethnicities besides White or Hispanic" (Emily, interview II). Referring to students with a Spanish-speaking background, Emily stated, "We shouldn't make assumptions about where they all come from and clump them together. There are different traditions and cultural norms and this sort of thing" (Emily, interview II). She strengthened her point by explaining that, "White people come from all over the place, too." She added that diversity leads to "doing things in different ways" (Emily, interview II). Emily saw that backgrounds could influence how students do math, but she also did not know how to respond as a teacher.

Emily saw cultural diversity as related to "religion, your traditions, maybe where you come from, [and] your family morals" (Emily, interview II). She was not sure whether the language spoken at home, or religion, count toward cultural diversity. However, Emily did not consider racial diversity to be necessarily connected to cultural diversity. Stating that she was concerned about sounding racist, she explained, "You do 
see that sometimes kids [of] color who don't have a lot of parents at home to rely [on] because they are working so hard" (Emily, interview II), that this would impact the way they do things at home. Emily indicted that she believed that therefore this family's culture is not directly determined by race. Finally, she explained that

environment has a lot more to do about [how] your morals develop or how you are brought up and is a lot different than just where your ancestors came from or that sort of thing - nature versus nurture. (Emily, interview II)

As an example she mentioned that "if you are White and you get adopted into an African American family, then they might have different traditions than your ancestors do, but you identify with your family and kind of grow up that way" (Emily, interview II). Consequently, Emily noted that it is important for a teacher to have "kind of a subtle awareness" (Emily, interview II) of the students' cultural diversity.

Emily saw culturally diverse students. On the one hand, Emily considered awareness of diversity to be important. She assumed that it might help to understand that "students can do things in their own way" (Emily, interview II). On the other hand, Emily stated, "I haven't seen that [diversity] quite matters to the students" (Emily, interview II). Emily thought there should not be a big focus on the students' diversity in the classroom. At first these statements seemed to be contradictory, but Emily also noted that she "is sure individually it matters to [students] where they come from" (Emily, interview II). She, therefore, saw diversity in the classroom as an enrichment and as a challenge. Emily believed that "everybody should feel welcomed and represented at the same level" (Emily, interview II). In the second interview, she explained that the "cultural class," (I assume Emily is referring to the required course on multicultural education in the 
program) which she took in the summer, "brought to light" that as a teacher you "really need to link [to students], and let them feel appreciated and welcomed into your class, and really be purposeful about what you present to the class" (Emily, interview II). These statements indicated that Emily was aware of diversity in a classroom, but might have still been unsure how diversity influenced teaching and learning.

The challenges which a diverse student population might pose to Emily could be related to her assumption that students from other backgrounds might do mathematics differently. During the focus group, Emily mentioned that a math student should "pay attention" to the teacher and "follow instructions." Doing so, the students could learn different ways of solving a mathematical problem. To clarify what learning in different ways meant to her, Emily explained that "to solve a problem [students] should be able to find algorithms or an algebraic equation, in lower grades a formula, and then pick the one that [they] understand" (Emily, interview I). In addition, students should also be able to identify their own ways of learning. Emily further elaborated that the way students do mathematics depends on the individual person. Therefore, she noted, the teacher is not always able to understand where the student is coming from and what their difficulty is. In such cases another student "might have a completely different way of doing it and that would make more sense to the [first] kid" (Emily, interview I). Emily explained that "peers can talk in kid-lingo, whereas the teacher may use different terms that they don't quite understand or they don't relate it quite as well as they maybe should have" (Emily, interview I). What this explanation shows is that Emily saw that students not only have different needs, but also have the potential to support their peers. Emily indicated that for 
a teacher who always tries to "help [students in] finding the easiest way" (Emily, interview I), diversity brings in more ways of doing mathematics.

Emily asserted that to affirm diversity in the classroom, teachers need to pay attention to the individual learner and not jump to conclusions based on ethnicity or race. However, Emily also reflected that she was not free of bias. Afraid of sounding racist, Emily mentioned that when she saw an African-American student, the achievement gap came to mind. She elaborated that she always had to remind herself to focus on the student and "how the student can be engaged in learning" (Emily, interview I). When I showed her the picture of a third grade classroom (see appendix D) and asked her what she noticed about the students, she was mainly focused on whether or not the students appeared to be engaged in learning. Even when directed by my questions toward the diversity in the classroom, Emily seemed to not pay any attention to the visible diversity in the classroom. She stated that it was not possible to say whether or not a student grew up in the US and what their language proficiency was. During the focus group when she saw a video clip of the same class during a math lesson (see chapter 3), Emily was surprised about the students' low level of engagement. She said that she assumed that because everybody has experience with money, the students should be more excited.

\section{Emily's Perception of Teaching Mathematics}

For Emily, the purpose of teaching mathematics in elementary school was "to get them familiar with what's coming" (Emily, interview I). In the first interview she further explained that "you have to start with the basics of math at an early age because it literally is everywhere," for example in games, food, and sports. Emily explained that 
teaching the basics first prepares the students for later, "when they do the tough stuff." Also in the first interview she explained that it is important for students to "develop their skills" early on and to have enough "time to [let] it sink in" (Emily, interview I). For example, she noted that teaching addition and subtraction and "covering everything" needs time because it will later provide a solid basis for teaching long division (Emily, interview II).

Although Emily saw mathematics primarily as a fixed set of rules and procedures that need to be followed (e.g., Emily, questionnaire; interview I), she also articulated the value and necessity of teaching mathematical concepts as the basis of her teaching because students need to understand these concepts first. Emily indicated that mathematics cannot be learned through learning the procedures-by which she perhaps meant, given her emphasis on procedures, that mathematics cannot be learned solely through learning procedures, given her emphasis on concepts as a foundation. At the same time she indicated that she considered it important that mathematics teachers strictly apply step-by-step instruction to explain mathematical concepts. Emily also believed that it is "particular[ly] important to know the student's entry level” (Emily, interview I) so that the teacher could help the student find a way to do the mathematics. According to Emily to understand mathematics, "it is important to memorize the facts and to practice the procedures" (Emily, questionnaire) so that through intensive practice the "mathematical concepts can become a second nature of the students" (Emily, interview I). 
Consequently, Emily indicated that it is important for the students to pay attention to the teacher's instruction. She said that "it is important be able to call the students by their names in case they are not paying attention" (Emily, interview I). Overall, drawing from her own school and college experience, Emily stated that she believed that mathematics teaching needs to be highly "sequenced" (e.g., Emily, math autobiography, focus group). She explained that because she was always confused whenever a teacher "skipped a step" (Emily, focus group) when they worked on a math problem in class, she would always follow procedures step-by-step when she teaches to help the students understand the concepts. In addition, Emily thinks that showing them the "tricks of the trade also helps... [such as] the 9's tricks on your fingers, when you count the number, [helps] the students to learn mathematics" (Emily, interview I). Emily saw this kind of teaching in "many different ways" (Emily, math autobiography; interview I) as good mathematics teaching:

I think being able for them to have manipulatives and working with their hands is a good way. I think visual images where they can watch you I think is good. Just hitting all those different entry points that we are learning about and getting kids up and moving and interacting with it I think is all important. (Emily, interview I)

Emily added that she was concerned that she might not be able to "stay on top of everything" (Emily, interview I). She mentioned that she was worried about encountering students who do math in a way that she does not understand and that she would not be able to help these students or even understand where they are coming from.

In the first interview, I raised the topic of differentiation. Emily considered differentiation to be "extremely important although it could be very hard for the teacher to do and be ready for" (Emily, interview I). Emily explained that she would either 
differentiate based on the students' skill levels and/or on the students' ways of learning. She added that a teacher has to "teach everybody and give them all the same attention and all the same help when they are in different areas" (Emily, interview I), when some might be well ahead of others. For example, Emily would adjust a math problem for a student who is "stuck with it" without "lowering the cognitive command level either" to differentiate (Emily, interview I). Specifically, she would "assess the students' levels" and provide "different materials that they can use and different resources to kind of get them to see the problem in a different way" (Emily, interview I). In addition, she might "say the question one more time" or she might "try to find a different way to do things and push [the students] a little harder" (Emily, interview I). In the first interview Emily also stated that differentiation is "very tricky" because one has to assure that, for example, so-called "Talented and Gifted" students who finish assignments easily are able to "develop their math skills;" in other words, these students learn quicker than other students. At the same time, "it is not fair for the slower students who just need a little more time, to say, sorry, move to the next problem, we are moving along and leave them in the dust."

Teaching mathematics with culturally diverse students. Highlighting the importance of finding the "best and easiest procedure" to "find the answer" to a math problem (Emily, Interview, I), Emily indicated throughout the research process that it is important to engage students. Emily stated in the second interview that engaging students from diverse backgrounds is "quite easy in mathematics" because "all you need to do is tweak ... a story problem a little," to make a connection to the student. In other words, 
Emily would change a generic setting of a story problem to a setting that is of interest to the students. Because Emily knew that most of her Hispanic boys liked soccer, she gave the example of a story problem about two teams on a soccer field for getting the students "hooked in" and "relating it to them" (Emily, interview I) Multiple times, Emily further noted that because "there are many different ways to do math," such as "using manipulatives, different entry points, and just telling them all these different ways that you can do it," it is possible to engage all students (Emily, interview I).

As outlined above, Emily believed that mathematics provides ample opportunities for teachers to differentiate instruction in order to engage all students in meaningful learning. According to Emily, there should not be a reason why any student might not be able to learn mathematical procedures and facts. However, she believed that it is important for the teacher to know the students' family situation. Emily explained that a student from a more wealthy background might get all the support and resources at home, while others might not have parents who are able to help them because they are working two jobs. This kind of knowledge would help Emily to make decisions about how much time she might spend on multiplication facts in the classroom.

However, Emily believed that it is always a good idea to give students the opportunity to bring their culture into the classroom, even when it is a "little hard" to do and even though she noted that the required curriculum is "very step-by-step" in the sense of prescribing exactly what teachers need to do (Emily, interview II). Furthermore, this curriculum left little room for teachers to make adjustments or to add materials. However, she reported that during her initial field experience practicum her two students from 
China were highly motivated when one of them brought in some money from China when the class was working on U.S. currency. Emily explained that these children were able to work with something from their own background, which helped them "feel that they are worth something" (Emily, interview II). In the second interview, Emily noted that seeing themselves represented is very important for children. She also further explained that the excitement spread through the entire class and all students were "more excited," asked a lot of questions and "learned from each other" (Emily, interview II). Emily was sure that being able to contribute in such a way meant a lot to the students. Referring to the Chinese student who brought the money in, Emily stated, "I think he just felt welcomed and really linked into the classroom and was appreciated" (Interview, II)

Furthermore, Emily explained that teachers need to be very intentional about when and what kind of material (e.g., books or maps) they use to represent the cultural diversity in the classroom. Also, the intention behind the use of the artifacts should never be disclosed to the class, explaining that she would not say the reason she brought "this problem is because Pung is from China" (Emily, interview II) so as to avoid singling out students. Emily explained that just presenting material related to the students' backgrounds gives them the opportunity to identify with the material. In addition, she thought that giving the students the opportunity to identify with material provided in the classroom encourages students to bring something that relates to their backgrounds.

Emily said that she thought culturally relevant math teaching could be everything from relating story problems to the students and their culture to representing the students' 
cultures through the use of artifacts. Emily had less of an idea what culturally relevant teaching might be, however. She said,

I don't know. I guess I kind of see that as just responding to what is in your class, maybe. I am kind of shooting in the dark. It is just responding to what is going on in the world and in your students' lives and then adapting it that way into the class. (Emily, interview II)

During the focus group and throughout the interviews, Emily also mentioned that responding the diversity in a mathematics classroom is important but maybe too complex to do if it goes beyond tweaking the story problems and occasionally letting students contribute. Although Emily had some intuitive sense that she needs to use culturally responsive materials and language, she saw this as an addition to rather than integral to math teaching.

\section{Researcher's Discussion: The Relationship between Emily's Images of Mathematics, Students, Culture, and Teaching}

Emily seemed to have a positive attitude toward math; by a positive attitude I mean, seeing mathematics as an approachable subject that is concerned with practical problems of daily life. Emily seemed to be grounded in her view of mathematics as a highly sequenced subject based on facts and procedures. She seemed to believe that this structure makes mathematics accessible and flexible enough to be relevant to almost all problems of daily life. At the same time, she believed that having multiple ways to approach mathematics makes math a difficult subject, but also accessible for all students. However, Emily also seemed to believe that understanding concepts of mathematicswhich she seemed to see as knowing and applying procedures and facts_-opens mathematics to students of all backgrounds. In summary, Emily believed that all students 
can learn how to do mathematics if the teacher provides the necessary structure and guidance as well as a welcoming classroom atmosphere.

Although Emily welcomed and acknowledged diversity in general, she seemed to be unsure how cultural diversity impacts the teaching and learning of mathematics. Emily assumed that students' social background and their experience with mathematics in school and at home influences the way they do mathematics. As a consequence, she believed that a math teacher should respond to the diversity in the classroom, for example by “tweaking" the story problem toward the students' interests and backgrounds. In addition, Emily believed that math teachers, as experts in mathematics, should help the students to find their own way of doing mathematics. At the same time a teacher should support the student in learning math facts and practicing procedures. Whereas she saw the teaching and learning of mathematics as independent from the students' culture, Emily considered relating teaching to the students' interests and backgrounds to be key in motivating students to learn. Emily also cautioned that teachers need to avoid making general conclusions about the students as a group, but respond more to individual students. However, this stance led her to ignore the child's background. Although Emily saw value in trying to motivate students through including some relevance, under Gay's (2010) framework of culturally responsive teaching, I would consider Emily's strategies to be only the first step toward culturally responsive teaching.

Emily seemed to care about each individual student's learning needs and even attempted to respond to the students' culture. However, I was under the impression that Emily was not able to follow through with seeing the whole child as a learner because she 
did not have strategies in place which would have allowed her to connect her perception of teaching mathematics and her view on diversity. One reason for not being able to make these connections could have been that at the time of the research Emily was still developing her view on diversity and culture. Another reason might have been that Emily seemed to be diligently applying what she had learned in the Elementary Methods to her teaching. I wonder whether she picked up frameworks to respond to the child as learner and a person (seeing the "whole child), which that she would also see the child's culture. Emily mentioned that participating in this research helped her to start thinking more about responding to her students' culture. Based on the course syllabus and a conversation with the instructor, she would have already been introduced to culturally responsive teaching in her coursework, so I was somewhat surprised about this statement, but also glad to hear that my research might have had a positive impact on her perception of teaching mathematics with diverse children.

\section{Introducing Christy}

Christy was a White female in her mid-30s at the time of her participation in the research study. She grew up in a lower-middle class family, held a Bachelor's degree with a major in science and a minor in elementary education, and was working on her master's thesis in science education. Christy attended a public neighborhood school in her hometown. She explained that her "elementary school was probably the vast majority White," (Christy, interview II) and added that starting in junior high school, there was "a large population of Vietnamese and Laotians, kids whose parents came as refugees" (Christy, interview II). 
Christy explained that in her working class family, "college was never really an option" (Christy, interview II). After finishing a degree at the local community college, she worked occasional jobs for a while. She decided to become a teacher in her early 20's, "but ended up doing the [job training] thing instead" (job altered to protect the identity of the participant). She noted that at this time she thought she was not "personally ready" (Christy, interview II) to become a teacher. Christy further explained that after starting a family and working in the field of her trained job, she saw the need for more education and was no longer satisfied with the kind of work she was able to get with her degree. At this time she finally decided to go back to school to become a teacher.

Christy had to overcome great difficulties in school before she learned to enjoy mathematics. She explained the struggles that she had experienced throughout her entire school and professional career. She noted that after elementary school she was always a struggling math student. By junior high school she "had developed a dislike for math" and decided to be "done with it" in high school (Christy, math autobiography).

Explaining her struggles with mathematics, Christy stated:

If I know exactly what kind of problem I'm facing I can follow a strict algorithmic approach, but if a problem involves multiple steps using different approaches, or it's out of context, then I have no idea how to begin. (Christy, math autobiography)

Since then, Christy had experienced mathematics as "challenging" and "difficult" (Christy, interview I). From Christy's perspective, these struggles in combination with her perfectionism always caused her to feel "horrified" when she had to do mathematics (Christy, math autobiography). She said that she always wanted to understand 
mathematical concepts completely before doing math or even explaining mathematics. However, the fact that she did not always understand fundamentals and tended to make basic calculation errors made Christy feel uncomfortable with mathematics. Christy explained that, in the mathematics for elementary teacher course series, she learned that understanding mathematical concepts could help her make sense of all the rules, facts and procedures. This was the time when she started enjoying mathematics. She said she now saw her struggles as an asset because she knew from her own experience where students might struggle and how to support them. She explained that her perception of mathematics changed as an adult when she started applying mathematics to real-life. Once she had learned how important math was in daily life, Christy now thought that mathematics was an interesting subject, still challenging, but a subject that can be learned and understood.

\section{Christy's Image of Mathematics}

"Hard," "boring," and "scary" were the first three words that came to Christy's mind when she heard the word math. Hard and scary seemed to reflect her overarching image of mathematics. She explained that she did not consider herself to be a person who was "naturally good at mathematics" because math was "difficult and complex" (Christy, interview I). Christy believed that one would need to have a "math mind" to understand all mathematical concepts or all algorithms (Christy, interview I). However, Christy indicated that she believed that mathematics is flexible and can be approached in different ways. She explained that, therefore, "to some extent" everybody can learn math, including students with autism and brain trauma (Christy, interview I). 
Christy believed that only through the understanding of mathematical concepts was it possible to make sense of procedures and not confuse them with one another. She explained that the only way of getting comfortable or even enjoying mathematics was by understanding the concepts rather than trying to learn algorithms. She noted that although it was important to memorize some basic facts, learning algorithms without understanding the concepts first would lead to frustration and failure. She added that understanding the concepts helped her to become much more confident with mathematics because now she did not need to try to memorize every single algorithm and formula.

Christy stated that mathematics was interconnected with everything we do and was always connected with a purpose, but she had some difficulties offering a variety of grounded examples tied to its use in everyday life. She explained that it was even "hard to say" what mathematics is all about because it ties to other disciplines (Christy, interview I). Christy elaborated that mathematics "relates to the application as opposed to an abstract concept of math" (Christy, interview II). As an example, Christy mentioned in the first interview that "if you are an astronaut, math is going to mean one thing, more than if you are designing an airplane and math might mean something totally different." In short, Christy stated, mathematics is defined by "kind of an individual feeling of what math is for you" (Christy, interview I). When I asked Christy what she thought professors of mathematics do when they are not teaching, she said that she thought that they were doing research on mathematics, such as looking for proofs and looking at mathematics from new perspectives. Christy's description of mathematics professors' work appeared 
to move their mathematical work into an abstract realm, which supported her notion that the nature of mathematics was interrelated to its application.

\section{Christy's Image of Students}

In the first interview, Christy asserted that the characteristics of a "good" student in general were that he or she would persist, take risks, and pay attention to the bigger picture, such as mathematical patterns and his or her own thinking. She declared that a "typical student who is good at math is a student who is able to persevere and ha[s...] good mega-cognitive ability, to be able to think about how they would best be able to solve a problem and what has worked for them in the past" (Christy, interview I). She added that a student who was a good math student would be able to understand patterns and would be "willing to try new strategies and to learn about new things" (Christy, interview I). Consequently, Christy believed that a struggling student was a student who needed strategies to move beyond basic understanding of mathematical patterns. Christy explained that when she saw a student struggling, she tried to assess "what makes a person less able to do math" (Christy, interview I) rather than exploring what strategies the student might not understand. Thus, teaching "is more about personal qualities of students and less about knowledge" (Christy, interview II). I saw this statement as a clear indication of Christy responding to who the student is.

\section{How Christy Perceived Diversity and Culture}

How Christy saw cultural diversity was reflected in a statement that she made during the second interview, when we had a conversation about teaching culturally diverse students: 
I think our perspective as educators is a little different than somebody outside the education system. I think if you ask most people to take a look at a class of White males, they would see no diversity, whereas I will look at it and still see a diverse classroom because I know that there is a lot of stuff going on in there. Even if they are all from the same neighborhood, they all have different things happening. I think every classroom is diverse. (Christy, interview II)

In addition to seeing classrooms as diverse in nature, throughout the entire research project, Christy connected diversity with different racial, ethnic and language backgrounds. For example, when I asked her to describe the diversity of her childhood neighborhood, or the diversity of her current field placement, Christy based her descriptions on "skin tone" and heritage, by which she meant a student's race in combination with where the student's family had lived (Christy, interview II). She further explained that skin tone itself is not necessarily an indicator of cultural diversity. Rather, Christy stated, "people do things differently because of their different experience" (Christy, interview II). According to Christy, people with different racial backgrounds could experience the same situation differently. At the same time, Christy explained, two people with the same skin color could experience the same situation very differently, too. For instance, in the second interview, she mentioned that a first generation immigrant from Africa might have a similar heritage to an African American whose family has lived in the U.S. for many generations, but they might have nothing more in common than skin tone. In this remark, Christy implied that heritage is related to race. Furthermore, Christy observed that although the classroom in which she was currently placed may have seemed very homogenous on the surface, the school was indeed very diverse because at this school students came from all over town, bringing different home experiences. Indeed, Christy saw cultural diversity as arising from that home experience. She stated: 
I would say that a lot of it comes from just the culture that you experience at home. So I think the obvious indicator would be their ethnic background but I don't think that is necessarily obvious within a classroom. I don't see a lot of different skin tone in our classroom but that doesn't necessarily mean that they don't have a lot of cultural diversity. I am just not necessarily aware of it. It is not necessarily something that is being brought to our attention in the classroom from the students or from their parents. I'm sure there is-obviously there is diversity within the room. They are all coming from different places, but as it being an overarching theme of how they interact with us, it is not something obvious. (Christy, interview II)

This statement also indicated that Christy saw her classroom as culturally diverse because the students in the class came from different places. I clarified with Christy that by different places she meant different countries and/or different neighborhoods groups. It appeared as though Christy was under the impression that this diversity might influence the interactions in the classroom, but not to a significant extent. Christy seemed to be at least aware that cultural diversity influences the learning of mathematics. At the same time, she seemed to have no clear perception of how culture might shape the learner.

How Christy saw culturally diverse students. Christy believed that teachers could never make general statements about the students' learning, which makes teaching children from a cultural background other than her own challenging. In the second interview, she explained that she does did not know how to teach "kids who are coming from very different cultures, with different priorities, different ways of interacting with education." Christy added that she also did not have "great resources for dealing with parents" which might be necessary because of "different viewpoints on what the goals of education are" or how math should be taught.

Not surprisingly, Christy considered it most important to know the students and to build relationships with them. She stated that "knowing your student and knowing 
what [knowledge and experience] they already have and what you can build on and knowing their strengths, [and] what is going to be the best way for them to learn" is important for a teacher (Christy, interview I). Christy argued that conversations with students to "find out more about their home life" are important for becoming familiar with the students (Christy, interview II). She had recently found it interesting to discover in conversation that in her classroom "one kid had only lived in Oregon," her entire life, but that others had lived in London and Paris and one was born in Germany (Christy, interview II). Christy noted that the child who had lived in London was currently in speech therapy because of her British accent. As a teacher, she believed that all this information about who the students are and where they are coming from is important. Christy assumed that all students should work toward the same goals and standards, but culturally diverse students might have different learning needs. She explained that she believed culturally diverse students do not need to learn "different things" (Christy, interview II). Everybody needs to learn the basic concepts and strategies, but the application for individual students might be different. Furthermore, Christy explained that she thought students "need to learn in different ways," but that it is not possible to make general statements about student learning based on their race or ethnicity (Christy, interview I). To clarify her statement, Christy explained that for example, she did not think that "African Americans really, really need this [strategy or artifact] in order to learn math and you don't necessarily have to do that for White kids or anything like that" (Christy, interview I). What students' learning needs are depends on the individual student. 


\section{Christy's Perception of Teaching Mathematics}

Christy's main belief about teaching mathematics was that "providing a really well-rounded base is critical for developing successful adults, and just being successful as citizens" (Christy, interview I). To reach this goal, she elaborated that she would focus " more on the big ideas of math and less on rote memorization and getting [students] to understand the processes of how things work" (Christy, interview I). Christy explained that it is important to teach mathematics with a focus on the deep understanding of mathematical "processes," rather than teaching "how to do it for a test and forget" (Christy, interview I).

Christy added that it is also important to "mak[e] mathematics relevant for the students and show...them how it is important." Moreover, for Christy it was also important to get the students "to be responsible for their own learning, and teaching them their own personal strategies for doing math" (Christy, interview I). She explained that such a focus could be reached through "inquiry-based instruction" (Christy, interview I). As an example for inquiry-based instruction, she mentioned that basing a unit about perimeter and area on the question of how many worms could fit into the new classroom worm bin could be an example of making learning relevant and giving students ownership over their learning. Christy explained,

Even though we weren't necessarily talking about area and perimeter right then, it was relevant and the kids got really engaged in that. We took it out and measured everything and looked inside and we estimated and looked at various strategies. We made it really relevant to them, and saw that this is a reason that you would want to have that. The kids were willing to do it. We also showed them various ways that they could come up with the same answer. (Christy, interview I) 
Christy strongly believed that students first need to understand foundational concept(s) before they could learn an algorithm to solve a problem. Referring to her initial field practicum, she explained that she had to "unpound" (Christy, interview II) algorithms from the students. From the entire conversation about the importance of concept understanding, I assume that Christy used "unpound" in the sense of trying to help the students to understand the concepts and not just blindly use a procedure they had learned, often at home. For instance, she referred to a student who was not able to show and communicate his work because through memorization and drill his father had "pounded " an addition algorithm into him. Christy explained that she had to "unpound" the algorithm because the student needed to understand the concepts to move on to the next level of understanding

However, Christy also argued that knowing the "facts" and practicing "skills" is important to all students (Christy, interview II). When Christy and I discussed what she was able to observe in her field placement, she mentioned that she was sometimes under the impression that the students she observed did not have enough opportunities to practice their math skills. Christy gave an example and explained that "kids lost a lot of their computation strategies over the summer and then not having any refresher on that at the beginning of the year," the students "really started to lose a lot of their math facts and how to do double digit additions, subtractions and things like that" (Christy, interview II). Christy noted that she was very impressed by the computer program that her cooperating teacher developed for the students to practice their math skills. Affirming the way her cooperating teacher provided additional options for practice, Christy further explained, 
"every once in a while she'll hand out a math worksheet with math problems on it" (Christy, interview II). However, unlike some parents who constantly complained that there was not enough drill and practice, Christy prefered to focus on content integration and mathematical concept understanding in combination with the practice of skills when necessary. Christy explained that "starting where [the students] are and building on that, instead of pushing them directly into whatever you need to accomplish that day" is one way of creating opportunities (Christy, interview I).

Christy also explained that she believed that lacking foundational skills is often a problem because students are missing "a chunk of something that they need to build on" (Christy, interview I). Because of this view of mathematics as sequentially structured, to prepare teaching a class Christy would like to "know what [the students] have been taught previously, how they have been taught, how they like being taught" (Christy, interview I). Christy stated that she wanted "to meet [the students] where they need to be met" (Christy, interview I). Doing so entails pushing the students, but not pushing them "further than they can be pushed" so that they could still succeed (Christy, interview I). At the same time, Christy explained, the teaching should have some redundancy, but needs to avoid "teaching them something that they already know" (Christy, interview I).

Christy mentioned that whenever a teacher did not try to help her understand the big ideas and mathematical concepts, she struggled. She, therefore, considers it important for every teacher "to pay close attention to knowing students and knowing what they already have and can build on and knowing their strengths, what is going to be the best way for them to learn" (Christy, interview I). Christy believed that because it was hard 
for her to learn mathematics, she was now able build the necessary teacher-student relationships. For Christy, building on these relationships and knowing the students as people was the foundation for a teacher to help the students. Christy explained that when she saw a student struggle, she was "not really thinking so much about this kid didn't get taught the right strategy when he was in first grade so he can't do that" (Christy, interview I). As noted before, she argued that teachers should pay attention to "what makes a person less able to do math" (Christy, interview I). Christy explained that this knowledge could be helpful for the teacher to create learning opportunities for students. In contrast to what Christy said earlier, that she would focus on the students' strengths, she now seemed to offer deficit thinking. Looking from both angles, Christy seemed to see students' strengths and challenges, which could be seen as an example for Christy seeing the whole child.

When I raised the topic of differentiated instruction, Christy indicated that she considered differentiated instruction as a way to effectively create learning opportunities and help all students to understand math. Christy explained that she would differentiate her teaching based on either students' "performance on math assessments or the types of ways that I know that they learn best" (Christy, interview I). In other words, she would provide different learning opportunities, such as hand-on activities and manipulative materials to address different learning styles, as well as grouping students based on their performance levels. In groups, the students would be able to learn from and challenge each other. "This pushes them, so [that they can] move on in their learning" (Christy, focus group). In the first interview, Christy explained that grouping has to be very 
intentional because "high achievers" do not benefit much from working with "students who struggle" because the high achievers might just show the low achievers how to do things instead of explaining how things work. Consequently the "low achiever" would not benefit either. Grouping by interests was the only other way to differentiate that Christy mentioned. Doing so might be challenging for a teacher, Christy stated, because the teacher needs to know the students very well to be able to create such groups.

Overall, Christy saw one of her main goals in teaching mathematics to be giving the students "lots of opportunities" so that they could "actually succeed in the classroom" (Christy, interview I). Christy assumed that providing opportunities to choose different ways to learn takes "the pressure off" learning math (Christy, interview I). Christy further noted that support from teachers and parents also help the students to succeed. She explained that "it is really important, and being on top of your students and knowing when they are falling behind so that they don't get left and see that it is going to be impossible for them to catch up" (Christy, interview I). Furthermore, Christy said that no matter how much the students get out of the teacher's support, the teacher has to structure teaching in a way that students learn to take ownership of their own learning. Without giving any examples, Christy explained that some ways of reaching this goal would include instances when the students could work in collaborative groups and learn from each other or when they could "do... something with their hands" (Christy, interview I).

Teaching mathematics with culturally diverse students. Christy's framework for teaching mathematics was based on conceptual understanding, building relationship 
in the classroom and focusing on the learners and their background. Regarding teaching mathematics with culturally diverse students, Christy stated,

The key there is that you don't need to teach different content but the way that you teach it needs to be adapted - not even adapted but you need to be thoughtful and intentional about it. It is not like somebody who comes from China needs to get a whole different content, necessarily, but you just need to make sure that you are making that relevant to them. (Christy, focus group)

Christy explained that a student who was originally from China needed to learn all about the U.S. currency because that was what they will use. She noted that knowing the students' background and building relationships between teacher and students was key to making teaching relevant. Christy stated that it might be "hard to figure out" (Christy, interview II) how to make math relevant for her students from culturally diverse backgrounds. She explained that, because it seemed impossible to find something that everybody likes, she thought it made sense to tie math teaching to more general topics related to the neighborhood and the age group in general. She explained that these topics were too "neighborhood specific" (Christy, interview II) to give an example. Christy further noted that in addition to making math relevant, it is also important to give students opportunities to develop their mathematical understanding and skills. Generally speaking, Christy would not employ different teaching strategies specially geared toward culturally diverse students. Because of the great diversity Christy seemed to perceive it as challenging to connect to the students and to build relationships. She seemed to see drawing on group identities as one way to teach mathematics with culturally diverse children. 
Christy believed that knowing the cultural background of the students provides a "lesson to lesson opportunity" to integrate the students' culture (Christy, interview II). She asserted that "because [students] are not necessarily bringing [their culture] to the table, it is not something that [I have] reached into a whole lot" (Christy, interview II). She stated, "I don't necessarily think that I need to really be intentional with [culture] for every single lesson" (Christy, interview II). Having made this statement, Christy explained that to make the necessary connection to students it is always important to know the background of English language learners and students who have lived outside the U.S. for most of their lives. Overall, to make the necessary connections between the students and mathematics, Christy thought it is important "to know how the students feel about themselves as mathematicians, if they like it, [and] if they think they are good at it" (Christy, interview I). She explained that knowing the students' perception of mathematics in combination with knowing what other subjects they liked and felt good about was important to be able to tie her math teaching to the students. Concluding from her own changing relationship with mathematics, Christy believed that, especially in lower grades, students did not see mathematics as relevant to them. Therefore it would be more challenging for the teacher to make the connection because the students were often less motivated.

Following the idea that culturally diverse students have different learning needs, Christy was concerned that she did not have great strategies for working with English language learners. According to Christy, one strategy to support ELL students would be giving them the opportunity to "say...out loud [what] they think and to be able to hear it 
multiple times would be really helpful in cementing those thoughts" (Christy, interview II). She explained that "this could be [useful] especially for kids who may be struggling because they may be coming from [a different country] not having been at school for a while" (Christy, interview II). Christy also assumed that this strategy might be useful for students who were "coming from a different way of teaching math" (Christy, interview II).

During the focus group as well as the second interview, Christy noted that she thought culturally responsive/relevant pedagogy (Christy noted that she thinks these terms were basically the same) could be only implemented when there was an opportunity. She argued that culturally relevant teaching "sometimes needs to be an extension rather than the core thing that is taught on any given day because it is too complex for everyday teaching" (Christy, focus group). In addition, Christy explained that students needed to focus on what was important in the U.S., but the teacher should never "waste" an opportunity to let students add something from their culture (e.g., the student from China who brought Chinese Yen to class). In addition, Christy explained that she assumed that culturally responsive teachers would provide English language learners the possibility "to say [their thoughts] out loud" (Christy, interview II). The teacher and other students would repeat what they say so that ELLs "are able to hear it multiple times." Christy argued that this "would be really helpful in cementing those thoughts" (Christy, interview II). She further noted that this way of teaching would benefit "especially kids who may be struggling" (Christy, interview) because they were not familiar with the concepts and strategies of teaching mathematics in this country. 


\section{Researcher's Discussion: The Relationship Between Christy's Images of Mathematics, Students, Culture, and Teaching}

Christy did not always have a positive perception of mathematics. In school she saw mathematics as challenging and scary and developed math anxieties and strong aversions against mathematics. This image changed when she developed a better understanding of mathematical concepts. This understanding, acquired in college, helped her to embrace the complexity of mathematical concepts and to bring order to the vast number of facts, rules and procedures. As a result, Christy, at the time of this research, now loved math and was eager to show children that mathematics is not scary. Because of her own experience, Christy believed that mathematics should be taught with a focus on concepts and patterns. Because of her negative experience, Christy rejected a strictly procedural approach to mathematics, but placed some merit on practicing skills and learning facts.

Christy saw mathematics as interrelated to specific disciplines and practical applications. This flexibility made mathematics, in Christy's eyes, applicable to all reallife situations. Consequently, she advocated for teaching mathematics as context- and inquiry-based, with emphasis on the understanding of patterns and relationships between mathematical concepts to construct an understanding of the world. I would see such an approach as conceptual, and therefore categorized Christy's images of mathematics as conceptual. Accordingly, Christy believed that problem-solving should be approached through inquiry. Even with the belief that there were some people better suited to do mathematics than others, she argued that everybody could learn mathematics. 
Although Christy seemed to have a clear understanding of diversity and culture, she struggled to connect these concepts to the mathematics classroom. She defined every classroom as culturally diverse because every student brings a different experience to the table. In addition, she seemed to be aware that students belong to groups (e.g., race, ethnic, socioeconomic status), which shape their experience and, therefore, influence the way they learn and interact in the classroom. Christy believed that culturally diverse students basically need to learn the same things as everybody else. She further seemed to believe that a focus on concepts and situating mathematics into real-life contexts is inclusive to all learners. Therefore, a teacher only needs to be aware of the struggles a culturally diverse student might have, but there is no need to make significant changes to pedagogy. Finally, because of the flexibility of mathematics, Christy assumed that the integration of multicultural content helps students relate to mathematics. Christy believed that culturally responsive teaching could be used to provide such opportunities, but is not necessary as a regular approach. Overall, it was important to Christy to build relationships and create a welcoming learning environment that enables all students to learn.

Christy's student-centered and inquiry-based teaching approach opened possibilities for culturally responsive teaching because it makes it possible to focus on the individual learning needs of the students and on their cultural backgrounds. Her perception of teaching mathematics already led into the direction of culturally responsive teaching. However, she seemed to be unaware that she appeared, at least to me, to be open-minded to culturally responsive teaching. I think culturally responsive teaching 
could fit very easily into her framework of teaching. Her comment that culturally responsive teaching might be difficult to sustain indicated that she might not have had a clear conception of culturally response teaching, which made me wonder how her awareness of culturally responsive teaching could be raised. A first step for Christy toward culturally responsive teaching could have been participating in this research project. She stated, "I think it is helpful to be able to articulate those sorts of things, and it is useful to have somebody make you really think through your answers and make sure you mean what you say" (Christy, interview II).

\section{Introducing Alison}

Alison was a non-White female in her late 20s at the time of her participation in the research study. She "grew up in a very white-bread community" (Alison, interview II) in a mid-sized city in the Northwest. Although both of her parents were White, Alison did not identify as White. She explained that in elementary school she used to be the only non-White child in her neighborhood, which did not give her room to explore her own racial identity. Because her mother and grandmother were teachers, Alison "really wanted to be a teacher my whole life until I got to middle school" (Alison, interview II). She explained that she decided in middle school that she "didn't like education" (Alison, interview II) any longer. Alison noted that education felt "painful" and that she felt "not smart enough" and she was "tired of working for school" (Alison, interview II). Consequently, after high school Alison worked in retail and fast food service. After six years, Alison decided to go back to school to become a teacher and enrolled in a large urban university. She explained that being at this university was the first time she was 
really exposed to diversity. Alison stated that "diversity is really exciting and [so is] the fact that White isn't the majority" because for her "schooling was very White-influenced" (Alison, interview II). For her final project for her Bachelor's degree in social sciences, Alison worked with refugees. In addition to her elementary teaching license she was also working toward a middle school teaching license at the time of this research. Therefore, Alison had taken a series of undergraduate middle school mathematics content courses prior to the teacher licensure program.

In her math autobiography, Alison described her relationship with math as something she had worked on for her entire academic career. She elaborated:

When I was in elementary school I have very limited memory of what it felt like to learn math and what type of activities I took part in. I would say that it was around middle school that I began to really struggle with math. I think the subject matter was too advanced for my cognitive stage at that time in my life and I also believe that teachers who instructed me in middle school considered me a "difficult student". By high school I considered math my most detested subject and was thrilled just to get a passing grade in algebra. (Alison, math autobiography)

Alison described that when she was enrolled in Job Corps and a local community college her experience with math was very negative at first, but that it was also the time when her "love of math" (Alison, math autobiography) started. Alison explained that for the first time she had a teacher who helped her understand the concepts behind what she was supposed to do. After graduating with an Associate degree from the local community college, Alison decided that she would like to "show other students that math isn't scary" and that it is "actually really enjoyable and fun" (Alison, math autobiography). 


\section{Alison's Image of Mathematics}

Alison believed that mathematics can explain the world and create meaning and understanding. The first three words that came to her mind when she heard the term mathematics were "understanding, rules, and the real world" (Alison, interview I). She clarified that she thinks the main goal of "mathematics in the education world is its main goal would be to create understanding, understanding of the rules or the ways in which math work in the real world" (Alison, interview I). She also indicated that, on the one hand, learners need to build a strong base of facts and processes to understand and do mathematics. On the other hand, Alison believed that one has to understand concepts first before "mathematical processes" (e.g., Alison, math auto biography) can be used successfully. She added that it is important for students to "understand mathematical concepts that are required to succeed, especially in scientific occupations" (Alison, interview I).

In addition, Alison's responses on the questionnaire also indicated that she believed that understanding of mathematical concepts is of highly important and that one cannot just follow procedures. She "strongly agrees" that "you need to understand each idea in mathematics before you can use it" (Alison, questionnaire). She also "strongly agrees" that mathematics entails memorizing a lot of facts and procedures (Alison, questionnaire). Moreover Alison also indicated on the questionnaire that she did not believe that mathematics is a universal language. Overall, Alison's responses seemed to indicate that she believed that mathematics is conceptual in nature, but mathematics is also based on procedural elements, such as facts, rules and algorithms. 
Alison seems to see a conceptual dimension of mathematics as a way to bring order and structure, in the meaning of rules. The order and rules can help to understand and bring answers to relevant, real-world problems. Alison described mathematics as "creating an understanding of variables and measurements and numbers, the things that we use numbers for in our culture, [and] creating a relationship with those things" (Alison, interview I). Alison said an example of numbers in the real world is "making predictions and stuff" such as companies using calculus and statistics "to look at trends of the past to control their decisions for the future" (Alison, interview I).

Furthermore, Alison also saw an abstract dimension (as in focused on numbers and problems not concerned with real-life problems) in mathematics, which provides a foundation for mathematical concepts. Alison thought mathematicians "try to find mathematical rules or formulas that...can be manipulated to prove or disprove proofs in the mathematical world" (Alison, interview I). That Alison saw mathematics as both an abstract tool as well as a practical tool to understand the world. On the one hand, she explained how excited she was in the history of mathematics course, when she saw a video clip of some "high level of mathematicians" (Alison, interview I) discussing the Pythagorean Theorem. On the other hand, she also explained that elementary students use mathematics on a daily basis to "estimate time," in "dealing with money," or for "spatial visualization stuff [such as] how to make it through a door" while carrying a lot of stuff (Alison, interview I). Video games, sports, and cooking were also examples that Alison gave to indicate the high relevance of mathematics in regular life. Despite the abstract dimension of mathematics, Alison indicated that she thought mathematics is accessible 
for all students because it can be learned and understood. However, whether mathematics is more abstract or more practical depends on the developmental state of the people who use mathematics to solve problems. Alison noted that elementary school mathematics should not be as "abstract" as middle school mathematics because students need to be "in [a] cognitive stage to actually understand what's going on" (Alison, interview I). Connecting mathematics to the developmental stage of students seemed to indicate that Alison took the human dimension of mathematics into account. In summary, in Alison's view, the abstract dimension and the practical dimension of mathematics are interdependent. The abstract dimension of mathematics provides order, structure and procedures as a basis for creative, practical problem solving.

Alison also considered mathematics to be the most "difficult subject" for most people. She believed that

it is almost like it is accepted in our culture - not really culture but just accepted that people feel insecure about their mathematical skills, and it is okay to not be good at math and to admit that to people. (Alison, interview I).

However, in the first interview and the questionnaire, Alison mentioned that she believed that there is no special talent required to be good at math and that everybody can learn math.

In her image of mathematics, Alison emphasized that mathematics is a tool to solve practical problems. To solve mathematical problems one needs to understand mathematical concepts in order use the rules and procedures correctly. She further described the mathematical problem solving process as "asking clarifying questions, applying...previous knowledge to the task at hand, [and] making connections between 
previous knowledge and their current task and maybe what they will do in the future" (Alison, interview I) and noted that knowing "real life examples," "rules," and “mathematical processes" are key to understanding mathematics and solving problems (Alison, math autobiography). She said that in a classroom, the problem solving process takes place when students "explain their steps [and] explain why they did what they did while solving the problem" (Alison, interview I). Although this statement was about teaching, I believe it implies that Alison perceived mathematics to be a conceptual tool that needs to be understood rather than just used. Although Alison considered the abstract component of mathematics to be important, she emphasized that the understanding of mathematical concepts is key for practical problem solving.

For Alison, the practical dimension of creative problem solving provided a way to approach mathematics. She explained that "even though there is only one answer for most problems, there are multiple ways to get there" (Alison, math autobiography). It was, therefore, not surprising that Alison assumed that "the way they do math in a different culture would be different than the way we do it here" (Alison, interview I). She explained that she did not have "any expertise" (Alison, interview I), but remembered a conversation she had with a Vietnamese friend in which the friend mentioned that in Vietnam the focus in learning mathematics is on working hard and doing a lot of homework, whereas in the U.S. the focus is on understanding the concepts. Alison also gave another example of how mathematics is shaped by culture, explaining that if mathematics were influenced "predominantly [by an] African American culture" and not the "predominantly white culture," then it would be "the other side of the coin - there 
wouldn't be that much money and stuff like that" (Alison, interview II). Alison

concluded that different cultural backgrounds have different ways of doing math.

\begin{abstract}
Alison's Image of Students
In this section I first describe how Alison perceived students in general and

relative to mathematics. Then I turn to her perceptions of culture, diversity, and culturally

diverse students.
\end{abstract}

To get an impression of how Alison perceived students in the math classroom, I

asked her how she would describe a student who was "good at math" and a student who

was "not good at math." To the describe a good student Alison stated,

they would be able to explain their steps, explain why they did what they did while solving the problem. I think they would-they could get an answer but if it is not right, they would still be good mathematicians if they looked over their work and find the mistake. It is not like they have to have the right answer to be a good math student. Yes, so they would be double checking their work, asking clarifying questions, applying their previous knowledge to the task at hand, making connections between previous knowledge and their current task and maybe what they will do in the future. (Alison, interview I)

What Allison described as a good student was a student who understands the mathematical concepts and knows how to apply those concepts to the task at hand. In addition, students need to see errors and correct them when they occur. Allison seemed to be not as strongly focused on getting the right answer, but more focused on understanding why an answer would be right or wrong.

Interestingly, when I asked Alison how she would describe a student who was "not good at math" she replied that such a student would show "a negative attitude, [and] refusal to participate" (Alison, interview I). She elaborated that 
it is not that they are not good at math but it is a bad attitude toward math. .... I guess somebody who just doesn't care, somebody who keeps getting the wrong answer and after you work with them, and they don't care, I guess. They don't take the time to understand what they are doing and change their errors. (Alison, interview I).

Alison, who believed that everybody could learn mathematics, seemed to see a student who is not doing well as a student who is not motivated and shows no interest in the task at hand. Therefore, she would try to find a way to motivate the student. In all, she focused on students' understanding of and engagement with mathematical concepts and processes.

\section{How Alison Perceived Diversity and Culture}

Alison stated that diversity is when people "look and act differently" (Alison, interview II) than other people. Throughout this research, Alison used the terms cultural diversity and diversity interchangeably. When I asked Alison what she meant when she talked about diversity, she stated that "it could mean race or it could also mean varied socioeconomic background, religious [beliefs], every kind of different culture there could be" (Alison, focus group). Based on her definition of diversity, Alison considered each classroom diverse. She stated that students

could have different religions at home. They could have a different family life. Some could be poor, some rich, some middle class. Some could have moved all over the place, some could speak different languages. Even their families could have moved from any place. (Alison, focus group)

Coming from a "very white-bread community," Alison stated that she "didn't really get educated" about diversity (Alison, focus group). She explained that because of her exposure to diversity at the university, she started to rethink her "pretty ingrained ideas of race and [how she] fits in" (Alison, focus group). Alison was very enthusiastic 
about being in a culturally diverse environment. She said that the diversity at TSU and in her school placement is "awesome" (Alison, interview II).

Furthermore, Alison explained that cultural diversity "would be more so than skin color" (Alison, interview II). She stated that cultural diversity is about "being different in an environment" (Alison, interview II) that is often dominated by one culture. Alison used herself as an example and explained, "I was raised in a very White culture so there weren't differences between me and my peers because we grew up in the same culture" (Alison, interview II). Alison continued to explain that "different cultures would mean different backgrounds, different history, different language, where you come from, where you were born, and traditions in your family" (Alison, interview II)

When asked to speak more about culture in particular, Alison said that "culture is the rituals and the way people are in a certain community" as well as what is "valued" in this community (Alison, interview II). Although, as mentioned earlier, she spoke about culture being beyond skin color, she also linked race and culture in the second interview, when she asserted that when "we are talking about culture and all the time I think about race as being the big cultural difference" (Alison, interview II). She elaborated that she "can see the other people are from different cultures, but just by looking at them [she] wouldn't be able to tell" (Alison, interview I) what their individual needs are and how they would do things. For example, trying to say something about diversity in a classroom, Alison replied,

Let's see, I guess it would be-I don't know-I guess it would be race or background. I'm not too sure where students were born, if they were born in the 
same house they live in now, if they came from a different state or different city, even, or a different country. (Alison, interview I)

Although Alison linked race, culture, and students, she did not have a clear understanding of how race shapes cultural identity. Alison stated that she was still struggling to understand the connection between her own race and her own cultural identity. She stated that participating in this research and the teacher education program has helped her reflect on her own identity.

How Alison saw culturally diverse students. According to Alison, the students' gender, culture, and race influence how they connect to the subject and what interests them. For example, Alison said that she, being female, was less interested in football than males were. She further explained that African Americans perceive the world differently than White Americans. Alison elaborated that, for example, the use of money is one thing that all cultures have in common. However, she argued that students perceive money differently, explaining that this different perception depends not only on their socioeconomic status, but also on the students' race. For example, when one of her Somali students read that African Americans made statistically less money than White Americans, he was very upset. She believed that the student's resulting emotions had blocked him from learning and stated that this was the reason why race mattered when looking at the student as a learner.

Alison noted that students' success depends on the "norms in our culture" because the students "need to know them if they are going to be successful" (e.g., "being on time, money, schooling, education, jobs") (Alison, interview II). From her own experience, Alison concluded that 
if you came from a white-bread education system like me-they had the money, they had all the resources, but at the same [time] the culture of the community was so horrible, I hated it and didn't want to be a part of it, so therefore I didn't succeed at math. (Alison, interview II)

Furthermore, Alison stated, attending a school in a white-bread community "made me culturally diverse because I was a different person and that meant it affected my experience negatively" (Alison, interview II).

\section{Alison's Perception of Teaching Mathematics}

Alison had a "deep interest to teach mathematical ideas to young students in a way that will make them feel like math is a subject that they are capable of learning" (Alison, math autobiography). She explained that her notion of teaching came from her own "deep interest and curiosity in the way mathematics works in the real world around us" (Alison, math autobiography). For her, teaching mathematics in elementary schools entailed teaching "addition, subtraction, multiplication and division, and problem solving skills" (Alison, interview I). She added that estimation (e.g., estimation in measurement, such as estimating the area and perimeter of a rectangle) would be "really helpful as well" (Alison, interview I). She also added that the students have to "learn rules" and "how numbers work" (Alison, interview I). Most importantly, the students "learn about life" (Alison, interview I). Some examples Alison provided were "how to carpet your floor, how to share things....how to win games, probabilities, how to make predictions, how to balance your checkbook, pay your bills...how to exercise enough, etc." (Alison, interview I).

Overall, the focus of a math lesson should be more on understanding the concepts and less on practicing procedures. Focusing more on the concepts could be accomplished 
by providing different activities and different opportunities for students to engage with each other. In practice, students could be given choices about what to learn and opportunities to collaborate in groups. Furthermore, Alison believed that teaching math in elementary school relies on daily routines and clearly set and communicated expectations about the lesson and learning in the classroom math environment.

Alison paid attention to students as individual learners and their personal development. She explained that because of the children's cognitive stage manipulatives are often used for teaching concepts in elementary schools. Alison noted that "it is important for students to understand the learning process" (Alison, interview I), so that they can make a connection to their personal interests. According to Alison, good math teachers "keep the dialogue going with the students," and are "not just telling them how to do it and having them do it on their own, but to communicate about what they are learning and how that is understood in their own minds because it is going to be different with other students" (Alison, interview I). Furthermore, teachers should communicate to the students "what they are learning" (Alison, interview I). Alison explained that this would mean that a teacher would not begin a math lesson saying. "It is time for math, we just have to do it" (Alison, interview I). Moreover, teachers should have a "deep understanding of why we teach math and why math is important" (Alison, interview I), stating that when a student asks why they need to learn something, the teacher should always explain why the topic they are working on is important. Alison continued that ideally there is immediate "real life" relevance, but the material is still just preparing the students to understand the next concept (Alison, interview II). Alison mentioned that 
math teachers need to have a "good attitude toward math to be able to see [its] importance in the world" (Alison, interview I) and to be able to convey that to their students.

Teaching mathematics with culturally diverse students. Alison believed that math learning should be meaningful. She considered keeping the students motivated all the time to be the most challenging part of teaching mathematics, especially in a culturally diverse classroom. In consequence, she would try to connect her teaching to the students and their backgrounds. Alison would try to assess what the students care about and who the students are as learners. The students' "previous knowledge" (Alison, interview I) and their "ability level[s]" (Alison, interview I) are as important as what they like to do in their spare time, whether they are involved in school activities or things like that, and maybe their parents' education level or maybe what their parents do for work or what they want to do, what their goals are for their schooling and occupations. (Alison, interview I)

Alison noted that, for example, to prepare a unit on measurement a teacher should ask questions like, "Do they know what a ruler is?" (Alison, interview I). In her view on teaching mathematics Alison not only seemed to pay attention to the learning needs of a student (e.g., preexisting knowledge, learning styles, ability levels), but she also paid attention to a student's background.

Alison believed that the best way to teach diverse students is making math instruction inclusive for all students. She saw differentiation and scaffolding as ways to reach all students in the classroom. She explained that, in her view, differentiation "is actually tailoring the assignment to a specific skill level" of the student, whereas scaffolding is "meeting the students where they are and giving them pieces to arrive at 
the same place" (Alison, interview I). Differentiation and scaffolding would also "make sure that, not necessarily the end goal, but that each student can be thinking about math in their own way and in an advancing way" (Alison, interview I). The students might each be at different skill levels so that they both would get new information. Alison explained

So maybe if we were working with fractions, like divide $43 / 4$ by $1 / 8$ or something and then for her it would be divide 1 by half or something. It would be the same idea but not as difficult numbers. We would be giving her the same opportunity. It is mostly-is that scaffolding, yeah, meeting her where she is and being able to create understanding for her just like we would create understanding for him. (Alison, interview I)

Recall that Alison included language as a part of diversity and also linked it to culture.

Alison believed that students from different linguistic backgrounds have different learning needs. She explained that a student who just moved from a foreign country to the U.S. might not have the necessary vocabulary to learn fractions. Alison elaborated that such a "language thing" (Alison, interview II) requires hard work from the student to understand mathematical concepts. Moreover, a teacher could help students overcome these language barriers by "acknowledging them and making accommodations" (Alison, interview II). For example, the teacher could "include visuals" to make the content more accessible for "students who struggle" (Alison, interview II) with the language.

Differentiation and scaffolding were other ways for Alison to respond to the needs of English language learners. To clarify how she would respond to an English language learner in her classroom, she said that "somebody who doesn't speak English very well" might not "have the same exact task" as another student who is more proficient in English (Alison, interview II). Both students would "have a task that is equally challenging for them" (Alison, interview II). 
For Alison, culturally relevant math teaching was "making every culture relevant, but that would include American culture, too" (Alison, interview II). She further stated that culturally relevant teaching is "making the concepts available to connect to any culture" (Alison, interview II). For example, "If you are talking about circles, talk about circles in Europe and then circles in India or something, not just circles in America" (Alison, interview II). She also referred to the student from Somalia again and explained that the lesson we watched in the focus group where the teacher used money to teach addition of decimals, "would be culturally relevant" because the student now "is in our culture" and "we do have to use money" (Alison, interview II). Alison further explained that she might "bring in different kinds of currency" (Alison, interview II). She mentioned that she would explain that there are "different kinds of currency in different countries" (Alison, interview II). Alison said that she would point out the importance of knowing other currencies, but that the dollar "is the kind of money that we use in America" (Alison, interview II). Therefore, she explained, it is important for all her students to "learn how to count the money and how to pay with it" (Alison, interview II). Sparked by participation in this research process and by her own search for her identity, Alison showed great interest in culturally responsive teaching. She stated that it "would almost be individualizing every curriculum to [the student's] culture. That is kind of cool, so you are culturally responsive to each student" (Alison, interview II). She explained that to make the lesson we watched in the focus group "culturally responsive to each student, then it would definitely encompass all the currencies" (Alison, interview II). She further stated that doing so is "like you are responding to something, not 
teaching" (Alison, interview II). Alison concluded her answer by stating that she likes the idea of culturally responsive teaching because it is "individualized" to the students (Alison, interview II). However, Alison was concerned that culturally responsive teaching is "like only teaching them things according to their culture, so that is almost like racial profiling" (Alison, interview II). Alison saw one strength of culturally responsive teaching as the "personal connection to the material" (Alison, interview II) the student would have and seeing that what they learn "affects their lives in a very specific way, versus [in] a generic way" (Alison, interview II).

When I asked Alison how culturally responsive teaching would take place in her classroom, she elaborated,

African American students in my math class only respond to math that has to do with sports, so then I would accommodate my instruction to encompass a lot of sports stuff and then they would fail to see-that could shove them in that direction by me trying to make is culturally relevant (Alison, interview II).

She continued to explain that to make math teaching culturally responsive she would in addition "try to teach them about the doctor professions or other professions that involve math" (Alison, interview II). Alison finally stated that the concept of culturally responsive math teaching is new to her and that she would like to learn more about it.

\section{The Relationship Between Alison's Image of Mathematics, Students, Culture and Teaching}

In this section I first summarize Alison's image of mathematics, culturally diverse students, and how she saw teaching. I then explain how her perceptions of the subject and the learner shaped her perception of teaching. 
Alison had a positive attitude toward mathematics, meaning that she considered mathematics as a practical problem-solving tool for problems of our daily life and that mathematics is accessible for everybody. She believed that how people do mathematics depends on their culture and experience. According to Alison, everybody can learn how to do math. Although Alison believed that concept understanding on the level of the students' developmental stage is most important, she also believed that there is some merit in routines and practicing processes. Alison connected her positive image of mathematics and her perception of the way mathematics should be taught to her own personal experiences as a learner. She explained that she did not like mathematics until college, when, in the Mathematics for Elementary course series, a teacher helped her to understand the concepts.

Alison acknowledged that mathematics entails conceptual as well as procedural dimensions. She seemed to believe that both dimensions were dependent upon each other. Thus, she also seemed to believe that understanding of mathematical concepts could help to make sense of rules, facts and procedures. I would therefore categorize her image of mathematics a conceptual. Recall that I previously defined a conceptual image of mathematics as one that is inquiry-based, with emphasis on the understanding of patterns and relationships between mathematical concepts in order to construct an understanding of the world.

When teaching mathematics, Alison reported that she would always try to differentiate and scaffold to take the students from where they are and give them tasks that lead the students to success. Because Alison defined diversity as being different from 
the dominant culture, she considered it important to incorporate each student's background into her teaching. She believed that a teacher has to make it meaningful to the students and build on students' previous knowledge and understanding of mathematical concepts, as well as connect mathematics to the students' cultural background. She explained that culturally relevant teaching is one way to affirm diversity in the classroom, but it bears the risk of "racial profiling." Yet, culturally responsive teaching sounded to Alison like a concept that was worth exploring because it focuses on all cultures.

On the one hand, the language Alison used during this research and the way she described teaching and learning indicates the mathematics related course work had some influence on her perception of teaching. On the other hand, it appeared as if Alison understood that diversity and culture relate to teaching and learning in the classroom.

\section{Looking Across Cases: Images of Mathematics and Students and the Perception of Teaching}

In this section I compare and contrast the participants' images of mathematics, their views of students, and their perceptions of teaching mathematics to culturally diverse students. For the data analysis I triangulated the data from all instruments of each participant to develop each participant's profile, which I have presented above. These profiles were the foundation for this cross-case analysis. If necessary or appropriate, I provide additional evidence from the data. Even though the themes presented appear across all the data, I refer back to particular examples when it serves to improve the readability of this cross-case analysis. 
First, I compare and contrast the images of mathematics held by the participants around the emergent themes of attitudes and feelings toward mathematics, images of the nature of mathematics (what math is all about), and key aspects of mathematics (e.g., problem solving, procedural vs. conceptual). In the second section, I compare and contrast the participants' images of culturally diverse students. I distinguish between how each candidate saw culture and diversity, as well as how each candidate saw students as learners in contrast to students as people. While focusing on the participants' perceptions of the student as a person, I also compare and contrast the participants' images of culturally diverse students in particular. In the third part of this cross-case analysis, I focus on the participants' perceptions of teaching mathematics with culturally diverse students in relation to the following themes: the purpose of teaching mathematics and curriculum and instruction, with its subthemes of teaching and learning, differentiation, and culturally responsive teaching. Finally, I synthesize the relationship between the candidates' images of mathematics, their images of culturally diverse students, and their perceptions of teaching mathematics to culturally diverse students.

\section{Images of Mathematics}

In this section I compare and contrast the images of mathematics held by the participants. Looking at participants' images of mathematics was important because I was interested in the way that teachers' images of math may have influenced their teaching practice, including whether or not they integrated culturally responsive teaching. To lead into this section, I first focus on the participants' attitudes about mathematics and how their attitudes changed during their education. Next, I analyze what the participants mean 
when they said math is a "difficult and hard subject," followed by an analysis of what the participants thought math is. I talk about how the candidates saw the relationship of concepts to procedures as a key dimension of mathematics and finally compare and contrast the participants' notions of different approaches to problem solving. This "images of mathematics section" provides basic information on the participants' perception of mathematics and lays a framework for their perception of teaching.

Changing attitudes. One of the research sub-questions in this study looked at the images of mathematics the teacher candidates held. Although all candidates described mathematics as hard and complex, they also saw it as learnable and even fun. Alison and Christy stated that mathematics was "fun" (Christy, math autobiography) and Alison identified math as "really enjoyable and fun" (Alison, math autobiography). Frank, Christy, and Alison mentioned that they liked mathematics. In particular, Frank enjoyed doing mathematics when he posed problems for himself to figure out. In school he felt positive about his accomplishments as long he had enough knowledge to pass a standardized test, but temporally struggled the first time he had to use his knowledge to solve problems. In general, all the candidates seemed to hold a positive attitude toward math. To reiterate, by positive attitude, I am referring to seeing mathematics as an approachable subject that is concerned with practical problems of daily life.

At the same time, all but Emily's math autobiographies showed that the participants' perceptions of mathematics had changed over time. A text analysis of the math autobiography and the interview protocols of the first interview showed that the participants enjoyed mathematics in elementary school, but three of them then started to 
"struggle" (Frank, math autobiography) when math became more complex in middle school. Alison even "hated" math (Alison, interview II), and Christy stated, "by junior high I had developed a dislike of math and a lack of self-confidence, and by high school I had decided I was done with it" (Christy, interview I). Christy also explained that she was "horrified" (Christy, math autobiography) when she found that she later need math in her job.

Confidence with, and understanding of, mathematics increased in the context of the prerequisite courses for elementary teachers, according to the participating teacher candidates. Christy explained that her aversion to math changed when she started to understand mathematical concepts in college during the mathematics for elementary course series. Frank, too, explained that he continued to "miserably fail" mathematics in college until he was taught mathematics in the mathematics for elementary teachers series, with what he called a "constructivist approach" (Frank, math autobiography). Although Emily's view of mathematics had apparently been consistent since elementary school, she too explained that the math for elementary teacher series helped her to become more confident using a variety of complex approaches to solve mathematical problems. Although all participants felt prepared to learn how to teach mathematics on an elementary level after completing the required prerequisite course series, toward the end of the required teacher licensure methods course, Christy was no longer sure whether she would be prepared to teach mathematics.

Mathematics is a difficult and hard subject. One aspect of the teacher candidates' images regards their attitudes and feelings toward mathematics. As I 
explained in the individual profiles, for different reasons, all participants agreed that mathematics is a difficult and hard subject. The participants perceived math as hard because of its complexity and/or because of the way math was taught and situated in realworld contexts, or not.

Emily and Frank perceived mathematics as a difficult subject because it is very complex. Frank used words such "challenging" and "struggle" to describe that mathematics is not an easy subject (e.g., Frank, interview I). Emily further explained that "mathematics is an extremely important subject" (Emily, math autobiography) but it has "so many little rules... and it is hard to keep them all straight" (Emily, interview I). Because of the sequenced structure and the rules, Emily believed that "math can be as simple as you want it and it can be as hard as you want it" (Emily, interview I). She explained that how hard math is depends on how it is presented. Emily added that you "have to be very orderly when you present math" (Emily, interview I), presumably because of its nature.

Alison, in contrast, believed that mathematics is only hard when it is disconnected from everyday or professional applications. Referring to the learning of mathematics, she explained that mathematics can sometimes be "really hard to grasp" when it is "like talking about outer space....you have no conceptual understanding of" what the problem is (Alison, interview II). Alison further noted that when children get older, the mathematical concepts they have to learn get more complex. However, because the children's brains are also developing, mathematics should not become harder. While Alison was focused more on mathematical concepts, Emily explained that math becomes 
more complex over time because there are more and more rules, facts and procedures to learn.

Christy, who also emphasized the importance of the context, added another perspective, explaining that mathematics is one of those "things that you should be doing that are hard but you should be doing them anyway" (Christy, interview I). In Christy's view, how hard mathematics is perceived to be by a learner depends on the teacher's attitude toward the subject, and the context in which mathematics is presented. Even though Christy's statement was about students' experiences of learning, it indicates that she perceived mathematics depending on the context as difficult in nature. Christy also explained that mathematics is very hard when it is simply focusing on rules and procedures and not on the understanding of concepts.

In the view of the participants, how "difficult" or "hard" mathematics is depends on different factors. What these factors were became apparent when the participants talked about the difficulties students might have. Frank saw the learner's motivation to engage in mathematics as the key factor of how difficult math is. Emily, on the other hand, thought that the teacher and the way that mathematics is presented determined how math is perceived. Alison and Christy both perceived that there are more factors involved. Christy named the context, the teacher's attitude and the teaching approach as key dimensions of how mathematics is perceived. Alison also emphasized the context and added the dimension of cognitive development and how the teacher coordinates these dimensions in his or her teaching. 
What is math all about. All participants agreed that mathematics can help people explain and understand the world and that mathematics is highly relevant and always present in our society and what we are doing. All participants believed that in schools mathematics should connect to students to and with the real world around them. Beyond this common theme, the teacher candidates held slightly different perceptions of the nature of mathematics, particularly around the issue of how to approach problem solving. Frank and Emily explained that problems should be approached through different ways. As previously explained, Frank would approach problems from different entry points and use different procedures to solve a problem. Emily would use a much more structured approach to solve a problem.

On the one hand, Frank believed that numbers are everywhere and that numbers can be used to explain everything and understanding the mathematical concepts is important to explain the world. However, Frank also believed that mathematical concepts are less relevant for younger children because their world is not as much based on mathematical concepts. Therefore, Frank tended to see mathematics as practical problemsolving that is more applicable in adult professions and sciences. When Emily talked about the nature of mathematics, she said math is "solving everything-I think it is how it represents things in the world, numbers. Student loans come to mind. It is kind of the life of numbers is what I would say" (Emily, interview I).

Christy, on the other hand, explained that "realizing that [mathematics] is not just a set of numbers that you have to learn how to manipulate" made her see "how applicable it is in real life" (Christy, interview I). She also added that when she "got out [of school] 
into the real world as an adult I started to feel how connected math can be to different disciplines" (Christy, interview I). Similarly, Alison believed that "mathematics in the education world...its main goal would be to create understanding, understanding of the rules or the ways in which math works in the real world" (Alison, interview I). Furthermore, Alison perceived mathematics as embedded in the human culture, explaining that mathematics "is about creating an understanding of variables and measurements and numbers, the things that we use numbers for in our culture, creating a relationship with those things" (Alison, interview I).

Compared to the other participants, Alison held an image of mathematics that is most connected and shaped by the environment and people. In addition, in a statement about culturally responsive teaching, Alison also described "that students have a personal connection to the material. They see that it affects their lives in a very specific way, versus a generic way" (Alison, interview II). Although this statement did not directly refer to Alison's perception of mathematics, it shows that Alison connects mathematics and culture. In the second interview Alison made other statements about the importance of connecting mathematics teaching with the student culture. She and Christy were the only candidates who made statements indicating that they believed mathematics is situated in context and culture. Frank and Emily also indicated that mathematics is situated in context, but were reluctant to say the whether or not mathematics is embedded in culture. I was under the impression that he tried to avoid this topic because of his fear of stereotyping. Although Emily stated that she does not know because she has never 
thought about the relationship between mathematics and culture, she added that she is generally open to seeing mathematics as embedded in culture.

Although all participants saw mathematics as highly relevant and embedded in daily life, there is a discrepancy in their thinking about the nature of mathematics. Emily and Frank's view of mathematics appears focused on the individual and how this individual can make sense of problems and the world. Christy and Alison's more holistic and situated approach, focusing on how to explain the world, seems to be more open to the notion of explaining and making sense of the world. This holistic and general approach might lead to the view that mathematics cannot be seen as free of culture. In addition, their beliefs about the nature of mathematics also seemed to shape how the candidates saw the relationship of key dimension of procedures vis-à-vis concepts.

Key dimension of mathematics: Procedures vs. concepts. Important for this section are the definitions of procedural and conceptual images of mathematics, which were developed in this text. As previously stated, a conceptual image of mathematics is defined as approaching problem-solving through inquiry with an emphasis is on the understanding of patterns and relationships between mathematical concepts to construct an understanding of the world. I have defined procedural image of mathematics as approaching mathematical problems by applying different procedures and algorithms, with an emphasis on facts, procedures, and rules, which can be used to explain the world.

As already generally indicated, the participants disagreed on the role and extent to which the nature of mathematics is procedural and/or conceptual. All participants agreed that, to some extent, mathematics is both procedural and conceptual. All participants 
stated that mathematical concepts are important and useful for understanding and doing mathematics.

Although Emily and Frank perceived somewhat differently the nature of mathematics in connection to the extent and role of procedures and concepts, their views are closely related as they lean toward viewing mathematics as primarily procedural. Throughout the research project Emily several times explained that for her sequence and order are important traits of mathematics. Moreover, as explained above, Emily thought about mathematics as strongly grounded in rules, facts, and procedures, but referred to them as concepts that need to be understood. Consequently, Emily's notion of concept understanding entails finding an equation or procedure to solve a mathematical problem. Frank saw concept understanding as equally important to rules, facts, and procedures, but thought mathematical concepts are less present in a childhood environment. Frank stated that students have to understand what they are doing, but in elementary school mathematics he did not seem to think helping students understand "the why" of mathematics as important. Frank's notion of understanding mathematical concepts also entailed the ability to use different approaches to solve a problem. He saw approaching a solution to a problem using a different way of solving it as using a different concept. Both Emily and Frank spoke very openly about the importance of concepts in mathematics. However, from my analysis of the collected data and my interaction with both candidates, I would assess their views of mathematics as more procedural, especially in the case of Emily. I wonder if what they both meant by "understanding the concepts" is more or less understanding how to apply an algorithm. 
Only Christy and Alison put mathematical concepts in the foreground over rules, facts and procedures. In Christy and Alison's views interdependence of concepts, facts and rules add structure, in the sense of patterns, which helps to interrelate the vast amount of ideas. These two teacher candidates further emphasized the importance of understanding mathematical concepts to solve a problem. Not dismissing the importance of mathematical procedures, Christy explained (in contrast to Frank) that, "I can apply an algorithm if I understand why I am doing it" (Christy, interview II). She further explained that "a more problem-based perspective and looking at it from different approaches and really going deep into actually understanding what it was instead of just learning an algorithm" helped her make sense of all the different rules, facts and algorithms (Christy, interview I). I conclude that she strongly believed mathematics is based on concepts, and that procedures, rules and facts are tools that follow these concepts.

Alison believed even more strongly than Christy in the conceptual nature of mathematics. As previously stated, she explained that the goal of mathematics "would be to create understanding, understanding of the rules or the ways in which math works in the real world" (Alison, interview I). She also explained that in middle schools math is getting harder "because it is trying to keep up with the math in our world, trying to get [the students] ready" (Alison, interview I) to understand mathematical concepts. Alison agreed with Christy that a strong focus on mathematical procedures could easily lead to confusion. For example, Alison explained that to multiply fractions students need "conceptual understanding because if they were getting confused with, like all they know was the algorithm and that is where they were getting confused" (Alison, interview I). 
What the teacher candidates considered to be conceptual understanding seemed to differ depending on their own experience with mathematics. The candidates' attitudes and experiences as learners of mathematics seemed to be influential to those images of the nature of mathematics. It seemed that the teacher candidates had a tendency to call conceptual understanding whatever they were comfortable with as a learner. For example, Emily was successful in mathematics whenever she strictly followed procedure. At the same time, Emily's notion of concept understanding appeared to be equal to knowing mathematical procedures. In contrast, Alison felt most confident in her math skills when she was able to use the understanding of the concepts to make sense of and organize all the rules and facts. Frank was very successful with a procedural approach during his pre-university education. After struggling for a time in college, he learned about doing mathematics in different ways. Frank believes that his notion of mathematics is not solely based on procedures, but his perception of teaching to be discussed later indicates otherwise.

Different approaches. When it came to problem-solving and learning mathematics, the participants believed that there are multiple methods and approaches. The use of different ways to solve a mathematical problem, different ways of explaining how to do mathematics, and the use of inquiry to solve a problem were all ways in which the candidates' perspectives could be categorized. Although Emily and Frank both saw the need to use different procedures to solve a mathematical problem, Christy and Alison believed that a math problem should be approached through different conceptual perspectives. Frank and Emily believed in multiple ways of finding the solution to the 
problem. They also believed there are multiple ways to explain a mathematical concept or procedures. Frank explained, "we all have different ideas and there are a lot of ways to approach math" (Frank, interview I). Consequently, Emily and Frank believed that it is often supportive of the learning process when students can learn from each other in a partner or group activity. Alison and Christy, in contrast, extended the idea of doing math in different ways to approaching a mathematical problem through inquiry. This notion leads the students to approach and solve the problem in the way that they think works best. Although none of the participants ever spoke about the possibility that there might be different answers to a mathematical problem, Alison and Christy at least mentioned during the second interview that, depending on the situation and the student's cultural background, there could be significant differences in how people do mathematics.

How each individual defined these multiple ways of doing math seemed to be influenced by their own experience as a learner of mathematics and, therefore, their perceptions of whether mathematics is more procedural or conceptual in nature. Their individual ideas of "multiple ways" seemed to also shape the candidates' perception of teaching, which I discuss below.

\section{Relationship of experiences learning mathematics with images of}

mathematics. Given the analyses of the individual cases and this cross-case interpretation of images of mathematics, I further speculate that the participants' images of mathematics and what they understand as concepts were likely shaped by their experiences as learners of mathematics. Most interesting, even participants who had very negative experiences in the past built their images of mathematics on their positive 
experiences. It appears as if the participants built their own images of mathematics around the framework they were most comfortable with as learners. For example, Frank explained that he felt most successful when he learned mathematics from a constructivist approach and was encouraged to approach math from different ways. As outlined before, he defined mathematics as problem solving through different approaches. Emily, explained that she was most comfortable with doing mathematics following step-by-step procedures. She held a procedural image of mathematics. Christy was successful in mathematics when she was taught to understand mathematical patterns and relationships in order to make sense of rules, facts and procedures; she held a conceptual image of mathematics. Alison started to enjoy mathematics and was successful when she was taught "rules and real live examples" (Alison, math autobiography). She further explained,

I enjoy math because even though there is only one answer for most problems, there are multiple ways to get there. I am a curious mathematician with a love for numbers. My history with math reminds me of meeting someone very important before I understood their importance in the world. (Alison, math autobiography)

In the first interview Alison also explained that math "is creating an understanding of variables and measurements and numbers, the things that we use numbers for in our culture, creating a relationship with those things." These statements indicated that Alison held a primarily conceptual image of mathematics. Even though the participants characterized math as a difficult subject, they also believed that they now understood it on a level that they could teach and enjoy it.

\section{Images of Students, Culture, and Diversity}


Because teaching is not possible without a learner, I first analyze how the participants perceived the student before shifting focus to their perception of teaching. In this section, I focus on the participants' perceptions of diversity and culture and how these perceptions shaped the candidates' image of students. I argue that participants did not see the "whole child" as a learner. By seeing the "whole child," I mean seeing the child as a learner and as a person, which means paying attention to the student's preexisting knowledge, learning style, ability level, etc. as well as seeing how the student's cultural background has shaped his or her identity and way to create, hold and present knowledge.

Whereas the participants mostly agreed on their definitions of culture, themes emerged regarding their definitions of diversity. Frank, Emily, and Alison believed culture is shaped by religious beliefs, linguistic background, traditions, heritage and the socioeconomic status. Not disagreeing with this definition of culture, Christy's notion of culture could be also described as the way people interact with each other. Alison added to this definition that "culture is the rituals and the way people are in a certain community" as well as family traditions and "where you were born" (Alison, interview II). Regarding race as it relates to culture, Emily did not see race as an indicator for cultural diversity. However, Frank seemed to believe that "skin tone" could be an indicator for cultural diversity, in the abstract, but regarding his students, he seemed to ignore race as an indicator for culture.

Regarding diversity, Alison and Christy perceived the idea as members of several different groups being together. Emily considered diversity to be the presence of at least 
one minority group in an otherwise majority group. She defined a diverse group as people of different heritages and different backgrounds interacting together. She also believed that members within a group do things differently than members within another group. Similar to Frank, she believed that "all children are diverse in a way because they come from different backgrounds."

The biggest differences between the participants' views on diversity had to do with the question of whether or not skin color is a dimension of diversity. As stated before, Alison identified as non-White, but grew up in a White family, and believed that everybody who is not part of the dominant culture is diverse. She explained that although diversity is more than a question of skin color, race is certainly part of diversity. Frank, however, tried to ignore the notion of racial diversity, instead explaining that "everybody is different," implying a focus primarily-or perhaps even, solely-on the individual. In contrast to Frank, Emily saw diversity as belonging to different groups. However, she believed that diversity does not imply "not White." In contrast to Emily, Christy believed that sometimes "skin tone" can be an indicator for cultural diversity. How the participants saw culture and diversity also shaped how they viewed the students.

Images of students as persons vs. student as learners. All four participants of this study paid significant attention to the individual students and their learning needs. They explained that every student brings a different set of knowledge, skills and personal interests to the classroom to which the teacher should respond. Christy and Alison, however, would also look to group membership to characterize those individuals. The image of students that each participant held can be categorized two ways: the student as 
an individual "person" and the student as an individual "learner." Emily and Frank saw the students as individual learners, which entailed paying attention to learning styles, interests, ability levels, learning needs, and what kind of support the students can get at home. Alison and Christy agreed with seeing the students as individual learners, but also considered paying attention to the students' cultures as contributors to their identities.

Frank and Emily both seemed unsure whether or not a student's cultural background should inform them as the teacher. Frank explained that other than the students' interests and the support a student could get at home, he would refrain from integrating the students' cultural backgrounds. He believed that it was easy to stereotype students and believed paying attention to students' cultural backgrounds is not worth the risk because all students are individuals and, therefore, diverse. Emily applied a similar reasoning to her focus on the individual students. She explained that students "come from all over the place" and with such different experiences, it would be impossible for the teacher to know to which culture to which a student belongs. Because Emily would be afraid of doing something wrong, she would strongly focus on the students' skills, knowledge, and interests, rather than their cultural backgrounds. Although Emily seemed to not actively include the child's cultural background, she allowed that students bring their culture to the classroom, for example by sharing an artifact they brought from home.

\section{The Perception of Teaching Mathematics With Culturally Diverse Students}

How the participants perceived teaching mathematics can be categorized as follows: the purpose of teaching mathematics, curriculum, instruction, and culturally 
responsive teaching. I first introduce the candidates' ideas about teaching mathematics to explain the world or to prepare students for more complex mathematical tasks. In the curriculum section, I focus on explaining if and how the participants would integrate the students' culture into their curriculum. Finally, in the instruction section I point out how mathematics-related teacher education courses seemed to impact the participants' perceptions of teaching. I also explain why I think the participants struggled with connecting cultural diversity and teaching mathematics. In each section I focus on how the participants saw teaching mathematics in general, and when possible, I also focus on the candidates' perception of teaching mathematics in particular with diverse students.

Purpose of teaching mathematics. During the focus group, all candidates agreed that the purpose of teaching is "to encourage students to think and to ask questions." Although all candidates agreed that in elementary schools mathematics teaching provides foundational knowledge and skills, they held different perspectives on the structure and purpose of the foundations. Emily and Frank made providing basic knowledge and skills their main purpose. Through the practice of solving problems, they believed that the students would become familiar with the subject, as the most important part of elementary mathematics. Christy and Alison, rather, placed their main focus on the students' understanding of mathematics as a tool for making sense of the world. Also, they were focused on making mathematics enjoyable, which is their way of preparing students for their upcoming school careers. Christy and Alison both valued the importance of teaching basic concepts and skills, but they both believed that students have to enjoy the subject in order to learn. Both Christy and Alison seemed to favor 
making mathematics a likeable subject because of their own struggles with mathematics. Emily, who never struggled with mathematics and always liked it, neither emphasized making mathematics enjoyable nor teaching basic mathematical concepts. Frank, who considered that students sometimes have to struggle to solve puzzles, believed the joy in doing mathematics comes with the ability to solve a problem.

Curriculum. Mathematics is best learned when it is meaningful to students and when it is something they care about. This statement summarizes the participants' reasoning for why teaching mathematics has to connect to the students' interests and experience. For example Alison explained, "I think it is going to play a lot into what you teach your lessons on and how you adapt your curriculum to [the] interest[s] of those students....so to try and make education meaningful for them" (Alison, interview II). Frank was always asking himself the question, "what can you do to make this meaningful for all these students?" by which he sometimes meant providing homework. Christy explained that, "the biggest challenge in teaching any kids is figuring out what is going to get them interested in the subject, what is going to engage them." Emily also mentioned "students need context" they can relate to in order to be successful.

Changing the names in a word problem and creating math problems based on the students' favorite sports were typical examples given by the participants to develop interest and meaningfulness on the part of their students. Christy explained that, for example, she asks herself the question "Is this kid really into castles? Then we can talk about measuring the outer wall of the castle for this kid, where for this kid I am going to talk about measuring the football field or something, trying to make it something that he 
cares a little bit more about?" Another way of making mathematics meaningful, mentioned by Emily was relating math to food and what they do in recess. She thought that the students could apply what they had learned immediately.

Seeing themselves as responsible for their students' learning, Frank and Emily did not know how to connect to all their students and considered it extremely difficult to make the necessary connection between the content and the students when there were students from many different backgrounds in the classroom. Frank, for example, mentioned that it was challenging for him when he did not know the students' neighborhoods. Not knowing the students very well was also an issue for Emily. Frank and Emily were very reluctant to connect mathematics to their students' cultures. Similar in both of their reasonings was the fear of doing something wrong. Frank was afraid to make judgments based on stereotypes and Emily was afraid of misjudging the students. While Frank saw it as appropriate to pay attention to the students' personal interests and not to the students' cultures, Emily thought that simply connecting to the students' cultures and not mentioning why she was making the connection would be an appropriate way to avoid errors. Alison and Christy seemed to not face this problem because they believed that students should be in charge of their own learning and they also saw culture playing a role in students' identities. Alison strongly believed in classroom community and also declared that it is important to draw on the students' cultural backgrounds and interests; at the same time it is "ok to be wrong."

The consistent language the teacher candidates used when they talked about making a lesson meaningful and connecting to the students' backgrounds indicated a 
possible impact of the methods course, which the students were attending during the time of this research. As one assignment in this course, the teacher candidates were explicitly asked to plan a lesson on making mathematics meaningful and to consider the student's background. In addition, the work sample (unit planning) guide in the course spoke in general terms of relating the lessons to the students' backgrounds.

Instruction. The teacher candidates' perceptions about the teaching of mathematics to culturally diverse students also seemed to be related to their math methods course. All teacher candidates used similar language to describe their teaching and planning of teaching. For example, they used some key terms that were employed in the course, such as meaningful, scaffolding, differentiation, learning style, and different ways. Because these terms were used on the course syllabi and lesson planning guides, it was not surprising-at least logically-that the participants' ideas and descriptions about teaching appeared to make use of them.

Making mathematics meaningful was the goal of all participants, not only in terms of the curriculum as they used student interest to make connections with the mathematical content, but also in terms of general instructional strategies that would help students connect one mathematical idea with another. One instructional way to create meaning, mentioned for example by Frank, was scaffolding. All participants understood scaffolding to mean "meeting the students where they are" and "build[ing] upon prior knowledge and keep[ing the students] moving forward to truly understanding [mathematics]" (e.g., Frank, interview I). He explained that scaffolding can help students to grasp a problem and understand the problem in their own terms. The described 
scaffolding process was, for all participants, the way to meet the needs of all students by creating meaning at the students' levels of understanding. In other words, the participants would try to choose problems according to the students' ability levels so that students are able to grasp what they are learning and relate what they have learned to their experience.

Differentiation. The analysis of the data indicates that the participants saw differentiation as providing students a variation of learning opportunities with the goal that every student can learn the same concepts and procedures. All participants considered effective differentiation strategies to provide different learning opportunities that respond to students' different learning styles and interests. Ability grouping was seen by all participants except Alison as a form of differentiation.

Although the consistency in their basic way of thinking about teaching might be related to the methods course that the participants attended during the time of this research, there were differences in their perceptions of differentiated instruction. The strategies mentioned by the candidates can be categorized into either teacher-centered individual differentiation or student-centered, group-based differentiation. Although all participants considered both approaches valuable, there were differences in their emphasis on each. These differences seem to be related to whether the participants saw mathematics as procedural or conceptual, as well as their images of the learners. Frank and Emily, who had a more procedural approach to teaching, emphasized practice and explaining mathematics in "different ways." For them, the focus was finding the right approach for each individual student. Emily and Frank described their ideas of teaching as differentiated and collaborative between students, but teacher-guided. As outlined 
above, Emily and Frank saw students as individual learners and paid attention to their preexisting content knowledge, learning styles, personal interests, and the support they might get from home. Peer support in their classrooms seemed to be limited to students providing additional ways of explaining material to each other.

Alison and Christy described their teaching styles in very similar ways to each

other, perhaps due to their similar conceptual images of mathematics. Especially Christy, but also Alison, thought of teaching as student-centered and "inquiry-based" (Christy, interview II). Alison and Christy's approaches incorporated peer support and seemed to focus more on solving a problem in a group or with a partner using "different approaches." After understanding the concepts upon which the solution is based, the students would practice solving other math problems.

In summary, the participants who saw the student as an individual learner tended more toward teacher-centered differentiation based on their perceptions of individuals, mathematically. The participants who saw the students as individual persons favored more student-centered, collaborative differentiation. Their predominant concept of students and teaching also related to the participants' view on culturally responsive teaching.

\section{Culturally Responsive Teaching}

In this section I compare and contrast the participants' perceptions of culturally responsive teaching. I show that the candidates seemed to have little or no awareness of the concepts of culturally responsive teaching. 
Concept of culturally responsive teaching. At the time the research was conducted, none of the participants seemed to be familiar with the term culturally responsive teaching, nor were they aware of, or able to articulate, the concepts of culturally responsive teaching. Emily and Alison seemed to have at least a foundational understanding of culturally responsive teaching.

These teacher candidates also expressed a confused understanding about how to work with culturally diverse students, although the participants all mentioned welcoming diversity and that they wanted to learn about teaching diverse students. Rather, they talked about trying to scaffold and differentiate their instruction in order to respond to the students' preexisting knowledge and learning styles. Although all participants saw the importance of connecting the context of the curriculum and instruction to the students' interests, Frank and Alison more prominently than the others referred to the importance of making mathematics meaningful. Recall for example, how Emily tied teaching to the students' backgrounds by “tweaking the world problem" (Emily, interview II) or how participants are always to open to "let[ting] the student bring in their culture" (e.g., Christy, focus group).

Nevertheless, during the focus group discussion, Emily, Christy and Frank rejected the concept of culturally responsive teaching as too much work and not sustainable over time. Frank agreed with Christy when she stated that being culturally relevant maybe sometimes needs to be an extension rather than the core thing that is taught on any given day. If there is an obvious distinction that folds in really nicely and you waste it, then that is a shame (Christy, focus group). 
Especially the candidates who dismissed the idea of culturally responsive teaching seemed to reduce that concept to integrating culturally-related content, for example using word problems that are based on the students' culture. Frank seemed to see doing so as an extra burden in addition to his already highly differentiated instruction. Christy also thought it was too much additional work but countered that because of her studentcentered teaching, there would be occasions when the opportunity to integrate culture naturally occurs.

For different reasons, both Emily and Alison welcomed the idea of culturally responsive teaching as something they would like to learn more about. Emily was eager to extend her knowledge and teaching skills and saw culturally responsive teaching as one way to teach to the needs of all her learners. Alison was exploring her own cultural identity as a beginning teacher and saw culturally responsive teaching as a way to help her students to explore their own cultural identities. Nonetheless, Frank and Christy were less enthusiastic about learning more about culturally responsive teaching, but they still thought it might be a good idea to look into it.

\section{Researcher's Discussion}

My analysis of the data suggests that the participants saw mathematics as a subject that is concerned with practical problem solving and embedded in daily life. Seeing mathematics as enjoyable and fun, but also difficult and hard, all participants believed that everybody can learn mathematics. Although all participants emphasized the importance of mathematical concepts, they seemed to define mathematical concepts differently. Two of the participants had a more procedural and sequenced view, whereas 
the other two saw mathematical concepts as more grounded in patterns and relationships. Moreover, although all participants saw the importance of promoting conceptual understanding, it seems as though, based on their eventual positive experience as learners of mathematics, they defined concepts differently. Frank and Emily's understanding of concepts seem to be more procedurally-oriented, whereas Alison and Christy's views are more conceptually-oriented. It appears as though the teacher candidates with a more procedural focus see teaching as more guided and teacher-centered, whereas the teacher candidates with a more conceptual image see teaching as more student-centered and inquiry-based. As it happens, the teacher candidates who have a more conceptual image of mathematics focus more on the child as an individual person, who is also a learner, rather than just on the child as a learner. It appears as though the candidates with a more conceptual view are more open to seeing the child as whole person with a cultural background.

The findings indicate that perceptions of mathematics can change though different experiences over time. In this case study, all four participants expressed that their attitudes toward math had improved and that they felt more confident when they had a positive experience. This positive attitude seemed to have lasted through the elementary math methods courses. All participants repeatedly stated during the entire research project how much they enjoy mathematics and teaching mathematics. For these teacher candidates, their positive experiences in the mathematics for elementary teacher series seem to have shaped their images of the nature of mathematics and their perceptions of teaching mathematics. These indications of a positive impact of the mathematics for 
elementary teachers course on the participants' attitudes toward mathematics make me wonder why it was possible to change to the participants' attitude during that time. My research conversations with the participants gave me reason to believe that the methodological concepts of the instruction were the main reason for this change. This circumstance indicates that culturally responsive teaching integrated and molded throughout all teacher education coursework might help to prepare elementary teacher candidates to teach mathematics while promoting a positive attitude toward mathematics.

All participants paid attention to the student as an individual learner; however, all the participants seemed to struggle to understand how diversity and culture influences teaching and learning in a mathematics classroom. Only the participants who had a conceptual framework for mathematics and their teaching seemed to consider the child as a person, to include their cultural backgrounds. Specifically, Alison and Christy used a student-centered and conceptual approach to their teaching. One could argue that doing so already counts as culturally responsive teaching. I would argue that their approach could be referred to as "good teaching" which seems to move toward culturally responsive teaching. Both Emily and Alison thought that culturally responsive teaching seemed to be a way to engage all students in meaningful learning. However, like Frank and Christy, who rejected culturally responsive teaching as too complicated, Emily and Alison were not aware that they already considered using some culturally responsive concepts, such as a student-centered inquiry approach.

All participants seemed to care for their students as learners as well as for their academic success and development. All four participants in this study expressed that they 
saw the individual needs of a child and wanted to promote the child's own way of learning. Although the participants' definitions of "the child's own learning" are, I believe, appropriate to the participants' stage in their teacher education program, their desire to respond to different learning styles moves toward culturally responsive teaching. Significantly, however, they do not consider learning styles as also based in culture, instead only thinking of learning styles as cognitive and physical inclinations. Still, the study participants do not seem to have had a clear understanding of diversity and culture in schools. The data also suggest that the conundrum the teacher candidates felt about how or whether to deal with diversity might have impacted their perceptions of culturally responsive teaching.

However, the teacher candidates seemed to have taken some ideas from the prerequisite mathematics for elementary teacher courses and the math methods courses that might lead them toward culturally responsive teaching. I observed that the teacher candidates used language when they talked about teaching that seemed to have originated in these courses (e.g., differentiation and scaffolding). In addition, it appears as though the teacher candidates defined as mathematical concepts the elements with which they were most successful in their own learning of mathematics. All participants' perceptions of teaching mathematics seemed to be grounded in their images of mathematics and in what they learned in mathematics-related coursework.

As previously mentioned, I see a positive attitude toward the subject as an important element of my theoretical framework of culturally responsive teaching. In particular, a positive attitude toward mathematics entails the belief that all students can 
learn mathematics and that mathematics is concerned with the practical problem solving of daily life. Even after strong aversions, anxiety, and struggles, three of the four participants seemed to have come to consider mathematics as enjoyable and fun. I have also noticed that all participants considered mathematics to be difficult, but they also thought that everybody can learn mathematics. The combination of mathematics being difficult, but at the same time enjoyable and fun, makes me wonder how both perceptions can go together. Maybe it is because the participants were able to overcome their struggles and now feel empathy with the learners and believe that everybody can learn mathematics. This sense of empathy is one of the basic elements of culturally responsive teaching. The observed belief that mathematics is concerned with the problems of real life makes it possible that participants at least considered the students' learning needs in their daily context. However, their perceptions of diversity seemed to hinder at least two candidates from taking the child as a learner and as a person, in other words as a "whole child" into account.

One reason why the participants seemed to be unaware of the idea of culturally responsive teaching was perhaps their struggle with the concepts of diversity, race, ethnicity, and culture in the context of education. Although all participants welcomed diversity in the classroom, they seemed not to know how race, ethnicity, socioeconomic status, and language might impact teaching and learning. It seems that the notion of diversity as "everybody is different" hindered the participants from developing an understanding of cultural diversity, based on group identity. The teacher candidates seemed to deal differently with this conundrum. All participants had chosen this specific 
teacher education program because they wanted to gain experience in working with diverse students. Yet, they all seemed to approach diversity in the classroom differently.

Frank in particular, but to a certain extent also Emily, wanted to try to avoid stereotyping students. They tended to ignore any group identity of students. They seemed to perceive that students should be judged based upon their individual characteristics rather than any group characteristics. Although I would agree that teachers should avoid stereotyping, I think Emily and Frank may have been overcompensating because they were afraid to misjudge students. Frank seemed to have learned that stereotyping could negatively impact students and their learning. Alison, in contrast, struggled with her own cultural identity and was aware that cultural identity is an important factor for each person and learner.

However, in their own ways, all four participants seemed to care deeply for their students and their learning. All four teacher candidates seem to put the student in the center of their teaching. I wonder if it is their strong focus on the individual learner that made Frank and Emily believe that culturally responsive teaching would lead to stereotyping and be unsustainable in day-to-day teaching. The participants' responses regarding culturally responsive teaching and their uncertainty about diversity in the classroom made me wonder if there was something missing in their teacher education, and how their teacher education experience could address their limited understanding of culturally responsive teaching.

One of the more positive observations I made during this research was that, I believe, the participants were learning from their coursework. I am under the impression 
that the teacher candidates used language that might stem from their courses, such as the math methods course and the mathematics for elementary courses. The use of this language and how the participants described teaching might indicate that participants have taken ideas from these courses into consideration for their teaching. Most participants seemed to define their thoughts about mathematical concepts according to what helped them be successful during their own school career as learners of mathematics. This analysis raised the question of how a positive learning experience could be created and utilized to better prepare mathematics teachers to enact culturally responsive teaching. 


\section{CHAPTER V \\ DISCUSSION, CONCLUSIONS, AND IMPLICATIONS}

The purpose of the study was to gain insights into elementary teacher candidates' perceptions of teaching mathematics with culturally diverse learners. A persistent opportunity gap in mathematics for students who are not from White, middle-class European-American backgrounds presents an intolerable situation of social injustice. Teachers who employ culturally relevant teaching (Gay, 2010) may help to close this opportunity gap and hence, the achievement gap. With the increasing number of students who are not from the dominant culture, culturally responsive mathematics teaching (Gay, 2009 ) is one way to provide equal learning opportunities for all students. An understanding of teacher candidates' perceptions of teaching can help to redesign teacher education, change policies, and provide a foundation for future research-all in response to this significant educational problem.

Following a critical constructivist framework, I conducted this study to gain insights into elementary teacher candidates' images of mathematics, culturally diverse students, and the teaching of mathematics. The study was guided by the overarching question: How do teacher candidates perceive teaching mathematics in a multicultural environment? Three sub-questions follow:

- What images of mathematics do elementary teacher candidates hold?

- What images of culturally diverse learners in the mathematics classroom do elementary teacher candidates hold?

- What is the relationship, if any, between and among the images of mathematics, culturally diverse learners, and the teacher candidates' perceptions about teaching mathematics to such learners? 
Four teacher candidates, selected through opportunistic sampling, participated in all phases of this research study, which was conducted during the second (Fall) term of a graduate teacher licensure program at an urban university in the Pacific Northwest. Because of their age, gender, and race they also happened to be a representative sample of the students enrolled in the elementary teacher licensure program.

The four participants of this multiple instrumental case study held different images of mathematics. The study showed that the participants held positive images of mathematics. I further categorized these images of mathematics as primarily procedural or conceptual. These perceptions seemed to influence the candidates' perceptions of teaching mathematics. At the same time, it happened that the candidates whose image of mathematics was primarily procedural only saw the child as a learner but not as a person in the classroom. The study also indicated that the participants' perceptions of mathematics, students, and teaching mathematics were shaped by their positive experiences in program prerequisite coursework, as well as by the math methods course in which the participants were enrolled during the study. The study also suggested that presenting culturally responsive teaching in just one course on multicultural education, and as a topic on one day in the methods class, led the participants to see culturally responsive teaching as a method rather than as a framework for teaching. I argue that a change in teacher education and policies is necessary to enable teacher candidates to enact culturally responsive pedagogy to provide equal learning opportunities for all students. 


\section{Summary and Conclusions}

Before I present how my research might answer the overarching research question, I first summarize the results of this research regarding the sub-questions. These sub-questions focus on the teacher candidates' images of mathematics, diverse learners, and the relationship between these images with regards to teaching mathematics with diverse learners.

\section{What Images of Mathematics Do Elementary Teacher Candidates Hold?}

I lay out two of the most important dimensions of the teacher candidates' images.

First, I show that their positive experiences with mathematics have shaped their images of the subject. Second, I describe how the participants' perceptions of mathematics as conceptual and/or procedural played an important role in their perceptions about teaching and about the learner.

Positive images of mathematics. The study showed that all participants held positive images of mathematics at the time of the study. They saw mathematics as approachable and learnable by all students (perhaps except those with severe learning disabilities), as well as concerned with the practical problems of day-to-day life. All participants believed that everyone can learn math and that mathematics can be enjoyable and fun, but difficult and hard at the same time. Although only one participant had a positive perception of mathematics throughout life, the perceptions of the other participants changed throughout their time as learners of mathematics. Guillaume and Kirtman (2010) stated that students' perceptions of mathematics are shaped by their experience with mathematics. My study suggested that it was the positive experiences 
and the moments of understanding which shaped the participants' images of mathematics.

Procedural image versus conceptual image. The images of mathematics that the participating teacher candidates held can be seen on a spectrum ranging from a primarily procedural image of mathematics to a primarily conceptual image of mathematics.

Although all participants expressed that concepts are most important in mathematics, they had different understandings of the nature of mathematical concepts. It seemed as if the participants oriented their images of mathematics and therefore what they presumed to be mathematical concepts upon their positive experiences with mathematics. A positive experience was defined as the moment the teacher candidates felt comfortable in their learning process and had the impression of understanding. On the one hand, the candidates with a procedural image of mathematics primarily approached mathematical problems by applying different procedures and algorithms. They emphasized facts, procedures, and rules, which can be used to explain the world. On the other hand, the candidates with a conceptual image of mathematics approached problem solving through inquiry. They emphasized the understanding of patterns and relationships between the mathematical concepts to construct an understanding of the world. I argue that the participants who held or leaned toward a conceptual view of mathematics are closer to what Ernest (2009) defined as a "humanistic image" of mathematics than the participants with a procedural view of mathematics, although all participants carried elements of both images that Ernest described as traditional and humanistic. Therefore, I consider the participants who held a conceptual image of mathematics to be closer to culturally responsive teaching than the participants with a procedural image (see Table 3). 
Table 3

Participants' Images of Mathematics

\begin{tabular}{|c|c|}
\hline Procedural & Conceptual \\
\hline Emily and Frank & Alison and Christy \\
\hline - Develop fundamental skills & - $\quad$ Focus more on the big ideas of math \\
\hline $\begin{array}{l}\text { - There not many concepts in elementary } \\
\text { math }\end{array}$ & - Understand how the world works \\
\hline $\begin{array}{l}\text { - Develop skills early and allow time to let } \\
\text { them sink in }\end{array}$ & $\begin{array}{l}\text { - Use concept understanding to make sense } \\
\text { of the rules, facts, and procedures }\end{array}$ \\
\hline $\begin{array}{l}\text { - Skills will later help to understand the } \\
\text { concepts }\end{array}$ & - Solve problems through inquiry \\
\hline $\begin{array}{l}\text { - Use different ways to explain a problem } \\
\text { or a procedure }\end{array}$ & - Construct understanding of the world \\
\hline - Teacher explains concepts step-by-step & - Students construct concept understanding \\
\hline
\end{tabular}

It also appears that the required prerequisite mathematics courses that all the participants took had a significant impact on their definition of mathematical concepts and their overall perception of mathematics. Judging from my own knowledge of these courses as a course assistant, the participants seemed to have learned that concept understanding should come before procedural practice (Skemp, 1976). I assume that the study participants now felt comfortable with doing math, had a feeling of understanding, and might define what they had been doing as concepts. Consequently all participants assumed that they had a conceptual approach to mathematics even though they were more or less using procedures. 


\section{What Images of Culturally Diverse Learners in the Mathematics Classroom Do Elementary Teacher Candidates Hold?}

In this study, the participants seemed to have held images of diversity and culture that made it challenging for them to see the student as an individual learner as well as a person. As an overarching theme, all participants saw the idea of diversity as being different, in the sense of being different from others, which translated into the notion that in a classroom everybody is different. However, the study participants saw student diversity in a variety of ways. As outlined in chapter four, Alison and Christy perceived a classroom as diverse when members of several different groups are together. Emily considered classroom diversity to be the presence of at least one minority group in an otherwise majority group. She defined a diverse group as people of different heritages and different backgrounds interacting together. She also believed that members within a group do things differently than members within another group. Similar to Frank, she believed that "all children are diverse in a way because they come from different backgrounds."

On the one hand, two of the teacher candidates emphasized this individualized image more than the other participants because of their fears of stereotyping students. Doing so led them to ignore any group identities of students, such as racial or ethnic identity. On the other hand, the other participants considered group identities to be important to the students and their learning.

Yet, all of the teacher candidates seemed to struggle to understand how diversity translates into the classroom. They, therefore, did not know how to respond to racial, 
ethnic, and cultural diversity and were not able to see the student as a learner as well as a person. At least three of the four participants were open to the idea of responding to diversity in the classroom, but they did not seem to have the frameworks for learning, diversity, and culture, which would support seeing the student as a learner and person. Therefore, I infer that teacher candidates need well-defined images of diversity and culture as well as guidance about how to appropriately enact these images in a classroom.

\section{What is the Relationship, if Any, Between and Among the Images of Mathematics, Culturally Diverse Learners, and the Teacher Candidates' Perceptions about Teaching Mathematics to Such Learners?}

Answers to the question about the relationships between and among the candidates' images are more speculative than the answers to my other sub-questions. Hence, I base my answers on the results I have discussed so far.

Teaching as they were "taught when they got it." The participants of this study seemed to favor approaches to teaching that they described as having been used when they experienced success and/or comfort in learning mathematics. It also appears logical that teacher candidates, having limited experience as teachers, would try to connect their teaching to a teaching approach with which they were successful. The participants of this study often reflected on their own learning to determine the way they would approach mathematics. In addition, they all expressed that they think students should learn the concepts before they learn a procedure to solve a mathematical problem. As previously outlined, the study participants seemed to define mathematical concepts differently based on their positive experiences with mathematics. 
The image of the subject matters. How the participants approached teaching mathematics seemed to be related to the images they held of the subject. In this study, the participants who held a more procedural image of mathematics seemed to favor a more teacher-guided approach to teaching, with a strong emphasis on practice. Teacher candidates with a more conceptual image of mathematics seemed to favor a more student-centered, inquiry approach to mathematics. Both kinds of participants considered mathematical rules, facts and procedures to be important elements of mathematics, which seemed to make practicing solving problems a part of their instructional strategies.

Judging from my own experience of teaching mathematics, I believe that an inquiry-based, student-centered approach to mathematics would lend itself more to culturally responsive teaching. In this study it happened that the participants in favor of a conceptual approach, and quite possibly the student-centered inquiry approach, were more open to responding to diversity based on group membership. The participants who favored a more procedural and teacher-guided approach happened to be the participants who felt less comfortable with the idea of culturally responsive teaching.

The image of the student matters. This study suggests that the images of students that teacher candidates held also impacted the way they perceived teaching mathematics. In the first place, all the study participants saw the students as learners. They, therefore, considered teaching strategies which good mathematics teachers would use to teach to the needs of the learner. For example, they would scaffold and differentiate their instruction, based on the students' learning styles, performance, and interests. Two of the teacher candidates chose to ignore the group identities of students. 
These participants seemed reluctant to include the child's culture into their image of the student, which meant that they did not see the child as a learner as well as a person. The two other participants, who considered group identities to be important parts of a student's identity, were more open to seeing the child as a learner and a person, but did not seem to know how to incorporate this image into their teaching.

\section{How do Teacher Candidates Perceive Teaching Mathematics in a Multicultural Environment?}

In their basic approach to teaching, the study's teacher candidates did not seem to perceive teaching as any different in classrooms they considered to be diverse and in classrooms they did not see as diverse. As outlined above, the participants would choose the teaching approach they deemed most appropriate to teach toward an understanding of what they defined as mathematical concepts. In the scope of their focus on the individual learner, the participants would relate their teaching to students' interests and perhaps their family backgrounds. The idea of responding to the students' cultures seemed to be challenging for all of the participants, and none of them seemed to have a well-developed idea of how to respond to cultural diversity in a classroom, much less in a mathematics classroom. "Tweaking a story problem" to make it more relevant to the students, working with money as a sort of universal cultural artifact, and giving the students the opportunity to bring in an artifact that reflects their culture, were some of the strategies the participants mentioned. None of the participants seemed to be familiar with the idea of culturally responsive teaching. They seemed to perceive culturally responsive teaching as more of a method that is difficult to use rather than a framework for teaching. 


\section{Conclusions Drawn from the Study}

Based on the results of this study as related to the research questions, I conclude

that:

- For these teacher candidates, images of mathematics, learners, and the teaching of mathematics to culturally diverse students were interrelated.

- These teacher candidates perceived their overall images of mathematics to be built upon their experience as learners.

- These teacher candidates struggled to understand how diversity based on group membership (e.g., culture) influences a mathematics classroom and their teaching.

- However, on the basis of these participants, teacher candidates who hold a conceptual image of mathematics could be more open to adopting culturally responsive teaching than teacher candidates who hold a procedural image of mathematics.

\section{Contributions of the Study}

This study confirms and adds new contributions to the existing body of educational research on teacher candidates' perceptions of mathematics, culturally diverse students, and the teaching of mathematics. Confirming the existing research on images of mathematics (e.g., Ernest, 1988, 2009) and the influence of images of mathematics (e.g., Ball, 1990b; Gill et al., 2004; Gregoire, 1999; Williams \& Baxter, 1996) on teaching, this study adds a more recent perspective. This study also makes important contributions to the research on culturally responsive mathematics education (e.g., Greer, Mukhopadhyay, Powell, \& Nelson-Barber, 2009). In particular, this study focuses on elementary teacher candidates' beliefs about mathematics and teaching mathematics with culturally diverse students. I argue that this area needs more research that helps to prepare teachers to teach in today's classrooms. 
In addition, a particularly important contribution to the field is this study's targeted focus on teacher candidates' perception of culturally diverse students. Most of the studies I read were concerned with the teaching and the curriculum of mathematics, but did not focus directly on how the learners were perceived by teacher candidates.

I agree with Ball (1990a) and Ukpokodu (2011) that a one-term math methods course and a one term course on multicultural education might not change teacher candidates' perception of teaching culturally diverse students. However, my study indicated that if these courses were part of an array of courses, elementary math methods courses as well as elementary math content courses might have a positive impact on teacher candidates' perceptions of teaching mathematics with culturally diverse students.

Guillaume and Kirtman (2010) claimed that teachers are products of the educational system and teachers tend to teach the way they were taught. Based on the results of my study, I generally agree with Guillaume and Kirtman, but I would make the distinction that teacher candidates build their perceptions of teaching upon their positive experiences with mathematics.

This study also showed that these teacher candidates struggled to see the difference between stereotyping and valuing the whole child and his or her culture. McDiarmid and Price (1990) already described that teacher candidates sometimes reject considering students' culture due to strong warnings against stereotyping in multicultural education. My study also indicated that teacher candidates might still not understand the concepts of culturally responsive education. 


\section{Limitations}

The framing of the research question limited the focus to the participants' perceptions. From this study it was not possible to make conclusions about the participants' practice in the field. For instance, because the study was conducted during the participants' second term of their teacher licensure program, when they had only limited experience in teaching, this study only reflects their perception of teaching, not how the participants would teach. The combination of the participants being enrolled in the elementary mathematics methods course and at the same time taking their field experience practicum made it difficult to distinguish between the influences the methods course and the field experience might have had. However, because the field experience and the methods course should complete each other, and because attributing learning to particular conditions or events was not the purpose of this study, this distinction was not important.

Further, conducting this study in the same term as the methods course also made it impossible to determine what perceptions the participants had when they entered the program and whether their perceptions might have since changed. Although a change in perceptions was not a focus of the study, I observed some language usage and thought patterns that might have been influenced by the coursework. While not directly a limitation, the timing of the study could well have made a difference in the language the participants used to describe teaching and learning during the interviews.

The data collection drew on self-reporting and bears the risk of being based on selective and incomplete memory. In the case of the math autobiography, this effect was 
intended as an element of the data triangulation. Based on the analysis of collected data, I made choices about the design of the next steps of the research project. It is therefore possible that I missed important data in the process. Another step where data may have been missed was in the data analysis process. The structural coding might have limited my view on the selected data. However, the application of different coding strategies, for example "in vivo coding," was intended to minimize this risk.

Nevertheless, while these findings are limited to the four cases and are not "generalizable" or "transferable" (Creswell, 2012), I did identify patterns that add missing perspectives to the existing body of literature and provide a solid basis for future research. Due to the design of the case-by-case data triangulation, my findings are trustworthy, and can therefore add to existing research on teacher education with a particular focus on concerns for closing the opportunity gap. I believe that, in combination with other research, my findings could support teacher education course design and program design. I agree with Grossman (1989) and Williams and Baxter (1996) that case studies are specific to the cases that are being studied, but in combination with other studies, case studies "can help us build richer conceptualization of the relationship between professional knowledge and preparation for teachers" (Grossman, 1989, p. 30). At the very least, this case study adds to the conversation that drives educators toward equal opportunities for all children-no small thing. The study certainly provides a foundation for my own future research. The study also helped the participants to begin thinking about culturally responsive teaching and to reflect on their own teaching. 


\section{Discussion}

Teachers need knowledge, skills and dispositions to teach to the needs of all students and to enact culturally responsive pedagogy. In this section I argue that these teacher candidates might have held a disposition towards teaching to the needs of all students, but they did not have an understanding of how diversity and cultural influences translate into the classroom nor were they prepared for culturally responsive teaching.

\section{Images of Mathematics and Their Impact on Teaching}

Earlier in this work I argued that certain dispositions are required in order to enact culturally responsive pedagogy in a culturally diverse environment. I also argued that, even with the knowledge and the "right" disposition for culturally responsive teaching, the way teachers see the subject might still influence their desires and capacities to act. My study showed that these teacher candidates held different images of mathematics that seemed to shape their dispositions toward culturally responsive teaching. I agree with Ernest (2009) that a wide variation of images of mathematics can be categorized into images which are more traditional and images which are more humanistic. For example, the study participants saw mathematics as "difficult," which would be an aspect of the traditional image and as "approachable," which Ernest described as an aspect of the humanistic image. The participants also believed simultaneously that mathematics follows rules, but is also flexible and uses knowledge to solve problems. On the one hand, the participating teacher candidates believed that there is only one right answer to each task; but on the other hand, they saw multiple ways to get there. Table 4 summarizes 
these overlapping views on aspects of both images (shaded grey). Table 4 also shows the participants' tendency toward a humanistic image of mathematics.

Table 4

Overlapping View Aspects of the Images

\begin{tabular}{|c|c|c|}
\hline Aspect & Traditional Image & Humanistic Image \\
\hline Approachability & Difficult (4), forbidding & $\begin{array}{l}\text { Approachable and accessible } \\
\text { (4) }\end{array}$ \\
\hline Key elements & $\begin{array}{l}\text { Theoretical abstract theories } \\
\text { (4) }\end{array}$ & $\begin{array}{l}\text { Practical problem solving and } \\
\text { conceptual tools (4) }\end{array}$ \\
\hline Procedures and methods & $\begin{array}{l}\text { Ultra-rational, strictly following } \\
\text { fixed rules (2) }\end{array}$ & $\begin{array}{l}\text { Creative and flexible uses of } \\
\text { knowledge to solve problems } \\
\text { (2) }\end{array}$ \\
\hline Focus & $\begin{array}{l}\text { Only interested in the right } \\
\text { answers and objective facts } \\
\text { (4) }\end{array}$ & $\begin{array}{l}\text { Concerned with processes of } \\
\text { personal inquiry and } \\
\text { understanding (2) }\end{array}$ \\
\hline Problem solutions & $\begin{array}{l}\text { Only one right answer exists } \\
\text { for each task (4) }\end{array}$ & $\begin{array}{l}\text { Problems have multiple } \\
\text { solutions methods (4) } \\
\text { and multiple answers (0) }\end{array}$ \\
\hline Source of correctness & Experts have all the answers & $\begin{array}{l}\text { Anyone should be able to } \\
\text { solve problems and check } \\
\text { answers (4) }\end{array}$ \\
\hline Ownership & $\begin{array}{l}\text { Accessible only to a gifted, } \\
\text { stereotypically male, minority }\end{array}$ & Accessible to all (4) \\
\hline Human dimension & $\begin{array}{l}\text { Cold, neutral, abstract and } \\
\text { impersonal ( } 2 \text { ) }\end{array}$ & Human and personal (2)) \\
\hline \multicolumn{3}{|c|}{$\begin{array}{l}\text { (The number in parentheses shows how many participants seem to hold the aspect) } \\
\text { Note. Adapted from "New philosophy of mathematics: Implication for mathematics education," by } \\
\text { P. Ernest, 2009, In B. Greer, S. Mukhopadhyay, A. B. Powell, \& S. Nelson-Barber (Eds.), } \\
\text { Culturally responsive mathematics education (pp. 43-64). New York, NY: Routledge. }\end{array}$} \\
\hline
\end{tabular}

Relating the participants' images of mathematics to Ernest's (2009) "humanistic" and "traditional" images of mathematics did not suggest substantial differences in the participants' dispositions toward culturally responsive teaching. It suggested that, based on their images of mathematics, all of my participants could be open to culturally 
responsive teaching. It remained unclear whether a difference in seeing mathematics as procedural or conceptual was important enough to influence the teacher candidates' perception toward culturally responsive teaching.

Still, teachers' images of mathematics can strongly influence their teaching (Ernest, 1988), and in order to further understand this relationship for the teacher candidates in my study, I turned to Thompson's (1984) three basic philosophies of mathematics: the instrumentalist view, the Platonist view, and the problem solving view. I argue that the more "procedural image" of mathematics that I described could be compared to an "Instrumentalist view" and a "Platonist view." The "conceptual image" that I described could be compared to a view of "mathematics as problem solving." Ernest (1988) described an instrumentalist teacher as one in which an "Instructor ... focuses on skills mastery with correct performance" (para 6). A teacher with a Platonist view is likely to be an "Explainer," focusing on "conceptual understanding with unified knowledge" (para. 7), which I would see as teacher-centered and practice-oriented. The "Facilitator" sees mathematics as problem solving and aims teaching toward posing and solving problems, which I described as inquiry-based, student-centered instruction. However, I agree that the student-centered and inquiry-based nature of the conceptual image of mathematics moves the teacher into the role of a learning Facilitator. Because of the flexible use and creation of knowledge, I see a Facilitator as more likely to respond to the needs of culturally diverse students than an "Instructor" or Explainer. In conclusion, it might be possible that a conceptual view of mathematics makes teacher candidates more receptive to culturally responsive teaching. 
Finally, I speak briefly to potential sources of teacher candidates' images of mathematics. Guillaume and Kirtman (2010) claimed that the way teacher candidates experience mathematics in schools shapes their perceptions of mathematics. They also reported that teacher education has a positive impact on the preparation of teacher candidates. Very similarly, my study suggested that the teacher candidates' perceptions of teaching mathematics were mostly shaped by their positive experiences as learners of mathematics. Participants in my study reported that a course series on Mathematics for Elementary Teachers had the most positive impact on their perception of mathematics. The findings of these studies indicate that mathematics content courses might not only prepare teacher candidates with the necessary content knowledge, but also shape their images of mathematics in way that is more receptive to culturally responsive teaching.

\section{Culturally Responsive Teaching}

The framework for culturally responsive teaching that I have applied to this research is based on Gay's (2002) definition of culturally responsive teaching as using the cultural characteristics, experiences, and perspectives of ethnically diverse students as conduits for teaching them more effectively. It is based on the assumption that when academic knowledge and skills are situated within the lived experiences and frames of reference of students, they are more personally meaningful, have higher interest appeal, and are learned more easily and thoroughly. (p. 106)

She defined four dimensions of culturally responsive teaching: caring, communication, curriculum, and instruction. Although my research primarily focused on curriculum and instruction, as well as the student, I was also able to relate data to the culturally responsive dimension of caring. 
Culturally responsive caring. Gay (2010) saw a culturally responsive caring teacher as one who attends to the culturally diverse child's "personal well-being and academic success" (p. 48). Gay explained that culturally responsive caring goes beyond feelings and creating relationships; it is about "caring for children as students and people" (Gay, 2010, p. 48). She elaborated that "teachers who really care for students honor their humanity, hold them in high esteem, expect high performance from them, and use strategies to fulfill their expectations" (p. 48). All participants of my study seemed to care about the academic success and the well-being of their students. I agree with Salazar et al. (2010) that such a disposition is a moral disposition that all teachers should have. However, my study suggested that teacher candidates struggled to act on this disposition because of their lack of knowledge of the dynamics of diversity and culture in the classroom. It is not surprising that teacher candidates in my study focused mainly on the child as a learner. They focused on the students' pre-existing knowledge, learning styles, interests, and the support they can get from home, but fell short of including the child's cultural background in an active way. They did not seem to know how to connect to the child's cultural background in the classroom, which could shape their students' sense of being cared for by their teacher.

Culturally responsive communication. Although in this study I did not focus on culturally responsive communication, it is important to recall that "Communication is strongly culturally influenced, experimentally situated and functionally strategic" (Gay, 2010, p. 125). I agree with Gay that all learners in the classroom have their own communication styles, which are shaped by cultural and societal norms, conventions, and 
assumptions. The inability of teachers to value cultural diversity in the classroom often causes academic failure due to miscommunication (Gay, 2010). I see communication as another reason why teacher candidates need to understand how diversity and culture influences the classroom.

Culturally responsive instruction. Teaching and learning in a culturally diverse classroom is undoubtedly a complex and multidimensional task. The participants in this study acknowledged that each child brings a unique style of learning to the classroom. The participants seemed to perceive teaching to the individual learner as their highest priority. Through differentiation for learning styles, student interests, pre-existing knowledge, and student achievement, they envisioned trying to create a learning environment in which everybody could learn. Through scaffolding assignments, they imagined trying to meet the students where they are. They all encouraged collaborative learning. They might have even considered what kind of support a student can get at home.

In terms of teaching approaches, the participants with a procedural image of mathematics would most likely pose a problem and let students come up with a solution. I agree that these approaches sound like ways teachers should respond to the individual learners in the classroom. However, I would also argue that, although these instructional strategies are a good foundation for culturally responsive instruction, they fall short of seeing the needs of the whole child. In other words, the teacher candidates were not able to see the child both as a person with an individual identity and group identities. Seeing more than the individual learner is a key aspect of culturally responsive teaching, because 
learning is shaped by the child's cultural background, values, and beliefs (Gay, 2010). Gay further explained that seeing the child's individual needs, as well as the collective needs of the group, is a task teachers have to perform during every single moment of teaching. Gay also cautioned teachers to see the child's individual needs, rather than assuming the child behaves as stereotypical of its social group. A teacher should help children discover their unique way of learning. My study suggested that the teacher candidates did not know how to balance the individual needs of the students. They therefore tended to focus on the individual needs of the learner rather than the whole child.

Therefore, these teacher candidates did not know how to avoid stereotyping and yet still value the student's group identities. In consequence, two of my participants ignored the students' group identities altogether and the others seemed to consider responding to cultural diversity, but did not know how to do it. I agree with McDiarmid and Price (1990) that most teacher candidates have "learned to reject explicit stereotypes. At the same time, some of them seem not to know what to do with generalizations they encounter about the values and behaviors of ethnic and religious groups" (p. 25). McDiarmid and Price explained that this conflict might be caused by the teacher education programs and textbooks which often strongly sanction generalization. More than twenty years later than McDiarmid and Price's claim, the participants in my study still did not know how to avoid stereotyping while still valuing the students' cultural background. One reason could be that culturally responsive teaching is still often 
presented in courses on multicultural education, and on a single day within a methods course, detached from other coursework in teacher education.

Culturally responsive curriculum. A culturally responsive curriculum should draw upon knowledge that relates to the learners' experiences within and outside of schools, including as in the above definition, "cultural characteristics, experiences, and perspectives" (Gay, 2002, p. 106). However, it appeared that none of my participants understood how cultural knowledge is built, held, used and represented in the classroom. Gay (2010) explained that knowledge can only be constructed in a meaningful interaction with a social environment. Gay (2002) also explained that "developing a knowledge base about cultural diversity, including ethnic and cultural diversity content in the curriculum, demonstrating caring, building learning communities, and responding to ethnic diversity in the delivery of instruction," (p. 116) are all essential elements of culturally responsive teaching. For teacher candidates, trying to attend to and integrate such elements and enactments as Gay includes might be overwhelming when they plan their first lessons, especially if they have never experienced culturally responsive teaching themselves. The participants in my study, even though they should have heard about culturally responsive teaching in their elementary mathematics methods course, seemed not to comprehend the concept or understand it as a fundamental framework, nor know how this framework could work in a classroom. Judging from the participants' struggles to employ their knowledge of diversity and culture in the classroom and their struggles to understand how cultural knowledge is held, it seemed that their knowledge base about culturally diverse students was not strong enough to enact a culturally responsive curriculum. I 
assume that this is one reason why the study participants seemed to reduce a culturally responsive curriculum to the integration of artifacts (when an occasion arises), and drawing upon student interests and family backgrounds. These strategies seemed to move in the direction of culturally responsive teaching, but fell short of "promot[ing] the sharing of cultural knowledge and encourag[ing] respect among the students for another, as well as the members of the community and people of the world." (Zaslavsky, 1996, p. 31). The participants in this study considered culturally responsive teaching to be merely when they "tweak a story problem" to fit it to students' background and interests.

I would agree that altering story problems in an attempt to engage students is a step in the right direction, but I agree with Zaslavsky (1996) that "dressing up a routine type of exercise by placing it in an unreal story context does not engage many students, regardless of the ethnic context" (p. 31). However, with regard to culturally responsive teaching, I assume that this method of altering a story problem is often, if anything, all that a teacher candidate might experience during their field experience practicum. The teacher in the field is often not modeling culturally responsive teaching. Teachers are often required to teach strictly from a scripted teaching guidebook, and "the curriculum" leaves little or no room for culturally responsive teaching. However, Toppel (2013) indicated that teachers can enhance scripted curricula by incorporating some of Gay's (2010) components of culturally responsive instruction without interfering with the integrity of the prescribed lessons. However, the practicing teachers in Toppel's study had extensive training on culturally responsive practices, which may not be true for teacher candidates. Providing teacher candidates with the necessary framework in 
university courses and placing teacher candidates in the field with teachers who enact culturally responsive pedagogy even when they have to follow a script would be an important element of teacher education.

\section{Conclusion to the Discussion}

Teachers need to be prepared to teach mathematics to the needs and background of all students. Culturally responsive pedagogy is one way to close the existing opportunity gap for students who are from a background other than the dominant culture. To be able to respond to the whole child as a learner, teachers need have an image of mathematics that fosters teaching strategies around collaborative, student-centered, and inquiry-based learning. Such images of mathematics might be shaped by the experiences a teacher has had as a learner of mathematics. Content courses in preparation for a teacher licensure program seem to be one way to prepare teachers. Even with a positive image of mathematics, teacher candidates might not be prepared to teach mathematics in a culturally diverse environment because they do not know how diversity and culture translate into the classroom and how cultural knowledge is held and represented. In addition, teacher candidates might perceive culturally responsive teaching as a method, rather than as a framework for teaching. Making culturally responsive teaching a major framework of all teacher education coursework and modeling it in all classes might help teacher candidates develop a framework of teaching based on culturally responsive teaching. 


\section{Implications and Recommendations}

Because of the persistence of the so-called achievement gap, which I see as an opportunity gap in pedagogy, I conducted this research to gain insight into teacher candidates' perceptions of teaching mathematics with culturally diverse learners. The study indicated that teacher candidates might not understand the implications of diversity and culture on teaching and learning mathematics. Even with the disposition toward teaching to the needs and backgrounds of all students, teacher candidates might not be able to enact culturally responsive teaching because of their images of mathematics as well as their images of students, and because they see culturally responsive teaching as a method and not as a framework for teaching. I argue that culturally responsive teaching has to become a framework for all teaching in order to help close the opportunity gap. Based on my findings and conclusions from this study, I therefore make recommendations for teacher education programs and policy makers that might help to better prepare teacher candidates to teach mathematics with culturally diverse students.

\section{Recommendations for Teacher Education Programs}

InTASC developed standards for teacher education programs to articulate what

effective teaching and learning looks like in a transformed public education system:

one that empowers every learner to take ownership of their learning, that emphasizes the learning of content and application of knowledge and skill to real world problems, that values the differences each learner brings to the learning experience, and that leverages rapidly changing learning environments by recognizing the possibilities they bring to maximize learning and engage learners. A transformed public education system requires a new vision of teaching. (CCSSO, 2011, p. 3) 
I do think that this statement provides an opportunity to enhance teacher education programs by strengthening the focus on culturally responsive teaching. Therefore my recommendations might be useful for teacher education programs to meet the InTASC standards.

Culturally responsive coursework. I recommend that culturally responsive pedagogy should be the underlying framework for all teacher education coursework and, particularly, for mathematics education related courses. Course instructors should model culturally responsive teaching and focus on the context of culturally responsive pedagogy and its implication in teaching. This might help teacher candidates to develop their framework based on culturally responsive teaching, which might help them to no longer see culturally responsive teaching as an additional burden.

Initial multicultural education coursework. Specifically, a carefully-designed course toward the beginning of the program might be helpful for teacher candidates to develop and strengthen their awareness and knowledge of diversity and culture. Doing so may offer a foundation which might later help them to understand how diversity influences a mathematics classroom and their teaching. This stand-alone course is meant to provide a foundation and framework for future course and field experiences; it is not meant to be the sole introduction to multicultural education.

As an important element toward becoming a facilitator of learning, teacher candidates can learn in this initial course to reflect upon their own identity and how it affects them as teachers. Teacher candidates would reflect upon their own identities and experiences-how they are shaped by their own culture and how they build, hold, use and 
represent cultural knowledge. Reflecting upon their own identities, assumptions, and biases might help the teacher candidates see the student as a learner and a person. In this course, the teacher candidates should also learn about how diversity and culture shapes our society. I argue that presenting diversity and culture as an asset, and not merely a negative and troubling issue to be managed, helps teachers embrace the framework of culturally responsive teaching. The framework of culturally responsive pedagogy, which is substantially introduced in this course, should be used throughout other courses and field experiences, for instance in the elementary mathematics methods course.

Elementary mathematics methods coursework. Elementary math methods courses should be based on culturally responsive pedagogy, and the course instructors should know what makes a lesson culturally responsive and model culturally responsive teaching. Similar to initial coursework on multicultural education, the methods course should, at the beginning of the course, show how the framework of culturally responsive teaching can and should be extended to the teaching of mathematics. Again, teacher candidates need to understand how (mathematical) knowledge is built, held, perceived, and represented in the classroom. For example, the teacher candidates could be asked to explore neighborhood or school projects, such as playground development, school and community gardens. Based on these projects, the teacher candidates could develop a unit which actively engages students and community experts in the project. During the planning of the lesson, the teacher candidate could interview community experts. Teacher candidates need to learn how to assess who holds the cultural knowledge in a community to be able create meaningful learning opportunities that serve the needs of all students. 
Community-based projects and reflection could help the teacher candidates to see both the individual identity and cultural identity at the same time. Doing so might help the teacher candidates differentiate between stereotyping and drawing on the students' cultural identities.

In addition, lesson planning templates and guides should explicitly ask for a reflection on how the lesson was culturally responsive. For example, the teacher candidates could be asked to reflect on the ways they cared for their students. I also have seen methods instructors asking teacher candidates to specifically explain how they would make a lesson meaningful for their students. In addition, if a math methods course is based on a culturally responsive framework, the instructor could simply ask "How is this lesson culturally responsive?" The teacher candidates could discuss this question with their peers.

Clinical experience. During their clinical experiences in schools and classrooms, the teacher candidates should co-teach with an experienced teacher who understands how to implement culturally responsive teaching even when faced with a scripted program. The teacher could then guide the teacher candidate's firsthand experiences in working to teach in a culturally responsive way. Such teachers could be identified by university supervisors and who maintain university-school partnerships.

Program policies. Teacher education programs should only admit elementary teacher candidates who have taken mathematics content courses that prepared them for teaching elementary mathematics. These courses should be specially geared toward creating understanding of mathematical concepts relevant to elementary mathematics 
education. This study indicated that these courses could help positively change teacher candidates' attitudes towards mathematics. These courses seem to also have the potential to influence teacher candidates' images of mathematics to become more of an image that helps them to teach to the needs of all students.

\section{Conclusion}

To create equal learning opportunities for all learners, and to close the opportunity gap, a reconceptualization of the educational system is needed. Teachers need to be able to act as professionals and make decisions on curriculum and instruction based on the needs and backgrounds of the learners in their classroom. This research has provided important insights into teacher candidates' perceptions of teaching mathematics with culturally diverse students, which might have implications for course and program design, as well as program polices. This study also showed that mathematics-related coursework itself cannot bring the necessary changes to better prepare elementary teacher candidates to teach mathematics to all learners. This study implied that the overall coursework in teacher education needs to be designed to help the teacher candidates see how diversity and culture influences a mathematics classroom and their teaching. Only a well-rounded teacher education can influence teacher candidates' images of mathematics and their perceptions of teaching in general and with culturally diverse learners.

Further research, situated in the redesigned teacher education program in which the teacher candidates from this study participated, could give additional insights into teacher candidates' perceptions of teaching mathematics with culturally diverse learners. In addition, research is needed to see how teacher candidates' perceptions of teaching 
mathematics with culturally diverse learners relate to and influence their actual teaching. It would be interesting as well to see whether there is a difference in teacher candidates' perceptions of mathematics between those candidates who took elementary mathematics content courses prior to entering a teacher education program and those who did not take such courses.

There is certainly action needed to change the nation's educational system to create equal opportunities for all students and to close the achievement gap. This study adds to the body of research that spurs such action through the power of teacher education.

\section{Final Reflection}

Early on in my career as a teacher, I always asked myself what I could do to engage my students in meaningful learning, and how I could teach to all of their needs. I often found myself unprepared to teach in a culturally diverse environment. Through research and professional development, I was able to improve my own teaching, but I also knew teachers coming into the profession who struggled in the same way I had. I entered the doctoral program with the intention to become a teacher educator and to help change teacher education.

Being a member of the learning community of the doctoral program was a time of professional and personal growth. Always holding and supporting me, my peers and mentors nurtured, encouraged, and challenged me, and they pushed me and pulled me back. In this learning community I was able to develop my passion for teaching the whole child into a dissertation project. This dissertation is only the beginning of my career in educational research. This research with the strong focus on teacher candidates and how 
they perceive students helped me as an instructor in teacher education to better see my students as learners and persons. I intend to continue my research on teacher education. For instance, I am considering following the participants of this study into their classrooms to investigate how their perceptions of mathematics and students influence their teaching. I am also considering the development of teaching cases based on profiles of this study's participants. These cases could be used in further research and as teaching tools in a teacher licensure program-for both teacher candidates and teacher educators.

After the first year of my doctoral program, I had the opportunity to leave my fifth-grade classroom to work as an instructor and in program administration. In this position, I have been involved in the revision process of a teacher education program, which involved the entire faculty of the department in collaboration. Within this process I started to take on a stronger leadership role, supported by my experience and the foundation of the doctoral program. The teacher licensure program coordinator has also been a great mentor for me in this ongoing journey.

I will continue to work in teacher education and as program administrator. In the future, I will continue working with university supervisors, teacher candidates, and cooperating teachers to build partnerships between PreK-12 schools and teacher education programs. These partnerships will not only improve teacher education, but also PreK-12 schools. I see coordinating our efforts to improve teacher education as a way to bring the necessary changes to our educational system. A well-rounded teacher education helps teachers grow into professionals. I will continue to be an advocate and activist for change. 


\section{REFERENCES}

Averill, R., Anderson, D., Easton, H., Maro, P. T., Smith, D., \& Hynds, A. (2009). Culturally responsive teaching of mathematics: Three models from linked studies. Journal for Research in Mathematics Education, 40(2), 157-186. Retrieved from http://www.jstor.org/stable/40539330

Ball, D. L. (1990a). Breaking with experience in learning to teach mathematics: The role of a preservice methods course. For the Learning of Mathematics, 10(2), 10-16. Retrieved from http://www.jstor.org/stable/40247978

Ball, D. L. (1990b). Reflections and deflections of policy: The case of Carol Turner. Educational Evaluation and Policy Analysis, 12(3), 247-259. Retrieved from http://epa.sagepub.com/content/12/3/247.abstract

Ball, D. L., \& Cohen, D. K. (1999). Developing practice, developing practitioners: Towards a practice-based theory of professional education. In L. DarlingHammond \& G. Sykes (Eds.), Teaching as the learning profession: Handbook of policy and practice (pp. 3-31). San Francisco, CA: Jossey-Bass.

Banks, J. A. (1993). The canon debate, knowledge construction, and multicultural education. Educational Researcher, 22(5), 4-14. Retrieved from http://www.jstor.org/stable/1176946

Banks, J. A. (1997). Multicultural education: Characteristics and goals. In J. A. Banks \& C. A. M. Banks (Eds.), Multicultural education: Issues an perspectives (3rd ed., pp. 2-31). Boston, MA: Allyn and Bacon.

Banks, J. A. (Ed.). (2006). Race, culture, and education: The selected works of James A. Banks (World Library Educationalists Series). New York, NY: Routledge.

Banks, J. A. (2008). An introduction to multicutural education (4th ed.). Boston, MA Pearson Education.

Banks, J. A. (2009). Multicultural education: Dimensions and paradigms. In J. A. Banks (Ed.), The Routledge international companion to multicultural education (pp. 932). New York, NY: Routledge.

Banks, J., Cochran-Smith, M., Moll, L., Richert, A., Zeichner, K., LePage, P., et al. (2005). Teaching diverse learners. In L. Darling-Hammond \& J. Bransford (Eds.), Preparing teachers for a changing world: What teachers should learn and be able to do (pp. 232-274). San Francisco, CA: Jossey-Bass. 
Battista, M. T. (1994). Teacher beliefs and the reform movement in mathematics education. The Phi Delta Kappan, 75(6), 462-470. Retrieved from http://www.jstor.org/stable/20405142

Bransford, J., Darling-Hammond, L., \& LePage, P. (2005). Introduction. In L. DarlingHammond \& J. Bransford (Eds.), Preparing teachers for a changing world: What teachers should learn and be able to do (pp. 1-39). San Francisco, CA: JosseyBass.

Chu, S. Y. (2009). Implementation of supportive school programs for immigrant students in the United States. Preventing School Failure, 53(2), 67-72. Retrieved from http://stats.lib.pdx.edu/proxy.php?url=http://search.ebscohost.com/login.aspx?dire $\mathrm{ct}=$ true \&db=eric\&AN=EJ822033\&site=ehost-live;http://heldref.metapress.com/ openurl.asp?genre=article\&id=doi:10.3200/PSFL.53.2.67-72

Council of Chief State School Officers. (2011). InTASC Model Core Teaching Standards. Retrieved from http:/www.ccsso.org/Resources/Publications/ InTASC Model_Core Teaching_Standards 2011 MS Word Version.html

Creswell, J. W. (2012). Educational research: Planning, conducting, and evaluating, quantitative and qualitative research (4th ed.). Boston, MA: Pearson Education.

Cummins, J. (2000). Language, power and pedagogy: Bilingual children in the crossfire. Buffalo, NY: Multilingual Matters.

Darling-Hammond, L. (2010). The flat world and education: How America's commitment to equity will determine our future (The Multicultural Education Series). New York, NY: Teacher College Press.

Darling-Hammond, L., \& Bransford, J. (Eds.). (2005). Preparing teachers for a changing world: What teachers should learn and be able to do. San Francisco, CA: JosseyBass.

Delpit, L. (2006). Other people's children: Cultural conflict in the classroom. New York, NY: New Press.

Diez, M. E., \& Murrell, P. C. (2010). Dispositions in teacher educationBstarting points for consideration. In P. C. Murrell, M. E. Diez, S. Feiman-Nemser, \& D. L. Schussler (Eds.), Teaching as a moral practice: Defining, developing, and assessing professional dispositions in teacher education (pp. 7-26). Cambridge, MA: Harvard Education Press.

Dunn, R., \& Griggs, S. (1998). Multiculturalism and learning styles: Teaching and counseling adolescents. Westport, CT: Praeger Publisher. 
Ernest, P. (1988, August). The impact of beliefs on the teaching of mathematics. Paper presented at the 6th International Congress of Mathematical Education, Budapest, Hungary. Retrieved from http://people.exeter.ac.uk/PErnest/impact.htm

Ernest, P. (2009). New philosophy of mathematics: Implication for mathematics education. In B. Greer, S. Mukhopadhyay, A. B. Powell, \& S. Nelson-Barber (Eds.), Culturally responsive mathematics education (pp. 43-64). New York, NY: Routledge.

Eynde, P. O., de Corte, E., \& Verschaffel, L. (2002). Framing students' mathematicsrelated beliefs. In G. C. Leder, E. Pehkonen, \& G. Törner (Eds.), Beliefs: A hidden variable in mathematics education? (Kindle ed., pp. 305-690). Boston, MA: Kluwer Academic Publisher.

Ferner, B. R., \& Tilley, T. (2011). Teachers' perception on teaching math in multicutral contexts. Unpublished manuscript, Department of Curriculum and Instruction, Portland State University, Portland, OR.

Gay, G. (2002). Preparing for culturally responsive teaching. Journal of Teacher Education, 53(2), 106-116. Retrieved from http://jte.sagepub.com/content/ $53 / 2 / 106$. short

Gay, G. (2009). Preparing culturally responsive mathematics teachers. In B. Greer, S. Mukhopadhyay, A. B. Powell, \& S. Nelson-Barber (Eds.), Culturally responsive mathematics education (pp. 189-206). New York, NY: Routledge.

Gay, G. (2010). Culturally responsive teaching: Theory, research, and practice (Multicultural Education Series, 2nd ed.). New York, NY: Teacher College Press.

Gill, M. G., Ashton, P. T., \& Algina, J. (2004). Changing preservice teachers epistemological beliefs about teaching and learning in mathematics: An intervention study. Contemporary Educational Psychology, 29(2), 164-185. doi:10.1016/j.cedpsych.2004.01.003

Gonzalez, N., Andrade, R., Civil, M., \& Moll, L. (2001). Bridging funds of distributed knowledge: Creating zones of practices in mathematics. Journal of Education for Students Placed at Risk, 6(1/2), 115-132. Retrieved from http://stats.lib.pdx.edu/ proxy.php?url=http://search.ebscohost.com/login.aspx?direct=true $\& d b=e h h \& A N$ $=4792944 \&$ site $=$ ehost-live

Greer, B., Mukhopadhyay, S., Powell, A. B., \& Nelson-Barber, S. (2009). Culturally responsive mathematics education. New York, NY: Routledge, Taylor \& Francis Group. 
Gregoire, M. (1999, April 19-23). Paradoxes and paradigms in an eith grade pre-algebra class: A case study of a good math teacher. Paper presented at the annual meetting of the American Educational Research Association Montreal, Canada. (ERIC Document Reproduction Service No. ED431600)

Grossman, P. L. (1989). A study of contrast: Sources of pedagogical content knowledge for secondary English. Journal of Teacher Education, 40, 24-31

Grossman, P. L. (1990). The making of a teacher: Teacher knowledge and teacher education. New York, NY: Columbia University, Teachers College Press.

Guba, E. G., \& Lincoln, Y. S. (2005). Paradigmatic controversies contradictions, and emerging confluences. In N. K. Denzin \& Y. S. Lincoln (Eds.), The Sage handbook of qualitative research (3 ed., pp. 191-215). Thousand Oaks, CA: Sage.

Guillaume, A. M., \& Kirtman, L. (2010). Mathematics stories: Preservice teachers' images and experiences as learners of mathematics. Issues in Teacher Education, 19(1), 121-143.

Gutstein, E. (2003). Teaching and learning mathematics for social justice in an urban, Latino school. Journal for Research in Mathematics Education, 34(1), 37-73. Retrieved from http://www.jstor.org/stable/30034699

Hammerness, K., Darling-Hammond, L., Bransford, J., Berliner, D., Cochran-Smith, M., McDonald, M., \& Zeichner, K. (2005). How teachers learn and develop. In L. Darling-Hammond \& J. Bransford (Eds.), Preparing teachers for a changing world: What teachers should learn and be able to do (pp. 358-389). San Francisco, CA: Jossey-Bass.

Hansen-Thomas, H., \& Cavagnetto, A. (2010). What do mainstream middle school teachers think about their English language learners? A tri-state case Study. Bilingual Research Journal, 33(2), 249-266. Retrieved from http://dx.doi.org/10.1080/15235882.2010.502803

Harris, K., \& Alexander, P. (1998). Integrated, constructivist education: Challenge and reality. Educational Psychology Review, 10(2), 115-127. Retrieved from http://dx.doi.org/10.1023/A:1022169018926

Hawkins, D. (1974). The informed vision: Essays on learning and human nature. New York, NY: Algora Publishing.

Hemphill, F. C., Vanneman, A., \& Rahman, T. (2011). Achievement gaps: How Hispanic and White students in public schools perform in mathematics and reading on the national assessment of educational progress. Retrieved from http://nces.ed.gov/ nationsreportcard/pdf/studies/2011459.pdf 
Horowitz, F. D., Darling-Hammond, L., Bransford, J., Comer, J., Rosebbrock, K., Austin, K., \& Rust, F. (2005). Educating teachers for developmentally appropriate practice. In L. Darling-Hammond \& J. Bransford (Eds.), Preparing teachers for a changing world: What teachers should learn an be able to do (pp. 88-125). San Francisco, CA: Jossey-Bass.

Huebner, D. (1975). Poetry and power: The politics of curricular development. In V. Hills \& W. F. Pinar (Eds.), The lure of the transcendent: Collected essays by Dwayne E. Huebner (pp. 231-240). New York, NY: Routledge.

Johnson, B., \& Christensen, L. (2008). Educational research: Quantitative, qualitative, and mixed approaches (Third ed.). Thousand Oaks, CA: Sage Publications.

Khisty, L. L. (1995). Making inequality: Issues of language and meanings in mathematical teaching with Hispanic students. In W. G. Secada, E. Fennema, \& L. B. Adajian (Eds.), New directions for equity in mathematics education (pp. 279-298). Cambridge, MA: Cambridge University Press.

Kincheloe, J. L. (1997). Fiction formulas: Critical constructivism and the representation of reality. In W. G. Tierney \& Y. S. Lincoln (Eds.), Representation and the text: Re-framing the narrative voice (pp. 53-74). Albany, NY: State University of New York Press.

Kincheloe, J. L. (2008). Critical constructivism primer. New York, NY: Peter Lang Publishing, Inc.

Krueger, R. A. (1998). Analyzing and reporting focus group results: Focus group kit 6. Thousand Oaks, CA: Sage Publication.

Ladson-Billings, G. (1995a). But that's just good teaching! The case for culturally relevant pedagogy. Theory into Practice, 34(3), 159-165. Retrieved from http://www.jstor.org/stable/1476635

Ladson-Billings, G. (1995b). Making mathematics meaningful in multicultural contexts. In W. G. Secada, E. Fennema, \& L. B. Adajian (Eds.), New directions for equity in mathematics education (pp. 126-145). New York, NY: Cambridge University Press.

Ladson-Billings, G. (1995c). Toward a theory of culturally relevant pedagogy. American Educational Research Journal, 32(3), 465-491. Retrieved from http://www.jstor.org/stable/1163320 
Ladson-Billings, G. (2006). From the achievement gap to the education debt: Understanding achievement in U.S. schools. Educational Researcher, 35(7), 3-12. Retrieved from http://edr.sagepub.com/cgi/content/abstract/35/7/3

Ladson-Billings, G. (2009). The dreamkeepers: Successful teaching for AfricanAmerican students (2nd ed.). San Francisco, CA: Jossey-Bass.

Lipka, J., Yanez, E., Andrew-Ihrke, D., \& Adam, S. (2009). A two-way process for developing effective culturally based math: Examples from math in a cultural context. In B. Greer, S. Mukhopadhyay, A. B. Powell, \& S. Nelson-Barber (Eds.), Culturally responsive mathematics education (pp. 257-280). New York, NY: Routledge.

McDiarmid, G. W., \& Clevenger-Bright, M. (2008). Rethinking teacher capacity. In M. Cochran-Smith, S. Feiman-Nemser, J. D. McIntyre, \& K. E. Demers (Eds.), Handbook of research on teacher education: Enduring questions in changing contexts ( $3^{\text {rd }}$ ed., pp. 134-157). New York, NY: Routledge.

McDiarmid, G. W., \& Price, J. (1990). Prospective teachers' views of diverse learners: A study of the participants in the ABCD project. Research report 90-6. Retrieved from http://ncrtl.msu.edu/http/rreports/html/pdf/rr906.pdf

McLaren, P. (2007). Life in schools: An introduction to critical pedagogy in the Foundations of Education (5th ed.). Boston, MA: Allyn and Bacon.

Merriam-Webster's collegiate dictionary $\left(10^{\text {th }}\right.$ ed.). (1993). Springfield, MA: MerriamWebster, Inc.

Morgan, D. L. (1998). The focus group guidebook: Focus group kit. Thousand Oaks, CA: Sage Publications.

Moschkovich, J. N. (2007). Examining mathematical discourse practices. For the Learning of Mathematics, 27 (1), 24-30. Retrieved from http://cemela.math. arizona.edu/english/content/workingpapers/Examiningmathematicaldiscourseprac ticesMoschkvichFLM2007\%5B1\%5D.pdf

Moschkovich, J. N. (2009). Using two languages when learning mathematics: How can research help us understand mathematics learners who use two languages? Retrieved from http://www.nctm.org/uploadedFiles/Research_News_ and_Advocacy/Research/Clips_and_Briefs/Research_brief_12_Using_2.pdf 
Moschkovich, J. N., \& Nelson-Barber, S. (2009). What mathematics teachers need to know about culture and language. In B. Greer, S. Mukhopadhyay, A. B. Powell, $\&$ S. Nelson-Barber (Eds.), Culturally responsive mathematics education (pp. 111-131). New York, NY: Routledge.

Moses, R., West, M. M., \& Davis, F. E. (2009). Culturally responsive mathematics education in the Algebra Project. In B. Greer, S. Mukhopadhyay, A. B. Powell, \& S. Nelson-Barber (Eds.), Culturally responsive mathematics education (pp. 239256). New York, NY: Routledge.

Mukhopadhyay, S., \& Greer, B. (2001). Modeling with a purpose: Mathematics as critical tool. In B. Atweb, H. Forgasz, \& B. Nerbes (Eds.), Sociocultural research on mathematics education (pp. 295-312). Mahwah, NJ: Lawrence Erlbaum Associates.

Mukhopadhyay, S., Powell, A. B., \& Frankenstein, M. (2009). An ethnomathematical perspective on culturally responsive mathematics education. In B. Greer, S. Mukhopadhyay, A. B. Powell, \& S. Nelson-Barber (Eds.), Culturally responsive mathematics education (pp. 65-84). New York, NY: Routlledge.

Mulligan, J., \& Vergnaud, G. (2006). Research on children's early mathematical development: Towards integrated perspectives. In A. Gutiérrez \& P. Boero (Eds.), Handbook of research on the psychology of mathematics education: Post, present and future (pp. 117-146). Rotterdam, The Netherlands: Sense Publisher.

National Center for Education Statistics. (2005). National assessment of educational progress (NAEP). Retrieved from_http://nces.ed.gov/nationsreportcard/

National Center for Education Statistics. (2013). Projections of education statistics to 2021 (40 ed.). Retrieved from http://nces.ed.gov/programs/projections/ projections $2021 / \mathrm{sec} 1 \mathrm{~b} . \mathrm{asp}$

National Council for Accreditation of Teacher Education. (2010). Professional standards for the accreditation of teacher preparation institutions. Retrieved from http://www.ncate.org/Standards/NCATEUnitStandards/UnitStandardsinEffect200 8/tabid/476/Default.aspx\#stnd1

National Council of Teachers of Mathematics. (1989). Curriculum and evaluation standards for school mathematics. Reston, VA: Author.

National Council of Teachers of Mathematics. (2000). Principles for school mathematics. Reston, VA: Author. 
National Council of Teachers of Mathematics. (2011). Principles for school mathematics. Reston, VA: Author. Retrieved from http://www.nctm.org/standards/ content.aspx?id=26802

Nieto, S. (2000). Placing equity front and center: Some thoughts on transforming teacher education for a new century. Journal of Teacher Education, 51(3), 180.

Nieto, S. (2005). Public education in the twentieth century and beyond: High hopes, broken promises, and an uncertain future. Harvard Educational Review, 75(1), 43-64. Retrieved from http://stats.lib.pdx.edu/proxy.php?url=http://search. ebscohost. com/ login.aspx?direct=true\&db=eric\&AN=EJ738662\&site=ehostlive;http://gseweb.harvard.edu/hepg/educationpastandpresent.html

Nieto, S., \& Bode, P. (2011). Affirming diversity: The sociopolitical context of multicultural education (6th ed.). Needham Heights, MA: Allyn \& Bacon.

Noordhoff, K. J. (1993). Teaching U.S. history to Alaska Native students: Knowledge and beliefs of prospective secondary teachers. Michigan State University, East Lansing, MI

Oregon Deparment of Education. (2010). Sample test mathematics: Grade 6, 2010-2013. Retrieved from http://www.ode.state.or.us/wma/teachlearn/testing/samples/ 2011_12/ma-sampletest-gr6_2010-13.pdf

Oregon Department of Education. (2011). Oregon statewide report card. Retrieved from www.ode.state.or.us

Oregon Deparment of Education (2013). Sample test mathematics: Grade 5, 2010-2013. Office of Assessment. Retrieved from http://www.ode.state.or.us/wma/teachlearn/ testing/samples/2011_12/ma-sampletest-gr5_2010-13.pdf

Ovando, C. J. (2003). Bilingual education in the United States: Historical development and current issues. Bilingual Research Journal, 27(1), 1-24. Retrieved from http://stats.lib.pdx.edu/proxy.php?url=http://search.ebscohost.com/login.aspx?dire $\mathrm{ct}=$ true $\& \mathrm{db}=$ eric \&AN=EJ666800\&site=ehost-live

Ovando, C. J., Combs, M. C., \& Collier, V. P. (2006). Bilingual and ESL classrooms: Teaching in multicultural contexts (4th ed.). New York, NY: McGraw-Hill.

Pajares, M. F. (1992, Fall). Teachers' beliefs and educational research: Cleaning up a messy construct. Review of Educational Research, 62(3), 307-332. Retrieved from http://rer.sagepub.com/content/62/3/307.abstract

Paris, D. (2012). Culturally sustaining pedagogy. Educational Researcher, 41(3), 93-97. Retrieved from http://edr.sagepub.com/content/41/3/93.abstract 
Philipp, R. A., Ambrose, R., Lamb, L. L. C., Sowder, J. T., Schappelle, B. P., Sowder, L. et al. (2007). Effects of early field experiences on the mathematical content knowledge and beliefs of prospective elementary school teachers: An experimental study. Journal for Research in Mathematics Education, 38(5), 438476. Retrieved from http://www.jstor.org/stable/30034961

Phillips, D. C. (1995). The good, the bad, and the ugly: The many faces of constructivism. Educational Researcher, 24(7), 5-12. Retrieved from http://edr.sagepub.com

Povey, H. (1997). Beginning mathemaits teacher' way of knowing: The link with working for emancipatory change. Curriculum Studies, 5(3), 329-343.

Raymond, A. M. (1993). Understanding relationships between beginning elementary teachers' mathematics beliefs and teaching practices (Doctoral dissertation). Available from ProQuest Dissertations and Theses database. Retrieved from http://stats.lib.pdx.edu/proxy.php?url=http://search.proquest.com/docview/304035 399 ? accountid $=13265$

Richardson, V. (1996). The role of attitudes and beliefs in learning to teach. In J. Sikula, T. J. Buttery, \& E. Guyton (Eds.), Handbook of research on teacher education (2nd ed., pp. 102-119). New York, NY: Simon \& Schuster Macmillan.

Salazar, M. C., Lowenstein, K. L., \& Brill, A. (2010). A journey toward humanization in education. In P. C. Murrell, Jr., M. E. Diez, S. Feiman-Nemser, \& D. Schussler (Eds.), teaching as a moral practice: Defining, developing and assing professional dispositions in teacher education (pp. 27-52). Cambridge, MA: Harvard Education Press.

Saldaña, J. (2009). The coding manual for qualitative research. Thousand Oaks, CA: Sage.

Schwab, J. J. (1971). The practical: Arts of eclectic. The School Review, 79(4), 493-542. Retrieved from http://www.jstor.org/stable/1084342

Schwab, J. J. (1973). The practical 3: Translation into curriculum. The School Review, 81(4), 501-522. Retrieved from http://www.jstor.org/stable/1084423

Seidman, I. (2006). Interviewing as qualitative research: A guide for researchers in education and the social sciences ( 3 ed.). New York, NY: Teachers College Press.

Shulman, L. S. (1986). Those who understand: Knowledge growth in teaching. Educational Researcher, 15(2), 4-14. Retrieved from http://www.jstor.org/stable/ 1175860 
Skemp, R. R. (1976). Relational understanding and instrumental understanding. Mathematics Teaching,(77), 20-26.

Sleeter, C. E., \& Grant, C. A. (1987). An analysis of multicultural education in the United States. Harvard Educational Review, 57(4), 421-444. Retrieved from www.eric.ed.gov/ERICWebPortal/recordDetail?accno=EJ363083

Sleeter, C. E., \& Grant, C. A. (2003). Making choices for multicultural education: Five approached to race, class, and gender (4th ed.). Hoboken, NJ: John Wiley and Sons.

Sleeter, C. E., \& Grant, C. A. (2009). Turning on learning: Five approaches for multicultural teaching plans for race, class, gender, and disability (5th ed.). Danvers, MA: John Wiley \& Sons.

Stinson, D. W. (2004). Mathematics as "gate-keeper"(?): Three theoretical perspectives that aim toward empowering all children with a key to the gate. The Mathematics Educator, 14(1), 8-18.

Swan, M. (1993). Assessing a wide range of student abilities. In N.L. Webb \& A. F. Corford (Eds.), Assessment in the mathematics classroom (pp. 26-39). Reston, VA: National Council of Teachers of Mathematics.

Tate, W. F. (2005). Race, retrenchment, and the reform of school mathematics. In E. Gutstein \& B. Peterson (Eds.), Rethinking mathematics: Teaching for social justice by the numbers (pp. 31-40). Milwaukee, WI: Rethinking Schools Publication.

Taylor, P. C. (1996). Mythmaking and mythbreaking in the mathematics classroom. Educational Studies in Mathematics, 31(1), 151-173. Retrieved from http://dx.doi.org/10.1007/BF00143930

Thompson, A. G. (1984). The relationship of teachers' conceptions of mathematics and mathematics teaching to instructional practice. Educational Studies in Mathematics, 15(2), 105-127. Retrieved from http://dx.doi.org/10.1007/ BF00305892

Thompson, A. G. (1992). Teacher's beliefs and conception: A synthesis of research. In D. A. Grouws (Ed.), Handbook of reserach on mathematics teaching and learning: A project of the National Council of Teachers of Mathematics (pp. 127-146). New York, NY: Macmillian.

Toppel, K. E. (2013). The call for cultural responsiveness: Teachers' perception about the interplay between culturally responsive instruction and scripted curricula. Portland, OR: Portland State University. 
Ukpokodu, O. N. (2011). How do I teach mathematics in a culturally responsive way?: Identifying empowering teaching practices. Multicultural Education, 19(3), 47-56. Retrieved from http://stats.lib.pdx.edu/proxy.php?url=http://search. ebscohost.com/login.aspx?direct=true \&db=eric\&AN=EJ955945\&site=ehostlive;http://www.caddogap.com/periodicals.shtml

United States Census Bureau. (2007). United States census 2007. Retrieved from http://www.census.gov/2007census/

United States Census Bureau. (2010). United States census 2010. Retrieved from http://www.census.gov/2010census/

Villegas, A.-M., \& Lucas, T. (2002). Preparing culturally responsive teachers. Journal of Teacher Education, 53(1), 20-32. Retrieved from http://jte.sagepub.com/content/ $53 / 1 / 20$.abstract

Weinstein, C. S., Tomlinson-Clarke, S., \& Curran, M. (2004). Toward a conception of culturally responsive classroom management. Journal of Teacher Education, 55(1), 25-38. Retrieved from http://jte.sagepub.com/content/55/1/25.abstract

Williams, S. R., \& Baxter, J. A. (1996). Dilemmas of discourse-oriented teaching in one middle school mathematics classroom. The Elementary School Journal, 97(1), 21-38. Retrieved from http://www.jstor.org/stable/1001790

Wilson, M., \& Cooney, T. (2002). Mathematics teacher change and development. In G. C. Leder, E. Pehkonen, \& G. Törner (Eds.), Beliefs: A hidden variable in mathematics education? (Kindle ed., pp. 2009-2351). Boston, MA: Kluwer.

Wolcott, H. F. (1999). Ethnography: A way of seeing (2nd ed.). Walnut Creek, CA: AltaMira.

Wood, T., \& Sellers, P. (1996). Assessment of a problem-centered mathematics program: Third grade. Journal for Research in Mathematics Education, 27(3), 337-353. Retrieved from http://www.jstor.org/stable/749368

Wood, T., \& Sellers, P. (1997). Deepening the analysis: Longitudinal assessment of a problem-centered mathematics program. Journal for Research in Mathematics Education, 28(2), 163-186. Retrieved from http://www.jstor.org/stable/749760

Woodward, T. (2010). Elementary math classroom observation. Retrieved from https://vimeo.com/7682473

Zaslavsky, C. (1996). The multicultural math classroom: Bringing in the world. Portsmounth, NH: Heinemann. 
APPENDIX A

CONSENT FORM 


\section{ELEMENTARY TEACHER CANDIDATES' IMAGES OF MATHEMATICS AND DIVERSE STUDENTS: IMPLICATIONS FOR CULTURALLY RESPONSIVE MATHEMATICS EDUCATION}

You are invited to participate in a research study conducted by Bernd Ferner from Portland State University, Department of Curriculum and Instruction. The researcher hopes to gain an understanding of how elementary teacher candidates think about teaching mathematics in a multicultural environment. The study will be conducted in partial fulfillment of the requirements for a doctor in education (Ed.D) degree, under supervision of Dr. Karen Noordhoff. If you decide to participate, you will be asked to give Bernd Ferner access to course materials that you produce in this term. In addition, you will be invited to participate in two 60 -minute interviews and in a 90-minute focus group discussion, each of which will be audio recorded and/or videotaped. While participating in this study, it is possible that you may gain additional insights about teaching mathematics and your own teacher identity. You may not receive any direct benefit from taking part in this study, but the study may increase knowledge which may help to improve teacher education and math methods instruction in the future. The findings also might be useful to support your own professional development. Thus, your participation is important and valuable.

Any information that is obtained in connection with this study and that can be linked to you or your identity you will be kept confidential. To maintain confidentiality, the researcher will keep the records in a locked file cabinet and on a password protected file on a laptop computer in his office.

Your participation is voluntary. You do not have to take part in this study, and it will not affect your relationship with the Graduate Teacher Education Program, or with Portland State University. You may also withdraw from this study at any time without affecting your relationship with the Graduate Teacher Education Program, or with Portland State University. The participation in this study or a decision to withdraw at a later time will not impact your grades. Without giving any reason, you may also choose not to respond to a particular question during the research project. Please be assured that there is never a right or wrong answer.

If you have questions about the study itself, contact Bernd Ferner, 615 SW Harrison Street, Portland, OR 97201, 503-725-4722, FernerB@pdx.edu or the Human Subjects Research Review Committee, Research \& Strategic Partnerships, PO BOX 751, Portland, OR 97207, $503-$ 725-4288, hsrrc@list.pdx.edu, or Dr. Karen Noordhoff, noordhoffk@pdx.edu.

Your signature indicates that you have read and understand the above information and agree to take part in this study. Please understand that you may withdraw your consent at any time without penalty, and that, by signing, you are not waiving any legal claims, rights or remedies. The researcher will provide you with a copy of this form for your own records.

Signature Print Name Date




\section{APPENDIX B}

SAMPLING QUESTIONNAIRE 


\begin{tabular}{|c|c|c|c|c|c|}
\hline $\begin{array}{l}\text { Name: } \\
\text { Preferred contact information (email/ phone) } \\
\text { Age: } \quad \text { Gender: } \\
\text { How do you see mathematics? Put a mark in one box next to each stater }\end{array}$ & el: & icate & your & - & \\
\hline Please remember there is no right or wrong answer. & 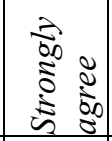 & $\underset{\tilde{8}}{\tilde{8}}$ & 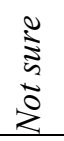 & 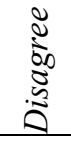 & 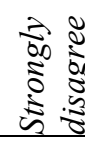 \\
\hline \multicolumn{6}{|l|}{$\begin{array}{l}\text { Learning mathematics is like learning a new cooking recipe. The teacher } \\
\text { or book gives you step-by-step instructions. You just do what they say. }\end{array}$} \\
\hline \multicolumn{6}{|l|}{$\begin{array}{l}\text { Mathematics is like a jungle. } \\
\text { The ideas are all jumbled up. }\end{array}$} \\
\hline \multicolumn{6}{|l|}{$\begin{array}{l}\text { Doing a mathematics problem is like crossing a river on stepping stones. } \\
\text { There is only one way to go. }\end{array}$} \\
\hline \multicolumn{6}{|l|}{$\begin{array}{l}\text { Learning mathematics is like building a wall. You have to lay the bricks } \\
\text { in a certain order. You have to learn mathematical concepts in a certain } \\
\text { order. }\end{array}$} \\
\hline \multicolumn{6}{|l|}{$\begin{array}{l}\text { You don't need to understand how mathematics works, you just need to } \\
\text { practice doing it. }\end{array}$} \\
\hline \multicolumn{6}{|l|}{$\begin{array}{l}\text { Learning mathematics is like exploring an unknown country. You make } \\
\text { lots of choices, where to go, what to do. }\end{array}$} \\
\hline \multicolumn{6}{|l|}{$\begin{array}{l}\text { Mathematics is like a jigsaw puzzle. The ideas fit neatly and beautifully } \\
\text { together. }\end{array}$} \\
\hline \multicolumn{6}{|l|}{$\begin{array}{l}\text { Doing mathematics problems is like finding your way through a maze. } \\
\text { There are lots of possible pathways to go down. }\end{array}$} \\
\hline \multicolumn{6}{|l|}{$\begin{array}{l}\text { Learning mathematics is like drawing a picture. It doesn't matter which } \\
\text { bit you do first. It will fit together in the end. }\end{array}$} \\
\hline \multicolumn{6}{|l|}{ You need to understand each idea in mathematics before you use it. } \\
\hline \multicolumn{6}{|l|}{ In mathematics you need to memorize a lot of facts and procedures. } \\
\hline \multicolumn{6}{|l|}{ Mathematics is useful in day to day life } \\
\hline \multicolumn{6}{|l|}{$\begin{array}{l}\text { In math, getting right answers is more important than } \\
\text { understanding why the answer works. }\end{array}$} \\
\hline \multicolumn{6}{|l|}{ Mathematics is a "universal language" and always the same. } \\
\hline \multicolumn{6}{|l|}{$\begin{array}{l}\text { Mathematics is a fixed set of rules and procedures which need to be } \\
\text { followed. }\end{array}$} \\
\hline \multicolumn{6}{|l|}{$\begin{array}{l}\text { Mathematics is abstract and } \\
\text { has no application to solving problems of the real world. }\end{array}$} \\
\hline \multicolumn{6}{|l|}{ People of different cultures understand and do mathematics differently. } \\
\hline & & & & & \\
\hline
\end{tabular}


APPENDIX C

MATH AUTOBIOGRAPHY 


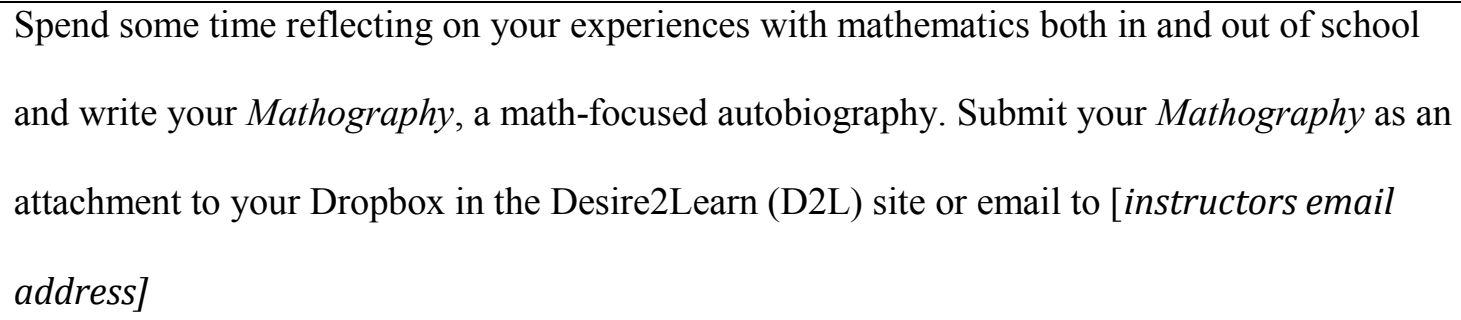

The purpose of your Mathography is for you to think about your history and relationship with mathematics. Please include your strengths, weaknesses, thoughts, feelings, and attitudes toward mathematics along with what you feel was most influential to you and why you think this was so influential.

- Describe 3 or 4 anecdotes that stand out for you as you think about your relationship with mathematics, both inside and outside of school, and over time.

- Tell the story of how you were taught mathematics and how you learned it. Describe yourself as a learner and a mathematician.

Excerpt from the Math-Methods course instructor's welcome letter to the teacher candidates. Used with permission of the Instructor. 
APPENDIX D

INTERVIEW I 


\section{Interview Protocol I}

Name: ___ Emily

Location:

Date: Oct 18, 2012

Time (beginning and ending): (2:30)

(Duration: $60 \mathrm{~min}$ )

- Remember to welcome the participant and thank him/her for taking the time

- Remind that this is a conversation

- Remind that there are no right or wrong answers

- Remind that it is okay not to answer a particular question

- Ask for permission to record and to take notes

\section{Remember:}

- Routinely ask for an example so that you can get a real idea of what they are thinking. It can be an actual or imagined example.

- Routinely asking “why/why not?" You can ask directly (why/why not) or indirectly (e.g., "How would that help you?" or "Can you talk a bit more about...")

\section{Warm up Question}

How the program is going for you? What about your experiences in your school?

Let's start talking about mathematics in general (Image of mathematics)

1. What is the first thing that comes to your mind when you hear the word "mathematics"

2. "What do you think mathematics is all about (Raymond, 1993)?" Can you give an example?

3. "What do you think mathematicians do when they do math?" (Raymond, 1993). Could you please give an example? 
4. Can you give me an example of a typical situation in which you use mathematics?" Explain how you use mathematics in this situation.

5. "Can you give me an example of a typical situation in which a student uses mathematics?"

○ Explain how the student uses mathematics in this situation. “

6. "It is time to look into a math classroom. We will focus on the students first and move into teaching. Image of (culturally diverse) students

7. In your opinion, how would you describe a typical student who is good at math? What is this person able to do?

8. In your opinion, how would you describe a typical student who is not good at math? What do you think the student needs to do to become a good math student?

9. What do you think the main purpose of teaching mathematics to elementary/mid-level students is? Explain. Give an example?

10. What do you consider good math teaching in an elementary / middle school classroom? Give examples.

\section{Now show the picture. (http://vimeo.com/768247)}

11. "What do you notice when you look at this classroom?"

12. "What do you notice about the students in this classroom?"

13. "How would you prepare to teach a math lesson in this class?"

14. "What kind of challenges would you expect when teaching this class?" 
15. In your opinion, what types of students might prove most challenging for you? Explain Why? Can you give an example?

16. "As a teacher of this class, what would you like to know about these students?"

○ "Let's talk more specifically now about teaching mathematics: In preparation for teaching a math lesson, what information would you want to have about these students?" Assume you are going to teach them about measurement.

- "What else do you need to know to teach these children mathematics?"

17. "Do you think students from different backgrounds do math differently?"

18. "Do you think all students can learn math? Why/Why not? How do you explain the difference among those students in learning mathematics [refer to students in the picture)]"(Raymond, 1993)

19. Do you think students from different cultural backgrounds have different learning needs in mathematics?

20. "What do you think is most important for these (pointing to the Vimeo picture) students to learn?"

21. What do you think is the best way for culturally diverse students to learn mathematics?

- What do you think is the best way for the students in this class to learn mathematics

22. What do you think about differentiating instruction for students?

○ On what would criteria would you base differentiation in your classroom. 
○ Give some examples how you would differentiate in your classroom.

- Can you think about way to differentiate your teaching for the students in this class (pointing to the picture)?

Finally I would like to ask some questions about your own experiences with math.

23. Do you like to add something to the conversation that you think I should know?

24. Math courses did you take before entering program? Tell me about some positive and negative experiences you have had in those courses. Explain Why? Open conversation 


\section{APPENDIX E}

EMAILS TO PARTICIPANTS 
Dear Teacher Candidate,

On Wednesday, I had the privilege of introducing my dissertation project to you and your cohort. As you may remember, I am looking for teacher candidates who would like to participate in a research project on how elementary teacher candidates think about teaching mathematics in a multicultural environment. If you have further questions regarding the project and potential participation, feel free to contact me (FernerB@pdx.edu, or 503-725-4722). I will be happy to answer any and all questions you might have.

If you decide to participate, please complete the attached questionnaire and send it back to me. You must also include the signed consent form.

Thanks for considering to participate in my dissertation research project.

Sincerely,

Bernd Ferner 


\section{APPENDIX F}

CLASSROOM FOTOGRAPH 


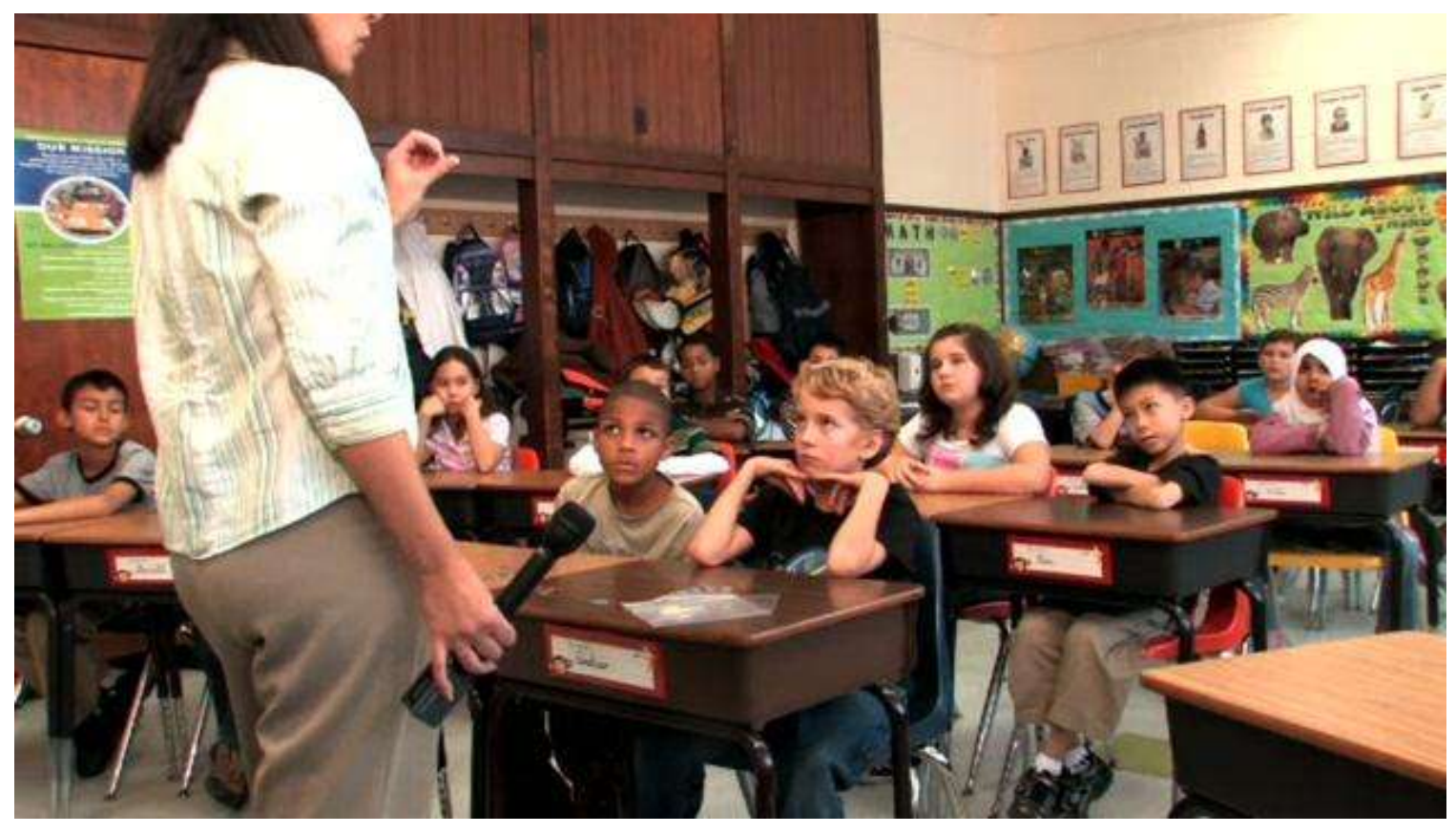

Video Screenshot retrieved from Woodward (2010) 
APPENDIX G

FOCUS GROUP PROTOCOL 
Names of Participants: Alison, Christy, Diane, Emily, Frank

Location: Date: Oct 21, 2012

Time: (beginning and ending): 11:55-12:55 Duration: $60 \mathrm{~min}$

3 min

- Remember to welcome the participants and thank them for taking the time.

- Remind the participants that this is a conversation.

- Remind the participants that there are no wrong answers.

- Remind the participants that it is okay not to answer a question.

- Ask for permission to record and videotape.

- Develop rules and boundaries for the focus group with the group and display them in a prominent position.

- Remind the students should indicate whether or not they agree with a statement or position and explain how they see it differently [slide] => post communication rules

While people arriving begin with a brief warm up activity and a check in. ( $7 \mathrm{~min}$ )

- Ask the candidates to write 3 words that come to their mind when they hear the phrase "teaching mathematics is ..." [Write on the poster using the colored pen on your desk]

Index Card activity: Teachers' purpose. (5min)

Every TC will have 3 color coded (same statements same colors) index cards in front of her/ him. The index cards will bear the participants' pseudonyms as well as one of 3 statements:

- "A teacher's main job is to transmit values of mainstream cultures" (McDiarmid \& Price, 1990)

- "A teacher's main job is to encourage students to think and question"(McDiarmid \& Price, 1990)

- "A teacher's main job is to teach subject matter" (McDiarmid \& Price, 1990) The participants will be asked to choose the index card they agree most with and write on the back of the card why they agree with the statement. When there is time left they should also elaborate on other cards why they did not choose those cards. Ask the TCs to use the starter "I agree" (so that it's clear which they agree with or not.)

Discussion: 10 min

The participants now put the cards with the statement they most agree with on top of the pile. The second in the middle and the statement they agree least with last.

Prompt: Please explain to the group why do you have chosen to order the cards they way you did it. Do you agree with other group members? Why? why not?

[I hope that this will spark a discussion on the purpose of teaching] How much time? 


\section{Initial Discussion on Diversity and Teaching Guidance Questions: (15min)}

- If someone says a classroom is full of "diversity," what do you think they are referring to in regard to the students? What do you think diversity is?

- What comes to your mind when you hear the specific term "cultural diversity?" Can you give an example of what counts as "cultural diversity" regarding your students?

- Should a math teacher respond to such diversity? If so, how should a math teacher do this? Can you give an example? Why is this important to do (or not do) in your opinion?

- What do you think culturally relevant math teaching might look and sound like? Can you give an example?

- In your opinion, what are the pro and cons of culturally responsive teaching, as you've described it?

- Do you consider CRT to be useful in your classroom? Why / Why not? How does culturally relevant/responsive teaching relate (or not) to your vision of teaching?

Video Sequences:

Show Video I "Elementary Classroom Observation" (Woodward, 2010) not culturally responsive. (5 $\mathrm{min}$ )

This video shows third grade teacher teaching how to count money. The teaching approach in the video is very teacher-centered and not differentiated for the students. The teacher seems to follow a script. Hands on activities are very structured and have to follow the teacher's instructions. I will choose a segment of this video that shows how the teacher introduces the "hands-on" activity as an example of direct instruction. The discussion after the video sequence will focus on in which way students benefit from this kind of activity.

Guidance Questions: Video Sequence 1

Prompt: Watch the video and pay attention to what is taught and how it is taught. TCs will receive these questions before they see the sequence.

- What is the teacher doing to ensure that all students can learn?

- What makes this teaching approach successful/not successful for this group of students?

- What did you notice about the interaction between teacher and students? What do you think was the intention behind the way the teacher interacted with the students?

- What did the teacher do to engage students? Did she engage all students? What makes you think that?

- What would you do differently and what would you do similarly? Explain why

- Is this activity "culturally relevant" in your opinion? Should it be "culturally relevant?"

- If so, please explain, in what ways is this activity culturally relevant?

○ If not, tell what you'd change to make it "culturally relevant." 


\section{Hand out the questions}

\section{Show the video}

2 minutes time for a quick write: "What stands out to you from this video?" (will be collected); each candidate share his/ her thoughts in about 1 min.

Discuss the questions teacher have received earlier 10 min

- Additional Questions if there is some time left: Did the teacher pay attention to the diversity of the students in this class? If so, how did the teacher pay attention to the diversity of the students? If not, what did you notice that indicates the teacher wasn't paying attention to the children's diversity?

- Describe whether or not you think the content was relevant to the students. Why/ Why not? Can you give an example?

- What could the teachers do to make the content relevant to the students' cultural background?

- What do you think the students have learned in the lesson we saw?

After the TCs respond in terms of the subject matter, ask: What else might they have learned in the lesson besides mathematics?

- Describe whether or not you think what the students have learned was meaningful for all students in the classroom. Explain why or why not.

- How did the teacher connect to the students' existing knowledge?

- What did the teacher do to address different learning styles? If anything, What would you do differently? Why?

\section{General Discussion}

- Please give us a brief description of the classroom you are working in. Please write on an index card first and only present to us what you have written

○ Who are the students? Grade levels? Neighborhood? Diversity?

[ this activity should give more indication of how TC see the student. It is important to me to know what they noticed about their students]

With your classroom in mind,

- How would you connect a unit on measurements to students outside school experiences?

- What are ways you would consider to respond to your students' diversities, when you teach a unit on measurements? If not mentioned, ask specifically: What would you consider doing to respond to your students' cultural diversity?

- What are the challenges you face when teaching students from a cultural background that is different from your own? Can you give me an example of a situation or student where you found yourself faced with a (or some) students who are culturally different from yourself? How did you handle that? What were the challenges you faced?

Questions for consideration in interview 2

- Thinking of your classroom, do you consider your students to be culturally diverse? If it is, in which ways? How does this situation impact your/ CT teaching (maybe at the very end after the very end)

- Explain in which ways your classroom is (not) diverse. 


\section{APPENDIX H}

FOCUS GROUP: VIDEO GUIDANCE 


\section{Video Guidance Questions}

- What did you notice about the interaction between teacher and students?

- What do you think was the intention behind the way the teacher interacted with the students?

-What did the teacher do to engage students? Did she engage all students?

- What makes you think that?

-What is the teacher doing to ensure that all students can learn?

- What makes this teaching approach successful/not successful for this group of students?

- What would you do differently and what would you do similarly? Explain why

- Is the hands-on activity "culturally relevant" in your opinion? Should it be "culturally relevant?"

- If so, please explain, in what ways is this activity culturally relevant?

- If not, tell what you'd change to make it "culturally relevant." 


\section{APPENDIX I}

INTERVIEW II 
Names of Participant: Location: Date:

Time: (beginning and ending): Duration: $60 \mathrm{~min}$

- Remember to welcome the participant and thank him/her for taking the time

- Remind that this is a conversation

- Remind that there are no right or wrong answers

- Remind that it is okay not to answer a particular question

- Ask for permission to record and to take notes

\section{Remember:}

- Routinely ask for an example so that you can get a real idea of what they are thinking. It can be an actual or imagined example.

- Check in how the program is going.

\section{Image of Culturally Diverse Students}

1. Please give a brief description of the classroom you are working in.

a. Who are the students? Grade levels? Neighborhood? Diversity? Anything else you think is important to know about your students?

2. During your field experience, what diversity did you observe in your math classroom? Can you give an example of what counts as "cultural diversity" regarding your students?

3. Thinking of your classroom, do you consider your students to be culturally diverse? If so, in which ways?

4. How do you feel about the cultural diversity in your classroom?

5. Looking back on to the term, have there been any significant learning moments regarding cultural diversity in the math classroom you have been in? What were these moments? Explain why these moments have been significant to you.

6. Has your perception of culturally diverse students changed during this term?

a. If yes, please explain what your perception was and how and why your perception has changed.

b. If not, please explain what your perception of culturally diverse students is and why you think your perception has not changed. 


\section{Teaching Culturally Diverse Students}

7. Should a math teacher respond to cultural diversity? If so, how should a math teacher do this? Can you give an example? Why is this important to do (or not do) in your opinion?

8. Do you think a student from a culturally diverse background faces different challenges in mathematics than a student from a "mainstream" background? Explain why or why not. If yes, what are these challenges?

9. What do you think culturally relevant math teaching might look and sound like? Can you give an example?

10. In your opinion, what are the pro and cons of culturally responsive teaching, as you have described it?

11. Do you consider culturally responsive teaching to be useful in your classroom? Why / Why not? How does culturally relevant teaching relate (or not) to your vision of teaching?

12. What are ways you would consider to respond to your students' diversities, when you teach a unit on measurements?

[If not mentioned, ask specifically: What would you consider doing to respond to your students' cultural diversity?]

13. How would you connect such a unit on measurements to students' experiences outside of school?

14. What are the challenges you face when teaching students from a cultural background that is different from your own?

a. Can you give me an example of a situation where you found yourself faced with a (or some) student who was (or were) culturally different from yourself? How did you handle that? What were the challenges you faced?

15. How do you think the cultural diversity in your classroom impacts your and your CT's teaching?

16. Do you think your own cultural background impacts the way you teach mathematics in general and in particular with culturally diverse students?

a. Can you explain why and how your own cultural background does (not) impact your teaching? 
We are now almost at the end of our formal conversation and I would like to add some questions about your personal background. I know that you have already answered some the questions before, but I would like to know more about who you are as a person.

\section{Attributes and Background [don't ask questions 17-20 if you run out of time]}

Please know that you do not have to answer the questions if you do not want to

17. After the focus group you mentioned that you were born in South America, and that you were adopted as baby and you grew up in West Lynn. Can you briefly describe your family and the neighborhood?

18. How would you describe that your family background and growing up in West Lynn has influenced who you are as a teacher?

19. You mentioned that you were enrolled in Job Corps after high school, earned Associate Degree from Astoria CC, and then transferred to PSU for your Bachelors (please remind me what your major and minors were). When did you decide to become a teacher? What were the main reasons for you to become a teacher?

20. How do you think this career has impacted you as a teacher? Which experiences were significant for you on your way to become a teacher? Explain how and why.

21. How would you describe your first experience as a teaching, which you have made in the classroom? In which ways is being a teacher (different) as you expected.

\section{Impact of Research}

Finally I would like to ask some questions about your experience with participating in my research project.

22. How do you feel about participating in this research project?

23. What questions did participating in this research bring up for you?

24. Do you think participating in this research has influenced the way you perceive culturally diverse learners and the way you think about teaching mathematics? Explain

25. Do you like to add something to the conversation that you think I should know [Ask if Alison needs a break before moving on to the conversation she likes to have] 